\title{
Audit quality : an empirical study of the attributes and determinants of audit quality perceptions
}

Citation for published version (APA):

Dassen, R. J. M. (1995). Audit quality : an empirical study of the attributes and determinants of audit quality perceptions. [Doctoral Thesis, Maastricht University]. Rijksuniversiteit Limburg. https://doi.org/10.26481/dis.19951025rd

Document status and date:

Published: 01/01/1995

DOI:

10.26481/dis.19951025rd

Document Version:

Publisher's PDF, also known as Version of record

\section{Please check the document version of this publication:}

- A submitted manuscript is the version of the article upon submission and before peer-review. There can be important differences between the submitted version and the official published version of record.

People interested in the research are advised to contact the author for the final version of the publication, or visit the DOI to the publisher's website.

- The final author version and the galley proof are versions of the publication after peer review.

- The final published version features the final layout of the paper including the volume, issue and page numbers.

Link to publication

\footnotetext{
General rights rights.

- You may freely distribute the URL identifying the publication in the public portal. please follow below link for the End User Agreement:

www.umlib.nl/taverne-license

Take down policy

If you believe that this document breaches copyright please contact us at:

repository@maastrichtuniversity.nl

providing details and we will investigate your claim.
}

Copyright and moral rights for the publications made accessible in the public portal are retained by the authors and/or other copyright owners and it is a condition of accessing publications that users recognise and abide by the legal requirements associated with these

- Users may download and print one copy of any publication from the public portal for the purpose of private study or research.

- You may not further distribute the material or use it for any profit-making activity or commercial gain

If the publication is distributed under the terms of Article $25 \mathrm{fa}$ of the Dutch Copyright Act, indicated by the "Taverne" license above, 


\section{Audit quality:}

An empirical study of the attributes and

determinants of audit quality

perceptions 



\title{
Audit quality:
}

\section{An empirical study of the attributes and \\ determinants of audit quality perceptions}

\author{
PROEFSCHRIFT
}

ter verkrijging van de graad van doctor aan de Rijksuniversiteit Limburg te Maastricht, op gezag van de Rector Magnificus, Prof. mr M.J. Cohen, volgens het besluit van het College van Dekanen, in het openbaar te verdedigen op woensdag 25 oktober 1995 om 16.00 uur

door

Roger Joseph Marie Dassen

geboren te Kerkrade 
Promotores:

Prof. dr A. Schilder RA

Prof. dr S.J. Maijoor

Prof. dr J.H.R. van de Poel

Beoordelingscommissie: $\quad$ Prof. dr J.D.P. Kasper (voorzitter)

Prof. dr W.F.J. Buijink

Prof. dr T.J. Mock

Prof. dr Ph. Wallage RA

(Universiteit van Amsterdam)

Ontwerp en druk: Drukkerij Groenevelt B.V., Landgraaf

Bindwerk: Martin van den Berg, Simpelveld

Omslagontwerp: M.H.L. Groenevelt 


\section{ACKNOWLEDGEMENTS}

This thesis is the result of ideas, cooperation, advices and criticisms of many.

First of all, I would like to thank my supervisors. Jan van de Poel, for making the arrangements between the University of Limburg and Bakker \& Versteegh/Deloitte \& Touche. Without his creative power and efforts, this dissertation would never have been started in the first place. Steven Maijoor, who was an important sparring partner in discussions about the research design and a much-appreciated critic in the remainder of the study. Arnold Schilder, who was the decisive power in the choice of the topic of this thesis and proved to be an indispensable stimulus and guide in many respects, not restricted to the $\mathrm{PhD}$ study as such.

In addition, I received constructive criticism from the Beoordelingscommissie and I thank Hans Kasper, Willem Buijink, Theodore Mock and Philip Wallage for their contribution.

The basis for this dissertation has been an agreement between the University of Limburg and Bakker \& Versteegh/Deloitte \& Touche. Ton Versteegh has been a true 'champion" of my $\mathrm{PhD}$ study, whose contribution was not confined to simply allowing me to spend some time on the dissertation. It was his decision to send me to the School of Accounting of the University of Southern California, in order to stimulate the development of the research design. The progress made during these three months, also enabled by the support in many ways of Theodore Mock, was an invaluable stimulus to my study. Further, I thank the partners (in particular, Jos Vercammen and Paul Op Heij) and my other colleagues at Deloitte \& Touche, for their patience, contribution and understanding throughout the study.

I thank my clients, for their understanding during those (hopefully rare) cases where they had to wait a bit longer for their services, due to my work on the dissertation. I hope that the insights gained during my research will be beneficial to the quality of my future service to them.

The very favourable research environment of the Faculty of Economics and Businesss Administration of the University of Limburg, in particular the Maastricht Accounting and Auditing Research Center (MARC), has proven to be an important contribution to this study, in particular the ideas and criticisms of Bram Beek, Jos and Tjeu Blommaert, Laury Bollen, Henk Brink, Jos Lemmink, Dirk Tempelaar, Eddy Vaassen and Martin Wetzels. I thank my former and current colleagues from the Postgraduate Accountancy Curriculum for their support of my study, in particular Hans Bijvoet, Wim 
Albers, Sabine Galama and Marian Keulen. I would also like to thank Viviana Voorwald and Rob Jacobs for their valuable assistance in the data processing and Eric Olders for his efforts and critical remarks in the execution of the statistical tests.

A substantial part of this thesis is built on the empirical data provided by the respondents. In particular, I would like to thank Henriette van Geertruiden (Van Lanschot Bankiers) for her never-ending enthusiasm to approach new respondents, and $\mathrm{ABN}$-Amro Bank (Mr. Strengers and Mrs. Peters), INGBank (Mr. Stevens, Mr. Jacobs, Mr. Renkens), Nationale Investeringsbank (Mr. Palmen) and Rabobank (Mrs. Jessen) for their efforts to select and approach both their own account managers and clients for participation in this study. I would also like to thank the notary's office of Mr. A. Huenges Wajer, which helped us with the processing of the questionnaires. I am grateful to the Council and Board of Management of Royal NIVRA, for their interest in this study and their consent to include a reference to this interest in the letter by which respondents were approached.

I thank Sen McGlinn for his editorial comments on a previous version of this dissertation and Ariane Bovens, who did a fine job in editing the manuscript.

Last, but definitely not least, I thank those who allowed me to spend so much of my spare time on writing these pages. My parents, who gave me the perseverance and the attitude to go through a process like this, and my wife Petra, whose enthusiastic support I will have to repay some day: she has recently started her own $\mathrm{PhD}$ study...

Kerkrade, August 1995 


\section{TABLE OF CONTENTS}

\section{Introduction}

1.1 Quality, service quality and audit quality 11

$\begin{array}{lll}1.2 & \text { Research questions } & 13\end{array}$

1.3 Research contribution 15

$\begin{array}{lll}1.4 & \text { Outline of the thesis } & 16\end{array}$

2. Quality, service quality and audit quality concepts

$\begin{array}{lll}2.1 & \text { Introduction } & 19\end{array}$

$\begin{array}{lll}2.2 & \text { Defining the modern concept of quality } & 19\end{array}$

$\begin{array}{lll}2.3 & \text { The importance of service quality } & 21\end{array}$

2.4 Typical characteristics of services and their impact on the quality concept 23

2.5 A general model of quality in service industries 23

$\begin{array}{ll}2.6 & \text { Expectations as determinants of quality } \\ 2.7 & 25\end{array}$

$\begin{array}{lll}2.7 & \text { Service quality attributes } & 29\end{array}$

$\begin{array}{lll}2.8 & 30\end{array}$

2.9 Summary 31

3. Nature and attributes of functional and technical audit quality

$\begin{array}{lll}3.1 & \text { Introduction } & 33\end{array}$

$\begin{array}{lll}3.2 & \text { Functional audit quality attributes } & 33\end{array}$

$\begin{array}{lll}3.3 & \text { Technical audit quality definitions } & 37\end{array}$

3.4 The importance of technical audit quality for
overall audit quality

$\begin{array}{ll}3.5 & \text { Attributes of technical audit quality } \\ 3.5 .12\end{array}$

3.5.1 Opinion on accuracy of financial statements 43

3.5.2 Opinion on ability to continue as a going concern 43

3.5.3 Opinion on the company's internal control system 44

3.5.4 Opinion on the occurrence of fraud 46

3.5.5 Opinion on the occurrence of illegal acts 49

$\begin{array}{lll}3.6 & \text { Summary } & 50\end{array}$ 
4. The influence of engagement characteristics on technical audit quality

4.1 Introduction $\quad 53$

4.2 Audit firm size $\quad 55$

4.3 Client size $\quad 60$

4.4 Client's financial health 61

4.5 Audit tenure 62

4.6 Provision of MAS $\quad 66$

$\begin{array}{lll}4.7 & \text { Summary } & 71\end{array}$

5. Research design

$\begin{array}{lll}5.1 & \text { Introduction } & 75\end{array}$

$\begin{array}{lll}5.2 & \text { Hypotheses } & 76\end{array}$

$\begin{array}{lll}5.3 & \text { Data collection method } & 78\end{array}$

$\begin{array}{lll}\text { 5.3.1 Questionnaire versus observation } & 78\end{array}$

5.3.2 Characteristics of the SERVQUAL questionnaire 79

$\begin{array}{ll}\text { 5.3.3 Evaluating the SERVQUAL questionnaire } & 80\end{array}$

5.3.4 Modification of the SERVQUAL questionnaire 84

5.3.5 Pretests of the data-gathering instrument 88

$\begin{array}{lll}\text { 5.3.6 Population and sample selection } & 89\end{array}$

5.4 Sample Characteristics 91

$\begin{array}{ll}\text { 5.4.1 Engagement characteristics } & 91\end{array}$

$\begin{array}{ll}5.4 .2 & \text { Questionmaire scores } \\ 5.52\end{array}$

$\begin{array}{lll}5.5 & \text { Summary } & 100\end{array}$

6. Determinants of overall audit quality

$\begin{array}{lll}6.1 & \text { Introduction } & 103\end{array}$

$\begin{array}{lll}6.2 & \text { Factor analyses } & 104\end{array}$

6.2.1 Introduction 104

$\begin{array}{ll}\text { 6.2.2 Introduction to factor analysis } & 105\end{array}$

6.2.3 Factor model at the performance level: clients 109

6.2.4 Factor model at the performance level: bankers 113

6.2.5 Factor model at the performance minus desired
expectations level: clients

6.2.6 Factor model at the performance minus desired expectations level: bankers

6.2.7 Factor model at the performance minus adequate expectations level: clients 
6.2.8 Factor model at the performance minus adequate expectations level: bankers

$\begin{array}{lr}\text { 6.2.9 Comparison of factor structures } & 132\end{array}$

$\begin{array}{lll}6.3 & \text { Regression analyses } & 135\end{array}$

$\begin{array}{lll}6.3 .1 & 135\end{array}$

6.3.2 Introduction to regression analysis 136

6.3.3 Regression analysis at the performance level: clients 138

6.3.4 Regression analysis at the performance level: bankers 139

6.3.5 Regression analysis at the performance minus desired expectations level: clients

6.3.6 Regression analysis at the performance minus desired expectations level: bankers

6.3.7 Regression analysis at the performance minus adequate expectations level: clients

6.3.8 Regression analysis at the performance minus adequate expectations level: bankers

6.4 Comparison of regression analyses $\quad 144$

6.5 Summary

7. Audit engagement characteristics and technical audit quality

$\begin{array}{lll}7.1 & \text { Introduction } & 155\end{array}$

$\begin{array}{lll}7.2 & \text { Regression model and results } & 157\end{array}$

$\begin{array}{lll}7.2 .1 & \text { Regression model } & 157\end{array}$

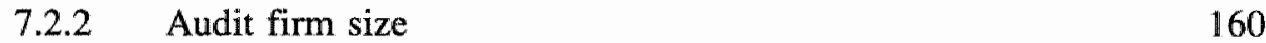

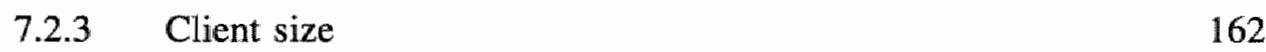

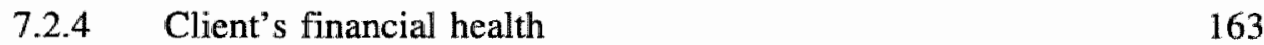

$\begin{array}{ll}7.2 .5 & \text { Length of tenure } \\ 7.2 .6 & 164\end{array}$

$\begin{array}{lll}\text { 7.2.6 Provision of MAS by incumbent auditor } & 165\end{array}$

$\begin{array}{lll}7.3 & \text { Summary } & 165\end{array}$

8. Summary and discussion

$\begin{array}{lll}8.1 & \text { Summary } & 171\end{array}$

$\begin{array}{lll}\text { 8.1.1 Introduction } & 171\end{array}$

$\begin{array}{lll}8.1 .2 & \text { Research design } & 171\end{array}$

8.1.3 Descriptive results 173

8.1.4 Methodology and results for research question 1: attributes

8.1.5 Methodology and results for research question 2: influence
of audit engagement characteristics

$\begin{array}{lll}8.2 & \text { Limitations of the study } & 182\end{array}$ 
8.3 Topics for further research

8.4 Theoretical implications

8.5 Practical implications

Appendix 1 SERVQUAL questionnaire (perceived performance level)

References 193

Nederlandse samenvatting (Summary in Dutch) 209

Curriculum Vitae 


\section{CHAPTER 1 INTRODUCTION}

\subsection{Quality, service quality and audit quality}

General interest in and attention for quality is not a recent phenomenon. From Aristotle on, philosophers have discussed 'quality', using it as a construct with various and constantly evolving meanings. A common element in modern definitions of quality is that the actual performance of a product is compared to a certain standard; the smaller the gap between the actual 'performance' and the 'standard', the higher the level of quality achieved.'

In manufacturing, this current concept of quality is quite straightforward: a product has to meet pre-established requirements, with a given tolerance: a valve for a specific engine should have a diameter within certain narrowly defined borders. If the actual output meets these requirements, then the required level of quality has been achieved; if not, the output is substandard and the quality level is not acceptable.

For services, however, this quality concept is not so easily applicable. Services cannot be technically measured or counted. And, interestingly, the production and consumption of a service are linked. Consumption and production of a haircut take place simultaneously: the consumer is involved in the production process. This has specific implications for the definition of service quality. First, what is the 'standard' to which the actual performance is compared? Over the last decade, extensive research has been done in this area. Through focus group interviews and surveys, Parasuraman et al. (1985) found that, in assessing quality, consumers compare their perceptions of the actual performance with their expectations about what the performance should ${ }^{2}$ be. The gap between perceived performance and these expectations determines the level of quality achieved by that service. Second, what are the attributes of service quality? In the example of a haircut: what are the items on which a hairdresser may or may not 'score' in terms of service quality? If a haircut was a manufacturing process, one might expect the consumer and producer to first agree on a certain type of haircut, explicitly stating the length required for each hair, with a given tolerance. However, this rather technical approach to haircut quality does not reflect all the relevant

\footnotetext{
${ }^{1}$ Assuming that the actual performance is below the standard.
}

${ }^{2}$ See Chapter 2 for the nature of these expectations. 
attributes of the service. Because of the link between production and consumption, the haircut process is also relevant for quality. This process includes items such as the appearance of personnel, instruments and even other consumers; the waiting time; the type and sound level of the music; the small-talk by the hairdresser. Even if the haircut is technically carried out in exact conformance with the type agreed upon - each hair being within the tolerance - it is possible that the overall quality of the haircut will be perceived as low, due to the low quality on these additional items. Chapter 2 of this thesis will refer to the first type of quality as technical quality and to the latter type as functional quality. Parasuraman et al. (1985) have concentrated on functional quality and have applied this concept to a large number of services.

What applies to a haircut, also applies to auditing, the subject area of this study. Again, production and consumption are linked: in conducting an audit, the auditor certainly involves the auditee. The audit team usually works within the auditee's premises, checking the auditee's accounts, asking the auditee's personnel questions or verifying the existence of the auditee's assets. But the crucial issue is: who is the customer? Is it the management of the company, which in most cases has a decisive role in the appointment of the auditor? Or is it the audit committee, or the supervisory board to whom the auditor should report any findings that are relevant to their supervisory role? Or the users of the financial. statements, such as stockholders, bankers, employees, government and a large number of other parties that have interests in the audited company? Probably, all of these stakeholders will consider themselves as consumers of audit services, but - given the diversity of stakeholders, their interests and the use they make of financial statements and hence audit services - they will hold different ideas about audit quality. One might argue that the management of the audited company is primarily interested in the advisory capacity of the auditor. Of course, the auditor should find errors in the financial statements, if any. But first of all the auditor should help management by identifying risks, opportunities and solutions in the areas of financial statements, tax, accounting information systems, internal organization and corporate finance. Bankers, on the other hand, might be expected to appreciate an auditor who is a genius in detecting errors in the financial statements or going concern problems. Although they may also appreciate any help the auditor can give the company by way of advice, they might like the auditor to act in the first place as a watch-dog, publicly signalling errors or irregularities that might be of concern to bankers. So it seems that the auditor should be able to adapt his service to very different and sometimes even conflicting quality concepts. 
This study will try to identify these quality concepts for two groups: the management of the audited company (clients) and account managers of commercial banks (bankers). Both groups benefit directly from audit services, and both groups have fairly frequent direct contacts with auditors. Therefore, both clients and bankers are able to make assessments of audit quality, based on their own perceptions. This study will examine whether the auditor is successful in finding the proper combination of technical and functional quality in response to the different desires of these groups.

\subsection{Research questions}

This thesis attempts to answer two research questions:

1. What technical and functional audit quality attributes are distinguished by clients and bankers, and what is their relationship with and influence on overall audit quality assessments by these two groups?

2. What is the influence of audit engagement characteristics on technical audit quality perceptions of clients and bankers?

Research question 1: What technical and functional audit quality attributes are distinguished by clients and bankers, and what is their relationship with and influence on overall audit quality assessments by these two groups? As illustrated in the previous section, different interest groups are expected to hold different views on the attributes of audit quality and their relative importance. This has received little attention in the audit literature. The expectations and perceptions of users of audit services regarding technical audit quality have been the subject of several expectation gap studies ${ }^{3}$ (see Chapter 3). These studies focused on the auditor's ability to detect errors in the financial statements and other irregularities (such as fraud) and on auditor independence concerning these matters, in line with the audit quality definition of DeAngelo (1981b). However, these studies did not relate these attributes to overall audit quality, implying that the relative importance of the gaps could not be measured. The number of studies regarding functional audit quality is very limited. Schroeder et al. (1986) and Carcello et al. (1992) did some research in this area; but their studies were limited to asking respondents to rate the importance of each technical and functional item appearing in their questionnaires.

${ }^{3}$ In the Netherlands, expectation gaps were studied by the Limperg Instituut (1987). 
In order to find empirical answers to the first research question, several technical and functional attributes were assessed, in this study, by clients and bankers. They made these assessments for actual engagements with which they were familiar. They were also asked to rate the overall audit quality for these engagements. ${ }^{4}$ By using factor analysis and regression techniques, it has been possible to identify relevant audit quality attributes and their importance for overall audit quality. The importance of exploring this relationship between overall audit quality and the underlying attributes is stressed by Dopuch and Simunic (1982, p. 406): 'A fundamental issue in studying the market for audits (...) is the identification of those characteristics of audit services which are valued by purchasers.'

Research question 2: What is the influence of audit engagement characteristics on technical ${ }^{5}$ audit quality perceptions of clients and bankers?

This topic has received considerably more attention in audit research than the first question. The effects of engagement characteristics such as audit firm size, client size and financial condition, length of tenure or the provision of Management Advisory Services (MAS) on technical audit quality have been the subject of several studies, notably in the US. The methods of data gathering in these studies varied widely. Some studied factual technical audit quality. For example, Palmrose (1988a) found that non-Big Eight firms were confronted with significantly higher meritorious litigation than Big Eight firms, implying that Big Eight firms had better technical audit quality than non-Big Eight firms. However it is widely acknowledged that, in addition to factual audit quality, the study of perceptions of technical audit quality is also necessary. Shockley (1981, p. 785) observes that '(...) credibility depends ultimately on the perception rather than on the fact of independence.' Schilder (1994) performed interviews with leading people in the financial community on the subject of auditor independence. He cites Professor Van Hulle, Head of Accounting in Directorate General XV of the European Commission, as saying 'the world is complex, and your independent state of mind is not

\footnotetext{
${ }^{4}$ In their assessments of overall audit quality and of the underlying attributes, respondents were asked to rate the auditor's performance of the audir function, so that other services provided by the auditor were not considered.

${ }^{5}$ A theoretical background for this research question and the associated hypotheses has been found in the agency theory (see Chapter 4). Since the agency argument can only be applied to the technical attributes, this research question does not address the influence of the engagement characteristics on functional attributes.
} 
enough. You have to appear to others as being independent. So perceptions are utterly important.' On the other hand, most of the perception studies have the limitation of being based on fictitious cases rather than on actual engagements. Shockley (1981, p. 296), who studied perceptions based on fictitious cases, acknowledges that 'subjects may not respond in an experimental setting in the same fashion as in more realistic contexts.' In this thesis, the advantages of using actual engagements have been combined with those of studying perceptions. By using regression techniques, the actual engagement characteristics were linked to the respondent's assessment of perceived technical audit quality.

\subsection{Research contribution}

We believe that this thesis can contribute to research in four ways:

1. As stated, it will study the influence of engagement characteristics on perceived technical audit quality by using data and assessments of actual engagements. In previous research, this combination is very rare. Given the importance of perceptions of audit quality for the credibility of the audit profession and the individual auditor, the study of quality perceptions based on actual engagements is a significant contribution to audit research.

2. It will test the importance of various technical and functional quality attributes for overall quality, based on assessments of actual engagements by various groups of users of audit services. By providing insight into the differences in the expectations and quality concepts of these groups, this study may provide a basis for future expectation gap studies.

3. Leading concepts and research techniques regarding service quality, widely used in marketing research, will be implemented here in the field of audit research. So far, the cross-fertilization between these two research areas has been rather limited.

4. This study will test the relevance of different levels of expectation in overall audit quality assessments. Performance is compared not only to the desired level of expectation - as suggested and done by Zeithaml et al. (1990) - but also to the adequate level of expectation - as suggested by Zeithaml et al. (1991). By testing the applicability of the latter level of expectations in overall quality assessment, this study will contribute to the current discussion on the proper conceptualization of service quality. 
In addition to these contributions to research, this study has important implications for auditing practice. Given the competitive nature of the audit market in the Netherlands (see Leeflang et al., 1992a), it is important for auditors to understand the needs and quality assessment process of the users of their services. Moreover, audit quality is not just a competitive instrument for the individual auditor. Attention to audit quality is crucial for the credibility of the entire audit profession. The Dutch professional body of auditors has acknowledged the importance of audit quality for the future of the profession and has started a discussion on profession-wide quality control (NIVRA, 1992).

\subsection{Outline of the thesis}

After this introduction, the concept of service quality will be discussed in Chapter 2. After a brief discussion of the current concepts of quality, the difficulties of applying the traditional quality concepts to services will be discussed. Then the SERVQUAL (service quality) concept developed by Parasuraman et al. (1985) will be discussed. This model and the accompanying questionnaire (see appendix 1) will be used in this thesis. An extensive discussion of the importance of expectations in the audit quality assessment will also be included in this chapter, which will close with a brief discussion of audit quality and definitions of functional and technical audit quality.

Chapter 3 discusses previous research on the nature and attributes of functional and technical audit quality and generates some hypotheses about the importance of several functional and technical audit quality attributes in the overall audit quality assessments of clients and bankers. As regards the functional audit quality attributes, the discussion will be based on the functional quality attributes identified by Zeithaml et al. (1990). For the technical audit quality attributes, we will discuss several expectation gap studies, which have identified the expectations and perceptions of several stakeholder groups regarding issues such as detection of errors in financial statements, detection of going concern problems, detection of weaknesses in the audited company's internal organization and detection of fraud and illegal acts. The independence expected of auditors in relation to these issues will
also be examined. 
Chapter 4 provides an overview of the large body of audit research on the influence of audit engagement characteristics on the auditor"s detection ability or independence. Theoretical and empirical findings regarding the influence of firm size, client size, client's financial health, length of tenure and the provision of MAS will be discussed in this chapter.

Chapter 5 discusses the design of the empirical study. The hypotheses generated in the previous chapters - based on existing theoretical and empirical research - will be summarized. Then the type of questionnaire and the methods for selecting engagements which have been used in this study will be explained. The final section of this chapter will give the descriptive results for all questions included in the questionnaire. Findings emerging from an analysis of the descriptive results will be discussed.

Chapter 6 presents the factor and regression analyses which were applied to find the relevant technical and functional audit quality attributes and to measure the influence of these attributes on overall audit quality. The factor structures and regression functions resulting from these analyses will be presented. They make it possible to compare the importance of attributes for overall audit quality as assessed by clients and bankers.

Chapter 7 presents the results of the regression analyses regarding the influence of engagement characteristics on technical audit quality. These findings will be discussed for clients and bankers separately, so that any differences can be highlighted.

Finally, Chapter 8 summarizes and discusses the findings from the empirical analyses, identifies the study"s limitations and topics for further research, and underscores the theoretical and practical implications. 


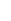




\section{CHAPTER 2 QUALITY, SERVICE QUALITY AND AUDIT QUALITY CONCEPTS}

\subsection{Introduction}

This chapter will discuss recent developments regarding the concept of quality, and audit quality in particular. After a discussion of the current concepts of quality in Section 2.2, Section 2.3 will address the importance of service quality. It will suggest that establishing a quality image may be a strategic instrument by which firms can differentiate their services, despite the typical characteristics of services - presented in Section 2.4 - which make 'quality' more difficult to measure and evaluate in service industries than in other industries. After identifying these typical characteristics, a conceptual framework of service quality is presented in Section 2.5. In this framework, service quality is determined as the difference between customer expectations and customer perceptions. Given the importance of this framework for the empirical analysis, the nature and determinants of customer expectations in quality assessments will be addressed in Section 2.6. Section 2.7 will consider the dimensions or attributes of service quality that were named in the literature as determinants of quality assessments in a broad range of service industries. This section also introduces the difference between technical and functional service quality. Then, in Section 2.8 , the concept of audit quality is briefly discussed within the framework of service quality. Finally, Section 2.9 will summarize the relevant topics in this chapter.

\subsection{Defining the modern concept of quality}

During its long period of development, several different interpretations have been given to the construct 'quality' (Neijzen and Trompetter, 1989). Initially, quality was regarded as an objectively measurable characteristic of a product (e.g. the chemical pureness of a product). Over time, however, the quality construct has come to be seen as an expression of subjective perceptions of the ability of a product or service to "satisfy the requirements of customers" (Ishikawa, 1985) or 'the extent to which the product successfully serves the purposes of the user during usage' (Juran, 1974).

Perhaps due to the extremely long - and perhaps: still enduring - period of development of the meaning of 'quality', many different definitions have emerged. 
The difficulty of finding a definition 'fitting' modern concepts of quality can be attributed to four characteristics of these modern concepts (Lemmink, 1991):

Multi-dimensionality: a product or service consists of various, more or less mutually dependent characteristics. A quality judgment is often given for a product or service as a whole, leading to problems in measuring and weighing the various product quality attributes;

Relativity: quality judgments depend on the framework in which the product or service is evaluated;

Subjectivity: 'Quality lies in the eyes of the beholder' (Garvin, 1984).

Quality depends on the needs of specific customers, who offset the observed quality against their own expectations and needs; and Dynamics: customers' needs and preferences vary over time, influencing the perceived level of quality.

Given these characteristics of the 'quality construct', Lemmink (1991) evaluates the prevailing quality definitions:

Conformance to requirements: this type of definition, first given by Crosby (1979, p.15), is production oriented. Customer expectations and perceptions are irrelevant in this definition.

Fitness for use/purposes: the 'fitness for use" concept of quality was introduced by Juran $(1974$, p. 2). In this concept, quality is seen as a subjective and dynamic phenomenon, depending on the use to which a customer intends to put the product. It refers to the usefulness of a specific product for particular - envisaged - purposes.

Needs and/or desires: this concept of quality refers to the ability of a service or product to satisfy the customer's needs and/or desires. Expectations: the "expectations" approach regards quality as the degree to which a product meets a customer's expectations."

The last three definitions have a lot in common, and - together - seem to cover the characteristics considered typical for the modern quality concept (multi-dimensionality, relativity, subjectivity and dynamics; see Lemmink, 1991). As illustrated in Section 2.6, "expectations' also include the elements of purpose, desire and needs. Thus the definition of quality given by Parasuraman et al. (1986, p. 6) appears to capture all the essential elements and can serve as the basis for the quality concepts in this thesis:

'For a discussion of the various levels of expectations, see Section 2.6 . 
'... perceived quality is the degree and direction of discrepancy between customer's perceptions and expectations.' 2

\subsection{The importance of service quality}

For a long time, the focus of attention in quality research has been on product quality. Sophisticated quality measures using statistical techniques have been developed, but they have been directed only at technical aspects of input, process and output. However, attention is now extending to service quality. According to Cronin and Taylor (1992, p. 55), 'there even appears to be executive consensus in the United States that service quality is one of the most important problems facing management today.' There are a number of reasons for this. First, the service industry is increasingly important in the Western world. Cronin and Taylor $(1992$, p. 55) report the findings of several studies which have demonstrated the growing importance of the service industry. According to these studies, 'the proportion of the US population employed in the service sector increased from $30 \%$ in 1900 to $74 \%$ in 1984 , (...), $85 \%$ of all new jobs created since 1982 have been in service industries' and "services currently account for $58 \%$ of the total worldwide GNP.' A similar development can be seen in the Netherlands. According to the CBS (1994), the share of the service sector in Dutch GNP increased from 30\% in 1950 to $50 \%$ in 1992 .

Second, quality is seen as an effective competitive instrument in most service industries, since other marketing instruments are generally less effective in the service market (Neijzen and Trompetter, 1989): ${ }^{3}$

The capital threshold to entry is rather low for most services. It is not easy to edge out competitors by high investments;

The diffusion of innovations is very rapid in services; therefore, it is very difficult to keep an edge on competitors in the long run by developing new types of services;

${ }^{2}$ Note that there is a negative relationship between 'perceived quality" and the 'discrepancy between customer's perceptions and expectations', as long as perceptions do not exceed expectations.

${ }^{3}$ Although this might apply to services in general, these characteristics do not necessarily apply to professional services like auditing. 
Price competition can easily be followed by competitors. Because of the quick diffusion of innovations, it is very difficult to maintain a long-term cost effectiveness advantage over competitors: therefore, price competition is possible only by decreasing the profit margin, which is not an attractive strategy in the long run;

Location is very important in most services; however, it will never be a dominant factor, since consumers are willing to travel further if this is beneficial to the total service package. Moreover, services are often delivered at the customer's home.

Therefore, the traditional marketing instruments can be expected to 'fall short' in distinguishing one's service from the competitors". Giving high attention to quality might be an important competitive instrument in the service market. ${ }^{4}$ Zeithaml et al. $(1988$, p. 35$)$ report the findings of several studies, revealing that "delivering high service quality produces measurable benefits in profit, cost savings and market share.'

Nonetheless, several findings in marketing research warn producers not to rely entirely on service quality. Cronin and Taylor (1992) found that service quality has no significant direct impact on purchase intentions. They conclude that 'perhaps consumers do not necessarily buy the highest quality service; convenience, price, or availability may enhance satisfaction ${ }^{5}$ while not actually affecting consumers' perceptions of service quality.' In contrast, Boulding et al. (1993) found 'that the greater customers' perceptions of a firm's overall service quality, the more likely the customers are to engage in behaviours beneficial to the strategic health of the firm." Bolton and Drew (1991, p. 383) report that 'most authors have viewed value as the outcome of a trade-off between a single "overall quality" construct and sacrifice. However, these results suggest that the customer's value function is more complex. (...) The results suggest that service providers must offer flexible services that satisfy the different tastes and expectations of each market segment.' Parasuraman et al. (1993) assert that 'value is a concept at a higher level of abstraction than quality, that incorporates not just the "get"

In a study of the reactions of competitors to quality improvements, Lemmink (1991) found that competitive reactions to service quality improvements were very tardy, since improvements in this area are difficult to imitate, and this cannot be done rapidly.

${ }^{5}$ According to Parasuraman et al. (1993), price, convenience and availability are not determinants of customer satisfaction, but instead determine "value'. 
components (benefits and desirable features) involved in quality but also the "give" components (price and other sacrifices)."

\subsection{Typical characteristics of services and their impact on the quality concept}

The specific characteristics of services require different quality approaches than those used for tangible products (Kasper and Lemmink, 1989):

Intangibility/perishability: a service cannot be demonstrated (Neijzen et al., 1989), counted, technically measured, inventoried, tested or verified (Parasuraman et al., 1985);

Inseparability: the production of services cannot be disconnected from consumption. The production of services, and the related quality, is highly influenced by the client's presence (DiPrivio, 1987). This interaction ('service encounter') between the service consumer and the service producer also implies that quality perceptions are based on both technical and functional attributes (see Section 2.7); and Heterogeneity: services vary from producer to producer, from customer to customer.

Given these characteristics of services, Parasuraman et al. (1985) conclude: Service quality is more difficult for the consumer to evaluate than physical goods quality. Objective indicators as durability and number of defects cannot be applied;

Service quality perceptions result from a comparison of consumer expectations with actual service performance (given the lack of an objective, easy-to-apply service quality measure); and Quality evaluations are not made solely on the outcome of a service; they also involve evaluations of the process of service delivery.

\subsection{A general model of quality in service industries}

Based on the 'expectations' approach to quality (see Section 2.2) and taking into account the specific features of service quality, Parasuraman et al. (1985) have designed a conceptual model of service quality. In interviews with executives from several service industries and focus group interviews with users of those services, they identified several gaps within the service delivery process that together make up the overall gap between the expected and the actually perceived service level. This is illustrated in Figure 2.1. 


\section{Customer}

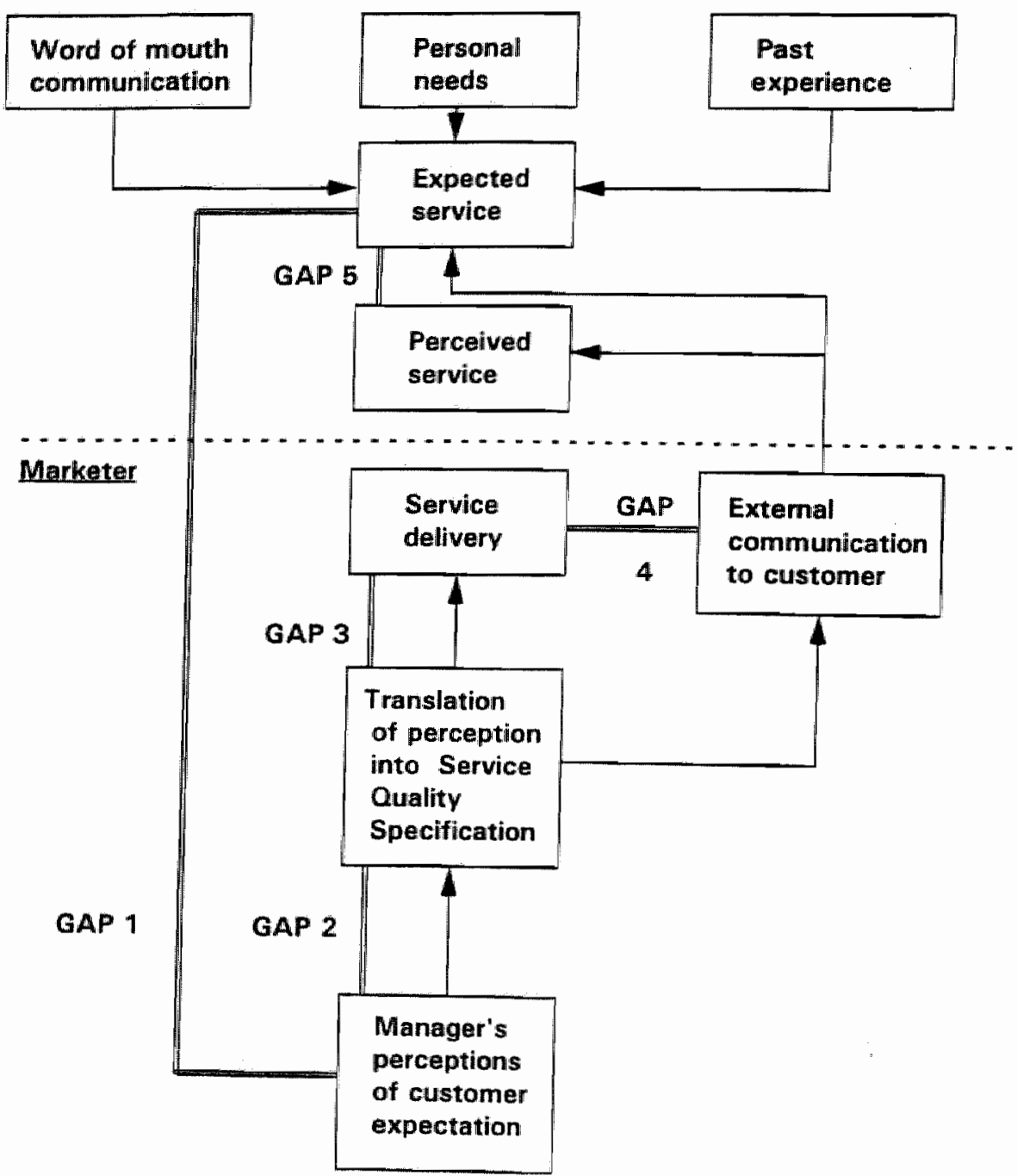

depicts information flows

depicts gaps within the system of service delivery

Figure 2.I The SERVQUAL-model (from: Parasuraman et al., 1985) 
In this model, the following gaps can be distinguished:

Gap 1: difference between consumer expectations and management perceptions of consumer expectations;

Gap 2: difference between management perceptions of consumer expectations and service quality specifications;

Gap 3: difference between service quality specifications and the service actually delivered;

Gap 4: difference between service delivery and what is communicated about the service to customers; and

Gap 5: perceived service quality. ${ }^{6}$

Although certain modifications (see, e.g., Zeithaml et al. ${ }^{7} 1991$; Brouwer et al., 1992) and even rejection (see, e.g., Cronin and Taylor, 1992 and 1994; Teas, 1993 and $1994^{8}$ ) of this gap-model have been suggested over time, there is ample support for its general structure (see, e.g., Brown and Swartz, 1989; Bolton and Drew, 1991). The model may help to explain how certain expectation or perception biases may result in inferior quality. For example, several studies have found that differences between clients' perceptions and managers' perceptions lie at the basis of quality gaps (see, e.g., Kasper and Lemmink, 1989). Although this study does not measure the expectations and evaluations of all parties involved in this process (in auditing: auditors, clients, users of financial statements and standard setters), it does measure expectations and performance evaluations of two important user groups (clients and bankers).

\subsection{Expectations as determinants of quality}

Because of the weight attributed in the SERVQUAL model to expectations, it is important to know more about customers' expectations of services. In the marketing literature, this topic has received considerable attention recently,

${ }^{6}$ Gap 5 results from all previous gaps. Zeithaml et al. (1988) present a conceptual model of the determinants of the several gaps. Their model provides an interesting framework for future empirical research, attempting to test what characteristics of a service company have an impact on the extent of the relevant gaps.

${ }^{7}$ See Section 2.6 for their extension of the model with regard to the nature of expectations.

${ }^{8}$ Their criticism of the SERVQUAL model will be discussed in Section 2.6 . 
but no consensus has yet been reached on the importance of expectations in the quality assessment process. This section will briefly review the recent research in this area.

In order to establish the nature and determinants of expectations, Zeithaml et al. (1991) made an extensive study of the relevant literature. In addition to this, they held 16 focus group interviews with customers of different service industries. Based on this research, they concluded that in perceiving service quality, the actual performance is compared with normative expectations. Under this 'desired service' standard, performance is compared to a 'wishedfor', ideal level of performance: how a brand should perform for the customer to be completely satisfied. Zeithaml et al. (1991) call this desired service 'a blend of what the customer believes can and should be (...) the level of service the customer ought to receive, or deserves, given a perceived set of costs." Their research also indicates that customers recognize it is not always possible to realize their service desires. 'Thus, they have another, lower expectation for the threshold of acceptable service. We define this lower expectation as adequate service, the level of service the customer will accept.' The difference between desired service and adequate ${ }^{9}$ service is called the zone of tolerance, which varies among customers and among service attributes. ${ }^{10}$

Based on their research, Zeithaml et al. (1991) redefined gap 5 (perceived service quality) as

the gap between desired service and perceived service: the perceived service superiority gap;

the gap between adequate service and perceived service: the perceived service adequacy gap.

An entirely different approach to the impact of expectations on perceived service quality is suggested by Cronin and Taylor (1992). In their opinion, service quality should not be viewed in the context of the satisfaction paradigm, but as an attitude. Based on Oliver (1980), they suggest that '(1)

${ }^{9}$ Miller (1977) defines this type of expectation as the minimum tolerable type of expectation.

${ }^{10}$ Zeithaml et al. (1991) made an extensive study of determinants of the different levels of expectations. Although these determinants are an important area of research, this
topic is beyond the scope of this research. 
in the absence of prior experience with a service provider, expectations initially define the level of perceived service quality, (2) upon the first experience with the service provider, the disconfirmation process leads to a revision in the initial level of perceived service quality, (3) subsequent experiences with the service provider will lead to further disconfirmation, which again modifies the level of perceived service quality, and (4) the redefined level of perceived service quality similarly modifies a consumer's purchase intentions towards that service provider." From this study, Cronin and Taylor (1992) conclude that the use of the disconfirmation framework as the primary measure of service quality - the bare essence of SERVQUAL ${ }^{11}$ - is called into question, 'because disconfirmation appears only to mediate, not define, consumer's perceptions of service quality': expectations influence the single-transaction-related disconfirmation process, ${ }^{12}$ which in turn indirectly - affects the service quality perception. Parasuraman et al. (1993), in a critical reaction to the Cronin and Taylor (1992) article, assert that 'SERVQUAL is a tool to obtain a reading of the attitude level, not a statement about how that level was developed' (p. 7): the measurement of quality at a certain point in time cannot be rejected on the basis of longitudinal studies that are merely concerned with the development of quality assessments over time.

Cronin and Taylor (1992) compared the explanatory power of the SERVQUAL model ${ }^{13}$ with the explanatory power of their own SERVPERF model, which was similar to SERVQUAL, except that it measured perceived service performance rather than the gap between perceived and expected service performance. Thus, in the SERVQUAL model quality is explained on the basis of the difference between expectations and perceptions, while in SERVPERF quality is explained on the basis of absolute perceptions.

"In a disconfirmation process, expectations are confronted with perceived perceptions, leading to a renewal of the perception of quality by disconfirmation of the previously held expectations and - to a limited extent - to the modification of the expectations level. This is characteristic for the SERVQUAL approach.

${ }^{12}$ According to Cronin and Taylor $(1992$, p. 56) "the most common explanation of the difference between the two is that perceived service quality is a form of attitude, a longrun overall evaluation, whereas satisfaction is a transaction-specific measure.'

${ }^{13}$ See Chapter 5 for an extensive discussion of the features of the SERVQUAL model. 
Cronin and Taylor (1992) found that the explanatory power was higher for the SERVPERF model than for the SERVQUAL model in each of the four service industries tested. ${ }^{14}$ 15 16 Their findings were confirmed by Boulding et al. (1993), but not confirmed by the results of Bolton and Drew (1991, p. 383), who found that 'a key determinant of overall service quality is the gap between performance and expectations (i.e., disconfirmation). (...) It is interesting to note that disconfirmation explains a larger proportion of the variance in service quality than performance, whereas, in previous studies, performance explains a larger proportion of the variance in customer satisfaction than disconfirmation (...)'. Parasuraman et al. (1994a, p. 120) cite several other studies that also found that the performance-only models had better predictive value than the performance-less-expectation models. However, 'the superior predictive power of the P-only measure must be balanced against its inferior diagnostic value' (Parasuraman et al., 1994a).

Another critical view on the relevance of expectations was provided by Teas (1993). He tested the (Perceived) Performance - Expectation (P-E) quality conceptualization and found several problems:

The expectation can be interpreted by respondents as an indication of the attribute importance or as a forecast instead of as a measure of what a service provider should deliver. This warning should be borne in mind when formulating the statements used in the questionnaire.

\footnotetext{
"SERVPERF"s $\mathrm{R}^{2}$ ranged from $39 \%$ to $48 \%$, whereas SERVQUAL's $\mathrm{R}^{2}$ ranged from $31 \%$ to $47 \%$.

${ }^{15}$ Cronin and Taylor (1992) also tested the weighted SERVQUAL and SERVPERF models. Zeithaml ef al. (1990) suggested the possibility of including importance neasures for each item in the questionnaire. It was suggested that the ability to measure service quality would be improved by multiplying the gap value by the importance value. However, in their tests, the explanatory power of the weighted models proved to be less than that of the unweighted models.
}

${ }^{16}$ Parasuraman et al. (1993, p. 24) found methodological weaknesses in this comparison between the explanatory power of SERVPERF and SERVQUAL. They argued that the dependent variable used in the regression analysis was performance-based rather than disconfirmation-based. 'Therefore, at least some of the improvement in explanatory power achieved by using SERVPERF instead of SERVQUAL may be merely an artifact of the "shared method variance" between the dependent and independent variables.' 
However using the revised SERVQUAL 'expectations' measure ('excellent companies have up-to-date-equipment' instead of the original wording 'They should have up-to-date equipment'; see Zeithaml et al., 1990) is expected to mitigate these interpretation difficulties;

The P-E conceptualization is problematic for attributes to which the 'classic ideal point' concept applies, i.e., for attributes on which a customer's ideal point is at a finite level, so that performance beyond this level will displease the customer (e.g., excessive friendliness of a salesperson in a retail store). Parasuraman et al. (1994a) agree that the P-E conceptualization is only appropriate if the attribute is a vector attribute or a classic ideal point attribute and perceived performance is less than or equal to performance. However, using data material from Teas (1993), they argue that classic ideal point attributes are rather rare and that the P-E conceptualization is therefore appropriate for more than $95 \%$ of the attributes; and

The P-E conceptualization appears to indicate that a service for which both the performance and the expectation scores are 7 (representing very high expectation and performance levels) is deemed to provide the same quality as a service for which both the performance and the expectation are 1 (representing very low expectation and performance levels). According to Teas (1993), additional research is required to test the validity of this assumption.

To summarize, the research findings regarding the effect of expectations on service quality perceptions are inconclusive. Parasuraman et al. (1994a, p. $112)$ conclude that ' $(\ldots)$ the issue of comparison norms and their interpretation has not yet been resolved fully.' Because of this lack of clarity, this study will test different models to conceptualize the relationship between overall audit quality and the underlying technical and functional audit quality attributes (see Chapter 5).

\subsection{Service quality attributes}

According to Grönroos (1984), quality can be classified into two categories: Technical quality, relating to the quality of the result or outcome of the service, i.e. what the customer is actually receiving from the service; and

Functional quality, relating to the manner in or process by which a service is provided, i.e. how the service is delivered. 
Because customers find it hard to assess the intrinsic quality of the service - the result of the service - Grönroos asserts that functional quality is critical in the evaluation of service quality.

As a result of the executive interviews and the focus group interviews with service consumers, Parasuraman et al. (1985) found that, "regardless of what type of service, customers used basically similar criteria in evaluating service quality.' In the first stage of development, they found 10 criteria or attributes, on which they based their initial service quality questionnaire. The development and refinement of this questionnaire will be discussed in Chapter 5. In its final version, this SERVQUAL questionnaire (see Zeithaml et al., 1990) consists of 22 items, grouped together into 5 attributes:

- Tangibles: physical facilities and equipment and the appearance of personnel;

Reliability: the ability to perform the promised service dependably and accurately;

Responsiveness: the willingness to help customers and provide prompt service;

Assurance: knowledge and courtesy of personnel and ability to convey trust and confidence;

Empathy: caring and individualized attention to customers.

Appendix 1 gives the underlying questions for each of these attributes. In Chapter 3, the five attributes will be discussed extensively. All the attributes included in this standard SERVQUAL questionnaire appear to be functional (see Lapierre and Filiatrault, 1995). Even the reliability dimension seems to be more related to the 'process' than to the 'outcome' of the service. Given the claim by Parasuraman et al. (1985) that these items are generic, this finding is hardly surprising. Since technical or output measures will necessarily reflect intrinsic aspects of the service provided, it would be most unlikely that a questionnaire including technical quality questions would be suitable for use regardless of the type of service.

\subsection{Audit quality}

In line with the service quality literature, audit quality will be defined as the degree to which perceived auditor's performance meets expectations. As in other service industries, quality in auditing can be subdivided into functional audit quality and technical audit quality. Functional audit quality can be defined as the degree to which the process of carrying out the audit and 
communicating its results meets a consumer's expectations. Not unlike the users of other (professional) services, the users of audit services (including auditees and third party beneficiaries, like bankers or stockholders) will - to some extent - base their quality assessment on items like the reliability or responsiveness of the auditor. Functional audit quality attributes will be discussed in Section 3.2. Technical audit quality can be described as a consumer' ${ }^{17}$ assessment of the degree to which the audit meets his expectations with respect to the detection and reporting of errors and irregularities regarding the audited company and its financial statements. ${ }^{18}$ Technical audit quality attributes will be discussed in Section 3.5.

\subsection{Summary}

In this chapter we addressed certain developments in the conceptualization of quality, service quality and audit quality. Parasuraman et al. (1985) have conceptualized perceived (service) quality as the gap between a consumer's perception and his expectations regarding attributes of a service. These attributes can be either functional - relating to the process of the service delivery - or technical - relating to the outcome of the service. The importance of customer expectations for service quality perceptions has been - and still is - the subject of extensive discussion in the marketing literature. As a result of this discussion, several service quality models have been proposed. In our empirical study, three different (audit) quality conceptualizations will be tested, based on concepts proposed in recent marketing research.

${ }^{17}$ The term 'consumer' refers to all individuals who rely on audits, i.e. both auditees and other users of financial statements.

${ }^{18}$ This definition is in line with previous definitions of technical audit quality, if the output of the audit is strictly defined as the detection of and reporting on errors and irregularities by the auditor. Since, in this study, respondents were explicitly asked to give their ratings purely based on the audit function, the definition holds. This means that, for example, the identification of points of interest regarding tax, corporate finance and internal organization is regarded as a functional rather than a technical aspect, since it is a side-product, resulting from the specific audit approach and communication conducted by the auditor in the process of carrying out his audit. 



\section{CHAPTER 3 NATURE AND ATTRIBUTES OF FUNCTIONAL AND TECHNICAL AUDIT QUALITY}

\section{I Introduction}

This chapter will discuss both functional and technical audit quality attributes. The research regarding functional audit quality is rather limited (Section 3.2). Therefore this section will be based on the 'generic' functional quality attributes found by Zeithaml et al. (1990). From Section 3.3 on, we will discuss technical audit quality. This topic has received considerably more interest in audit research. The definition of technical audit quality which is used here will first be compared with the (technical) audit quality concept of DeAngelo (1981b). Section 3.4 will then provide a framework for formulating hypotheses on the importance of technical attributes for overall audit quality assessments by clients and bankers. The framework is based on agency theory and previous empirical evidence. Section 3.5 will discuss the technical audit quality attributes that appeared to be important in several previous expectation gap studies, in which expectations and perceived performance regarding various auditors' duties were measured among several groups within the financial community. Expectations regarding the importance of each of these attributes for overall audit quality will then be formulated. Finally, Section 3.6 will summarize the hypotheses on the importance of functional and technical attributes for the overall audit quality assessments of clients and bankers.

\subsection{Functional audit quality attributes}

In Section 2.8, functional audit quality was defined as the degree to which the process of carrying out the audit and communicating its results meets a consumer's expectations. As discussed in Chapter 2, functional quality seems to play a very important part in overall quality assessments by clients. ${ }^{1}$ Since the body of previous audit research on functional quality is rather limited

${ }^{1}$ The importance of functional quality will vary for the different types of services and client-marketer relationships. However, most of the SERVQUAL based research - with quite some variation in the types of services and relationships - has demonstrated the relevance of functional attributes. This research included professional services and business to business service relationships (e.g., Kasper and Lemmink, 1989). 
(e.g., Shockley and Holt, 1983; Schroeder et al., 1986; Carcello et al., 1992; Vriens et al., 1992; Scott and Van der Walt, 1995), we will focus primarily on the functional audit quality attributes identified as generic by Zeithaml $e t$ al. (1990). Their claim of generic applicability is not undisputed, however. Carman (1990) found that some factors are generic, while others are industryspecific. Therefore, we will perform separate factor analyses on the data from this study, and hence will create specific factor structures (in Chapter 6). However, the hypotheses regarding the importance of the functional attributes for overall audit quality will be based on the 'generic' attributes.

Zeithaml et al. (1990) identified the following generic factors:

\section{Tangibles.}

This factor relates to the physical facilities and equipment used in delivering the service and to the appearance of personnel. In SERVQUAL, questions are asked regarding the visual and technical aspects of facilities used in providing the service. Also, the physical appearance of contact personnel is addressed. For example, Carcello et al. (1992) found that extensive use of micro-computers in conducting the audit had a positive effect on the quality assessments of their respondents. Since both clients and bankers have personal experiences with the auditor, we assume a positive relationship between their overall quality assessments and the score on the tangibles dimension.

\section{Reliability.}

This is defined as the ability to perform the promised service dependably and accurately. In the SERVQUAL questionnaire, questions regarding the timeliness of the provision of services and the dependability and attitude of the service company in solving the client's problems measure this attribute. Shockley and Holt (1983) asked 30 Chief Financial Officers of large US banks to rate the importance of 10 attributes; reliability was rated as the fourth most important attribute. Vriens et al. (1992) found reliability as an important factor in the assessment of the performance of an auditor by auditees. The reliability dimension is expected to be of interest to both clients and bankers. Both groups will appreciate an auditor who delivers his services at the time that was agreed upon. And, since both groups have more or less frequent contacts with the auditor, they are assumed to appreciate a dependable attitude. Because such an attitude 
is considered crucial for an auditor and a key issue in his image, this attribute is expected to be a very significant determinant of overall audit quality for both clients and bankers.

\section{Responsiveness.}

This factor relates to the willingness to help customers and provide prompt service. In the SERVQUAL questionnaire, this attribute is measured by questions regarding the service company's willingness to promise deadlines, to provide prompt responses to service requests and to show a helping attitude to customers. Carcello et al. (1992) found that responsiveness to a client's was the third most important factor in explaining audit quality judgments by clients, audit partners and bankers; ${ }^{2}$ so did Shockley and Holt (1983). We hypothesize a direct relationship between a client's overall audit quality assessment and an auditor's responsiveness to his needs. As discussed previously, bankers are also exposed to contacts with auditors. An auditor's prompt reaction to requests for information by a banker - within the limitations of client confidentiality - will also be appreciated by the banker. However it seems reasonable to suppose that bankers will be immediately exposed to an auditor's responsiveness less often than clients. Again, a positive relationship between responsiveness to a banker's needs and a banker's overall quality assessment is hypothesized, although weaker than for clients.

\section{Assurance.}

Assurance deals with the knowledge and courtesy of employees and their ability to convey trust and confidence. SERVQUAL measures this dimension by asking questions about security or confidentiality, knowledge and politeness of personnel and backing of the personnel by the firm. Client's feelings of assurance would be expected to be enhanced by a high degree of knowledge and experience on the part of

${ }^{2}$ Since their survey addressed responsiveness to a client's needs, there was a big difference between clients' and bankers' evaluations of the contribution of this attribute to audit quality. Where clients thought this attribute provided a very significant contribution to audit quality, bankers did not think so. Perhaps bankers understood "responsiveness to client's needs' as an auditor's willingness to go along with misrepresentations suggested by clients. However our study did not directly ask bankers how they regard an auditor's responsiveness to a client. Instead, we are interested in the impact on a banker's quality assessment of functional service attributes in the relationship between the auditor and the banker himse]f. 
the auditor. Shockley and Holt (1983) found 'competence' and 'professionalism' as the two most desirable characteristics of auditors. Schroeder et al. (1986) report that audit-committee chairpersons found that the skills and experience of team members have a strong impact on perceived audit quality. Carcello et al. (1992) found that the industry expertise of the key personnel was the second most important factor in explaining audit quality assessments by their respondents. Vriens et al. (1992) found expertise as the criterion most frequently mentioned (by auditees) in judging an auditor"s performance. Finally, Scott and Van der Walt (1995) found that 'wide range of services offered' - indicating a high degree of knowledge and expertise was the third most important variable in the choice of an audit firm. Brouwer and Reuyl (1992) found that assurance was the third most important factor in explaining quality in the banking industry. We hypothesize that there is a positive relationship, for both clients and bankers, between assurance and their overall quality assessments. As was the case with reliability, this attribute is so important for an auditor's image that it is expected to have a similar impact on the overall audit quality perceptions of both clients and bankers.

\section{Empathy.}

This factor deals with the caring and the individualized attention the firm provides to its customers. SERVQUAL measures this dimension by asking questions regarding knowledge of and care for client-specific and industry-specific needs and clients' ease of access to the firm's employees. Vriens et al. (1992) found a personal relationship as one of the crucial criteria for auditees in making judgments about an auditor's performance. Scott and Van der Walt (1995) found that 'personal service' (including accessibility and providing 'one-to-one' service) was the second most important factor for CEOs in New Zealand in choosing an accounting firm. According to Hunger (1981), the ease of access to the firm was an important criterion in the selection of an audit firm for $36 \%$ of the respondents, which made it the second most important criterion (after the competence of the auditor). It seems reasonable to assume that, in auditing, understanding a client's business and needs and ease of access to an audit firm's employees will be appreciated by the client. Empathy will also be appreciated by bankers, since it is essential for a good service to the client. However, because of the auditor's greater distance to the banker and the specific client orientation of this factor, it is expected to be less important for overall audit quality in the case of bankers. 


\subsection{Technical audit quality definitions}

In Section 2.8, technical audit quality was defined as a consumer"s assessment of the degree to which the audit meets his expectations with respect to the detection and reporting of errors and irregularities regarding the audited company and its financial statements. This definition is more or less in line with DeAngelo (1981b, p. 186), who defines the quality of audit services as 'the market-assessed joint probability that a given auditor will both

(a) discover a breach in the client's accounting system, ${ }^{3}$ and

(b) report the breach'. ${ }^{56} 6$

This definition is widely accepted in audit research (see Menon and Williams, 1991; Deis and Giroux, 1992).

The following remarks should be made regarding the application of this definition in this study:

The focus of the definition is on technical audit quality. Given the discussion in the previous section of the importance of considering functional attributes in studying audit quality assessments, it seems evident that these attributes should be included in an audit quality definition;

Using quality constructs from marketing research, Chapter 2 has modelled audit quality as a comparison of expectations and perceptions. The impact of expectations on audit quality judgments is not made explicit in the definition of DeAngelo (1981b). However, some expectation gap studies illustrate the importance of considering expectations regarding audit services. These studies demonstrate that the expectation the financial community has of the attestation function

"In this study, this part of the definition will be referred to as the "detection part".

"In this study, this part of the definition will be referred to as the "reporting part".

${ }^{5}$ In DeAngelo (1981a), this second part of the definition reads: 'withstand client pressures to disclose selectively in the event a breach is discovered.' It focuses on the most important element of the disclosure part of the definition: 'independence'.

${ }^{6}$ Knapp (1985) stresses that the second part of the definition is an essential addition to definitions in which audit quality is solely related to the reduction of detection risk to an acceptable level. The inclusion of 'independence' as a prominent part in the international audit quality guidelines (e.g., IFAC Exposure Draft on Quality Assurance, $1991)$ suggests that the professional bodies agree on its importance for audit quality. 
of auditors goes beyond giving an opinion on the accuracy of financial statements. In the words of the Cohen Commission (AICPA, 1978, p. xxii): "Traditionally, this engagement, has been referred to as an audit of financial statements. However, this concept is not sufficiently flexible for the future evolution of the auditor's role and responsibilities. The audit function must be broader than the traditional association with financial statements.' According to this and other expectation gap studies - which will be discussed in this chapter expectations might include auditors' opinions on

The audited company's ability to continue as a going concern;

The quality of the internal control system;

The occurrence of fraud; and

The occurrence of illegal acts.

Each of these areas can be put into the framework of technical audit quality that is used in this study and can therefore be regarded as an attribute of technical audit quality. The next sections examine the findings of previous research, as a basis for the formulation of hypotheses regarding the effect of these attributes on overall audit quality.

\subsection{The importance of technical audit quality for overall audit quality}

There are numerous anecdotal justifications for giving attention to technical audit quality on a profession-wide level. ${ }^{7}$ Mautz and Matusiak (1988, p. 56) cite James C. Treadway, Jr., then SEC commissioner and later Chairman of the National Commission on Fraudulent Financial Reporting, in an address at the 1985 AICPA Conference on Current SEC Developments: 'I finally predict that the $[\mathrm{SEC}]$ and the accounting profession will find no respite from public criticism until we, along with the issuer community, are willing to say together, without quibble or qualification, that our common goal is zero audit failures. That means no protestations of 'it costs too much to achieve perfection", and no hiding behind cost-benefit equivocations. That zero audit

${ }^{7}$ Watts and Zimmerman (1983, p. 633), putting the development of the audit profession in a historic perspective, conclude that 'the pervasiveness of voluntary (costly) auditing in the precursors to the modern corporation is consistent with auditors' developing quality-assuring devices - in particular, mechanisms that increase the probability the auditor will report a breach in a contract he is to monitor (that is, be independent).' 
failures may not be achievable is not the issue; the failure to make this commitment will only strengthen the existing negative perceptions.'

The importance of delivering good technical audit quality as a competitive factor can be derived from agency theory. ${ }^{8}$ In this theory, the appointment of a reputable auditor - an auditor who is perceived to meet expectations - is not only in the interest of third parties, but also in the interest of management. In agency theory, a company is viewed as the result of more or less formal 'contracts', in which several groups make some kind of contribution to the company, given a certain 'price'. Company management tries to get these contributions under conditions optimum for management: low interest rates from bankers, high share prices from stockholders, low wages from employees. In these relationships, management is seen as the 'agent', trying to obtain contributions from 'principals' such as bankers, stockholders and employees. Several types of complexities arise in these relationships, one being information asymmetry (Van de Poel, 1986; Dassen, 1989). Agent 'management' has a considerable advantage over the principals regarding information about the company. Basically, management knows more about the company's ability to repay loans than the banker does, and it knows better than the stockholders what the actual profit is, or whether it enjoys excessive perquisites. And management knows better than the employees whether the company's financial condition is such that everybody will still be employed next year. Reducing this information asymmetry can be a successful strategy by agent 'management' to get the principals' contributions under favourable conditions. In order for this voluntary provision of information to work, the information must be reliable. According to Benston (1985, p. 41), the engagement of a reputable firm of public accountants is particularly desirable for a large enterprise with dispersed ownership, "because the original owners realize that, if they sell a majority of their voting shares and if the resulting equity ownership is diffuse, they will be ceding the power to hire and fire the auditors to the managers.' The incentive of both managers and outside investors to engage reputable auditors

${ }^{8}$ Agency theory is typically used to explain the economic behavior of contracting parties. According to Abdel-Khalik and Solomon (1988, p. 159), agency theory is well suited to explain the hiring of an auditor in a situation where a company engages in external financing. Other explanations for the demand of audit services are regulation, suppliers (including employees) and customers and internal management. As described in Abdel-Khalik and Solomon (1988), the potentially conflicting demands of these different sources of demand for audit services might require additional theory development, not necessarily restricted to agency theory. 
and, conversely, the incentives of auditors to maintain or improve their reputations, are stressed by Benston (1985, p. 39): 'Public accountants are useful to owner-managers for assuring outside investors that the internal control system will be maintained and that the owner-managers' reports will not be false or misleading because they have a strong incentive not to be suborned by the owner-managers. Since public accountants are organized as continuing partnerships, they also are likely to be in business for a long time and have a continuing interest in maintaining their reputations. Indeed, it seems likely that public accounting firms structured themselves as continuing partnerships to assure clients that they would continue to be in business and would be individually and jointly liable for breaches of contract.'

An empirical study by Wilson and Grimlund (1990) illustrates this point made by Benston (1985). Their findings indicate that SEC disciplinary actions against an audit firm affected both market share, and the ability to retain clients, adversely. Dopuch and Simunic (1982) tested the impact of the public rebuke Peat, Marwick, Mitchell and Co. received after the firm was involved in a series of highly publicized audit failures. They demonstrated that, in this period of negative publicity, the firm experienced a considerable loss in audits of publicly held over-the-counter (OTC) companies. Firth (1990) found that firms which had been criticized by the U.K. Department of Trade suffered a small loss in market share. Menon and Williams (1991) tested the hypothesis that a company"s initial price offering (IPO) is an incentive to engage a more credible auditor. They found moderate evidence that IPOs were associated with changes to more credible auditors. Finally, they found that bankers charged a smaller fee to clients with a more reputable auditor.

Agency theory, the findings of the above-mentioned empirical research and the findings of voluntary external audit studies (see Maijoor, 1991, Chapter 5) suggest that both agent 'management' (in this study: clients) and principals (in this study: bankers) will benefit from high technical audit quality. Therefore, a positive relationship between technical audit quality and overall audit quality seems obvious. For the detection part of the audit quality definition, this relationship can be expected to hold for both clients and bankers, based on the theoretical and empirical research discussed. For bankers, a good detection ability is seen as crucial, since failure to detect errors might reduce the reliability of the financial statements. For clients, an auditor with a well-developed detection ability is valuable, because he can draw management's attention to errors or irregularities within the financial 
statements or the company that were not detected or reported by the internal control system. Furthermore, the reputation of a well-developed detection ability is beneficial for clients, since it enhances the value of the audit function for stakeholders and so reduces agency costs. For the reporting part of quality (independence), however, this relationship is less clear. For bankers, a positive relationship can be assumed, because they will benefit from auditor independence, since it helps to reduce information asymmetry. Clients, on the other hand, might perceive a negative relationship. Although they, too, will benefit from the appearance of independence of their auditor, they might perceive factual independence as awkward, since it might reveal information to the principals that management would rather have kept a secret. Put differently: clients (management) are expected to like the auditor to be 'tough' on other clients (enhancing his appearance of independence and thus his value to management), but 'soft' on themselves.

Several studies have been conducted in this area. DeAngelo (1982), referring to the Chow and Rice (1982) study, asserts that an initial qualification of an audit report might lead to auditor change. ${ }^{9}$ Roberts et al. (1990), in their study of determinants of auditor change in the public school district sector, found 'that reports by independent auditors of material weaknesses in internal accounting controls or violations of nepotism, pecuniary interests, or competitive bidding laws are related to auditor changes.' These studies confirm that auditors incur a serious risk of losing an engagement by resisting management pressure against qualification of their opinion or other unfavourable types of reporting. On the other hand, of course, there is the risk of losing reputation by succumbing to management's pressure. In Chapter 4 , the influence of audit engagement characteristics on the issue of independence will be discussed.

To summarize, high detection ability is expected to increase overall audit quality for both clients and bankers. Bankers are also expected to perceive a positive relationship between independence and overall audit quality. Clients' perceptions of overall audit quality are expected to decrease with independence.

"The removal of a publicly-known qualified opinion, however, is unlikely to be an important motivation for changing auditors. A new auditor who thas his reputation at stake will be reluctant to issue an unqualified opinion when the prior auditor has qualified" (DeAngelo, 1982, p. 184). 
Section 3.5 will discuss the various technical audit quality attributes. Although the above-mentioned relationships are assumed to hold for each of these attributes, the relative weights of these attributes for overall audit quality will vary. For each attribute identified in Section 3.5, we will generate expectations about its relative weight in the explanation of overall audit quality.

\subsection{Attributes of technical audit quality}

Agency theory has been primarily used to explain the demand for services regarding the audit of financial statements. However, expectation gap studies have demonstrated that the public demand goes beyond the audit of financial statements. According to most of these studies, the auditors' duties are expected to (ideally) include the detection and (public) reporting of potential going concern problems, internal control weaknesses, fraud or illegal acts. Although different in their nature and their importance for overall audit quality, each of these attributes can be viewed in the context of agency theory as a potential demand for reliable company information on behalf of several 'principals'. ${ }^{10}$

The discussion below will be based on the outcomes of the following expectation gap studies:

Commission on Auditor's Responsibilities/Cohen Commission (USA, 1978);

Hunger (Germany, 1981);

Limperg Instituut (The Netherlands, 1987);

CICA (Canada, 1988);

Porter (New Zealand, 1991); and

Humphrey et al. (UK, 1991a,b,c).

The outcomes of these studies will be used to generate hypotheses about the importance of these technical audit quality attributes for overall audit quality.

${ }^{10}$ Within the framework of the audit quality definition of DeAngelo (1981b), each of these attributes can be seen as the discovery and reporting of a breach in the client's accounting system. 


\subsubsection{Opinion on accuracy of financial statements}

Giving an opinion on the accuracy of the financial statements is generally regarded as the auditor"s "core business'. In the terminology of DeAngelo (1981b), this attribute is determined by the auditor's ability to discover an error in the financial statements ("detection part') and his willingness to report the error ('reporting part'/independence). Given its traditional importance and its status as the 'core business', it is hardly surprising that this attribute gets considerable attention in national and international auditing guidelines.

With regard to the detection part, the expectation gap studies demonstrate that public expectations are quite high. The inherent limitations of auditing, expressed in materiality and audit risk, are not entirely accepted and/or understood by all groups of users of financial statements, although the more knowledgeable groups (to which both clients and bankers belong) are more or less familiar with these concepts (CICA, 1988; Porter, 1991). Auditor independence with regard to the reporting of errors in the financial statements was also tested in the expectation gap studies. Overall, the expectations with regard to this type of auditor independence were very high and - in most studies - exceeded the auditors' perceived performance in this area (Hunger, 1980; CICA, 1988; Humphrey et al., 1991a).

Summarizing, public expectations of the auditor's duties regarding the detection and reporting of errors in the financial statements are high. This attribute is expected to be regarded as the auditor's traditional core business by both bankers and clients. Failure to meet expectations regarding these attributes - either the detection or the reporting part - is therefore expected to have a high negative impact on bankers" overall audit quality assessments. For clients, this is expected to be the case for the detection part, but they are expected to perceive a negative relationship between independence (the reporting part), and overall audit quality, given the general analysis in Section 3.4 .

\subsubsection{Opinion on ability to continue as a going concern}

Perhaps the most 'disturbing' events for the public's trust in the audit profession are cases where an unqualified auditor's report has been issued shortly before a company's bankruptcy. Under the regulations of the American (SAS 59), the British (SAS 130) and the Dutch profession, auditors need to determine whether the audited entity is able to continue as a going 
concern. If there are serious doubts about this ability, both the financial statements and the auditor's opinion need to express these doubts. However, it is generally felt that auditors face a dilemma in this regard (see Porter, 1989). Although warning the users of financial statements of any threatening financial distress is appropriate, the disclosure of the indications of a possible future bankruptcy - especially when the future course of events is hard to predict - may prove to be a self-fulfilling prophecy which deprives management of its remaining means to save the company.

The expectation gap studies reveal that expectations with regard to this attribute are quite high; the auditors' performance, however, is generally rated as unsatisfactory (Limperg Instituut, 1987; Porter, 1991). Further, these studies show that the expectations of some groups within the financial community clearly exceed the auditor's current duties under the prevailing national and international audit guidelines. An important minority seems to believe that an unqualified audit report means that the continuity of the company is not endangered (Hunger, 1980; Limperg Instituut, 1987; CICA, 1988).

In short, public expectations of the auditor's duties regarding the detection and reporting of going concern risks are quite high. Auditors" perceived performance falls short in this respect. Given the regulations, this duty is regarded as a traditional duty, belonging to the auditor's current obligations. Bankers are expected to consider the auditor's detection ability and independence regarding the going concern issue crucial in their overall audit quality assessments, since they are expected to believe that a timely warning about going concern risks enables them to take the necessary action to safeguard their interests. Clients are also expected to perceive the timely detection of going concern risks as essential for overall audit quality. However, as addressed in Section 3.4, they are expected to perceive public reporting of going concern warnings as a negative factor in overall audit quality assessment.

\subsubsection{Opinion on the company's internal control system}

The issue of testing and reporting on the quality of a company's internal control system has been recognized as one of the focal issues in auditing.
Hooton and Landsittel $(1991$, p. 11), who are audit partners themselves, assert that testing and reporting on the effectiveness of a company's internal control system would serve 'the ultimate public interest': 'We report on results 
- that is, a snapshot of an enterprise's financial position at a given moment in time and the results of its efforts for an elapsed period, but not on the processes that generated these results and the financial presentation of them. (...) Investors are eager to know whether the company is in control.' The present regulation in the Dutch auditing profession does not require an examination of the internal control structure. If the audit objectives can be met by substantive testing, it is acceptable not to examine the internal control structure. However, reliance on the firm's internal controls in performing an audit became a major pillar in Dutch auditing during the 1980s (Wallage, 1991). Reporting on the effectiveness of internal controls has become a predominant item in management letters (NIVRA, 1994). In the UK and the US, the examination of internal controls is increasingly being acknowledged as part of the audit function; ${ }^{11}$ the outcomes of the Cadbury report (Committee on the Financial Aspects of Corporate Governance, 1992) in the UK and the COSO report (Committee of Sponsoring Organisations of the Treadway Commission, 1992) in the US may carry this development even further.

The expectation gap surveys show high expectations of the auditor's role in testing whether a satisfactory system of internal control is being operated. Interestingly, these expectations are even high among auditors themselves (Porter, 1991; Humphrey et al, 1991a), even though it is currently not required. Perhaps current practice is such that the system of internal control is tested in nearly all cases for efficiency reasons, suggesting to users of audit services and even auditors themselves that these tests are required. Again, however, the perceived performance of auditors does not meet these high expectations (Limperg Instituut, 1987).

To summarize, the public expectations of auditors" duties regarding the detection and reporting of internal control weaknesses are quite high; auditors" perceived performance falls short in this respect. This duty is probably perceived as a traditional duty of auditors. Although it is not an 'official' duty of auditors, testing internal controls has become a very familiar

"In fact there are already several guidelines in the UK and the US that require the auditor to report to regulatory authorities if there are severe weaknesses in the internal control system of companies in a number of industries (e.g., financial institutions). 
audit procedure. ${ }^{12}$ Failure to meet expectations regarding these attributes on either the detection or the reporting part - is therefore hypothesized to have a relatively high negative impact on bankers' assessments of overall audit quality. The quality of a company's internal control system is important for bankers" risk assessments. Timely warning about shortcomings in this system might enable them to take action to safeguard their interests. For clients, the detection of shortcomings in the internal control system is also traditionally seen as one of the important spin-offs of the audit process. However, as was said in Section 3.4, the public reporting of these shortcomings is expected to have a negative impact on the client's perception of overall audit quality.

\subsubsection{Opinion on the occurrence of fraud}

According to Humphrey et al. (1991b), "the auditor's responsibility with respect to fraud has been one of the issues which has been associated most persistently with questioning the adequacy of audit performance and with the notion of an audit "expectation gap".'. The fact that this part of the expectation gap has attracted so much attention is partly attributable to the evolution of auditing.

In their review of the historical development of the audit profession's views regarding the issue of 'fraud', Humphrey et al. (1991b) cite from Dicksee's 1900 edition of 'Auditing - A Practical Manual for Auditors', which states: 'The object of an audit may be said to be threefold:

1. The detection of fraud

2. The detection of technical errors

3. The detection of errors of principle

(...) The detection of fraud is a most important portion of the auditor's duties. Auditors, therefore, should assiduously cultivate this branch of their activities.'

\footnotetext{
${ }^{12}$ Another reason for assuming that the financial community considers this duty as 'traditional' is related to the system of audit reports in the Netherlands. For many small and nedium-sized companies, a disclaimer of opinion is given. This disclaimer is justified by stating that the company's internal organization is such that it does not permit the auditor to test the completeness of sales recognition. The knowledge that this type of opinion exists might lead users of financial statements to believe that the test of the internal controls is an auditor's traditional duty.
} 
Gradually, the auditor's responsibilities began to change, with fraud no longer being a key priority. This has been demonstrated by some researchers (Porter, 1989 , p. 9; Humphrey et al, 1991b, p. 7) by the changing priority of the fraud issue in Montgomery's Auditing. In its first three editions, fraud was labelled as a chief audit objective but its priority was gradually eroded until, in the 1957 Eighth Edition, it was described as a 'responsibility not assumed'.

According to Humphrey et al. (1991b), this development 'away from fraud' was due to several circumstances:

Growth of the size of businesses, making integral audits aimed at detecting all types of fraud virtually impossible;

Assumption by corporate management of a greater responsibility for fraud detection; and

Broad acceptance of the increasingly uneconomic nature of audit-based fraud detection.

The 'total' rejection of responsibility for fraud which is evident from this historical outline has given way to a renewed discussion in the 1980s. Under public pressure, culminating in the installation of several committees such as the Cohen Commission (Commission on Auditor's Responsibilities, 1978) and Treadway Commission (Committee of Sponsoring Organisations of the Treadway Commission, 1987) and the 1988 Dingell Committee in the US, and the Davison and Benson Committees in 1985 in the UK, to investigate the reasonableness of the auditors' position regarding fraud, the profession was forced to reconsider its 'total rejection' stance.

After extensive discussion between the Dutch professional bodies and the Dutch government, the auditors' duty regarding the detection of and reporting on fraud has been regulated recently (NIVRA, 1995). To summarize the regulation in a few words, the auditor is basically held responsible for the detection of material fraud. If a fraud is discovered, this should be reported to management, and in many circumstances to the supervisory board. If material fraud or indications of material fraud have been reported to the management and supervisory board, but no action has been taken to eliminate the consequences of the fraud or to avoid repetition of the fraud, the auditor should resign and report his resignation and his reasons to a government agency. Succeeding auditors are required to report their acceptance of the audit engagement to this agency and are only allowed to accept if certain conditions are met (elimination of consequences and initiation of measures to avoid future repetition). In many other countries, auditors' responsibilities 
regarding the detection of (material) fraud are comparable to the situation in the Netherlands. As far as compulsory withdrawal and reporting of withdrawal due to fraud to the authorities is concerned, the Dutch regulations go beyond those in most other countries (including the US and the UK). ${ }^{13}$ As far as the public's expectations regarding the detection and reporting of fraud are concerned, the expectation gap studies again show very high expectations with regard to the detection of fraud. With regard to the public reporting of fraud - either in the audit report or to authorities - the studies are inconclusive, since there is no consensus between the several groups of respondents. The auditors' performance with regard to the detection of fraud also provides mixed results, depending on the type of fraud (Porter, 1991) and the study involved (Limperg Instituut, 1987; Porter, 1991). The auditors' performance on the public reporting of fraud is generally perceived as low. Thus it is hardly surprising that most expectation gap studies indicate that respondents do not believe that an unqualified audit report guarantees the absence of fraud.

To summarize, public expectations of the auditors' duties regarding the detection of fraud are quite high (performance: mixed). Expectations regarding the reporting of fraud are mixed, given the variation in expectations over the user groups (performance: low). Apparently this duty is not seen as a traditional duty, given both the inconclusive results of the expectation gap studies and the fact that - at the time of the empirical survey - no agreement had been reached in the Netherlands on auditors' responsibilities in this matter.

Bankers are not expected to find this attribute very important for their overall audit quality assessments, since a fraud does not directly affect their interests unless it would significantly influence the company's going concern ability or the financial statements. Clients, however, are expected to find the detection of fraud important for overall audit quality, since fraud is normally perceived by management as potentially dangerous for the organization's discipline.

${ }^{19}$ However, in these countries additional requirements apply for specific industries, especially financial institutions. For example, the UK has the Financial Service Act of 1986, the Building Societies Act of 1986 and the Banking Act of 1987. These three acts give the auditor the right (not the duty) to inform the supervisory authority, if 'he or she thinks it is expedient to do so to protect shareholders and depositors, or at the regulators" request' (Humphrey et al., 1991b). This right enables them to report without breaking the regulations regarding confidentiality. 
Nonetheless, the impact of this attribute on overall audit quality will be less than for the more traditional items, since clients might recognize that the auditors' duties in this regard were still being publicly debated at the time the study was conducted. The public reporting of illegal acts is expected to have a negative impact on the client's perception of overal audit quality, given the analysis in Section 3.4 .

\subsubsection{Opinion on the occurrence of illegal acts}

Closely related to the subject of fraud is the auditor's reaction to the occurrence of illegal acts in a company. The AICPA's SAS no. 54 'Illegal Acts by Clients' (AICPA, 1988b) states that the auditor's responsibility in this area is restricted to designing and executing his audit in such a way that he has a reasonable expectation of detecting material illegal acts which have a direct impact on the form and content of the financial statements. The regulations in the UK are similar.

As far as the reporting of illegal acts is concerned, both the US and UK regulations require the auditor to assess the (potential) impact on the financial statements and determine the consequences of the uncertainty or error in the financial statements for the nature of the opinion. Apart from reporting the acts through the report, US auditors are required by SAS no. 54 to inform members of the audit committee or board of directors. Informing third parties is not allowed, except for some very special, narrowly-defined circumstances. The latter also applies to the UK. In the Netherlands, the auditor's responsibility with regard to the detection of illegal acts is basically restricted to the detection of illegal acts that are relevant for the audit of the financial statements. The responsibility with regard to the reporting of illegal acts is comparable with the regulations regarding fraud in the Netherlands (NIVRA, 1995).

As was the case for the fraud issue, the expectation gap studies reveal mixed results. Again, the responses vary with the type of illegal act, the study involved and the type of respondent group. Most studies reveal, however, that respondents expect the auditor to detect and report illegal acts that have a significant impact on the financial statements. Both bankers and clients are expected to give this 'non-traditional' duty the same weight in assessing overall audit quality as the duties regarding fraud. Thus the impact of both the detection and public reporting of illegal acts on overall audit quality is expected to be limited for bankers. For clients, the impact of the detection of 
illegal acts on overall audit quality is expected to be more important, while the impact of public reporting of illegal acts is expected to be negative, given the analysis in Section 3.4.

\subsection{Summary}

In discussing the functional quality attributes identified by Zeithaml et al. (1990), we concluded that some functional audit quality attributes (in particular: responsiveness and empathy) will be more important in the assessment of overall audit quality by clients than by bankers, due primarily to the fact that the auditor's interaction with clients is considerably more frequent than his interaction with bankers. Moreover, it is reasonable to expect that bankers will be primarily interested in the outcome of the audit rather than in its process, because they are less involved in the process itself. Thus we hypothesize that clients will base their overall audit quality judgments primarily on functional audit quality attributes, whereas bankers will base their overall audit quality judgments primarily on technical audit quality attributes.

In the light of what has already been said about the relevance of these factors, all five (functional) factors identified by Zeithaml et al. (1990) are also expected to be positively related to the overall audit quality assessments of both cllients and bankers.

Based on the discussion in Section 3.2, the following hypotheses were generated:

Hypothesis 1 Functional audit quality attributes have higher weights in clients" overall audit quality assessments than technical audit quality attributes; on the other hand, technical audit quality attributes have higher weights in bankers' overall audit quality assessments than functional audit quality attributes. 


\begin{tabular}{|l|l|}
\hline Hypothesis 2 & $\begin{array}{l}\text { Overall audit quality perceived by clients and bankers } \\
\text { is positively affected by perceptions of } \\
\text { a. tangibles; } \\
\text { b. reliability; } \\
\text { c. responsiveness; } \\
\text { d. assurance; and } \\
\text { e. empathy. }\end{array}$ \\
\hline
\end{tabular}

In Section 3.4 we have hypothesized that, based on agency theory, both bankers and clients could be expected to appreciate an auditor's detection ability. While bankers are also expected to appreciate auditor independence, it is expected to have a negative effect on the overall audit quality assessment of clients. Although they also benefit from an auditor's independence, clients are expected to want the auditor to keep his findings regarding errors or irregularities in the audited company confidential, since revealing those might negatively reflect on management: they want an auditor who is tough on other clients, soft on themselves.

Several attributes of technical audit quality have been identified in this chapter. These attributes have been classified as either 'traditional' or 'nontraditional', in the light of current practice or the regulation of the attributes by the auditing profession. The following duties/attributes have been characterized as 'traditional' duties:

Detecting and reporting errors in the financial statements;

Detecting and reporting going concern risks; and

Detecting and reporting weaknesses in the internal control system.

The attributes concerning fraud and illegal acts have been characterized as 'non-traditional' or 'whistle blowing' items.

The hypotheses generated in Sections 3.4 and 3.5 are summarized below:

Hypothesis 3

Technical audit quality attributes related to an auditor's 'traditional' duties have a higher weight in the determination of overall audit quality than those related to 'non-traditional' duties, for both clients and bankers. 


\begin{tabular}{||l|l||}
\hline Hypothesis 4 & $\begin{array}{l}\text { Perceived detection ability has a positive impact on } \\
\text { overall audit quality, for both clients and bankers. }\end{array}$ \\
\hline Hypothesis 5 & $\begin{array}{l}\text { For bankers, perceived auditor independence has a } \\
\text { positive impact on overall audit quality. }\end{array}$ \\
\hline Hypothesis 6 & $\begin{array}{l}\text { For clients, perceived auditor independence has a } \\
\text { negative impact on overall audit quality. }\end{array}$ \\
\hline
\end{tabular}

With regard to these technical audit quality attributes, the findings of several expectation gap studies have already been discussed. It is interesting to see that most studies (with the exception of Humphrey et al., 1991a) found that respondents had quite positive overall impressions of the audit profession, although the perceived performance of auditors falls short on the individual items. Based on the discussion of service quality above, two possible explanations can be given for this phenomenon:

As discussed in Chapter 2, two levels of expectation are used in quality assessments. In measuring expectation gaps, most studies mentioned in this chapter asked respondents what duties auditors should perform or how they should react. This type of question gives information about the desired level of auditors" duties and performance. But, as discussed in Chapter 2, consumers understand that this desired level will not (always) be delivered and therefore use a second level of expectation, the adequate level. Although the performances of auditors seem to fall short of desired expectations, obviously - given the overall audit quality level - performance falls within the zone of tolerance;

Another reason might be that the issues with a big gap between expectations and performance are not very important for overall quality assessments. This chapter has analyzed why 'substandard' performance on 'fraud' and 'illegal acts' might be perceived as less important for overall audit quality than failure to meet expectations regarding the auditor's traditional duties. This would imply that the traditional technical audit quality attributes and the functional audit quality attributes might have a higher weight in the overall quality assessment. This will be tested in Chapter 6 . 


\section{CHAPTER 4 THE INFLUENCE OF ENGAGEMENT \\ CHARACTERISTICS ON TECHNICAL AUDIT QUALITY}

\subsection{Introduction}

Chapter 3 discussed the attributes of technical audit quality: what are the essential elements of technical audit quality and what auditors' duties have been identified in customer-oriented expectation gap studies. For each of these duties, a distinction was made between detection ability and independence. This chapter will discuss the impact on detection ability and auditor independence of engagement characteristics in the relationship between the client and his auditor. Extensive theoretical and empirical research has been conducted on the effect of characteristics in the relationship between client and auditor on technical audit quality, in particular on auditor independence. DeAngelo (1981a) looked upon the issue of auditor independence from an economic point of view. Independence in a specific engagement can be impaired, if the auditor is not indifferent towards termination of this engagement, because he might loose future quasi-rents.' DeAngelo (1981a) assumes that contracting in the auditing market is costly, for example as a result of the existence of client-specific start-up costs (which give the incumbent auditor a technological advantage) or as a result of transaction costs of changing auditors (e.g., the US requirement to disclose an auditor change for listed companies). Under this assumption, the economic relationship between the auditor and his client can be described as a bilateral monopoly, in which each party can impose real costs on the other party by termination of the engagement. Assuming a competitive market for initial audit engagements, "low balling' will occur. Hence, the price of the initial engagement will be below the current costs of the audit engagement. DeAngelo (1981a) asserts that 'low balling' as such does not impair auditor

${ }^{\mathrm{I}}$ DeAngelo's (1981a, p. 116) defines quasi-rents as the excess of revenues over avoidable costs, including the opportunity cost of auditing the next-best alternative client. If an auditor enjoys learning and experience gains, quasi-rents will increase, provided that the auditor does not transfer his entire learning and experience gain to the client. 
independence, because the fee cutting in the first engagement year(s) is sunk. ${ }^{2}$ Audit independence, however, is impaired by the existence of quasirents, which make the retention of a client attractive to an auditor. In addition, it can be noted that Simon and Francis (1988, p. 266) cite psychological research findings indicating that 'sunk costs do significantly affect subsequent decision-making, contrary to predictions from economic theory." This implies that initial investments to obtain a new client by price cutting will, for a limited period of time, serve as an even stronger incentive to retain the client than would be expected on the basis of the effect of the potential loss of quasi-rents alone.

This chapter will analyze engagement characteristics within this framework of auditor independence. It will examine whether these features will enhance or impair an auditor's incentive to maintain independence. Also, since independence is only one side of technical audit quality (the reporting side), we will also analyze whether these engagement characteristics might affect the detection side. In previous literature, the relationships discussed in this chapter were developed only for the auditor's detection and reporting of errors in the financial statements. But the framework described in this section for analyzing the effect of engagement characteristics on auditor independence can also be applied to the auditor's other duties or technical audit quality attributes identified in Chapter 3, given that each of these duties has been described as a combination of detection ability and independence.

Hypotheses about the relationships between engagement characteristics and technical audit quality attributes will be compiled on the basis of previous empirical research and a priori reasoning. These features are also expected to play a decisive role in the assessment of perceived technical audit quality, in two possible ways:

One way is the 'surrogate' assumption. Knapp (1991) asserts that consumers, unable to observe de facto audit quality, will be forced to

"For this reason, DeAngelo (1981a) asserts, it is useless to forbid low-balling - as suggested by the Cohen Commission (AICPA, 1978). Similarly, DeAngelo (1981a) argues that suggestions by the Cohen Commission (Commission on Auditor's Responsibilities, 1978) and (later) the MacDonald Commission (CICA 1988) with regard to requirements to make the reasons for any auditor change known to the public, have an important disadvantage. As a result of these disclosure requirements, the transaction costs of an auditor switch will increase, which positively affects quasi-rents, resulting in higher auditor incentives to retain the client. In this way, DeAngelo (1981) argues, auditor
independence might be lowered! 
use surrogate measures, such as the engagement characteristics. Since they will understand the auditor's incentives to limit his detection efforts or his independence, and how engagement characteristics affect auditor behaviour in this respect, the engagement characteristics will be used as surrogate measures, providing an acceptable approximation of technical audit quality;

The other way is the assumption that consumers are indeed able to assess de facto technical audit quality. In assessing audit quality they will not pay specific attention to the engagement characteristics but, since de facto technical audit quality is expected to be associated with these characteristics, we can hypothesize that consumers' objective assessments of technical audit quality will also be associated with these.

Based on the general framework presented in this section, we will discuss the effects, for technical audit quality, of the following engagement characteristics: ${ }^{3}$

Audit firm size (Section 4.2);

Client size (Section 4.3);

Client's financial health (Section 4.4);

Audit tenure (Section 4.5 ); and

Provision of management advisory services, or MAS (Section 4.6). Finally, Section 4.7 will summarize the hypotheses for the relationships between engagement characteristics and perceived detection ability and independence.

\subsection{Audit firm size}

Theory

\section{Independence}

DeAngelo (1981b) asserts that the customer"s quality evaluation costs are an important part of the transaction costs involved in finding an auditor. An auditor who succeeds in maintaining a constant level of audit quality over his

${ }^{3}$ These characteristics have been selected, since their impact on technical audit quality can be hypothesized on the basis of the agency theory and the economic framework discussed by DeAngelo (1981b). Of course, (technical) audit quality might be affected by many other engagement characteristics. The types of relationships possible between a marketer and a customer are addressed in relationship marketing studies (e.g., Gummesson, 1987; Grönroos, 1990; Kasper et al., 1996). 
customers and over time saves his customers the costs of continuously reevaluating technical audit quality. Such an auditor can, therefore, demand a higher fee. An auditor who turns out to have "cheated" in order to retain one client will be 'punished" by the market because he has lost his record for constant quality. 'Agents' will have incentives to end the engagement, since the audit service will no longer be rewarded by the 'principals', who have lost their faith in the auditor. In this way, the auditor risks losing some or all of the present value of the quasi-rents of all other current ${ }^{4}$ engagements: the client-specific brand-name collateral ${ }^{5}$ created at the start of these 'other' audit engagements by absorbing - now sunk! - start-up costs. Thus a large audit firm has more to lose from cheating than a small firm: its collateral is bigger. $^{6}$ This explanation of the relationship between audit engagement and audit quality is referred to as the 'auditor-reputation explanation' (Deis and Giroux, 1992). For the individual auditor, the 'collateral' argument also applies. According to DeAngelo (1981b), it can be expected that "when partners share proportionately in audit firm profits, the greater the number of clients, the less the wealth of the partner-in-charge of a given client depends on retaining that client. Therefore, the greater is the probability that he will report a discovered breach'.

\section{Detection ability}

Basically, the auditor-reputation explanation also holds for the relationship between firm size and detection ability. Because a larger firm has more to lose in the event of an audit failure, it has a greater incentive to perform a

"Assuming perfect competition in auditing, DeAngelo (1981b) takes only the present value of current clients into account, because under this assumption there will be no
quasi-rents on future engagements.

"Based on this thought, most professional bodies have attempted to limit this collateral by limiting the share of one client's fee in the overall auditor's portfolio. Although this element is not specifically regulated in the Netherlands, Berendsen (1990) found in a survey among Dutch auditors that their perceived maximum was between $2 \%$
and $5 \%$.

'Anecdotal evidence for the market-perceived importance and vulnerability of this brand name collateral can be found in Benston (1985, p. 50). He cites several sources indicating that, at the end of the nineteenth century, Price Waterhouse \& Co did not 
better audit job (Moore and Scott, 1989). Knapp (1991, p. 38) concludes that several publicly available studies would induce members of audit committees 'to assume that Big Eight firms possess technological advantages over smaller firms that enhance their ability to detect material errors in client financial statements.'

\section{Empirical research}

\section{Factual audit quality}

Wyer et al. (1988) found no significant relationship between the size class of the audit firm (big versus small firms) and the number of other-thanunqualified opinions. Hence, they could not provide further proof for the size argument. Davidson and Neu (1993) found that larger audit firms tended to be associated with larger differences between management's earning forecasts and audited, reported actual earnings. This is consistent with their proposition that larger auditing firms provide higher quality audits. Palmrose (1988a) found that non-Big Eight firms as a group were confronted with significantly higher (meritorious) litigation activity than Big Eight firms. She also performed comparisons among Big Eight firms, which revealed some significant differences, although these outcomes were quite sensitive to the type of analysis conducted. This finding might suggest that size is not the only auditor-related characteristic that influences technical audit quality. Deis and Giroux (1992, p. 476) found that the quality of audits of independent school districts (ISD) ${ }^{7}$ improved with the number of ISD clients the auditor had, which might be explained by both 'auditor's concern for reputation and improved technical capabilities as a result of industry expertise.' Finally, at a more indirect level, Singhvi and Desai (1971) found a significant positive association between the quality of corporate financial disclosure and auditor size.

\section{Perceived audit quality}

Firth (1981) found that bankers were concerned about the impairment of auditor independence in cases where one client's audit fee was more than $15 \%$ of total fee earned by the audit firm. This circumstance had a significant impact on their loan decision. McKinley et al. (1985) found that loan officers perceived financial statement quality and auditor independence to be higher if a Big Eight firm was involved. However, they did not find a significant effect

${ }^{7}$ Quality was measured by using the Quality Control Review findings of the Audit Division of the Texas Education Agency. 
on loan officer decisions. Eichenseher (1989) found slightly positive and statistically significant OTC market reactions to companies switching to Big Eight firms. Nichols and Smith (1983) also found a positive market reaction to changes from non-Big Eight to Big Eight firms, although the reaction was not statistically significant. Knapp (1991) found that audit committee members perceived that small audit firms were less likely to report discovered material errors. ${ }^{8}$ However, they did not perceive that small audit firms were less likely to discover material errors. Menon and Williams (1991) tested whether initial public offerings induced companies to change to more credible auditors. Although the number of changes was rather small, the observed tendency was for companies to change to larger, more credible, audit firms. They also found that investment bankers charged a lower fee for their offerings if clients were associated with Big Eight auditors. DeFond (1992) tested whether changes in agency conflicts resulted in a shift in audit quality. He assumed and found that increases in management ownership (resulting in a lower agency conflict level) are associated with switches to lower quality audit firms (e.g., from Big Eight to second tier or from second tier to local firm), while increases in leverage were found to be associated with switches to higher quality firms.

The extensive body of research on audit fees also provides some insight into the relationship between auditor size and perceived technical audit quality. On the basis of a short review of this research, Palmrose (1986a) distinguishes three hypotheses concerning the expected relationship between auditor size and audit fee rates:

Larger audit firms charge higher fee rates because of their market (monopolistic) power;

Larger audit firms charge higher fee rates to reflect the higher quality of their audit services; and

Larger audit firms charge lower audit fee rates, because of their economies of scale (Benston, 1985, p. 52).

Palmrose (1986a) found a significant positive market premium for Big Eight firms in the small auditees segment, but no significant price differentiation for large auditees. She concluded that this result indicated competition with differentiated products or services by the Big Eight together with diseconomies to non-Big Eight with large auditees. Therefore, the second

${ }^{8}$ Material errors are errors in the financial statements that might have a significant importance on the decision making of the user of the financial statements. 
hypothesis is not refuted, adding some credibility to the hypothesis of a relationship between auditor size and technical audit quality.

Simunic (1980) found no significant fee difference for either small or large auditees. ${ }^{9}$ Francis and Simon (1987) found a Big Eight premium in the segment of small auditees. Simon and Francis (1988) found a Big Eight premium (not differentiated for size). They compared this premium to those found in other studies and concluded that the premiums found were remarkably close (16\% to $18 \%$ ). Craswell et al. (1994) found a Big Eight premium ranging from 22 to $39 \%$. They also found that Big Eight firms can earn an additional premium for industry specialization. Finally, Brinn et al. (1994) also report a Big Eight fee premium in the audit market of independent companies. ${ }^{10}$ Thus, although the results are not entirely conclusive, the majority of these fee studies indicate a fee premium for Big Eight firms, probably reflecting their higher (perceived) quality.

To summarize, the effect of firm size on audit quality has received considerable attention in audit research. Based on this previous research, there appears to be ample theoretical and empirical support for the hypothesis that detection ability and auditor independence increase with firm size. The empirical part of the study will use the dichotomous variable Big Six/non-Big Six to measure audit firm size."

${ }^{9}$ However, the results indicated a slightly negative premium for Big Eight firms; 'the results suggest that the Big Eight firms enjoy scale economies which are passed on as lower prices to auditees.'

${ }^{10}$ Independent companies were described as non-subsidiaries.

${ }^{11}$ A simple dichotomous variable was used because, for reasons of confidentiality, the researchers were not allowed to know the identity of the audit firms associated with the engagements included in the sample. However, it was known to the researchers whether or not a Big Six firm was involved in an engagement. The Big Six firms are Arthur Andersem \& Co., Coopers \& Lybrand, Deloitte \& Touche, Ernst \& Young, KPMG and Price Waterhouse. 


\subsection{Client size}

\section{Theory}

\section{Independence}

Assuming that the percentage of a client's audit fee in the total fees earned by an auditor ${ }^{12}$ is a surrogate for client-specific quasi-rents (DeAngelo, 1981b), it is obvious that a client's audit fee should also be considered as a variable possibly affecting auditor independence. However, fee data may not be directly available to those assessing or perceiving technical audit quality. Given the high degree of correlation between audit fee and client size, client size can be regarded as a surrogate for the client-specific audit fee. ${ }^{13}$ One may hypothesize that larger clients are more likely to impair auditor independence than small clients: given the higher quasi-rents associated with larger clients they are likely to be more successful in using the threat of audit engagement termination. This argument is called the 'power-conflict explanation' (Deis and Giroux, 1992).

\section{Detection ability}

The relationship between client size and the detection of errors has not received much attention in audit research. One might expect that the greater complexity of large companies might make it more difficult for external auditors to gain an integral understanding of the client"s business and systems. Under these circumstances, auditors might be perceived to be more dependent on the clients' internal control mechanisms. The users of audit services might consider that the extra reliability which the auditor can add to the financial statements - and thus his technical audit quality - would therefore be lower.

"Total fees earned by an auditor are measured by audit firm size.

${ }^{13}$ Although client size has been found to be the most important determinant of audit fee, there are other variables that affect audit fee, such as the complexity of the client's operation or the geographic dispersion of its activities. O' Keefe et al. $(1992$, p. 39) state that 'previous studies have shown that client size alone can explain about $50 \%$ of the cross-sectional variation in audit fees, although many other client characteristics are correlated with size." 


\section{Empirical research}

In contrast to the extensive research on the effect of audit firm size on technical audit quality, the empirical research on the effect of client size is limited. In their study of the audit quality of independent school districts, Deis and Giroux (1992) found that the number of students - as a measure of client size - was a significant, and negative, independent variable explaining audit quality.

In short, the theoretical and empirical research on the relationship between client size and technical audit quality is very scarce. Based on this limited amount of research, client size is expected to have a negative relationship with both independence and detection ability.

\subsection{Client's financial health}

\section{Theory}

\section{Independence}

Knapp (1985) assumes that auditors who perceive 'little risk of legal exposure, due to the client's excellent financial condition, may be less motivated to resist management pressure.' This can be explained by using the framework for auditor independence which was presented in Section 4.1. If there is a dispute with the client, the auditor makes a trade-off between the (certain) loss of quasi-rents of this particular client if he reports a detected error against the client's wish, and the expected loss because of reputation damage or litigation. This expected loss consists of the chance of discovery of the 'auditor cheating' and the price of the discovery in terms of the loss of future quasi-rents of current clients and the costs of litigation. The expected loss is hypothesized to increase if the audited company has a bad financial condition, given the probability of a bankruptcy and, as a result, the risk of negative publicity and litigation.

\section{Detection ability}

The same line of reasoning can be applied to the detection ability. In making decisions on the amount of audit work to be performed, the auditor will compare the marginal expected loss because of 'shirking' and the marginal costs of an extra unit of audit work (Watts and Zimmerman, 1983). Since the marginal expected loss will be dependent on the probability of the discovery of auditor cheating, an auditor is more likely to perform less audit work if the client is financially sound. 


\section{Empirical research}

\section{Factual audit quality}

In their study of audit quality of independent school districts, Deis and Giroux (1992) found that a client's financial condition was a significant, negative variable explaining audit quality. Farmer et al. (1987) found that the potential threat of lawsuits against an auditor was positively associated with auditor independence. Assuming that the chance of a lawsuit increases with the possibility of bankruptcy, this finding indicates that auditors behave more independently when the client's financial condition is weak.

\section{Perceived audit quality}

Schultz and Gustavson (1978) found that actuaries perceived an inverse relationship between an audit firm"s risk of legal liability and the relative financial well-being of the client, i.e. the expected loss of reputation is dependent on a client's financial condition. Knapp (1985) found that loan officers perceived that clients in a good financial condition would be better able to impair auditor independence than clients in a poor financial condition. Knapp (1987) found that Audit Committee members were more inclined to support an auditor involved in a major dispute with management when the auditee's financial position is weak. This provides additional support for the hypothesis of an inverse relationship between financial health and auditor independence.

To summarize, the theoretical and empirical research on this topic is rather limited. Based on this previous research, a negative relationship between a client's financial health and both detection ability and independence is hypothesized.

\subsection{Audit tenure}

\section{Theory}

\section{Independence}

The importance of audit tenure for independence has been given some attention by audit standard-setters. Schilder (1992) gives an overview of regulation requiring audit firm rotation (e.g., Italy) or (limited) partner rotation (US). A theoretical background for measures like these is given by Knapp (1991). He assumes a negative relationship between the length of auditor tenure and independence, pointing to the steady accumulation of client-specific expertise over the term of the auditor-client relationship. 
This explanation can be studied within the framework of auditor independence in Section 4.1. According to DeAngelo (1981b, p. 119), the quasi-rents an auditor earns arise because of (1) transaction costs suffered by clients and (2) start-up costs which a potential new auditor faces, but which are sunk for the incumbent auditor. With regard to the first component of quasi-rents, it seems hard to predict the relationship between client transaction costs and length of tenure. On the one hand, one might hypothesize that changing auditors quickly is harmful to a client's image, since it might be perceived by third parties as 'opinion shopping' or 'settling arguments', given the finding of DeAngelo (1982) and Roberts et al. (1990) that negative reports might lead to auditor change. On the other hand, changing an auditor after a long period might be interpreted by third parties as an indication for a significant problem or dispute. With regard to the second component, start-up costs, one might assume that these increase with auditor tenure, reflecting the learning effect for the incumbent auditor compared to the potential new auditor. However, an important weakness in this reasoning is stressed by O'Keefe et al. (1992, p. 15): 'To date, there is no strong evidence for the existence of a learning curve. ${ }^{14}$ In their study of the determination of audit costs, they did not find a 'systematic effect of the number of years an audit has been performed for the client upon audit hours" ${ }^{15}$ (p. 25).

Although the empirical literature on audit fee price setting is not conclusive, several studies report empirical support for 'low balling'. Because of the extensive nature of their study and its multi-period character, the study of Simon and Francis (1988) is very noteworthy in this respect. ${ }^{16}$ They found a significant fee reduction in the first year, a moderate fee reduction in the

"The absence of this evidence means that the 'low balling" and 'quasi-rents' analysis of DeAngelo (1981a) has not yet been directly supported by empirical evidence.

${ }^{15}$ However, this finding does not necessarily imply that there is no learning effect. $O^{\prime}$ Keefe et al. (1992) assumed that audit quality was fixed for the engagements they studied. It might be that learning effects are not demonstrated in the number of audit hours, but in technical audit quality.

${ }^{16}$ Other interesting support for low-balling can be found in Roberts et al. (1990), who found that school districts changing auditors were more likely to have current-year audit fees lower than previous year's. However, the authors explain that low balling is not the only potential explanation for this finding. It might also imply that schools change to more efficient auditors, or to lower quality audits. 
second and third years and a stabilization at a 'normal' fee level by the fourth year. Assuming that 'low balling' does occur, there is reason to hypothesize that auditor independence is at a lower level during the first years of the audit engagement, considering the finding in Section 4.1 that sunk costs do seem to influence decision making: 'This desire to not lose the new client, because of the prior investment commitment, could lead to an additional auditor independence problem during the period of investment recovery, over and above normal investment problems' (Simon and Francis, 1988, p. 266).

\section{Detection ability}

With regard to detection, Shockley $(1981$, p. 789$)$ assumes that long tenure may induce 'complacency, lack of innovation, less rigorous audit procedures, and a learned confidence in the client.' Knapp (1991, p. 38) recaps the Metcalf Committee, asserting that 'long association between an audit firm and its clients may damage the quality of professional services provided by the audit furm.' On the other hand, Knapp (1991) mentions the inferences of both the Cohen Commission and the Treadway Commission that 'substandard audits occur more frequently when auditor tenure is relatively short. ${ }^{17}$ Deis and Giroux (1992, p. 465) assume a negative relationship between an auditor's tenure and his ability to detect errors. They assert that 'an incumbent auditor can choose to lower audit quality and audit price contemporaneously to retain the client and preserve quasi-rents.' However, this argument fails to take into account the finding of Palmrose (1986a). She found significantly lower fees in fixed-fee arrangements (compared to costreimbursement contracts), while there was no significant effect on audit hours. She concluded that price cutting due to competitive pressure does not

${ }^{17}$ This effect might be explained in two ways:

There is a learning effect. However, as previously mentioned, the existence of a learning effect has not yet been demonstrated. In line with this argument, Shockley (1981) mentions the argument of opponents of mandatory rotation that 'a CPA firm gains a deeper familiarity and insight into the client's operations through audit repetition, thus facilitating more efficient, less costly audit service than is possible for a 'fresh' auditor. Because the client is likely to consider the 'tenured' auditor more valuable, the audit firm becomes less dependent on the client and better able to resist client pressure.'

Audit quality might increase over the years, because the budget increases (see Simon and Francis (1988) for the dynamic development of audit fees). However, this assumption is inconsistent with Palmrose's (1986a) finding that audit fee and audit hours need not be related. 
automatically imply a lower degree of audit work. ${ }^{18}$ Further, the explanation of Deis and Giroux (1992) does not explain why the auditor's decision would change over the years, or why the auditor's incentives would change with the length of tenure. In addition, Deis and Giroux (1992) cite several studies indicating that an auditor's use of innovative audit techniques and his attitude of professional scepticism deteriorate over time.

\section{Empirical research}

\section{Factual audit quality}

Deis and Giroux (1992) found empirical evidence that auditor tenure and audit quality in US independent school districts are significantly negatively related. Copley and Doucet (1993b) found a (weak) negative relationship between length of tenure and substandard performance, as measured by audit quality assessments by Offices of Regional Inspectors General.

\section{Perceived audit quality}

Knapp (1991) found significant support for his hypothesis that audit committee members will impute a higher likelihood of discovering material errors to an auditor with five years tenure, than to an auditor with twenty years of tenure or than to a newly retained auditor. He found no support for his hypothesis that audit committee members will impute a lower conditional likelihood of the auditor reporting a discovered material error as auditor tenure lengthens. Schilder (1994) interviewed several leading, knowledgeable members of the financial community (representing clients, third parties and audit firms) with regard to issues on auditor independence. Mandatory rotation of firms was not perceived as a positive contribution to auditor independence. However, mandatory rotation of audit partners after seven years (currently not regulated in the Netherlands) was rated positively by respondents, as was the institution of a fixed engagement period for statutory auditors of three or six years (reelection allowed). This illustrates that length of tenure at the firm level is not perceived as a major problem (although a periodic discussion between client and auditor in the course of a potential renewal of the audit engagement is welcome), but that tenure at the partner level is considered to be more critical.

${ }^{18}$ This finding is consistent with the previously mentioned concept, in which the level of audit work is determined by comparing the marginal expected loss from reputation and litigation damage due to shirking and the marginal costs of a unit of audit work. 
All in all, the relationship between technical audit quality and auditor tenure is quite complicated. The results of both a priori reasoning and empirical research regarding this relationship are inconclusive. Therefore some relationship is expected, without making any prediction about the sign.

\subsection{Provision of MAS}

\section{Theory}

\section{Independence}

Like audit tenure, the provision of MAS by the incumbent auditor has received some attention by audit standard-setters. Schilder (1992) reports that in several countries (Italy, France), statutory auditors are not allowed to provide MAS to their audit clients. In audit research, both positive and negative relationships have been hypothesized between the provision of MAS and auditor independence. According to Benston (1985, p. 69), MAS can be supplied at lower costs in conjunction with audits. Based on a discussion of demand and supply in auditing, he asserts that 'prohibiting accounting firms from providing these services is likely to increase the costs and decrease the effectiveness of audits.' According to Shockley (1981) this might imply that auditors become more "nearly unique' to their clients, and thus more powerful in their relationship towards the client and better able to resist client pressure. However, the impact of the provision of MAS by the incumbent auditor on independence can also be assumed to be negative. This can be explained within the framework of auditor independence presented in Section 4.1. Assuming, as Benston (1985) does, that the provision of MAS (including tax services) increases the learning effects (knowledge externalities/spillovers), the quasi-rents will increase, ${ }^{19}$ resulting in a likely lower degree of auditor independence. According to Simunic (1984), "the joint performance of auditing and MAS may (...) reduce the probability that an auditor will report truthfully in arcas totally umrelated to past consulting services if (1) performance of the service is "tied" together - dismissal as auditor increases the probability of losing consulting opportunities for the client, and (2) the CPA firm is earning economic rents in MAS on specialized resources which could not be transferred to an equally profitable alternative use.' Davis et al. (1993) consider the question of audit demand elasticity. Given the empirical findings of, for example, Simunic (1984) and Palmrose (1986b) that there is a ${ }^{19}$ Quasi-rents will increase, if the auditor does not transfer his entire experience and
leaming gain to the client. 
positive relationship between audit fees and non-audit services fees, and assuming elastic demand, total audit fees would be expected to increase where the auditor provides MAS because the audit service is then less expensive (assuming that some of the spillover efficiencies are transferred to the client) so more audit is demanded. This is the 'joint-supply scenario'.

Another potential threat of management advisory services to auditor independence is given by Bartlett (1991), discussing the SEC's position on the relationships between Arthur Andersen \& Co. and Andersen Consulting. $\mathrm{He}$ asserts that a relevant concern 'would be the auditor's independence "in fact" when auditing the results of consulting work performed by a related entity.' He cites a study by Plumlee (1985), who 'found that internal auditors exhibited significant biases when evaluating internal control systems which they designed, being much better at identifying strengths than weaknesses and attributing weaknesses to factors other than the design of the system". ${ }^{20} 21$

\section{Detection ability}

Provision of MAS may increase the knowledge of the client's operations and its accounting and control system and in general the audit team expertise. ${ }^{22}$ These are factors that Sutton and Lampe (1991) found as key audit quality factors. Related to this subject, they also found that the availability of firmwide resources was a key quality factor. Therefore, the provision of MAS by

${ }^{20}$ In its quality concept, NIVRA (1992, p. 12) asserts that this risk of 'collision' between audit and advisory services can be eliminated if the auditor requires the client to make the company's policy decisions. However, even if the auditor 'only" provides the advice and does not decide, clients and other users of audit services might perceive a threat to independence.

${ }^{21}$ The AICPA acknowledges the independence problem of auditors providing MAS. Members of an SEC Practice Section are prohibited to provide certain types of MAS (for example, client officer recruitment). Also, members have to report to the audit committee or Board of Directors about the MAS provided and the related fees.

${ }^{22}$ The Cohen Commission (AICPA, 1978, p. xxxix) acknowledges this potential influence of the provision of advisory services to the audit function. The Commission advises that the requirement should be added to the professional standards, that firms design policies and procedures in a way to ensure that 'knowledge gained from other services is made available to the partner in charge of the audit so that he can consider its implications for the audit function (...)'. 
the incumbent auditor is hypothesized to increase the probability of detecting errors.

\section{Empirical research}

\section{Factual audit quality}

On the empirical level, some research has been done to test the hypothesis of the existence of knowledge spillovers and the associated impairment of auditor independence. Simunic (1984) found that the audit fees of clients who also purchase MAS from their auditors were significantly higher. If efficiencies are partially appropriated as rents to the CPA firm, a threat to independence is created. This finding is consistent with the assumption of knowledge spillovers and an elastic demand for auditing, provided that there are no systematic differences between the High-MAS and Low-MAS population. Palmrose (1986b) also tested the relationship between audit fees and non-audit service fees. She looked at the non-audit services provided by the incumbent auditor, and also those provided by any 'non-incumbent' auditor (i.e., an auditor providing incidental services but not auditing the financial statements). She found a positive relationship for MAS provided by both incumbent and non-incumbent auditors. This finding was considered inconsistent with the joint-supply scenario. An alternative explanation for the finding of correlation between non-audit and audit fees might be that there are significant differences between clients who demand a high level of MAS and those who demand a lower level.

Davis et al. (1993) also found a positive relationship between audit fees and non-audit service fees. However they also found a proportional increase in audit hours. They concluded that 'these findings are inconsistent with one interpretation of prior research: that performing non-audit services for audit clients may provide the auditor with incentives to compromise objectivity.' Beck et al. (1988, p. 82) found that "some evidence was reported indicating that auditor tenure is longer and less variable when high levels of certain MAS are purchased from the incumbent auditor. Despite the presence of statistically significant results, the small tenure differences and the long (average) tenure for the auditee subpopulation imply that the incremental bonding effects due to MAS are small in relation to the base level of bonding associated with the audit engagement. Hence, the results do not provide evidence that auditor independence is impaired substantially by MAS involvement.' Schilder (1994, p. 92) asserts that 'the combination of audit work and non-audit services in smaller firms is probably more in the hands of 
the same group of people, whereas bigger firms usually have them separately organized." This would imply that the threat to the perception of independence might be bigger for non-Big Six firms. Finally, Barkess and Simnett (1994) failed to find a significant relationship between the level of MAS services and either the type of audit report issued or audit tenure, indicating that there is no relationship between MAS and auditor independence.

\section{Perceived audit quality}

The results of empirical research on the relationship between the provision of MAS and perceived auditor independence are mixed. Shockley (1981, pp. 787,788 ) summarizes a review of the empirical research by saying: 'in general, these studies report conflicting results; their data can be used to support both sides of the MAS question' but adds, 'the empirical evidence against MAS appears more convincing than the evidence for it." The Cohen Commission (AICPA, 1978, p. xxviii) stated that: 'Surveys have produced mixed and conflicting results, but generally they have shown that a significant minority of users are concerned about the potential conflict between management services and the audit function. The concern of users decreases as their familiarity with the nature of the services offered by public accounting firms increases, and it diminishes substantially when the services are provided by different staff, such as a separate management services division.' In addition to this, the Commission is cited by Simunic (1984) as stating that it failed to find 'any significant relationship between the provision of management services and substandard audits.'

In a survey of bankers, Firth (1981) found a negative relationship between bankers' assessment of auditor independence and the provision of MAS. He also found that this had a significant impact on their loan decisions. Knapp (1985) found that senior loan officers were significantly less likely to believe that auditors would report a detected error if the auditors provided MAS. However, although very significant, the explanatory power of this variable with regard to auditor independence was very weak, a finding consistent with Shockley (1981). McKinley et al. (1985) did not find any significant impact of MAS provision by the incumbent auditor on loan officer's decisions, their perceptions of financial statement quality or auditor independence.

The Limperg Instituut (1987) found that only $12 \%$ of respondents from the Dutch financial community disagreed moderately or strongly with the statement that an auditor is able to perform both audit and advisory services for one client, without losing independence as an auditor. 
The CICA (1988,p. 13) reported that "fifty percent of the public surveyed indicated moderate to strong agreement with the belief that there is a serious potential for auditors to lose their objectivity when the audit firm provides services such as management consulting or tax services to an audit client. Members of the financial community also recognize the potential for-loss of objectivity but do not have a strong belief that such losses in objectivity are actually occurring."

Palmrose (1988b) tested whether the implementation between 1978 and 1982 of the SEC's ASR 250 - requiring disclosure and monitoring of (certain) MAS services provided by the incumbent auditor - led to differences in the MAS acquired from the incumbent by public clients (who were subjected to these requirements) versus closely-held clients. She hypothesized that agency costs associated with the incumbent providing MAS would be higher for public companies and would therefore lead to a lower degree of MAS by the incumbent. However, she did not find evidence for this hypothesis.

In their survey, Humphrey et al. (1991a) tested the reaction of the British financial community to the statement that an audit firm should not provide MAS to its audit clients. On a 7-point scale (from disagree to agree), financial directors (representing clients) and bankers scored 3.1 and 3.0, showing slight disagreement with this statement. A market research survey in the Netherlands (Nederlands Instituut voor de Publieke Opinie en het Marktonderzoek, 1991) found that approximately two thirds of the respondents from their survey of audit clients appreciated the combination of audit and advisory services. Approximately $25 \%$ of the respondents found that these services should not be offered by one firm; approximately $11 \%$ of the respondents held this opinion because they saw a potential independence problem. Parkash and Venable (1993) found that variables related to expected agency costs (management ownership, outside investment concentration, leverage) significantly explain cross-sectional differences in the demand for recurring non-audit services. ${ }^{23}$ Overall agency costs did not explain the level of nonrecurring services purchased from the auditor. This is consistent with their expectations, since nonrecurring services provide only minimal future knowledge spillovers and incremental economic bonding.

${ }^{23}$ If respondents perceive that auditor independence is impaired by the provision of MAS, one might assume that MAS would be lower where agency costs are higher, because the drawback of having a 'less reliable' auditor perform the monitoring activities
would then be greater. 
From this research one might conclude that incumbent MAS provision is perceived to influence agency costs or principals' perceptions of auditor independence. Schilder (1994), interviewing leading, knowledgeable members of the financial community on the issue of auditor independence, found mixed but overall negative reactions to the suggestion of limiting the level of MAS. In particular, respondents referred to the fact that MAS makes an auditor valuable to a client and increases the auditor's 'power' with respect to the client, which in turn increases his independence. Nonetheless, they also recognized that supplying too much MAS was a potential threat to the perception of independence.

Concluding, both a priori reasons and empirical evidence are mixed with regard to the relationship between the provision of management advisory and tax services and auditor independence. Therefore different types of relationships will be tested. For an auditor's detection ability, there is both theoretical and empirical ${ }^{24}$ evidence for a positive relationship with the incumbent's provision of MAS.

\subsection{Summary}

This chapter discussed the potential effects of engagement characteristics on perceived and actual technical audit quality, based on theoretical considerations and empirical research. Although the research findings were not always entirely conclusive, we have generated hypotheses for each of the engagement characteristics included in this chapter. Based on agency theory, these relationships are expected to hold equally for bankers and clients. The hypotheses listed below will therefore be tested for both groups.

${ }^{24}$ See the finding of a positive relationship between non-audit and audit fees (e.g., Simunic, 1984; Palmrose $1986 \mathrm{~b}$ ), implying that there is a positive relationship between MAS provision and audit effort. 


\begin{tabular}{|l|l|}
\hline Hypothesis 7 & $\begin{array}{l}\text { An auditor's perceived detection ability is higher for } \\
\text { Big Six firms than for non-Big Six firms. }\end{array}$ \\
\hline Hypothesis 8 & $\begin{array}{l}\text { An auditor's perceived detection ability increases } \\
\text { with the incumbent auditor's level of MAS } \\
\text { provision. }\end{array}$ \\
\hline Hypothesis 9 & $\begin{array}{l}\text { An auditor's perceived detection ability decreases } \\
\text { with } \\
\text { a. client size; and } \\
\text { b. client's financial health. }\end{array}$ \\
\hline Hypothesis 10 & $\begin{array}{l}\text { An auditor's perceived detection ability is related to } \\
\text { tenure. }\end{array}$ \\
\hline Hypothesis 11 & $\begin{array}{l}\text { Perceived auditor independence is higher for Big } \\
\text { Six firms than for non-Big Six firms. }\end{array}$ \\
\hline Hypothesis 12 & $\begin{array}{l}\text { Perceived auditor independence decreases with } \\
\text { a. client size; and } \\
\text { b. client's financial health. }\end{array}$ \\
\hline Hypothesis 13 & $\begin{array}{l}\text { Perceived auditor independence is related to } \\
\text { a. tenure; and } \\
\text { b. incumbent auditor's level of MAS provision. }\end{array}$ \\
\hline \hline
\end{tabular}

These hypotheses are summarized in Figure 4.1, illustrating the hypothesized relationships between engagement characteristics and technical audit quality. 


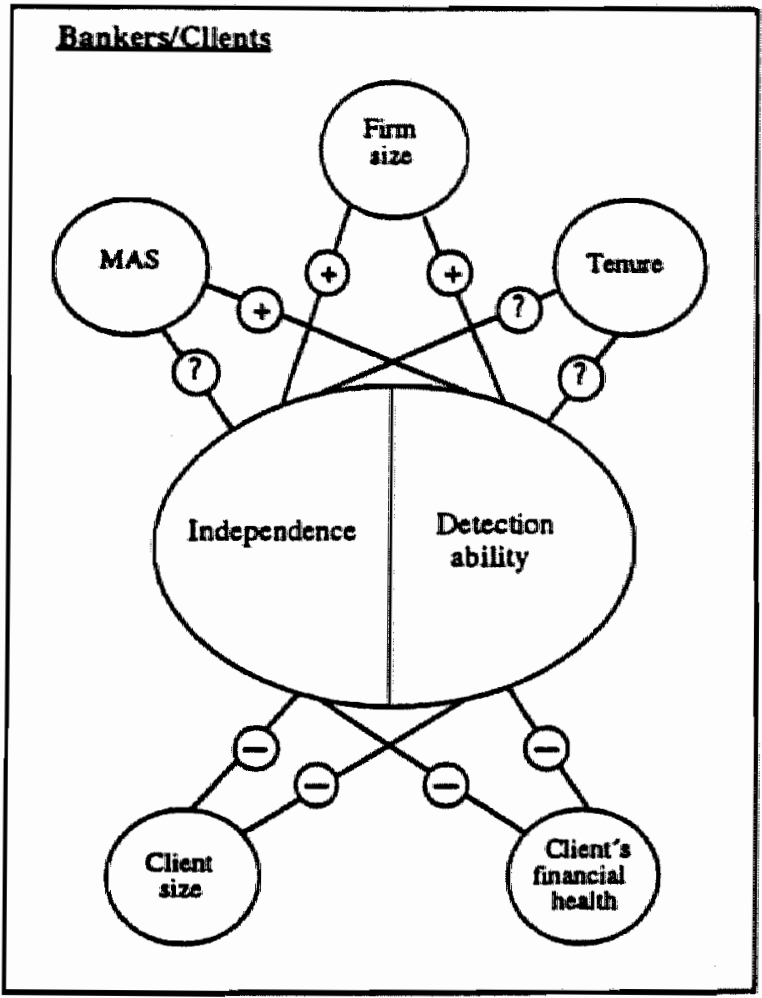

Figure 4.1 Hypothesized relationships between audit engagement characteristics and technical audit quality

$(=$ positive impact of audit engagement characteristic on technical audit quality attribute.

$\Theta=$ negative impact of audit engagement characteristic on technical audit quality attribute.

7 - inconclusive relationship between audit engagement characteristic and technical audit quality attribute. 



\section{CHAPTER 5 RESEARCH DESIGN}

\section{I Introduction}

As discussed in Chapter 1, two research questions are addressed in this study:

1. What technical and functional audit quality attributes are distinguished by clients and bankers, and what is their relationship with and influence on overall audit quality assessments by these two groups?

2. What is the influence of audit engagement characteristics on technical audit quality perceptions of clients and bankers?

Given these research questions and the specific research design, this study differs from most of the previous audit quality studies in several respects: In this study, perceptions of audit quality are assessed, using actual audit engagements. Although previous research includes studies regarding perceptions of audit quality and studies based on actual engagements, this combination is rare. In order to obtain insights into perceptions of actual engagements, a research instrument had to be developed in which respondents could freely express their ideas about the performance of a specific auditor in a specific audit engagement. In particular, total confidentiality was required by the bankers, in exchange for their cooperation in this study. Furthermore, confidentiality was crucial since it was necessary to have access to audit engagement characteristics that are not publicly available, such as audit and consultancy fees or financial health assessments by bankers. One of the research objectives was to measure the differences in the quality assessment processes of clients and bankers. In order to control for differences in the audit engagements, an attempt was made to obtain audit quality assessments of clients and bankers for the same engagements.

The mainstream of audit research has concentrated on technical audit quality. This study attempts also to assess the importance of functional audit quality attributes in overall audit quality judgments.

This chapter will describe the research design that was developed in order to meet the specific requirements of these research questions. Section 5.2 will recap the hypotheses generated in the previous chapters and briefly discuss the statistical techniques employed for each category of hypotheses. 
Section 5.3 will describe the data collection method. This section will illustrate how the requirement of confidentiality led to the use of a questionnaire-based approach, supplemented with questions to elicit factual information on engagement characteristics, and will report on other measures taken to maintain confidentiality, such as the assistance of a notary's office in making the data anonymous. It will also discuss the use of the SERVQUALtechnique as a basis for gathering audit quality assessments. Section 5.3 will also explain the arrangements made to enable direct comparisons of bankers' and clients' quality assessments. Section 5.4 will present the descriptive results (i.e. mean and standard deviation) for the scores on the individual questions, for clients and bankers separately. Finally, Section 5.5 will summarize the findings in this chapter.

\subsection{Hypotheses}

In the previous chapters, the following hypotheses were generated:

I Impact of functional audit quality attributes on overall audit quality (Section 3.6)

\begin{tabular}{|l|l|}
\hline Hypothesis 1 & $\begin{array}{l}\text { Functional audit quality attributes have higher weights } \\
\text { in clients' overall audit quality assessments than } \\
\text { technical audit quality attributes; on the other hand, } \\
\text { technical audit quality attributes have higher weights in } \\
\text { bankers' overall audit quality assessments than } \\
\text { functional audit quality attributes. }\end{array}$ \\
\hline Hypothesis 2 & $\begin{array}{l}\text { Overall audit quality perceived by clients and bankers } \\
\text { is positively affected by perceptions of } \\
\text { a. tangibles; } \\
\text { b. reliability; } \\
\text { c. responsiveness; } \\
\text { d. assurance; and } \\
\text { e. empathy. }\end{array}$ \\
\hline
\end{tabular}

In order to test these hypotheses, factor analyses were done on the statements included in the questionnaire. Factor analysis is used to identify a rellatively small number of factors that represent several underlying (individual) statements. In this study, factor analysis was useful in two respects. 
First, it offers more insight into the quality assessment process by identifying relationships among the statements. In other words, it was used as a systematic procedure to identify the statements that compose the factors included in the hypotheses (e.g., empathy). Second, it was necessary for statistical reasons to reduce the number of variables, since the factors were regressed as independent variables on the overall audit quality assessments made by the respondents. By using these regression techniques it was possible to determine the relative weights of the functional audit quality factors in the determination of overall audit quality. The results of both the factor analyses and the regression analyses will be presented in Chapter 6 .

II Impact of technical audit quality attributes on overall audit quality $\underline{\text { (Section 3.6) }}$

\begin{tabular}{|l|l|}
\hline Hypothesis 3 & $\begin{array}{l}\text { Technical audit quality attributes related to an } \\
\text { auditor's 'traditional' duties have a higher weight in } \\
\text { the determination of overall audit quality than those } \\
\text { related to 'non-traditional' duties, for both clients and } \\
\text { bankers. }\end{array}$ \\
\hline Hypothesis 4 & $\begin{array}{l}\text { Perceived detection ability has a positive impact on } \\
\text { overall audit quality, for both clients and bankers. }\end{array}$ \\
\hline Hypothesis 5 & $\begin{array}{l}\text { For bankers, perceived auditor independence has a } \\
\text { positive impact on overall audit quality. }\end{array}$ \\
\hline Hypothesis 6 & $\begin{array}{l}\text { For clients, perceived auditor independence has a } \\
\text { negative impact on overall audit quality. }\end{array}$ \\
\hline
\end{tabular}

As with the functional audit quality attributes, factor analyses were done on the technical audit quality questions included in the questionnaire. Then regression analyses were performed, in order to determine the relative weights of the technical audit quality factors in the determination of overall audit quality. The results of both the factor analyses and the regression analyses will be presented in Chapter 6. 
III Impact of engagement characteristics on technical audit quality attributes (Section 4.7)

\begin{tabular}{|l|l|}
\hline Hypothesis 7 & $\begin{array}{l}\text { An auditor's perceived detection ability is higher for } \\
\text { Big Six firms than for non-Big Six firms. }\end{array}$ \\
\hline Hypothesis 8 & $\begin{array}{l}\text { An auditor's perceived detection ability increases } \\
\text { with the incumbent auditor's level of MAS } \\
\text { provision. }\end{array}$ \\
\hline Hypothesis 9 & $\begin{array}{l}\text { An auditor's perceived detection ability decreases } \\
\text { with } \\
\text { a. client size; and } \\
\text { b. client's financial health. }\end{array}$ \\
\hline Hypothesis 10 & $\begin{array}{l}\text { An auditor's perceived detection ability is related to } \\
\text { tenure. }\end{array}$ \\
\hline Hypothesis 11 & $\begin{array}{l}\text { Perceived auditor independence is higher for Big } \\
\text { Six firms than for non-Big Six firms. }\end{array}$ \\
\hline Hypothesis 12 & $\begin{array}{l}\text { Perceived auditor independence decreases with } \\
\text { a. client size; and } \\
\text { b. client's financial health. }\end{array}$ \\
\hline Hypothesis 13 & $\begin{array}{l}\text { Perceived auditor independence is related to } \\
\text { a. tenure; and } \\
\text { b. incumbent auditor's level of MAS provision. }\end{array}$ \\
\hline
\end{tabular}

In order to test these hypotheses, regression analyses were performed. In these regression analyses, the engagement characteristics were regressed as independent variables on the technical audit quality statements. The results of these tests are presented in Chapter 7.

\subsection{Data collection method}

\subsubsection{Questionnaire versus observation}

Audit quality can be directly measured using either the observational method (e.g., an experiment) or the questionnaire method. According to Boyd et al. (1985, p. 148), 'probably the most limiting factor in the use of observation is 
the inability to observe such things as attitudes, motivations, and plans. Only as these factors are reflected in actions can they be observed, and then they are confounded with so many other factors as to make their identification difficult, if not impossible.' Another limiting factor in using the observational method is its inability to measure events of more than short-term duration (Boyd et al., 1985). Given the complexity and the long term development of individual quality perceptions, the observational method is not suitable for measuring audit quality assessments. Further, the need to treat both the quality assessments and the audit engagement characteristics confidentially limited the possibility of using observations as the principal method of data collection. Therefore a questionnaire was used to collect data in this study. Because of its wide use in marketing research assessing service quality, we decided to use the SERVQUAL questionnaire technique as a basis for this study. This SERVQUAL technique, a structured non-disguised questioning method, will be discussed in Section 5.3.2.

\subsubsection{Characteristics of the SERVQUAL questionnaire}

The SERVQUAL technique has been used extensively by marketing researchers in assessing service quality. Lapierre and Filiatrault (1995) note that 'the majority of empirical studies conducted on professional services quality has been influenced by the Parasuraman, Zeithaml, and Berry's approach, and have used accordingly the SERVQUAL scale'. Section 2.7 discussed the results of the focus group interviews by Parasuraman et al. (1985). They found 10 generic key attributes that customers use to evaluate service quality. Based on these interviews, Parasuraman et al. (1986) developed the first version of the SERVQUAL questionnaire with the following features:

97 items, relating to the 10 key attributes, were included in the questionnaire;

A 7-point Likert scale was used, with a pair of statements for each item. Since they defined quality on the basis of the difference between expectation and (perceived) performance, Parasuraman et al. (1986) chose to measure both expectation and perceived performance for each item. They preferred this to the alternative form - a one statement lay-out asking respondents to indicate the gap between expectation and performance - for three reasons:

1. By using the paired statements, it is possible to analyze the reasons for the gaps found. In particular, this lay-out makes it possible to analyze whether a certain gap originates from high 
expectations or from low perceived performance;

2. The range of potential values will be wider (from -6 to +6 ); ${ }^{1}$

3. It might be less confusing and more meaningful to respondents.

Roughly half of the statement pairs were worded positively, the other half negatively.

In Parasuraman et al. (1986), two hundred customers of five different services (not including audit services) were asked to rate their expectations and perceived performance regarding 97 items for one particular firm in the chosen service industry. This list was reduced to 54 items by correlating the perceived quality score (performance statement score minus expectation statement score) per item with the scores of all other items per key attribute. By redefining the key attributes it was possible to further reduce the list to 34 items (on 7 key attributes). The revised questionnaire was used in another survey of 200 customers for four different types of services (again, not including audit services). A factor analysis of this set resulted in the final questionnaire, with 22 items spread among the five key attributes (Zeithaml et al., 1990) discussed in Section 3.2:

Tangibles;

Reliability;

Responsiveness;

Assurance; and

Empathy.

The final version of this questionnaire is included in Appendix 1.

\subsubsection{Evaluating the SERVQUAL questionnaire}

Given the very high degree of validity and reliability found, Parasuraman et al. (1985) conclude that the model is very well applicable to all types of service industries. They found that irrespective of the type of service industry in the sample, consumers' expectations were highest on the reliability dimension, followed in order by assurance, tangibles, responsiveness and empathy. Brouwer and Reuyl (1992, p. 7) support the applicability of the questionnaire, reporting that the SERVQUAL model 'has been used by several researchers (e.g., Carman, 1990; Nillesen and Reuyl, 1991) and found

\footnotetext{
'Although a similar range could be obtained using a 13 -point single statement layout, it is questionable whether respondents could effectively cope with such a wide range.
} 
to be stable.' In their study of customers' assessments of service quality and value in local telephone service, Bolton and Drew (1991) used dimensions similar but not identical to SERVQUAL. Brown and Swartz (1989) report that 'the recent work of Parasuraman, Zeithaml, and Berry (1986) on the development of SERVQUAL provides an excellent illustration of how to begin measuring both expectations and experiences.' In their study of the quality of medical services, Brown and Swartz (1989) used a questionnaire that was very similar to the SERVQUAL questionnaire.

Although very critical of SERVQUAL's conceptualization of service quality as the difference between expectations and perceived performance, Cronin and Taylor (1992) used the SERVQUAL questionnaire in their assessment of the service quality in four different service industries. They conclude (p. 58); 'The current measurement of perceived service quality can be traced to the research of Parasuraman, Zeithaml, and Berry. (...) The scale development procedures employed appear to support the face validity of the 22 scale items (individual questions) included in the scale (...).' Moreover, they state that 'the validity of the 22 individual performance scale items that make up the SERVQUAL scale appears to be well supported both by the procedures used to develop the items and by their subsequent use as reported in the literature (e.g. Carman 1990). We therefore conclude that these 22 performance items adequately define the domain of service quality (...).'

In spite of this broad acceptance, some critical remarks have been made about the use of the SERVQUAL questionnaire (Hentschel, 1990; Vogels et al., 1990; Hedvall and Paltschik, 1991a, b; Andersson, 1992; Cronin and Taylor, 1992 and 1994; Teas, 1993 and 1994):

Measurement of expectations is done at the 'desired level'. This is consistent with the view Parasuraman et al. (1986) held regarding the nature of expectations in quality assessment at that moment - i.e., before they changed their view in Zeithaml et al. (1991) by acknowledging that 'adequate level' also plays an important role in the quality assessment process. This might explain some of the findings of Parasuraman et al. (1986):

1. Customer expectations tend to be very high. On a 1 to 7 scale, the average scores for the several key attributes range from 5.30 to 6.72 ;

2. The SERVQUAL scores are negative on all the items, indicating that - over the whole range - customers' perceived performance falls short of expectations; and 
3. Although the SERVQUAL scores are all negative, the overall quality ratings by customers for the relevant service companies vary from 'good' to 'excellent'. Parasuraman et al. (1986) conclude that 'even meeting customer expectations may be sufficient to project an excellent-quality image.'

Given the findings of Zeithaml et al. (1991), it is desirable to introduce the concept of 'adequate level' into the SERVQUAL questionnaire. This implies that, instead of a dual set of questions per item, a triple set should be presented to respondents: adequate expectations level, desired expectations level and (perceived) performance level (see Parasuraman et al., 1994b).

As discussed in Section 2.6, Cronin and Taylor (1992) reject the conceptualization of audit quality as the gap between perceived and expected performance. Therefore, they suggested using only the 22 perceived performance items as service quality measures. Their findings supported this suggestion. In spite of the possible theoretical and empirical defects in their study (see Parasuraman et al., 1994a), we will use both the service gaps and the perceived performance on the various items as determinants of overall audit quality.

Parasuraman et al. (1986) claim that the items in the questionnaire are both generic (industry-wide applicable) and sufficiently exhaustive. By contrast, Carman (1990) found that there are both generic and industry-specific attributes. However, the fact that some of the items in the SERVQUAL questionnaire are not generic does not impair its generic applicability, as long as the list is sufficiently exhaustive. It does mean that some items will be highly significant in some industries and less significant in other types of service industry. Moreover, the results of studies - based on the variables of the SERVQUAL model - in different service industries, e.g., medical industries (Brown and Swartz, 1989), telephone companies (Bolton and Drew, 1991) and banks, pest control, dry cleaning and fast foods (Cronin and Taylor, 1992), all based on the statements of the SERVQUAL model, seem promising and provide justification for the generic use of SERVQUAL. As was mentioned in Chapter 3, research findings with regard to functional quality in auditing are scarce. Schroeder et al. (1986) and Carcello et al. (1992) have developed questionnaires including some functional audit quality attributes. SERVQUAL includes more functional quality items and includes all 
attributes of Schroeder et al. (1986) and Carcello et al. (1992), whereas these studies did not contain attributes that are not included in the SERVQUAL questionnaire.

Performing factor analysis and regression analysis on data obtained with Likert scales is statistically invalid (Andersson, 1992). Siegel and Castellan (1988) state that variables must be measured on at least an interval scale if parametric tests are to be used. On an interval scale, in contrast to an ordinal scale, the distances or differences between any two numbers on the scale have meaning. Thus there is a common and constant unit of measurement between the objects on the scale. However, Boyd et al. $(1985$, p. 320$)$ report that 'there is a growing tendency to treat many ordinal scales as if they are interval scales, and tests show this is a reasonable assumption in many cases. The degree of association between the most simple ordinal scale and an interval scale has been shown to be quite high. There appears to be little loss in accuracy and considerable gain in interpretability if ordinal data are treated as interval data.' A review of research in the service quality area - both in marketing and in audit research - demonstrates a broad use of parametric statistical methods (in particular: factor and regression analysis) on data obtained with ordinal scales (e.g. Schroeder et al., 1986; Brown and Swartz, 1989; Bolton and Drew, 1991; Cronin and Taylor, 1992; Carcello et al., 1992). ${ }^{2}$

Several authors (e.g., Carman, 1990; Cronin and Taylor, 1992) were unable to find the same factor structure as in Parasuraman et al. (1986). Cronin and Taylor (1992, p. 58) conclude that 'the veracity of conceptualizing the SERVQUAL scale as consisting of the five distinct components identified by Parasuraman et al. (1988) has been questioned (...)'. Therefore, it is advisable to reperform factor analysis for each new data set.

${ }^{2}$ Peter et al. (1993) discuss several other potential methodological problems in using difference scores, including problems regarding reliability, discriminant validity, spurious comelation and variance restriction. However, Parasuraman et al. (1994b, p. 220) state that 'contrary to criticisms of difference-score measures on psychometric grounds, the (...) constructs operationalized as difference scores are by and large as sound as their direct-measure counterpart, except in terms of predictive power'.. 
Overall, it is evident that the SERVQUAL questionnaire has been accepted as a useful instrument to measure service quality, despite the criticisms. Section 5.3.4 will summarize the modifications which were made to the basic SERVQUAL model in the light of its application to audit quality.

\subsubsection{Modification of the SERVQUAL questionnaire}

In order to enhance the applicability of the SERVQUAL technique as an instrument to measure audit quality, several modifications have been implemented for this study:

Inclusion of technical audit quality attributes;

More specific framing of some items in terms of audit services;

Inclusion of a set of questions regarding adequate leve] expectations; and

- Identification of the engagement characteristics.

Two questionnaires were developed: one for clients, one for bankers. ${ }^{3}$ Although basically similar, the questions for clients and bankers are framed from their respective perspectives. Each of the four modifications will be discussed below.

\section{Inclusion of technical audit quality attributes}

As discussed in Section 2.7, the SERVQUAL questionnaire is primarily directed at measuring functional service quality attributes. Lapierre and Filiatrault (1995) note that 'accepting the five dimensions of Parasuraman, Zeithaml, and Berry (...) amounts to saying that the evaluation of quality relates only to the evaluation of the process, i.e. the functional quality. Thus technical quality has de facto been set aside. Yet, we note that several empirical studies, that have dealt with professional services rendered to both individual and organizational customers, have recognized that competence is the most important factor in the evaluation of professional service industries'. Therefore it appeared that the validity of the SERVQUAL questionnaire for the assessment of audit quality could be enhanced by including technical audit quality attributes. Chapter 3 discussed several expectation gap studies and concluded that at least a significant minority of the financial community expects auditors to perform services (by detecting and reporting errors or

'A copy of the two questionnaires (18 pages each) is not included in this thesis but is available on request for those interested. The items included in the questionnaire are summarized in Tables 5.1, 5.2 and 5.3. 
irregularities) with regard to the following objectives:

Financial statements accuracy;

Ability to continue as a going concern;

Internal organization (including internal control system);

Fraud (both fraud harming the company and fraud harming society as a whole); and

Illegal acts.

More specific framing of some items in terms of audit services

As a result of discussions with auditors and the remarks of respondents in the pretests (see Section 5.3.5), some modifications were made to the basic 22 questions in the 1990 SERVQUAL questionnaire:

The standard question 'Excellent companies will insist on error-free records' was modified to 'Ideal ${ }^{4}$ audit firms keep their working files accurately' and 'Ideal audit firms provide an adequate specification of their bills'. Keeping the files accurately might be appreciated by clients, since it enhances the speed of retrieving certain documents at the request of a client. Specification of the bills of an audit firm might be appreciated, since sometimes an audit firm provides a broad range of services to one client. Under these circumstances, clients are interested in the amount charged for each activity, especially if some of these services have budget constraints.

The standard question 'Employees in excellent companies have the knowledge to answer customers' questions" has been differentiated, given the very broad range of services that auditors typically provide.

"The change from 'excellent companies" to 'ideal audit firms" was made because "excellent" might be interpreted by respondents as a more 'objective' qualification, whereas this study focuses on their subjective assessments. For instance, clients might find that an excellent audit firm would serve the interests of third parties first, without finding this behaviour ideal from their own perspective. Since "ideal' better captures this subjective element, it was used instead of 'excellent'. 
Since respondents were explicitly asked to complete the questionnaire only for the audit function of the audit firm, ${ }^{5}$ the question is limited to the ability of members of the audit team to identify risks and opportunities in the areas of financial statements, tax, corporate finance, internal organization and accounting information systems (IO \& AIS) and general business matters.

The standard question 'Excellent companies give you individual attention' has been differentiated. Based on discussions with clients and bankers this question was developed into 'A client has one service-coordinator at an ideal audit firm' and 'The composition of the audit team is stable at an ideal audit firm'.

The standard question 'Excellent companies will have operating hours convenient to all customers' has been modified to say 'Employees of ideal audit firms should always be available for clients' questions.' Clients might well appreciate it if an audit firm's employees were available not only during, but also after the official office hours. The standard question 'Excellent companies have your best interests at heart" has been differentiated, given the typical agency problem an auditor faces, in that he should serve the interests of both clients and third parties. Therefore, the questions 'Ideal audit firms put the client's interests first' and 'Ideal audit firms put third parties' interests first' were included in the questionnaire.

Based on discussions with clients and bankers and given the findings of the pretests, the question 'Employees of an ideal audit firm frequently discuss their findings with the client's management' was added.

In this way, the number of items was extended from 22 in the original SERVQUAL questionnaire to 43 in our instrument (13 technical and 30 functional items).

${ }^{5}$ This was done because large audit firms offer a scope of business services that exceeds the traditional services provided by auditors, such as international tax planning or a broad range of MAS. Since this study focusses primarily on the quality of the audit function, respondents were only asked about the ability of the 'regular' auditor to identify risks and opportunities in several areas in the process of conducting his audit. Therefore, the questions related to the identification of risks and opportunities in these areas are regarded as 'functional", since, in this context, they are a "natural' by-product of the audit function, emerging from the process rather than being an (output) objective. 


\section{Inclusion of a set of questions regarding adequate level expectations} As discussed in Section 2.6, the research findings regarding (the nature of) the impact of expectations on service quality perceptions are inconclusive. Therefore, several concepts will be tested to determine which best explains the variance in overall audit quality perceptions from the individual quality attributes. In order to enable these different quality conceptualizations, questions were asked at three levels: perceived performance, and both desired and adequate levels of expectation. The operationalization of adequate level expectations is a rather new development in service marketing research. Zeithaml et al. (1991) suggest that the zone of tolerance should either be measured directly ${ }^{6}$, or by asking separate questions for desired and adequate level constructs. In this study, the latter suggestion has been followed. ${ }^{7}$ Adequate level expectation statements were constructed as 'It is unacceptable if (employees of) an audit firm do (does) not ..... ${ }^{89}$

Although this construction might induce problems of readability and interpretability - because of the double negatives - it was decided to use this type of operationalization, based on the following considerations:

In the pretests (see Section 5.3.5), pilot respondents confirmed that they had no problems interpreting the adequate level expectation statements. The difference between desired and adequate level expectations was clear to them.

Because of this 'double negatives' construction, the scale anchors for the adequate and the desired level expectations have the same meaning. In both cases ' 1 ' indicates very low expectations, whereas ' 7 ' indicates very high expectations.

\footnotetext{
${ }^{6}$ See, e.g., Liljander and Strandvik. (1992).
}

${ }^{7}$ Parasuraman et al. (1994) have compared direct and indirect measures of service quality. They found that difference scores - as has been done in this study - are by and large as sound as direct measures (except for predictive power), but have superior diagnostic value.

${ }^{8}$ E.g., it is unacceptable if employees of an audit firm do not offer prompt serwice.

${ }^{9}$ Parasuraman et el. (1994b) conceptualized the adequate (or minimum) service level slightly different, as 'When it comes to (e.g., prompt service), my minimum service level is ... (low ... high)'. 
Double negatives are not unfamiliar in auditing. Both in a Dutch disclaimer of opinion and in a review report, negative assurance is expressed by double negatives. ${ }^{10}$

Nonetheless, the conceptualization of adequate level expectations used in this study is debatable. Further research in this area is necessary in order to compare the different ways to operationalize adequate level expectations. To date, the empirical research in this area is, however, very rare (see Liljander and Strandvik, 1992; Parasuraman et al., 1994b).

\section{Identification of the engagement characteristics}

The research questions with regard to the correlation between engagement characteristics and the level of technical audit quality require identification of some relevant engagement characteristics for each questionnaire. Therefore the following data were asked in the questionnaire:

Client's 1992 annual sales;

Client's 31 December, 1992 total assets;

Client's 1992 average number of employees;

Auditor's length of tenure;

Audit firm name;

1992 audit fee;

1992 MAS fee; and

Client's financial health (classified by the banker on a 5-point scale).

Because the responses should be anonymous and the researchers were not supposed to know the identity of either the client or the audit firm involved in a specific engagement, data involving the identity of the audit firm was transformed by a notary's office. ${ }^{1 /}$

\subsubsection{Pretests of the data-gathering instrument}

Several draft versions of the questionnaire were discussed with bankers, clients, auditors and academics. Based on their comments, a final draft

${ }^{10} \mathrm{By}$ expressing 'negative assurance', the auditor states that he has not found an error in the financial statements. This level of assurance is below the level of the regular 'positive' assurance, where the auditor states that the financial statements give a true and fair view.

"More specifically, the notary's office classified the audit firm as either a Big Six or a non-Big Six firm. 
version was made. This version was pre-tested on 5 clients and 6 bankers. The 5 clients represented very different companies (different in terms of size, financial health, and industry), the 6 bankers were from one bank corporation. The pretest respondents received the questionnaire by mail. After they had completed the questionnaire, they were contacted using a standard set of pretest evaluation questions. All respondents found the questionnaire realistic and clear. The use of a 7-point scale was found to be adequate. The pretest respondents indicated that they understood the difference between the 'adequate' and 'desired' level expectations. The respondents believed most questions relevant for the assessment of audit quality were included. Several suggestions were made for additional questions. Most of these suggestions were followed.

\subsubsection{Population and sample selection}

Since clients and third party beneficiaries might be expected to have different structures in determining audit quality, both groups were included in the survey. For the client group, the respondents were the firm representatives at the management level who had most 'service encounters' with employees of the audit firm. For third party beneficiaries, the account managers of banks ('bankers') were chosen, because of their relatively frequent direct service encounters with auditors. Furthermore, bankers would appear to be one of the most important user groups of audit services, in particular in the case of small and medium-sized companies.

One of the research objectives was to gain insight into the differences in audit quality judgments between clients and bankers. Therefore it was necessary to obtain the best possible match between the clients and bankers samples, since any differences between the conditions of engagement in the bankers and clients samples would affect their respective assessments. In order to achieve this, the following, somewhat complicated, procedure was followed. Five Dutch banks - working on a nation-wide scale - were approached to cooperate in the study. After an extensive description of the measures used to obtain full confidentiality (see below), all banks agreed to participate. After gaining the cooperation of the regional bank management, the banks' account managers (who have direct contacts with both the client and the client's auditor) were approached by regional management, asking them to randomly select clients from their portfolio, meeting the following characteristics: 
The auditor"s assignment should be to perform an audit. Given the study's specific attention to quality in audit engagements, compilation and/or review engagements were not selected;

The bank involved should be a major financial stakeholder. Specifically, it should finance at least $20 \%$ of total assets of the companies selected. This characteristic was introduced because the questions included in the questionnaire required a good insight into the work of the auditor and hence a rather intensive contact with both the client and the auditor, and this appears most likely where the banker has an important financial stake in the company and therefore might rely heavily on the audit report.

The account managers were then asked to give the names of the clients selected to the regional bank management. The questionnaire and accompanying letters were then mailed by the regional bank management to both the bank's account manager and the client officer identified as the client's key contact (at management level) for the auditor, mostly the chief financial officer or the general manager. The accompanying letter included a reference to the interest of the Dutch professional body of Registered Accountants (NIVRA) in the outcome of this study. The NIVRA board had granted permission for this reference to be included in the letter. Several nonresponse follow-up actions were made by the regional bank management.

Special consideration was given to confidentiality. The importance of confidentiality was stressed by the cooperating banks, the clients who participated in the pretests and the NIVRA board. It was therefore decided that the researchers should not be able to identify either the client or the audit firm involved. For the purpose of follow-up on non-response and because of the need for information on the size of the audit firm involved (audit firm size being an important element of several hypotheses to be tested), the following procedure was followed:

Questionnaires did not contain the client company name. To enable non-response follow-ups, each questionnaire had a specific number. Each bank held a code list in which this number was related to the name of the client and the account manager involved. The bank was informed by the researchers about the non-response numbers; Completed questionnaires were mailed by the respondents to a specific notary's office. The notary removed the page containing the name of the audit firm and registered on a separate form whether the firm for a specific engagement was a Big Six or a non-Big Six firm. 


\subsection{Sample Characteristics}

\subsubsection{Engagement characteristics}

Because of the confidentiality of the data required (fee data, assessments of clients' financial health, explicit opinions on the performance of auditors by both bankers and clients), and given the length of the questionnaire (completion time would typically be approximately 30 minutes), high response rates were not expected, although the cooperation of the bank companies' staff and the inclusion of the notary's office in the process were expected to enhance these response rates.

A total of 185 questionnaires were mailed to both clients and bankers. Of these, 89 were returned by bankers $(48.1 \%$ ), and 66 were returned by clients $(35.7 \%)$. For 12 engagements there were client responses only, and only banker responses for 35 engagements. For 54 engagements both the banker and the client returned usable responses. This figure was important, since the objective was to compare client and banker assessments for similar engagements. ${ }^{12}$

These response levels were more or less anticipated. All the questionnaires returned were useful, although sometimes questionnaires were not fully completed. For some statistical tests the incomplete questionnaires were disregarded.

The audit engagement characteristics for the questionnaires that were returned are specified in Table 5.1.

${ }^{12}$ Both the matching and non-matching engagennents were used in the study. This was decided after tests revealed that these subsets were nearly identical in terms of engagement characteristics and scores on the individual statements. The advantage of also using the non-matching engagements is purely statistical: both factor analysis and regression analysis require a relatively high number of cases. 


\begin{tabular}{|c|c|c|c|c|}
\hline 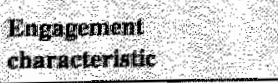 & Mininimuma & Maxtmum & Mean & $\begin{array}{l}\text { Stamiard } \\
\text { Deviation }\end{array}$ \\
\hline Total salles (NLG) & 500,000 & $600,800,000$ & $50,140,000$ & $107,870,000$ \\
\hline Tokal assets (NLG) & 600,000 & $456,800,000$ & $34,170,000$ & $79,130,000$ \\
\hline Employees & $\Downarrow$ & 3,894 & 189.59 & 562.02 \\
\hline Tinanciall condition $(1-5)$ & 1 (excellent) & 5 (bad) & 1.92 & 1.04 \\
\hline Audit fee (NLG) & 4,800 & 520,000 & 60,280 & 71,510 \\
\hline MAS fee (NLG) & 0 & 300,000 & 23,650 & 51,320 \\
\hline Tenure (years) & 1 & 40 & 11.95 & 8.81 \\
\hline
\end{tabular}

\section{Table 5.1 Audit engagement characteristics}

As Table 5.1 illustrates, there is considerable variation in the engagement characteristics. The standard deviations for all characteristics are quite large, indicating that many types of audit engagements are included, with the exception of 'mega-companies', since the high end of total sales is only 600 million Dutch Guilders (NLG). The sample also includes (a small number of) non-statutory audits for very small companies, that are not legally required to be audited. The companies' average financial condition is fairly good, although the standard deviation indicates that there is sufficient spread over this variable. Of the 66 client observations, 40 were Big Six engagements, 23 were non-Big Six engagements, whereas the audit firm was not revealed for 3 cases. Of the 89 banker observations, 38 were Big Six engagements, 30 were non-Big six engagements, whereas the audit firm was not revealed for 21 cases.

\subsubsection{Questionnaire scores}

\section{Overall audit quality}

Overall audit quality received ratings that can be considered as rather high. On a 7-point Likert scale, bankers gave a mean rating of 5.47 (standard deviation 1.13) over $81^{13}$ cases, while clients gave a rating of 5.42 (standard deviation 0.97 ) over $64^{14}$ cases. At $\mathrm{p}=0.05$, the difference between the two

\footnotetext{
${ }^{13}$ Of the 89 bankers that responded, 8 did not rate overall audit quality.

${ }^{14}$ Of the 66 clients that responded, 2 did not rate overall audit quality.
} 
samples is not significant. It is interesting to note that these ratings are quite good, although - as will be seen in the discussion of Tables 5.2 and 5.3 there is considerable underperformance at the desired level and even - on some occasions - at the adequate level for the individual statements. This finding is not uncommon in SERVQUAL studies (see Section 5.3).

\section{Technical audit quality variables}

Table 5.2 gives the mean and standard deviation for the technical audit quality variables. The significance levels of the differences in performance ratings between the bankers and clients samples were obtained by using independent $t$-tests. ${ }^{15}$

\begin{tabular}{|c|c|c|c|c|}
\hline \multirow{2}{*}{ Variable } & \multirow{2}{*}{ Hanker } & \multicolumn{3}{|c|}{ Mean (and standard den intion) at lovelt. } \\
\hline & & Performance & $\begin{array}{l}\text { Performance } \\
\text { minus } \\
\text { Desired }\end{array}$ & $\begin{array}{l}\text { Performance } \\
\text { nimus } \\
\text { Adequate }\end{array}$ \\
\hline \multirow[t]{2}{*}{ * Detect errors in fimpancial statements } & $\mathrm{B}$ & $5.55(0.97)$ & $-0.89(1.03)$ & $-0.66(1.18)$ \\
\hline & $\mathrm{C}$ & $5.08(1.36)$ & $-0.80(1.53)$ & $-0.74(1.36)$ \\
\hline \multirow[t]{2}{*}{ Repont errors in financial statements } & $\mathbf{B}$ & $5.65(1,09)$ & $-0.87(1.10)$ & $0.84(1.21)$ \\
\hline & $\mathrm{C}$ & $5.52(\mathbb{1} .18)$ & $-0.41(0.99)$ & $-0.27(1.05)$ \\
\hline \multirow{2}{*}{$\begin{array}{l}\text { Derect smoothing in financial } \\
\text { statements }\end{array}$} & B & $5,60(0,97)$ & $-0.86(0.98)$ & $-0.53(1.19)$ \\
\hline & $\mathrm{C}$ & $4.81(1.43)$ & $-0.65(1.20)$ & $-0.20(1.13)$ \\
\hline \multirow{2}{*}{$\begin{array}{l}\text { * Report smoothing in financial } \\
\text { statcments. }\end{array}$} & $\mathrm{B}$ & $5.56(0.95)$ & $-0.85(0.99)$ & $-0.73(1.00)$ \\
\hline & $\mathrm{C}$ & $4,86(1.45)$ & $0.48(1.28)$ & $0.0901 .09)$ \\
\hline \multirow[t]{2}{*}{ Detect going-concerm problems } & $B$ & $6.03(1.02)$ & $.0 .79(1,02)$ & $-0.74(1.02)$ \\
\hline & $\mathrm{C}$ & $5.78(1.14)$ & $-0.58(1.01)$ & $0.33(1.52)$ \\
\hline \multirow{2}{*}{$\begin{array}{l}\text { * Publicly report going-coneem } \\
\text { problems }\end{array}$} & B & $5.54(1.11)$ & $-0.83(1.14)$ & $0.70,1,00)$ \\
\hline & $\mathrm{C}$ & $4.96(1.64)$ & $-0.11(1.08)$ & $-0.02(1.23)$ \\
\hline
\end{tabular}

${ }^{15}$ To determine whether the differences between the clients sample and the bankers sample were disturbed by variations in their respective samples, the significance of these differences for the 54 'matching' engagements (the engagements for which we had both client and banker assessments) was also tested. The differences and their significance levels were similar to the differences between the complete sample (including both matching and non-matching engagements), except for 'detect going-concern problems", which was significant at $p=0.01$ for the matching engagements. Given this high degree of similarity, the data of the complete sample is used from here on. 


\begin{tabular}{|c|c|c|c|c|}
\hline \multirow[t]{2}{*}{ Variable } & \multirow{2}{*}{$\begin{array}{l}\text { Banker } \\
\text { Clilent }\end{array}$} & \multicolumn{3}{|c|}{ Mean (and standard deviation) at level: } \\
\hline & & Performance & $\begin{array}{l}\text { Pefformance } \\
\text { mihius } \\
\text { Desired }\end{array}$ & $\begin{array}{l}\text { Performance } \\
\text { miniss } \\
\text { Adequate }\end{array}$ \\
\hline \multirow{2}{*}{$\begin{array}{l}\text { * Detect deficiencies in internal } \\
\text { organization }\end{array}$} & B & $5.47(1.06)$ & $-0.39(1.02)$ & $-0.56(0.92)$ \\
\hline & $c$ & $4.86(1.41)$ & $-0.45(1.27)$ & $-0.18(1.37)$ \\
\hline \multirow{2}{*}{$\begin{array}{l}\text { * Publicly repori deficiencies in } \\
\text { internal organization }\end{array}$} & $B$ & $5.33(1.26)$ & $-0.64(1.20)$ & $-0.56(1.04)$ \\
\hline & $\mathrm{C}$ & $4.33(1.64)$ & $-0.27(1.48)$ & $0.09(1.72)$ \\
\hline \multirow[t]{2}{*}{ Detect fraud } & $\mathbf{B}$ & $5.83(0.87)$ & $-0.81(0.88)$ & $-0.66(0.88)$ \\
\hline & c & $5.60(1.36)$ & $-0.55(1.14)$ & $-0.30(1.50)$ \\
\hline \multirow[t]{2}{*}{ * Publicly report internal fraiud } & $\mathrm{B}$ & $5.09(1.37)$ & $-0.43(1.22)$ & $-0.21(1.32)$ \\
\hline & $\mathrm{C}$ & $4.42(1.98)$ & $.0 .111(1.07)$ & $0.09(1.22)$ \\
\hline \multirow[t]{2}{*}{ * Report fraud to tax authorities } & B & $4.75(1.52)$ & $-0.40(1.48)$ & $-0.16(1.34)$ \\
\hline & $\mathrm{C}$ & $4.17(2.02)$ & $-0.09(1.20)$ & $-0.09(0.72)$ \\
\hline \multirow[t]{2}{*}{ * Detect illegal acts } & $\mathrm{B}$ & $4.74(11.27)$ & $-0.51(1.12)$ & $-0.26(1.09)$ \\
\hline & $\mathrm{C}$ & $4.10(1.70)$ & $-0.48(1.11)$ & $-0.55(1.48)$ \\
\hline \multirow[t]{2}{*}{ Publicly report illegal acts } & $B$ & $4.99(1.27)$ & $.0 .56(1.20)$ & $-0,33(1,14)$ \\
\hline & C & $4.69(1.65)$ & $-0.09(0.85)$ & $0.00(0.82)$ \\
\hline
\end{tabular}

Table 5.2 Descriptive statistics of technical audit quality variables

* = significant difference in mean at the performance level between bankers and clients at $\mathrm{p}=.05$

* = significant difference in mean at the performance level between bankers and cllients at $\mathrm{p}=01$

In studying the results in Table 5.2 and comparing the answers to the technical audit quality questions with the results of the expectation gap studies mentioned in Chapter 3, several interesting points emerge:

On all items, bankers perceive a 'better' performance (higher score) than clients. For most items, this difference is statistically significant; However, on nearly all the items, clients perceive a much smaller gap (in absolute values) than bankers. Obviously, bankers" expectations regarding technical audit quality attributes are much higher than clients';

Although detection of errors and smoothing in the financial statements shows a reasonably good score for both groups, it is interesting to note that the gaps between performance and the desired and even adequate levels are considerable. This reflects the fact that clients' and 
bankers" expectations regarding this 'core business' of auditors are extremely high. Further, it is interesting to note that clients are relatively sceptical with regard to the auditors' ability to detect smoothing. Obviously, clients think they are able to 'outsmart' the auditor in this respect. It is also interesting to see that the zone of tolerance ${ }^{16}$ for the detection of 'smoothing' is much wider for clients than for bankers. Since smoothing is a deliberate action on the part of clients, clients (the auditees!) seem to reason that they do not need an auditor to detect smoothing;

The reporting of errors and smoothing is also at a reasonably high level for both groups, although, again, the gaps between performance and the desired and adequate levels are considerable, notably in the case of bankers. Again, the zone of tolerance is wider for clients than for bankers. Clients seem to bother much less about an auditor who, after detecting an error, does not report this;

Both bankers and clients perceive that auditors are very capable of detecting going concern problems, although, again, the gaps between performance and the desired and adequate expectations are considerable. For this variable, it is interesting to see that the zone of tolerance for bankers is extremely small;

With regard to the reporting of going concern problems, it seems that the very high standards that bankers adopt are not met, which is consistent with the findings of the expectation gap studies. Clients' expectations are significantly lower, which means that the gap for clients is moderate;

The detection of deficiencies in the internal organization shows a smaller gap for bankers than the previous technical audit quality issues. ${ }^{17}$ This time, however, the gap is wider for clients, probably reflecting their perception of insufficient auditor's feed-back on this issue;

With regard to reporting on internal organization deficiencies, the pattern of a wider gap for bankers emerges again. In contrast to clients, bankers expect the auditor to report deficiencies in this area, as

${ }^{16}$ The zone of tolerance is the gap between the 'desired' and 'adequate' level of expectations. In Table 5.2, it is the gap between 'Performance minus Desired' and "Performance minus Adequate".

${ }^{17}$ Intriguingly, the bankers' adequate expectations exceed their desired expectations. No explanation was obtained for this finding. 
was the case in most of the expectation gap studies;

Both bankers and clients have very high expectations with regard to the detection of fraud, in line with the expectation gap studies; However, for both publicly reporting internal fraud and reporting fraud to tax authorities, bankers' expectations are again considerably higher than clients', resulting in a very small gap for clients and a considerable gap between performance and the desired level expectations for bankers;

Expectations with regard to the detection of illegal acts are much lower than for the other detection issues, possibly indicating that this duty is not considered to be 'core business' for the auditor. The performance minus desired gap for bankers and clients is comparable, although expectations and perceived performance are on a lower overall level for clients. Intriguingly, the clients" adequate expectations are higher than their desired expectations; and

For the issue of publicly reporting illegal acts, there is hardly any expectation gap for clients, whereas the gap for bankers - on both the desired and adequate level - is significantly wider.

Thus bankers, overall, expect a significantly higher technical audit quality than clients, both on the detection and on the reporting/independence side. This is not unexpected, since they have considerably fewer sources of information on the company and therefore rely on the auditor to detect and report items that are of concern to them. The client has a variety of sources of information about his company and is not fully dependent on the auditor in this respect. The clients" lower expectations can also be explained by the fact that they are directly involved in the trade-off between quality and audit costs. Their lower expectation with regard to the reporting issue is not unexpected. As was discussed in Section 3.4, clients might perceive 'factual independence' as awkward, since it might reveal information to outside stakeholders that the client"s management would rather have kept a secret.

The fact that the performance rating given by clients is significantly lower than that of bankers for nearly all the issues is interesting. Perhaps the clients" direct involvement with the audit process makes them more critical of the auditor's activities. The fact that the clients are the auditees and are therefore subject to the auditor's judgments might also make them more critical in the assessment of their auditor's performance.

Finally, it is remarkable that the gaps for non-traditional items are not wider than for the traditional items. The 'expectation gaps' regarding 'whistle 
blowing items' such as the detection and reporting of fraud or illegal acts are not as wide as for the traditional duties, which was unexpected, given the findings of most of the expectation gap research in Chapter 3.

\section{Functional audit quality variables}

Table 5.3 gives the mean and standard deviation for the functional audit quality variables. The significance levels of the differences in performance ratings between the bankers and clients samples were obtained using independent $t$-tests. ${ }^{18}$

\begin{tabular}{|c|c|c|c|c|}
\hline \multirow{2}{*}{ Variable } & \multirow{2}{*}{ Gavilker } & \multicolumn{3}{|c|}{ Meam (and standard devintori) at livall } \\
\hline & & Performance & $\begin{array}{l}\text { Perfommanee } \\
\text { minus } \\
\text { Peired }\end{array}$ & $\begin{array}{l}\text { performance } \\
\text { niluus. } \\
\text { Milequalo }\end{array}$ \\
\hline \multirow[t]{2}{*}{ Timely delivery } & $\mathrm{B}$ & $5.48(1.18)$ & $-0.7^{\prime} 1(1.48)$ & $-0.30(1.42)$ \\
\hline & $\mathrm{C}$ & $5.34(1.15)$ & $0.92(1.64)$ & $.0 .52(1.83)$ \\
\hline \multirow[t]{2}{*}{ Be able to trust audit firm's employees } & $\mathbf{B}$ & $5.81(1.0 * 1)$ & $-0.49(1,22)$ & $-0,36(1.08)$ \\
\hline & $\mathrm{C}$ & $5.83(1.02)$ & $-0.50(1.22)$ & $-0.39(1.30)$ \\
\hline \multirow[t]{2}{*}{ Working files in good order } & $B$ & $5.70(0.97)$ & $-0.84(1.09)$ & $-0.45(2.10)$ \\
\hline & $\mathrm{C}$ & $5.83(0.92)$ & $-0.65(1.00)$ & $-0.27(1.23)$ \\
\hline \multirow[t]{2}{*}{ **Adequate bill specification } & $\mathrm{B}$ & $4.86(1.46)$ & $-1.44(1.80)$ & $-1.10(1.66)$ \\
\hline & $\mathrm{C}$ & $3.61(1.77)$ & $-2.73(2.09)$ & $-2.18(2,10)$ \\
\hline \multirow[t]{2}{*}{ Well dressed/neat appearance } & $B$ & $5.86 \cdot(0.95)$ & $-0,29(1,30)$ & $0.50(1.20)$ \\
\hline & $\mathrm{C}$ & $5.96(0.82)$ & $0.09(0.99)$ & $0.86(1.14)$ \\
\hline
\end{tabular}

${ }^{18}$ To determine whether the differences between the clients sample and the bankers sample were disturbed by variations in their respective samples, the significance of these differences for the 54 'matching' engagements (the engagements for which we had both client and banker assessments) was again tested. The differences and their significance were similar to the differences between the complete samples (including both matching and non-matching engagements $\rangle$, except for two questions. 'Personal attention", which revealed a significant difference for the complete sample, just failed to be significant for the matching engagements (although it would have been significant at $p=0.058$ ). Further, bankers rated 'identify points of attention regarding tax' significantly higher than clients for the matching engagements $(p=0.042)$, in contrast to the complete sample. However, given this high degree of similarity, the data of the complete sample is used from here on. 


\begin{tabular}{|c|c|c|c|c|}
\hline \multirow{2}{*}{ Varrabile } & \multirow{2}{*}{ Hanker } & \multicolumn{3}{|c|}{ Mean (and xtandand deviafion), at level. } \\
\hline & & Prempramance & $\begin{array}{l}\text { Pefrommanos } \\
\text { minus } \\
\text { Desired }\end{array}$ & $\begin{array}{l}\text { Pertorminince } \\
\text { minis } \\
\text { Adequate }\end{array}$ \\
\hline \multirow[t]{2}{*}{ Thime for cliens: questions } & $\mathbf{B}$ & $5.25(0.95)$ & $-0.25(1.43)$ & $-0.86(1.05)$ \\
\hline & $\mathrm{C}$ & $5.48(1.23)$ & $-0.08(1.41)$ & $-0.44(1.39)$ \\
\hline \multirow{2}{*}{ Client" s interests first } & B & $5.53(0.99)$ & $-0.64(1.33)$ & $-0.35(1.35)$ \\
\hline & C & $5.51(1.25)$ & $0.47(1.54)$ & $-0.55(1.46)$ \\
\hline \multirow{2}{*}{$\begin{array}{l}\text { "Thuird partices" (including bankers") } \\
\text { interests first }\end{array}$} & B & $4.17(1.37)$ & $-0.35(1.22)$ & $-0.10(1.37)$ \\
\hline & $\mathrm{C}$ & $3.58(1.53)$ & $0.26(1.52)$ & $0.45(1.29)$ \\
\hline \multirow[t]{2}{*}{ Employes tarrive on time } & $\mathrm{B}$ & $5.50(1.01)$ & $0.33(1.12)$ & $-0.24(1.43)$ \\
\hline & $\mathrm{C}$ & $5.52(1.27)$ & $-0.65(1.57)$ & $-0.56(1.45)$ \\
\hline \multirow[t]{2}{*}{ Helpful attitude } & $\mathrm{B}$ & $5.70(0.86)$ & $-0.54(1.18)$ & $-0.05(1.07)$ \\
\hline & C & $5.95(1.18)$ & $-0.32(1.20)$ & $0.06(1.15)$ \\
\hline \multirow[t]{2}{*}{ Pleasant and polite } & $\mathbf{B}$ & $5.55(0.83)$ & $0.07(1.39)$ & $0.73(1.09)$ \\
\hline & $\mathbb{C}$ & $6.04(0.85)$ & $0.35(1.18)$ & $1.01(1.21)$ \\
\hline \multirow[t]{2}{*}{ - Persontal attention } & B & $5.67(0.92)$ & $-0.36(1.02)$ & $-0.18(1.16)$ \\
\hline & $\mathrm{C}$ & $5.28(1.02)$ & $-0.97(1.10)$ & $-0.47(1.26)$ \\
\hline \multirow[t]{2}{*}{ Know client's needs } & $\mathrm{B}$ & $5.53(1.06)$ & $-0.42(1.50)$ & $-0.01(1.62)$ \\
\hline & C & $5.64(1.12)$ & $-0.35(1.23)$ & $0.05(1.57)$ \\
\hline \multirow[t]{2}{*}{ *Modern equipment } & $B$ & $6.00(0.93)$ & $-0.32(1.18)$ & $0.33(1.32)$ \\
\hline & $\mathrm{c}$ & $5.63(1.00)$ & $-0.20(1.27)$ & $0.41(1.25)$ \\
\hline \multirow{2}{*}{$\begin{array}{l}\text { * Make exact appoimtments to perform } \\
\text { services }\end{array}$} & $B$ & $5.40(0.98)$ & $-0.78(1.16)$ & $-0.07(1.42)$ \\
\hline & $\mathrm{C}$ & $5.92(1.10)$ & $-0.39(1.09)$ & $0.23(1.29)$ \\
\hline \multirow[t]{2}{*}{ One service-coordinator } & $B$ & $5.85(1.23)$ & $-0.66(1.37)$ & $0.41(1,59)$ \\
\hline & $\mathrm{C}$ & $5.83(1.37)$ & $0.29(1.33)$ & $0.65(1.53)$ \\
\hline \multirow{2}{*}{$\begin{array}{l}\text { Idontify points of thention regarding } \\
\text { tak }\end{array}$} & $\mathbb{B}$ & $5.80(1.10)$ & $-0.65(1.17)$ & $-0.13(1.34)$ \\
\hline & $C$ & $5.57(1,18)$ & $-0.70(1.46)$ & $-0.30(1.35)$ \\
\hline \multirow{2}{*}{$\begin{array}{l}\text { Identify points of interest regarding } \\
\text { findancial statements }\end{array}$} & $B$ & $5.91(0.85)$ & $-0.63(0.84)$ & $-0.44(0.92)$ \\
\hline & $\mathrm{C}$ & $5.92(0.98)$ & $-0.50(1.06)$ & $-0.11(1.20)$ \\
\hline \multirow{2}{*}{$\begin{array}{l}\text { Identify points of interest regarding } \\
\text { corporate firance }\end{array}$} & $\mathrm{B}$ & $5,47(1,14)$ & $-0.90(1.19)$ & $-0.116(1.16)$ \\
\hline & $\mathrm{C}$ & $4.93(1.46)$ & $-0.94(1.32)$ & $-0.30(1.23)$ \\
\hline \multirow{2}{*}{$\begin{array}{l}\text { Identify points of interrest regarding } \\
\text { IO } \mathrm{A} \text { AIS }\end{array}$} & $B$ & $5.60(1.11)$ & $-0.53(1.06)$ & $.0 .09(1.00)$ \\
\hline & $\mathrm{C}$ & $5.23(1.19)$ & $.0 .42(1.53)$ & $0.06(1.36)$ \\
\hline
\end{tabular}




\begin{tabular}{|c|c|c|c|c|}
\hline \multirow[t]{2}{*}{ Varinble } & \multirow{2}{*}{$\begin{array}{l}\text { Banker } \\
\text { fClient }\end{array}$} & \multicolumn{3}{|c|}{ Mean (and standard deviation) at level. } \\
\hline & & Performance & $\begin{array}{l}\text { Perforruange. } \\
\text { minuss } \\
\text { Destred }\end{array}$ & $\begin{array}{l}\text { Performance } \\
\text { minus. } \\
\text { Adequate. }\end{array}$ \\
\hline \multirow{2}{*}{$\begin{array}{l}\text { *Identify points of interest regarding } \\
\text { general management }\end{array}$} & B & $5.52(1.0 \mathrm{~d})$ & $-0.35(1.04)$ & $0.11(1.23)$ \\
\hline & $\mathrm{C}$ & $4.93(1.42)$ & $-0.18(1.38)$ & $0.12(1.25)$ \\
\hline \multirow[t]{2}{*}{ Stable audit team } & $\mathbf{B}$ & $5.49(1.15)$ & $=0.37(1.41)$ & $0.41(1.81)$ \\
\hline & $\mathrm{C}$ & $5.30(1.60)$ & $-0.61(1.98)$ & $0.02(2.38)$ \\
\hline \multirow[t]{2}{*}{ Polished reports and letters } & $B$ & $6.06(0.82)$ & $-0.49(0.92)$ & $-0,06(1.03)$ \\
\hline & $\mathrm{C}$ & $6.22(0.78)$ & $-0.20(0.79)$ & $0.30(0.99)$ \\
\hline \multirow[t]{2}{*}{ Available for questions: } & B & $5.19(0.93)$ & $-0.69(1.13)$ & $-0.08(1.20)$ \\
\hline & $\mathrm{C}$ & $5.37(0.99)$ & $-0.39(1.39)$ & $0.32(1.25)$ \\
\hline \multirow[t]{2}{*}{ Genwine interest in slient"s problems } & B & $5.74(0.96)$ & $-0.64(1.09)$ & $-0.31(1.09)$ \\
\hline & $\mathrm{C}$ & $5.96(1.15)$ & $-0.30(1.26)$ & $-0.09(1.37)$ \\
\hline \multirow[t]{2}{*}{ * Service right the first time } & B & $5.60(0.84)$ & $-0.51(1.05)$ & $0.45(1.36)$ \\
\hline & $\mathrm{C}$ & $5.32(1.16)$ & $-0.81(1.29)$ & $-0.04(1.62)$ \\
\hline \multirow[t]{2}{*}{ Prompt service } & $\mathrm{B}$ & $5.50(0.80)$ & $0.39(1.00)$ & $0.32(1.1 .3)$ \\
\hline & $\mathrm{C}$ & $5.51(1.15)$ & $-0.56(1.30)$ & $0.02(1.29)$ \\
\hline \multirow[t]{2}{*}{ Feel secure in dealing with auditor } & $\mathbf{B}$ & $5.83(0.93)$ & $-0.80(0.96)$ & $.0 .39(0.86)$ \\
\hline & $\mathrm{C}$ & $5.83,(0.95)$ & $-0.42(1.25)$ & $-0.32(1.43)$ \\
\hline \multirow[t]{2}{*}{ Discuss finding frequently } & B & $5.45(1.03)$ & $-0.87(1.13)$ & $-0.53(1.42)$ \\
\hline & $C$ & $5.34(1.43)$ & $-0.65(1.43)$ & $-0.17(1.74)$ \\
\hline \multirow[t]{2}{*}{ Visually appealing building } & B & $5.55(1.18)$ & $0.83(1.61)$ & $1.66(1.59)$ \\
\hline & $\mathrm{C}$ & $5.77(1.29)$ & $1.50(1.72)$ & $1.97(1.72)$ \\
\hline
\end{tabular}

Table 5.3 Descriptive statistics of functional audit quality variables

* = significant difference in mean at the performance levell between bankers and clients at $\mathrm{p}=0.05$

** = significant difference in mean at the performance lewel between bankers and clients at $\mathrm{p}=.01$

It is obvious from Table 5.3 that bankers' and clients' performance assessments are much more alike for the functional audit quality attributes than for the technical audit quality attributes. Significant differences are present in areas that are less well observable to bankers, such as bill specification and the identification to the client of specific points of interest. 
The following interesting conclusions can be drawn from studying the scores on functional audit quality in Table 5.3:

The most significant gaps (P-D and P-A) are on bill specification. A poor (bankers) or even very poor (clients) perceived performance falls well short of very high expectations on the desired and even the adequate level;

Auditors are obviously very well dressed, have a neat appearance and are pleasant and polite. The results show, however, that in the eyes of clients this appearance might be 'overdone', since the perceived performance clearly exceeds the optimum or desired level. Very clearly this is the case for having a visually appealing building. There are high performance ratings on this item, but only modest expectations, resulting in extreme overperformance. This overperformance might have a negative influence on overall audit quality assessments by both clients and bankers. This will be tested in Chapter 6;

For both bankers and clients, the adequate expectations regarding time for clients' questions exceed desired expectations. Although no direct explanation can be provided for this phenomenon, it illustrates their obvious lack of tolerance regarding the performance on this issue; Both bankers and clients agree that clients' interests should come first. Both groups believe that the auditors succeed reasonably well in this respect. However, personal attention falls short of clients' expectations. Again, clients' adequate expectations exceed their desired expectations; and

Clients are much more sceptical about the auditor serving third parties' interests than bankers, who represent these third parties. Obviously, the auditor has chameleon-like traits! As might be expected, bankers have higher expectations with regard to this issue than clients, resulting in a negative gap for bankers and a positive gap (more than ideal) for clients.

\subsection{Summary}

This chapter has discussed the research design and presented the descriptive results for the scores on the individual statements in the questionnaire. On the basis of the SERVQUAL questionnaire - often used in marketing research - we developed an instrument reflecting the specific characteristics of the audit market. This instrument was used to ask bankers and clients to rate their 
expectations and perceptions of performance regarding audit services. In addition, factual information about the relationship between the auditor and his client was requested. Specific measures were taken to meet the requirements of confidentiality and to ensure the comparability of the assessments of bankers and clients. Based on the descriptive results, several interesting differences between the assessments of these two groups emerged. These will be explored further in the next chapters. 


\section{CHAPTER 6 DETERMINANTS OF OVERALL AUDIT QUALITY}

\section{I Introduction}

One of the goals of this study is to gain insight into the relative importance of technical and functional quality factors in overall audit quality assessments. ${ }^{1}$ To investigate the weights of the various quality factors, we first performed a factor analysis on all technical and functional audit quality questions. Factor analysis is a statistical technique used to identify a relatively small number of factors that can be used to represent relationships among sets of many interrelated variables (Norusis, 1993a). In this study, factor analysis helped in identifying the relationships between the large numbers of technical and functional quality items that were included in the questionnaire. The results of the factor analysis are presented in Section 6.2. The factors identified in the factor analyses were used as the independent variables in several regression analyses, with overall audit quality as the dependent variable. This combination, first performing factor analysis and then using these factors as independent variables in regression analysis, is not uncommon in marketing research (see Brown and Swartz, 1989; Hentschel, 1990; Brouwer and Reuyl, 1992). ${ }^{2}$ The results of these regression analyses are presented for the clients sample and the bankers sample separately in Section 6.3. Section 6.4 will compare the bankers' and clients' regressions and draw final conclusions regarding this part of the analysis. Finally, Section 6.5 will give a summary of the findings regarding the research objective discussed in this chapter.

${ }^{\prime}$ Remember that the gap between perceived performance and expectations is not an indication of the impact of this variable on overall audit quality. Respondents might perceive a very significant gap between expectations and perceived performance for an attribute, even though the impact of this gap on overall audit quality perceptions is low, given the irrelevance of this attribute to the respondent.

${ }^{2}$ The advantage of using factors as independent variables instead of the individual statements is threefold. First there is a statistical advantage, given that the sample was limited and that regression analysis require a certain number of observations, based on the number of independent variables. A second statistical advantage is the fact that factor analysis, providing it is carried out in a particular way, generates factors which are mutually independent, eliminating the risk of multicollinearity between the independent variables in the regression analysis. Finally, the results can be interpreted at a higher level. Instead of discussing the importance of individual statements, this procedures makes it possible to draw conclusions about the importance off 'aggregate' factors. 


\subsection{Factor analyses}

\subsubsection{Introduction}

Chapter 2 discussed the claim made by Parasuraman et al. (1985) that the factor structure they developed for service quality, is generic. However, Chapter 2 also included several critical remarks in the relevant literature with respect to this claim. Therefore a specific factor analysis was performed for this study, instead of merely following the structure suggested by this group of researchers, as described in Zeithaml et al. (1990). Furthermore, in the light of the ongoing debate in the service quality and marketing literature on the proper conceptualization of service quality (see Section 2.6), we decided to test the impact of expectations at various levels on (audit) quality assessments. From the research of Zeithaml et al. (1991) on the types of expectations used in quality assessments (see Section 2.6), two categories of expectations were considered to be relevant: adequate level expectations and desired level expectations. Therefore factor analyses were carried out using three different audit quality concepts: ${ }^{3}$

(perceived) performance ${ }^{4}$ level;

(perceived) performance minus desired expectation level (P-D); and (perceived) performance minus adequate expectation level (P-A).

It seemed appropriate to design specific factor structures for clients and bankers separately, hypothesizing that their quality judgments will be different.

Another reason for using separate factor structures for clients and bankers was the avoidance of multicollinearity in regression analyses, in which the

'In the remainder of this study these concepts will be referred to as 'levels'. level.

"In the remainder of this chapter, this level will be referred to as the performance 
factors would be treated as independent variables (see next section). ${ }^{5}$

The following sub-sections will first discuss the factor analysis procedures, and then will present the findings of the factor analyses for each of the six combinations mentioned above (clients and bankers, using three different quality concepts). Finally, the factor structures found for the combinations are compared with each other and with the ('generic') factor structure suggested by Zeithaml et al. (1990).

Different factor structures were found for the two respondent groups: bankers combine the detection and reporting of errors and irregularities into one factor, whereas clients treat these items differently. This is not surprising, given the agency theory analysis in Chapter 3, which indicated that both bankers and clients would appreciate detection ability, whereas independence would be appreciated by bankers only. The results will also show that bankers clearly distinguish between the auditors' responsibilities regarding reporting on the traditional and the 'whistle blowing' items, in contrast to clients. The 'generic' factor structure of Zeithaml et al. (1990) appears not to be perfectly applicable to the audit market. Some of the (technical) factors identified in the analyses are more or less unique to the audit market and are therefore not reflected in the generic factors. Other factors can be seen as 'translations' of the generic factors, given the specific characteristics of the audit market.

\subsubsection{Introduction to factor analysis}

In order to test the suitability of the data for factor analysis, two tests were applied (Norusis, 1993a):

Bartlett's test of sphericity: this technique is used to test the hypothesis that the correlation matrix is an identity matrix. If this is the case, the

"The factor analysis technique used here (see further on in this section) generates factors which are strictly independent of each other. However, this only holds for the sample for which the factor analysis was performed. It would have been possible to perform the factor analysis for the complete sample, including both the bankers and the clients data. However, if the factor structure was then used in separate regression analyses for bankers and clients (which was one of the research objectives), it is possible that for these sub-sets (either bankers or clients) the factors would no longer be independent of each other, introducing multicollinearity. Therefore, it was necessary to generate factor structures at sub-set level. 
lack of correlation between the variables makes the data unsuitable for factor analysis.

Kaiser-Meyer-Olkin measure (KMO) of sampling: this is an index for comparing the magnitudes of the observed correlation coefficients to the magnitudes of the partial correlation coefficients. Small KMO values indicate that correlations between pairs of variables cannot be explained by the other variables. ${ }^{6}$

After testing the suitability of the data for factor analysis, the principal component analysis was performed. In this method of factor extraction, linear combinations of observed variables are formed: "Successive components explain progressively smaller portions of the total sample variance and are all uncorrelated with each other' (Norusis, 1993a). The latter characteristic was an important reason for using principal component analysis. Because the resulting factors were then to be used as independent variables in a regression analysis explaining overall audit quality, the factors had to be independent to avoid multicollinearity.

After factor extraction, the number of factors to be used in the model had to be determined. In most cases the criterion was to select only factors with an Eigenvalue (total variance explained by the factor) greater than 1, which is the criterion most often used (Norusis, 1993a). However, for some analyses this criterion resulted in a high number of factors. In these cases the number of factors was reduced for both statistical reasons ${ }^{7}$ and interpretation purposes. $^{8}$

To enhance the interpretability of the factors, the matrices were subjected to specific rotations which transform complicated matrices into forms which are easier to interpret. Rotation limits the number of non-zero loadings of the variables on the factors identified, and also limits the number of factors for

Measures in the $0.90 \mathrm{~s}$ are characterized as marvellous, in the $0.80 \mathrm{~s}$ as meritorious, in the $0.70 \mathrm{~s}$ as middling, in the $0.60 \mathrm{~s}$ as mediocre, in the $0.50 \mathrm{~s}$ as miserable and below 0.50 as unacceptable (see Norusis, 1993a).

${ }^{7}$ Given the relatively small number of cases in this study, it was necessary to limit the number of factors for regression analyses.

The determination of the number of factors is, basically, a subjective process (see Backhaus et al., 1994, p. 225). 
each of the variables. ${ }^{9}$ Although some SERVQUAL studies (e.g. Cronin and Taylor, 1992) used oblique rotation, this alternative was rejected since it creates factors that are not necessarily uncorrelated. Since the factors were to be used as independent variables in regression analyses, uncorrelated factors were required, which can be obtained from orthogonal rotation techniques. The following are the most commonly used:

Varimax rotation: this method minimizes the number of variables that have high loadings on a factor;

Quartimax rotation: this method minimizes the number of factors needed to explain a variable; and

Equamax rotation: this method combines the Varimax and Quartimax rotation techniques.

Only Varimax and Equamax were considered, since Quartimax might be problematic in the interpretation stage, because it typically combines a large number of variables under one factor.

After rotation, the factors were interpreted on the basis of the factor matrix. For interpretation purposes, we started the identification of each factor by considering only variables with factor loadings ${ }^{10}$ on that factor exceeding $0.5 .{ }^{11}$ If interpretation of the variables proved to be difficult or ambiguous, variables with factor loadings between 0.4 and 0.5 were also considered.

Interpretation of the factors that result from a factor analysis is the most difficult and most subjective part of the analysis. The subjectivity of the factor interpretation and labelling process is discussed by Boyd et al. (1985, p. 643): 'In some cases, the (...) statements associated with an identified factor may not give a clear indication as to how the factor should be named. The naming of the factors then becomes quite subjective, and this subjectivity

${ }^{9}$ Rotation does not affect the quality of fit of a factor solution. Although the factor matrix changes, the commonalities (i.e. the proportion of a variable's variance accounted for by the factors included in the model) and the percentage of total variance explained. do not change. The percentage of variance accounted for by each of the individual factors, however, does change (see Norusis, 1993a).

10 For uncorrelated (orthogonal) factors, factor loadings are the correlations between the factors and the variables (see Norusis, 1993a).

${ }^{11}$ Primarily considering factor loadings higher than 0.5 is generally advised (see Backhaus et al., 1994). 
is disturbing to many researchers." In most marketing research studies, no particular procedures are described for reducing the subjectivity. In this study the labelling was done independently by two researchers. In the event of ambiguous results, the variables making up one factor were presented to a forum of five individuals. This forum consisted of one client, one banker, one audit partner and two auditing professors. The members of the forum were asked to individually labell the variables. As a result of this procedure and the relatively high consensus achieved by the forum, the inherent subjectivity of the factor interpretation process has been limited. The identified factors were then compared with the factor structure suggested by Zeithaml et al. (1990). Finally, for each factor Cronbach's (Coefficient) Alpha was computed. ${ }^{12}$

After interpretation of the factors, the factor scores, representing the values the factors assume for each respondent, were computed. We used the regression factor scores, which is the most commonly used method (Backhaus et al., 1994, p. 232). ${ }^{13}$ The factor scores were then used in regression analyses (see Section 6.3).

Since the size was rather limited ( 89 cases for bankers, 66 cases for clients), additional tests were performed in order to test the stability of the factor structures found. Specifically, five randomly selected cases were deleted from the sample. For these limited samples, the factor analyses at the different levels of analysis were rerun. The factor structures resulting from these limited samples were nearly identical ${ }^{14}$ to the factor structures found for the original (full) samples. Based on this finding, the factor structures were considered to be stable. This finding is consistent with Molz (1988, p. 241),

"Green et al. (1988, p. 255) describe this measure in the following way: 'Coefficient alpha $(. .$.$) is a type of mean reliability coefficient for all possible ways of splitting an$ item in half. Whenever possible, alpha should be used as a measure of the internal consistency of multi-item scales'. According to Brouwer and Reuyl (1992), a score above 0.70 is interpreted as acceptable, a score between 0.70 and 0.60 is interpreted as reliable and a score below 0.60 is interpreted as weak.

${ }^{13}$ In principal components analysis, as used here, all commonly used factor score methods will produce the same factor scores, 'which are no longer estimated but are exact' (Nonisis, 1993a). values.

${ }^{14}$ Only minor differences appeared, notably for factors that had low Cronbach Alpha 
who claims that 'prior research has shown only small improvements in factor patterns as the sample size is increased above [50]".

As stated earlier, the results of the factor analyses will be presented separately for each combination of the two samples and the three audit quality concepts. Each combination will be discussed in a separate subsection.

\subsubsection{Factor model at the performance level: clients}

For the combination of the clients' sample and analysis at the performance level, both Varimax and Equamax rotation techniques were performed.

Interpretation turned out to be more logical after Equamax rotation; in the Varimax rotations, several negative factor loadings were obtained, giving results that were difficult to interpret. The Equamax results were therefore chosen, and the $\mathbb{K M O}$ value and Bartlett's test of sphericity on these results indicated that the data was suitable for factor analysis.

In phase 1, 13 factors were extracted, based on the criterion of an Eigenvalue greater than 1 . This was considered to be too many for proper interpretation or further use in regression analyses. Therefore in phase 2 the number of factors to be extracted was limited to 8. Except for factor 8, the Cronbach Alpha scores were satisfactory for all factors, indicating a high degree of reliability.

\begin{tabular}{|c|c|c|}
\hline Features & Phase 1 & Phase 2 (finall) \\
\hline KMOMSA & 0.64 & 0.64 \\
\hline Bartiett's p-level & 0.00 & 0.00 \\
\hline Number of variables & 43 & 43 \\
\hline Extraction criterion & Eigenwalue $>1$ & Number of factors $=8$ \\
\hline Number of factors. & 13 & 8 \\
\hline Rotation method & Equamax & Equamax \\
\hline
\end{tabular}

Table 6.1 Factor analysis process for the clients sample, analyzed at the performance level 
The results of the factor interpretation process (in phase 2) are shown in Table 6.2. The factor descriptions were based on the following considerations:

Factor 1 (Empathy) is dominated by items that are related to knowing the client (files, specific needs) and being willing to serve his interests (helpful attitude, personal attention, genuine interest in problems).

Factor 2 (Detection ability) consists of items that are related to an auditor's ability to detect errors in the financial statements (including fraud). The identification of points of attention regarding the financial statements and doing things right the first time confirm that this factor is related to the auditor's 'craftsmanship'.

Factor 3 (Straightforwardness) was presented to the forum. The answers by the experts confirmed our initial label 'straightforwardness'. This factor combines the characteristics of an auditor who will, on the one hand, report errors in the financial statements if he has found them, and on the other hand delivers when promised, gives an adequate specification of his bill and is there when the client needs him. The auditor 'scoring high' on this factor is straight in both his client contacts and his public duties.

Factor 4 (Whistle blowing) incorporates those characteristics that go beyond the auditor"s 'traditional' duties. However, it should be noted that the factor also includes several duties which were labelled as 'traditional' in Chapter 3. It seems that clients regard the detection and reporting of going concern problems and IO deficiencies as something beyond the auditor's basic duties and put these in the same category as 'fraud' and 'illegal acts'.

Factor 5 (Partner in business) reflects the auditor's alertness to identify points of attention in the client's business. Feeling secure in dealing with the auditor is a logical attribute in this factor, because the client must feel that the auditor is really willing to think and work in the client's best interest. If the client feels he cannot discuss business items with his auditor because he does not feel secure, the auditor's role as a partner in business will be impaired. 
Factor 6 (Appearance) consists of items that are related to the behaviour and appearance of employees and to the appearance of letters and reports.

Factor 7 (Communication) consists of items related to an auditor's 'open ear and open mouth'. An auditor who is appreciated on the basis of this factor will frequently have meetings with his client in order to hear about the client's needs and to inform him about his own findings. In order to avoid communication problems, he will have one service coordinator.

Factor 8 (Quasi-professional) is a factor that should be treated with caution; the Cronbach Alpha on this factor is only 0.51, indicating that the reliability of this factor is rather low. This is primarily due to the item 'put third parties' interests first'. This variable significantly lowers the factor's reliability (without considering this variable, the factor's Cronbach Alpha would increase to 0.66). This low degree of reliability should be considered when using the factor in further analysis (e.g., the regression analysis in Section 6.3). As far as the interpretation of this variable is concerned, it is interesting to note that this factor has equivalents at the P-D and P-A levels. At the P-D level, this factor was presented to a forum and also labelled as such. In Chapter 5 it was seen that the items included in this factor all show 'overperformance' in clients' eyes. It seems that an audit firm scoring high on this factor is perceived by clients as providing a fancy show without any substance to the client.

\begin{tabular}{|c|c|c|}
\hline $\begin{array}{l}\text { TACroR } \\
\text { Variables (factor losding) }\end{array}$ & $\begin{array}{l}\text { Factor } \\
\text { characteristics }\end{array}$ & \\
\hline I. EMPATHY & \multirow{8}{*}{$\begin{array}{l}\text { Cronhach } \alpha= \\
\text { Eigenvalue = } \\
\text { \%o of variance }=\end{array}$} & \multirow{8}{*}{$\begin{array}{r}.90 \\
13.91 \\
32.4\end{array}$} \\
\hline 1. Eimployces arrive on time (75) & & \\
\hline 2. Helpful attitude $(.71)$ & & \\
\hline 3. Working files in good order $(60)$ & & \\
\hline 4. Know client's needs (.58) & & \\
\hline 5. Personal attention (.53) & & \\
\hline 6. Be able to trust audit firm"s employees (.52) & & \\
\hline 7. Genuine interest in client's problems (51) & & \\
\hline
\end{tabular}




\begin{tabular}{|c|c|c|}
\hline 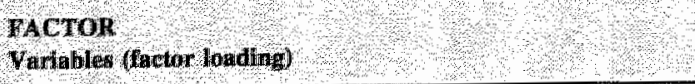 & \multicolumn{2}{|l|}{ Factor } \\
\hline II DETEC TION ABIMTYY & \multirow{6}{*}{$\begin{array}{l}\text { Cronbach } \alpha= \\
\text { Eigenvalue = } \\
\text { \%o of vartance = }\end{array}$} & \multirow{6}{*}{$\begin{array}{r}.83 \\
3.0 I \\
7.0\end{array}$} \\
\hline IIf DETEC TION ABMTIO & & \\
\hline 2. Deffect fraud (.63) & & \\
\hline 3. Detect smoothing in fimancial statements (.62) & & \\
\hline 4. Identify points of interest regarding financial statements $(.60)$ & & \\
\hline 5. Service right the first time $(.56)$ & & \\
\hline III STRAIGHTYORWARDNESS & \multirow{6}{*}{$\begin{array}{l}\text { Cronbach } \alpha= \\
\text { Eigenvalue }= \\
\text { \% of variance = }\end{array}$} & \multirow{6}{*}{$\begin{array}{r}.79 \\
2.71 \\
6.3\end{array}$} \\
\hline 1. Report smoothing in financial statements (80) & & \\
\hline 2. Adequate bill specification $(.68)$ & & \\
\hline 3. Timely delivery $(.58)$ & & \\
\hline 4. Report errors in financial statements (57) & & \\
\hline 5. Available for questions (.56) & & \\
\hline IV WHISTLE BLOWING & \multirow{7}{*}{$\begin{array}{l}\text { Cronbach } \alpha= \\
\text { Eigenvalue = } \\
\% \text { of variance }=\end{array}$} & \multirow{7}{*}{$\begin{array}{r}.81 \\
2.36 \\
5.5\end{array}$} \\
\hline 1. Publicly report illegal acts (.76) & & \\
\hline 2. Publicly report internal fraud $(.72)$ & & \\
\hline 3. Publicly report going concern problems (.66) & & \\
\hline 4. Publicly report 10 deficiencies (66) & & \\
\hline 5. Detect going concern problems (.58) & & \\
\hline 6. Detect IO deficiencies $(.58)$ & & \\
\hline V PARTNLER IN BUSINESS & \multirow{5}{*}{$\begin{array}{l}\text { Cronbach } \alpha= \\
\text { Eigenvalue }= \\
\text { \%o of wariance = }\end{array}$} & \multirow{5}{*}{$\begin{array}{r}.79 \\
1.94 \\
4.5\end{array}$} \\
\hline 1. Identify points of interest negarding tax (83) & & \\
\hline 2. Leritify points of interest regarding IO \& AIS (.63) & & \\
\hline 3. Wdentify points of interest riggarding corporate finance (59) & & \\
\hline 4. Feel secure in dealing with auditor $(.57)$ & & \\
\hline VI APPEARANCE & & \\
\hline 1. Well dressed/neat appearance (76) & Evoromutive = & 90 \\
\hline 2. Polished reports and letters (.73) & & 4.4 \\
\hline 3. Pleasunt and polite $(.50)$ & & \\
\hline VII COMMUNICATION & & \\
\hline 1. One service coordinator (.70) & Eigentuatue $=$ & 104 \\
\hline 2. Discuss findings frequently (59) & of variance $=$ & 3.8 \\
\hline 3. Genuine interest in client's problems $(.55)$ & & \\
\hline
\end{tabular}




\begin{tabular}{|c|c|c|}
\hline $\begin{array}{l}\text { FAcrof } \\
\text { Variables (factor loading) }\end{array}$ & $\begin{array}{l}\text { Wactort } \\
\text { charfacterlytics }\end{array}$ & \\
\hline VTI QUASI-PROHESSIONAL & \multirow{4}{*}{$\begin{array}{l}\text { Crombach } a= \\
\text { Eigunuature = } \\
\text { \% of wariance = }\end{array}$} & \multirow{4}{*}{$\begin{array}{r}.51 \\
1.45 \\
3.4\end{array}$} \\
\hline 1. Visually appealing building (.66) & & \\
\hline 2. Thind parties" interests first (.66) & & \\
\hline 3. Modern equipment (.57) & & \\
\hline
\end{tabular}

Table 6.2 Factor structure for the clients sample, analyzed at the performance level

\subsubsection{Factor model at the performance level: bankers}

Both Varimax and Equamax rotations were performed, as for the clients sample at the performance level, giving nearly the same results.

Consequently, it was decided to proceed with the Varimax method, being the most commonly used method. Both the KMO and Bartlett's test of sphericity showed very good values, so that the data material seemed suitable for factor analysis.

In phase 1, 9 factors were extracted, based on the criterion of an Eigenvalue greater than 1. Although interpretation was rather straightforward, the factor structure contained one factor on which only one variable loaded. Therefore, the number of factors was limited to 8 for phase 2 . However, the 'unique factor' $^{35}$ - reporting fraud to tax authorities - still remained in phase 2. The interpretability in phase 2 was slightly better than in phase 1 . The results of phase 2 are therefore the final results. The Cronbach alpha scores are quite good for all factors, indicating a high degree of reliability.

${ }^{15}$ Strictly speaking, the factor was not unique. It just had only one variable with a high factor loading. 


\begin{tabular}{|c|c|c|}
\hline \multicolumn{3}{|c|}{ Bankers (Perfomance level) } \\
\hline Features & Plhase 1 & Phase 2 (finall) \\
\hline KMO-MSA & 0.83 & 0.83 \\
\hline Bartitlett's p-level & 0.00 & 0,00 \\
\hline Number of variabless & 43 & 43 \\
\hline Extraction criberion & Eigenvalue $>1$ & Number of factors $=8$ \\
\hline Number of factors. & 9 & 8 \\
\hline Rotation method & Varimax & Varimax \\
\hline
\end{tabular}

Table 6.3 Factor analysis process for the bankers sample, analyzed at the performance level

The results of the factor interpretation process (in phase 2) are shown in Table 6.4. The factor descriptions were based on the following considerations:

Factor 1 (Empathy) includes a large number of functional quality items. All variables are related to a helpful service attitude, in which the client's interests and problems are the focal issue.

Factor 2 (Traditional audit function) is obviously a technical quality factor, incorporating all the items that typically make up the traditional audit function.

Factor 3 (Reliability) includes items that are related to the auditor's ability to avoid problems for his client. The auditor should warn the client about problems involving financial statements or tax issues, he should meet specific deadlines, should be reassuring and should be accurate in his reports, using modern equipment.

Factor 4 (Appearance) is quite straightforward. A pleasant appearance, politeness and arrival at the time arranged are characteristics typical for pleasing service providers.

Factor 5 (Whistle blowing) is also quite straightforward, since it incorporates those characteristics that obviously exceed an auditor's current duties (except, to some degree, for the reporting of deficiencies 
in the internal organization: see the discussion in Sub-section 3.5.3).

Factor 6 (Thoroughness) was presented to the forum. Ample support was found for the label 'thoroughness'.

Factor 7 (Accessibility) was also presented to and labelled by the forum. Their assessment confirmed the factor label initially chosen.

Factor 8 (Reporting fraud to tax authorities) consists of only 1 variable with a high factor loading: the reporting of fraud to tax authorities. Obviously, bankers regard this variable as unique.

\begin{tabular}{|c|c|c|}
\hline $\begin{array}{l}\text { WACTOR } \\
\text { Vartables (factor londing) }\end{array}$ & $\begin{array}{l}\text { Mactor, } \\
\text { eharnateristics. } \\
\text { Crombach } \alpha= \\
\text { Eugenvalue = } \\
\text { \%o of variance = }\end{array}$ & \\
\hline I EMPATHY & \multirow{13}{*}{$\begin{array}{l}\text { Crombach } \alpha= \\
\text { Eigenvalue = } \\
\% \text { of variance = }\end{array}$} & \multirow{13}{*}{$\begin{array}{r}93 \\
17.67 \\
41.1\end{array}$} \\
\hline 1. Personal attention (.80) & & \\
\hline 2. Available for questions $(.71)$ & & \\
\hline 3. Prompi sarvice (69) & & \\
\hline 4. Know client's meeds (.68) & & \\
\hline 5. Helpful attitude $(64)$ & & \\
\hline 6. One service coordinator $(.63)$ & & \\
\hline 7. Genuine interest in client's problems (.63) & & \\
\hline 8. Client"s interests first (.63) & & \\
\hline 9. Identify points of attention regarding IO \& AIS $(.59)$ & & \\
\hline 10. Plevesant and pollite $(58)$ & & \\
\hline 11. Time for client questions (.55) & & \\
\hline 12. Discuiss findings $(.53)$ & & \\
\hline II TRADITIONAL AUDTT FUNCTION & & \\
\hline 1. Publicly report going concern problems (.83) & Propenumiluer = & 3.85 \\
\hline 2. Report smoothing in finamcial staternents (.76) & Tof wariance $=$ & \\
\hline 3. Report errors in financial statements $(, 76)$ & & \\
\hline 4. Detect going concem problems (.75) & & \\
\hline 5. Detect 10 defictencies (.69) & & \\
\hline 6. Detect smoothing in financial statements $(61)$ & & \\
\hline 7. Publicly report IO deficiencies (60) & & \\
\hline 8. Detect errors in inancial statements (.50) & & \\
\hline
\end{tabular}




\begin{tabular}{|c|c|c|}
\hline MACTOR & $\begin{array}{l}\text { Facthor } \\
\text { Chantetertsties, } \\
\text { Cronbach } \alpha= \\
\text { Eigenvalue = } \\
\text { \% of wariance = }\end{array}$ & \\
\hline DII RELIABILITY & \multirow{7}{*}{$\begin{array}{l}\text { Cronbach } \alpha= \\
\text { Eigenvalue = } \\
\text { \% of wariance = }\end{array}$} & \multirow{7}{*}{$\begin{array}{r}.88 \\
2.48 \\
5.8\end{array}$} \\
\hline 1. Identify points of interest regarding financial statements (81) & & \\
\hline 2. Modern equipment (.75) & & \\
\hline 3. Polished reports and lletters $(68)$ & & \\
\hline 4. Identify points of interest regarding tax (.59) & & \\
\hline 5. Timelly delivery $(.55)$ & & \\
\hline 6. Feel secure in dealing with auditor $(.54)$ & & \\
\hline IV APPEARANCE & \multirow{5}{*}{$\begin{array}{l}\text { Cronbach } \alpha= \\
\text { Elgenvalue = } \\
\% \text { of variance = }\end{array}$} & \multirow{5}{*}{$\begin{array}{r}.81 \\
1.92 \\
4.5\end{array}$} \\
\hline 1. Employees arrive on time $(80)$ & & \\
\hline 2. Well dressed/neat appearance (.76) & & \\
\hline 3. Visually appealing buillding $(.67)$ & & \\
\hline 4. Pleasiank and polite (51) & & \\
\hline V WHISTLE BLOWING & \multirow{5}{*}{$\begin{array}{l}\text { Crombach } \alpha= \\
\text { Eigenvalue = } \\
\% \text { of variance = }\end{array}$} & \multirow{5}{*}{$\begin{array}{r}.84 \\
1.56 \\
3.6\end{array}$} \\
\hline 1. Publicly report illegal acts (.83) & & \\
\hline 2. Detect illegal acts (.73) & & \\
\hline 3. Publicly report internal fraud $(.64)$ & & \\
\hline 4. Publicly report 10 deficiencies $(.63)$ & & \\
\hline WI THOROUGHNESS & \multirow{3}{*}{$\begin{array}{l}\text { Cronbach } \alpha= \\
\text { Eigenvalue = } \\
\% \text { of variance = }\end{array}$} & \multirow{3}{*}{$\begin{array}{r}.68 \\
1.54 \\
3.6\end{array}$} \\
\hline 1. Detect errors in financiall statements $(.63)$ & & \\
\hline 2. Working files in good order (.62) & & \\
\hline VII ACCESSIHILITY & \multirow{3}{*}{$\begin{array}{l}\text { Crombach } \alpha= \\
\text { Eigenwalue }= \\
\text { \% of variance = }\end{array}$} & \multirow{3}{*}{$\begin{array}{r}.70 \\
1.40 \\
3.3\end{array}$} \\
\hline 1. Adequate bill specification $(.81)$ & & \\
\hline 2. Time for clients" questions ( .58$)$ & & \\
\hline VIII REPORTING FRAUD TO TAX AUTHORTTIES & \multirow{2}{*}{$\begin{array}{l}\text { Crombact } \alpha= \\
\text { Etigenvalue = } \\
\text { \% of vamance = }\end{array}$} & \multirow{2}{*}{$\begin{array}{l}\text { m.e. } \\
1.14 \\
2.6\end{array}$} \\
\hline 1. Reporting fraud to tax authorities (.66) & & \\
\hline
\end{tabular}

Table 6.4 Factor structure for the bankers sample, analyzed at the performance level 


\subsubsection{Factor model at the performance minus desired expectations level: clients}

In line with Zeithaml et al. (1990), the 'performance minus desired expectations' concept of audit quality was also tested. For the clients sample, both Varimax and Equamax rotation techniques were performed for this analysis. Interpretation turned out to be more logical after Equamax rotation. In the Varimax rotations, the Cronbach Alphas which were obtained for some factors were suspect, so the outcomes of the Equamax rotation technique were chosen. The KMO value was 0.64 , which is the same as the $\mathrm{KMO}$ value for the clients sample at the performance level. Bartlett's test of sphericity gave a good value. Therefore, the data material seemed suitable for factor analysis.

In phase 1, 13 factors were extracted, based on the criterion of an Eigenvalue greater than 1 (as was the case at the performance level). This was considered too many for proper interpretation or further use in regression analyses.

Therefore in phase 2 the number of factors to be extracted was limited to 8 . For three factors, the Cronbach Alpha values were around 0.50 and therefore quite low. For the other factors, reliability was adequate.

\begin{tabular}{|c|c|c|}
\hline \multicolumn{3}{|c|}{ Clients (P.D level) } \\
\hline Features & Phase 1 & Phase 2 (final) \\
\hline $\mathrm{KMO} \cdot \mathrm{MSA}$ & 0.64 & 0.64 \\
\hline Bartilett's p-level & 0.00 & 0.00 \\
\hline Number of variables & 43 & 43 \\
\hline Extraction criterion & Eigenvalue $>1$ & Number of fuctots $=8$ \\
\hline Number of factors & 13 & 8 \\
\hline Rotation method & Equamax & Equamax \\
\hline
\end{tabular}

Table 6.5 Factor analysis process for the clients sample, analyzed at the P-D level

Table 6.6 shows the results of the factor analysis for the clients sample at the P-D level. The considerations for the labelling of the individual factors are discussed below: 
Factor 1 (Responsiveness) incorporates items such as timely, prompt and error free delivery, availability and attention to the client's problems or needs.

Factor 2 (Independence) addresses the auditor's willingness and perseverance to report issues that have come to his attention during the audit. All 'technical' issues concerning reporting included in the questionnaire, except for the fraud issue, ${ }^{16}$ are combined in this factor.

Factor 3 (Reporting accuracy) was very difficult to interpret. This is largely due to the low degree of reliability of this factor, and to the fact that this factor comprises one variable that contributes negatively to the factor's reliability. Actually, the exclusion of this variable from the analysis would have improved the Cronbach Alpha on this factor from 0.52 to 0.65 . Hence, in the further analyses, caution is needed with regard to this factor, since the variable 'publicly report IO deficiencies' has a negative impact on both the interpretation and the statistical reliability of this factor.

Factor 4 (Thoroughness) was presented to the forum. The forum's responses confirmed that the combination of having the files in good order and using modern equipment on the one hand and making exact appointments with clients and having time for client questions reflects a thorough, well structured, audit service approach.

Factor 5 (Assurance) was also presented to the forum. Labels included 'trust' and 'dependable'. ${ }^{17}$

Factor 6 (Client's agent) is another difficult factor. The factor's Cronbach Alpha is 0.49 , which is suspect, so that further analyses using this factor must be made with caution. Interpretation of the

${ }^{16}$ Actually, the auditor's duty to publicly report internal fraud also loaded on this factor, with a factor loading of $(0.44)$, just under the critical value of 0.50 .

${ }^{17}$ Intriguingly, two out of five forum members referred to popular Dutch commercials to motivate their labels. Both commercials were from insurance companies (Zwitser Leven and Centraal Beheer). 
factor was not easy either. The forum to which the factor was presented gave reactions such as 'this is my kind of auditor' and 'subjective, interest-seeking approach'. Client's agent integrates these labels and reflects the attitude of an auditor who tries to appeal exclusively to the client.

Factor 7 (Partner in business) was straightforward. Besides the variables included in Table 6.6 which had factor loadings above 0.5 , the items 'identify points of attention regarding IO \& AIS' and 'discover fraud' had factor loadings above 0.4 on this factor.

Factor 8 (Quasi professional) again proved to be a difficult factor, having a Cronbach Alpha of 0.47 . The forum, to which this factor was presented, was quite unanimous in its interpretation and labelled this factor as 'fake auditor', 'quasi professional' and 'superficial service".

\begin{tabular}{|c|c|c|}
\hline $\begin{array}{l}\text { FACTOR } \\
\text { Variables (factor landing) }\end{array}$ & \multicolumn{2}{|l|}{$\begin{array}{l}\text { Factor } \\
\text { characteristics }\end{array}$} \\
\hline 1 RESPONSTVENESS & \multirow{7}{*}{$\begin{array}{l}\text { Cronbach } \alpha= \\
\text { Eigenvalue }= \\
\text { \% of wariance }=\end{array}$} & \multirow{7}{*}{$\begin{array}{r}.89 \\
10.82 \\
25.2\end{array}$} \\
\hline 1. Timely delivery $(.84)$ & & \\
\hline 2. Prompt service $(.67)$ & & \\
\hline 3. Serwice right the first time $(66)$ & & \\
\hline 4. Discuss findings frequently $(.62)$ & & \\
\hline 5. Genuine interest in ellient's problems $(.58)$ & & \\
\hline 6. Avallable for questions $(55)$ & & \\
\hline II INDEPENDENCE & Cunk & \\
\hline 1. Report smoothing in financial statements (.83) & Eigervalue $=$ & 3.38 \\
\hline 2. Publicly report going concern problems (.62) & \% of variance $=$ & \\
\hline 3. Publicly report illegal acts $(57)$ & & \\
\hline 4. Publicly report 10 deficiencies $(.55)$ & & \\
\hline 5. Detect going concem problems $(52)$ & & \\
\hline 6. Report errors in financial statements $\{.51\}$ & & \\
\hline III REPORTING ACCURACY & & 5 \\
\hline 1. ldentify points of interest regarding financiall statements: $(.59)$ & Eigenvathe $=$ & 260 \\
\hline 2. Polished reports and letters $(53)$ & \% of varianct $=$ & 6.0 \\
\hline 3. Publicly report 10 deficiencies $(.52)$ & & \\
\hline
\end{tabular}




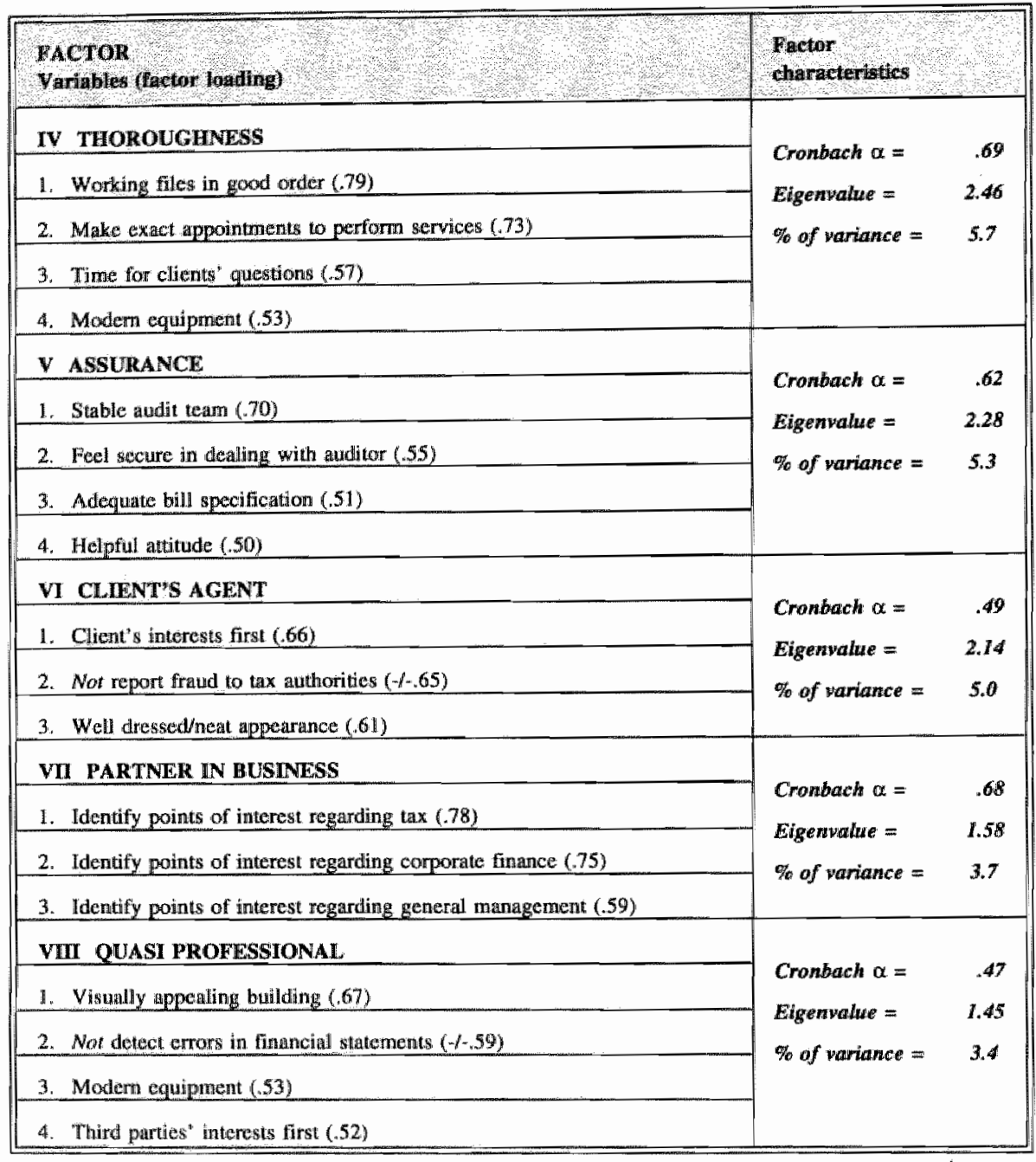

Table 6.6 Factor structure for the clients sample, analyzed at the P-D level

\subsubsection{Factor model at the performance minus desired expectations level: bankers}

Both Varimax and Equamax rotation techniques were used for the analysis of the bankers sample at the P-D level, as with clients sample. Interpretation turned out to be easier after Equamax rotation, so the outcomes of the Equamax rotation were chosen. The KMO and Bartlett's test of sphericity were acceptable, so the data seemed suitable for factor analysis. 
In phase 1, 11 factors were extracted, based on the criterion of an Eigenvalue greater than 1. This was considered too many for proper interpretation or further use in regression analyses. Therefore in phase 2 the number of factors to be extracted was limited to 8 . For all factors but one, the Cronbach Alpha values were good. Factor 6 had a Cronbach Alpha value of 0.55 , indicating that caution is needed in further interpretation of this variable.

\begin{tabular}{|c|c|c|}
\hline$\sqrt{10}$ & Bankers & 8 \\
\hline Features & Phase 1 & Phase 2 (final) \\
\hline KMO-MSA & 0.65 & 0.65 \\
\hline Bartiett's p-level & 0.00 & 0.00 \\
\hline Number of variables & 43 & 43 \\
\hline Extraction criterion & Eigenvalue $>1$ & Number of factors $=8$ \\
\hline Number of factors & 11 & 8 \\
\hline Rotation method & Equamax & Equamax \\
\hline
\end{tabular}

Table 6.7 Factor analysis process for the bankers sample, analyzed at the $P-D$ level

The results of the factor interpretation process (in phase 2) are shown in Table 6.8. The factor labelling was based on the following considerations:

Factor 1 (Traditional audit function) incorporates most of the technical quality items included in the questionnaire. As was the case at the performance level, both detection and reporting items are included in this factor (although the reporting issues dominate this factor). The reporting of fraud to the tax authorities might seem to be an unexpected item in this 'traditional audit' factor, because it exceeded the auditor's formal duties at the time the questionnaire was completed. However the public discussion about the auditor's responsibility in this regard was then at its height. At the time it was rather obvious that Dutch auditors would soon be required to report certain types of (tax) fraud to the authorities under specific circumstances.

Factor 2 (Partner in business) includes all items related to an auditor's 'duty' to identify points of attention with regard to the client's 
business, and combines these with the auditor's genuine interest in the client's problems, the use of modern facilities and polished letters and reports. The latter elements represent to some degree the factor that was identified as 'reliability' at the performance level. However, at this stage, they are more in line with the auditor's appearance as a modern partner in business.

Factor 3 (Thoroughness) includes elements typically related to the approach of a 'thorough' auditor. There was quite some overlap with the corresponding factor at the performance level, which was presented to the forum.

Factor 4 (Punctuality) incorporates items such as arriving on time, planning ahead, doing things right the first time or team stability. The only variable that was atypical for this factor was 'putting third parties' interests first'. However, the factor reliability score would have improved if this variable were deleted. Therefore, it is justifiable to let the other items dominate the identification process.

Factor 5 (Appearance) consists of the items listed in Table 6.8. Based on these items, the labelling was quite straightforward.

Factor 6 (Communication) includes variables that are typical for the auditor who cares about both active and passive client contacts. However, the factor's Cronbach Alpha is rather low, so caution is needed in further analysis with regard to this factor.

Factor 7 (Whistle blowing) includes the elements of detecting illegal acts and fraud (the latter having a factor loading between 0.4 and 0.5 ), and reporting on these issues. However, the factor also includes the item 'having a visually appealing building', which hardly matches the other items in this factor. As was the case with factor 4 , leaving this variable out of the factor would have improved the factor's Cronbach Alpha. So, in identifying the factor, the other variables were given more weight.

Factor 8 (Empathy) again has some similarity to the corresponding factor at the performance level. Apart from the items listed in Table 6.8 , the item 'personal attention' has a factor score between 0.4 and 0.5 , underlining the factor label chosen. 


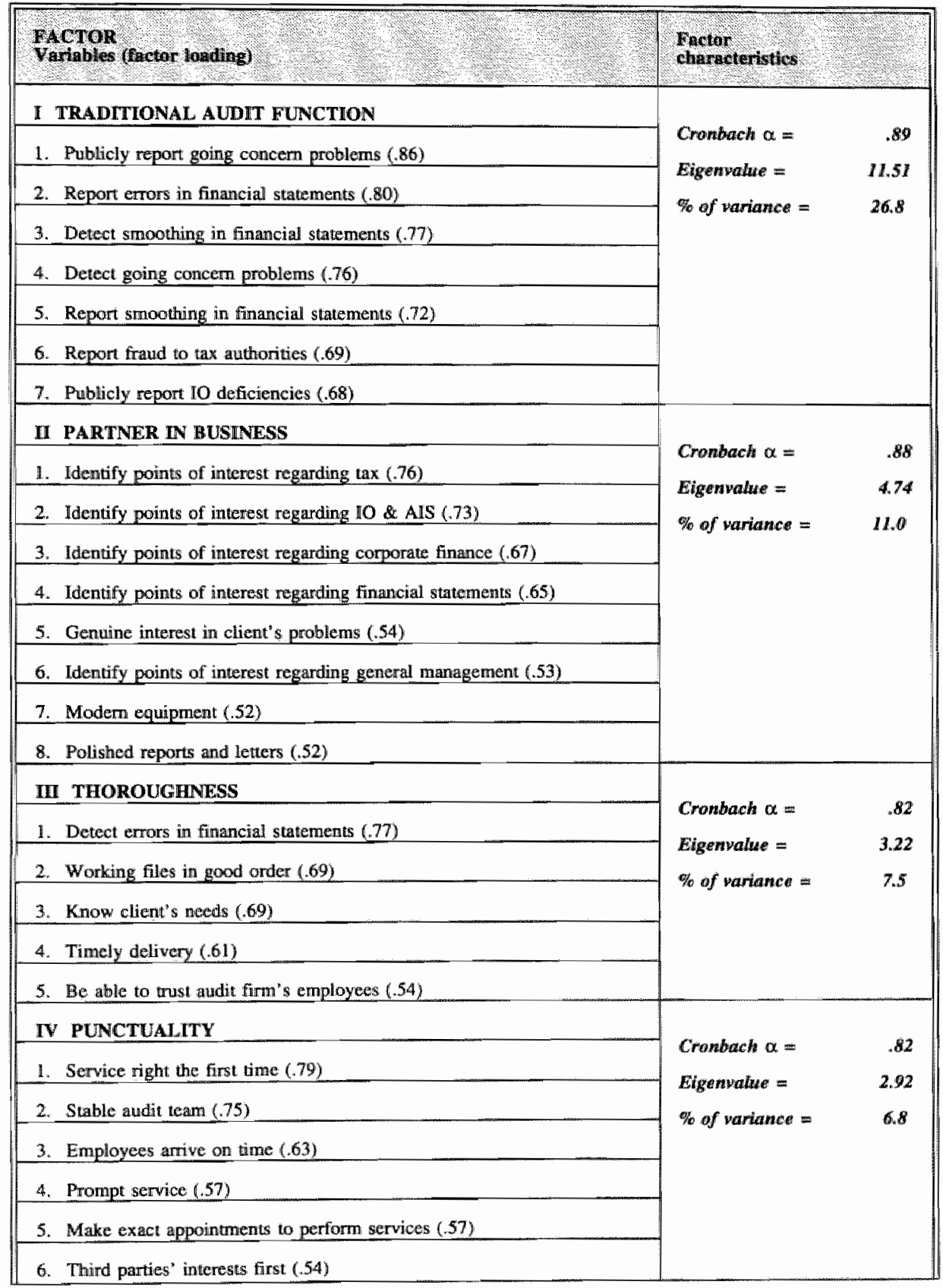




\begin{tabular}{|c|c|c|}
\hline $\begin{array}{l}\text { IACTOR } \\
\text { Vartables (factor loudling) }\end{array}$ & $\begin{array}{l}\text { Factor } \\
\text { characteristios }\end{array}$ & \\
\hline V APPEARANCE & \multirow{4}{*}{$\begin{array}{l}\text { Cronbach } \alpha= \\
\text { Eigenvalue }= \\
\% \text { of variance = }\end{array}$} & \multirow{4}{*}{$\begin{array}{r}.68 \\
2.28 \\
5.3\end{array}$} \\
\hline 1. Well dressed/neat appearance $(.81)$ & & \\
\hline 2. Helpfiul attitude (.66) & & \\
\hline 3. Pollished reports and lenters $(.58)$ & & \\
\hline VI COMMUNICATION & \multirow{3}{*}{$\begin{array}{l}\text { Cronbach } \alpha= \\
\text { Eigenvalue = } \\
\text { \%o of variance = }\end{array}$} & \multirow{3}{*}{$\begin{array}{l}.55 \\
1.84 \\
4.3\end{array}$} \\
\hline 1. Disctus findings frequently (.75) & & \\
\hline 2. Time for clients* questions (.68) & & \\
\hline VII WHISTLE BLOWING & \multirow{5}{*}{$\begin{array}{l}\text { Cronbach } \alpha= \\
\text { Eigenvalue = } \\
\text { \% of wariance = }\end{array}$} & \multirow{5}{*}{$\begin{array}{r}.71 \\
1.67 \\
3.9\end{array}$} \\
\hline 1. Detect illegal acts $(80)$ & & \\
\hline 2. Publicly report internal fraud (.63) & & \\
\hline 3. Publicly report illegall acts (.55) & & \\
\hline 4. Visually appealing building (.55) & & \\
\hline VIII EMPATHY & \multirow{4}{*}{$\begin{array}{l}\text { Cronbach } \alpha= \\
\text { Eigenvalue = } \\
\text { \% af variance = }\end{array}$} & \multirow{4}{*}{$\begin{array}{r}.69 \\
1.58 \\
3.7\end{array}$} \\
\hline 1. Client's interest first $(.76)$ & & \\
\hline 2. A vailable for questions (73) & & \\
\hline 3. Prompt service (51) & & \\
\hline
\end{tabular}

Table 6.8 Factor structure for the bankers sample, analyzed at the $P-D$ level

\subsubsection{Factor model at the performance minus adequate expectations level: clients}

As has been said previously, the 'performance minus adequate expectations' concept of audit quality was also used. The values for this P-A analysis were obtained by computing the gap between the performance score and the adequate expectations score for each statement in the questionnaire. Based on these values, both Varimax and Equamax rotations were performed.

Interpretation turned out to be more logical after Equamax rotation. The KMO value and Bartlett's test of sphericity were acceptable, so the data seemed suitable for factor analysis.

In phase 1, 12 factors were extracted, based on the criterion of an Eigenvalue greater than 1. This was considered too many for proper interpretation or further use in regression analyses. Therefore in phase 2 the number of factors 
to be extracted was limited to 8 . However, interpretation proved to be quite difficult, because some factors resulting from analyses at the other levels seemed to be split at this level of analysis. We therefore decided to test a 7 factor solution. For one factor, the Cronbach Alpha value was less than 0.50 and therefore quite low. For the other factors, reliability was adequate, most being in the $0.70 \mathrm{~s}$.

\begin{tabular}{|c|c|c|c|}
\hline Features & Phase 1 & Phase 2 & Phase 3 (final) \\
\hline KMO-MSA & 0.63 & 0.63 & 0.63 \\
\hline Bartlett's pulevel & 0.000 & 0.00 & 0.00 \\
\hline Number of variables & 43 & 43 & 43 \\
\hline Extraction criterion & Eigenvalues 1 & $\begin{array}{l}\text { Number of } \\
\text { factors }=8\end{array}$ & $\begin{array}{l}\text { Number of } \\
\text { factiors }=7\end{array}$ \\
\hline Number of tactors & 12 & 8 & 7 \\
\hline Rotation method & Equarnax & Equarnax & Equanmax \\
\hline
\end{tabular}

Table 6.9 Factor analysis process for the clients sample, analyzed at the P-A level

The results of the factor interpretation process (in phase 3 ) are shown in Table 6.10. Factor labelling was characterized by the following considerations:

Factor 1 (Appearance) incorporates items that are related to a pleasant, trust-inspiring appearance.

Factor 2 (Accessibility) was quite easy to label. Having time for questions and providing specified bills are items related to the accessibility of the auditor.

Factor 3 (Partner in business) includes items traditionally linked to this factor (identifying points of attention), but also items such as knowing the client's needs and discussing findings, which are also essential characteristics of being a partner in business. 
Factor 4 (Detection ability) is a mix of technical 'detection' items and some items related to the identification of points of attention.

Obviously, these points of attention are seen as part of the auditor's core business: failing to identify these is as unacceptable as failing to detect errors in the financial statements. Interestingly, this factor also included the reporting of fraud to tax authorities, which is rather unexpected from a client's perspective. As was suggested earlier, the debate on this duty at the time the survey was conducted may have induced clients to believe that this duty was indispensable for a good auditor.

Factor 5 (Independence) was straightforward in its interpretation. This factor combines the reporting on 'traditional' and 'non-traditional' duties.

Factor 6 (Thoroughness) was closely linked to factors that were labelled as such in previous levels' analyses. However, the very low Cronbach Alpha value of this factor indicates that further interpretation should be done with caution.

Factor 7 (Quasi-professional) shared some characteristics with a similarly labelled factor in analyses at previous levels. As discussed in Chapter 5, all three variables included in this factor showed 'overperformance' for clients, i.e. the perceived performance level exceeded the desired or adequate level. It seems that, in the eyes of the client, an auditor scoring high on this factor gives attention to items that the client does not appreciate. 


\begin{tabular}{|c|c|c|}
\hline $\begin{array}{l}\text { PAgroR } \\
\text { Yariables (factor loading) }\end{array}$ & $\begin{array}{l}\text { Euctor } \\
\text { eharacteristics }\end{array}$ & \\
\hline 1 APPEARANCE & \multirow{6}{*}{$\begin{array}{l}\text { Cronbach } \alpha= \\
\text { Eigenvalue }= \\
\% \text { of variance = }\end{array}$} & \multirow{6}{*}{$\begin{array}{r}.77 \\
11.39 \\
26.5\end{array}$} \\
\hline 1. Pleasant and polite (.75) & & \\
\hline 2. Be able to tust andit firm's employees $(.70)$ & & \\
\hline 3. Feel secure in dealing with auditor $(62)$ & & \\
\hline 4. Persomal attention (.52) & & \\
\hline 5. Well dressed/neat appearance ( 5.1) & & \\
\hline II ACCESSIBILTY & \multirow{5}{*}{$\begin{array}{l}\text { Cronbach } \alpha= \\
\text { Eigenvalue }= \\
\% \text { of variance }=\end{array}$} & \multirow{5}{*}{$\begin{array}{l}.72 \\
3.92 \\
9.1\end{array}$} \\
\hline 1. Available for questions $(71)$ & & \\
\hline 2. Timely delivery (.66) & & \\
\hline 3. Adequate bill specification $(.63)$ & & \\
\hline 4. Time for questions $(.56)$ & & \\
\hline III PARTNER IN BUSINESS & \multirow{6}{*}{$\begin{array}{l}\text { Cronbach } \alpha= \\
\text { Eigenvalue = } \\
\% \text { of variance = }\end{array}$} & \multirow{6}{*}{$\begin{array}{r}.69 \\
2.62 \\
6.1\end{array}$} \\
\hline 1. Know client's needs $(.76)$ & & \\
\hline 2. Identify points of interest regarding 10 \& AIS (.75) & & \\
\hline 3. Discuss findings frequently $(.51)$ & & \\
\hline 4. Stable audit team $(51)$ & & \\
\hline 5. Identify points of interest regarding financial statements (51) & & \\
\hline IV DETECTION ABN.ITY & \multirow{8}{*}{$\begin{array}{l}\text { Cronbach } \alpha= \\
\text { Eigenvalue = } \\
\% \text { of variance = }\end{array}$} & \multirow{8}{*}{$\begin{array}{r}.77 \\
2.31 \\
5.4\end{array}$} \\
\hline 1. Identify points of interest regarding $\operatorname{tax}(.64)$ & & \\
\hline 2. Detect fraud $(61)$ & & \\
\hline 3. Detect errors in financial statements (60) & & \\
\hline 4. Detect illegal acts $(.55)$ & & \\
\hline 5. Identify points of interest regarding corporate finarice $(52)$ & & \\
\hline 6. Detect going concem problenss $(.52)$ & & \\
\hline 7. Report fraud to tax authorities $(.51)$ & & \\
\hline V INDEPENDENCE & \multirow{6}{*}{$\begin{array}{l}\text { Cronbach } \alpha= \\
\text { Eigenvalue }= \\
\% \text { of wariance = }\end{array}$} & \multirow{6}{*}{$\begin{array}{r}.75 \\
2.12 \\
4.9\end{array}$} \\
\hline 1. Publicly report internal fraud $(.74)$ & & \\
\hline 2. Report smoothing in financial statements $(.66)$ & & \\
\hline 3. Publicly report illegal acts (.61) & & \\
\hline 4. Detect smoothing in financial statements (.57) & & \\
\hline 5. Publicly report enrors in tinancial statements $(.53)$ & & \\
\hline
\end{tabular}




\begin{tabular}{|c|c|c|}
\hline $\begin{array}{l}\text { IACTOR } \\
\text { Variables fractor loading) }\end{array}$ & $\begin{array}{l}\text { Factor } \\
\text { eharacteristics }\end{array}$ & \\
\hline VI THOROUGRNESS & \multirow{3}{*}{$\begin{array}{l}\text { Crombach } \alpha= \\
\text { Eigenvalue = } \\
\text { \%o of variance = }\end{array}$} & \multirow{3}{*}{$\begin{array}{r}47 \\
1.72 \\
4.0\end{array}$} \\
\hline 1. Make exact appointments to perform services (74) & & \\
\hline 2. Working filles in good order $(.52)$ & & \\
\hline VI QUASI-PROFESSIONAL & \multirow{4}{*}{$\begin{array}{l}\text { Cronbach } a= \\
\text { Eigenvatue = } \\
\% \text { of variance = }\end{array}$} & \multirow{4}{*}{$\begin{array}{r}.61 \\
1.69 \\
3.9\end{array}$} \\
\hline 1. Visually appealing building (.78) & & \\
\hline 2. Thind parties" interests first (70) & & \\
\hline 3. Well dressed/neat appearance (59) & & \\
\hline
\end{tabular}

Table 6.10 Factor structure for the clients sample, analyzed at the P-A level

\subsubsection{Factor model at the performance minus adequate expectations level: bankers}

Both Varimax and Equamax rotations were performed for bankers at the P-A level, as for clients. Interpretation turned out to be more logical after Equamax rotation, because Varimax gave factor solutions with considerable negative factor loadings for some factors, which reduced the interpretability; so the outcomes of the Equamax rotation were chosen. The KMO value and Bartlett's test of sphericity were acceptable, so the data material seemed suitable for factor analysis.

In phase 1, 11 factors were extracted, based on the criterion of an Eigenvalue greater than 1. This was considered too many for proper interpretation or further use in regression analyses. Therefore in phase 2 the number of factors to be extracted was limited to 8 . However, as in the case of clients at the P-A level, two identifiable factors from analyses at other levels were split at this level. The number of factors to be extracted in phase 3 was therefore limited to 6. The interpretability of these factors was better than in the previous stage, and this stage was therefore considered final. For all but one of the factors (the exception being Factor 6, with Cronbach Alpha $=0.50$ ), the Cronbach Alpha values were very good. 


\begin{tabular}{|l|l|l|l|}
\hline \hline Features & \multicolumn{2}{|c|}{ Bankers ( F/A level) } \\
\hline KMO-MSA & Phase 1 & Phase 2 & Phase 3 (final) \\
\hline Bartlett's p-level & 0.64 & 0.64 & 0.64 \\
\hline Number of wariables & 0.00 & 0.00 & 0.00 \\
\hline Extraction criterion & 43 & 43 & 43 \\
\hline Number of factors & Eigenvalue> 1 & $\begin{array}{l}\text { Number of } \\
\text { factors }=8\end{array}$ & $\begin{array}{l}\text { Number of } \\
\text { factors }=6\end{array}$ \\
\hline Rotation method & 11 & 8 & 6 \\
\hline
\end{tabular}

Table 6.11 Factor analysis process for the bankers sample, analyzed at the $P$-A level

Table 6.12 gives the final factor structure. The factor labelling was characterized by the following considerations:

Factor 1 (Empathy) incorporates a large number of functional quality items. Most of these are closely related to empathy. Interestingly, the factor also includes putting both client's and third party's interests first. This is a fascinating aspect which might be a result of the P-A conceptualization: obviously, bankers believe that an auditor scoring on the 'empathy' item should give an adequate level of attention to both 'principals'.

Factor 2 (Traditional audit function) includes all items related to an auditor's detection ability and independence with regard to 'traditional' errors or irregularities.

Factor 3 (Communication) includes elements typically related to having time for questions, discussing findings and the feeling that employees can be trusted when spoken to.

Factor 4 (Partner in business) incorporates several items regarding the identification of points of interest, but also items such as genuine interest in the client's problems and having one service coordinator for all types of services. 
Factor 5 (Whistle blowing) consists of duties regarding fraud and illegal acts, but also public reporting of IO deficiencies and going concern problems.

Factor 6 (Thoroughness) is quite straightforward, since it includes variables that were previously labelled as such. However, as already mentioned, the low Cronbach Alpha value indicates that caution is needed in further interpretation of this factor.

\begin{tabular}{|l|l|}
\hline Yactor & Factor \\
Variables (factor loading) & characteristics
\end{tabular}




\begin{tabular}{|c|c|c|}
\hline $\begin{array}{l}\text { FACTOR } \\
\text { Variables (factor loading) }\end{array}$ & \multicolumn{2}{|l|}{$\begin{array}{l}\text { Factor } \\
\text { eharneteristics }\end{array}$} \\
\hline III COMMUNICATION & \multirow{8}{*}{$\begin{array}{l}\text { Cronhack } \alpha= \\
\text { Elgenwalue = } \\
\% \text { of wariance = }\end{array}$} & \multirow{8}{*}{$\begin{array}{r}.81 \\
3.34 \\
7.4\end{array}$} \\
\hline 1. Be able to trust audit firm's employees (.70) & & \\
\hline 2. Employees arrive on time (.66) & & \\
\hline 3. Discuss findings frequently (.65) & & \\
\hline 4. Time for questions (.63) & & \\
\hline 5. Helpful attitudie ( 54$)$ & & \\
\hline 6. Available for questions (.52) & & \\
\hline 7. Visually appealing building $(.51)$ & & \\
\hline IV PARTNER IN BUSINESS & & \\
\hline 1. Identify points of interest regarding tax (.75) & 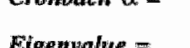 & 356 \\
\hline 2. Identify points of interest regarding financial statements (.62) & & \\
\hline 3. One service-coordinator $(.61)$ & & \\
\hline 4. Genuine interest in clients" problems (.59) & & \\
\hline $\begin{array}{l}\text { 5. Identify points of interest regarding corporate } \\
\text { finance }(.58)\end{array}$ & & \\
\hline V WHISTLE BLOWING & & \\
\hline 1. Publicly report illegal acts (.82) & 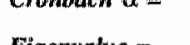 & .00 \\
\hline 2. Detect illegal acts (.75) & & 4.8 \\
\hline 3. Publicly report internal fraud (.60) & & \\
\hline 4. Deteet fraud $(60)$ & & \\
\hline 5. Publicly report IO deficiencies (.55) & & \\
\hline 6. Publicly report going-concern problems (.50) & & \\
\hline VI THOROUGENESS & & \\
\hline 1. Working files in good onder $(.65)$ & Eirenvalue = & 80 \\
\hline 2. Modern equipment (.62) & of of pariance $=$ & 4.4 \\
\hline 3. Feel seeure in dealing with auditor $(.52)$ & & \\
\hline
\end{tabular}

Table 6.12 Factor structure for the bankers sample, analyzed at the $P$-A level 


\subsubsection{Comparison of factor structures}

Table 6.13 summarizes the factor structures found for each of the six combinations of respondent groups and audit quality concepts. The list starts with the five-factor structure found by Zeithaml et al. (1990). The claim of this group of researchers (see, e.g., Parasuraman, 1985) that this factor structure is generic holds only to some degree. First, it is obvious that, at least in the audit market, there are several specific factors that are either not covered by the generic factors (such as the technical factors) or that can be regarded as industry-specific translations of the 'generic' factors (such as the 'partner in business' factor). Second, it seems that the factor structure is dependent not only on the type of industry, but also on the respondent and the level of analysis. This finding was not unexpected. In their review of research based on SERVQUAL, Lapierre and Filiatrault (1995) conclude that 'the structures of the dimensions of the model of Parasuraman, Zeithaml, and Berry $(1988,1986)$ are rarely identical $(\ldots)^{\prime}$. The remainder of this section will discuss interesting issues emerging from the comparison of the different factor structures.

\begin{tabular}{|c|c|c|c|c|c|c|}
\hline Audit quality concept & \multicolumn{2}{|c|}{ Performance } & \multicolumn{2}{|c|}{$\begin{array}{l}\text { Performance } \\
\text { minus desined } \\
\text { (PD) }\end{array}$} & \multicolumn{2}{|c|}{$\begin{array}{c}\text { Performance minos } \\
\text { adequate } \\
(\mathbf{P A})\end{array}$} \\
\hline Clients/bankers? & c & B & c & B & $2 \mathrm{C}$ & $\mathbf{B}$ \\
\hline \multicolumn{7}{|c|}{ FUNCTIONAL FACTORS } \\
\hline Empathy & $x$ & $\mathrm{x}$ & & $x$ & & $\mathrm{x}$ \\
\hline Relinability & & $\mathrm{x}$ & & & & \\
\hline Assurance & & & $\mathrm{x}$ & & & \\
\hline Responsiveness & & & $\mathrm{x}$ & & & \\
\hline \multicolumn{7}{|l|}{ Tungibles } \\
\hline Partner in Business & $\mathrm{x}$ & & $\mathrm{x}$ & $\mathrm{x}$ & $\mathrm{x}$ & $\mathrm{x}$ \\
\hline Appearance & $x$ & $\mathrm{x}$ & & $x$ & $x$ & \\
\hline Communication & $x$ & & & $x$ & & $x$ \\
\hline Accessibility & & $\mathrm{x}$ & & & $\mathrm{x}$ & \\
\hline Puncruality & & & & $x$ & & \\
\hline
\end{tabular}




\begin{tabular}{|c|c|c|c|c|c|c|}
\hline \multirow{2}{*}{$\begin{array}{l}\text { Aldit qualli concept, } \\
\text { Clients Barkikers: }\end{array}$} & \multicolumn{2}{|c|}{ Perommines } & \multicolumn{2}{|c|}{ 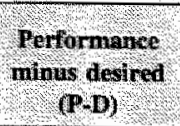 } & \multicolumn{2}{|c|}{ 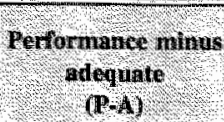 } \\
\hline & $c$ & B & $\mathrm{C}$ & D & $\mathrm{C}$ & $\mathrm{B}$ \\
\hline \multicolumn{7}{|l|}{ TECHNICAL FACTORS } \\
\hline Traditional Audit function & & $x$ & & $x$ & & $X$ \\
\hline Detection ability & $x$ & & & & $x$ & \\
\hline Independence & & & $\mathrm{x}$ & & $X$ & \\
\hline Whisdle blowing & $\mathrm{x}$ & $\mathrm{x}$ & & $x$ & & $\mathrm{x}$ \\
\hline $\begin{array}{l}\text { Reporting fraud to tax } \\
\text { authorities }\end{array}$ & & $\mathrm{X}$ & & & & \\
\hline \multicolumn{7}{|l|}{ MLXED FACTORS } \\
\hline Thoroughness & & $\mathrm{X}$ & $x$ & $x$ & $x$ & $x$ \\
\hline Straightforwardness & $\mathbf{X}$ & & & & & \\
\hline Reporting accuracy & & & $x$ & & & \\
\hline Quasi-professional & $x$ & & $\mathrm{X}$ & & $x$ & \\
\hline Client's agent & & & $X$ & & & \\
\hline
\end{tabular}

\section{Table 6.13 Comparison of findings of factor analyses}

$X=$ factor is included in the factor structure for that specific combination of respondent group and audit quality concept ${ }^{\text {tis }}$

The empathy factor identified by Zeithaml et al. (1990) emerges on the performance level and - at least for bankers - on the P-D and P-A level. At the other levels, the factor disappears into factors such as 'client's agent', 'communication', 'assurance' and - to some degree - 'partner in business'.

The reliability factor identified by Zeithaml et al. (1990) is reflected in most factor structures. Apart from the factor 'reliability', the factor 'thoroughness' also reflects elements of reliability.

${ }^{18}$ As can be seen in previous tables, factors with the same label do not necessarily include the same variables. Even though the exact composition may differ, factor labels can be similar, given the degree of overlap between the variables included in the factor. 
The assurance factor identified by Zeithaml et al. (1990) is reflected in 'assurance' and - to some degree ${ }^{19}$ - in 'partner in business'. Together, these two factors represent 'assurance' at all levels of analysis, except for the clients/performance combination.

The responsiveness factor identified by Zeithaml et al. (1990) returns at the client's P-D level of analysis. However, important elements of responsiveness are also reflected by accessibility, straightforwardness and punctuality. These factors express responsiveness more clearly within the framework of the audit market.

The tangibles factor identified by Zeithaml et al. (1990) is not reflected in the bankers' factor structure. However, for clients, 'tangibles' are included in the 'quasi-professional' factor. As illustrated previously, this factor is composed of variables on which the auditors' performance is considered to be overdone. The regression analyses in the remainder of this chapter are expected to demonstrate that the auditors' current overperformance on the tangibles included in the quasi-professional factor is perceived as negative for overall audit quality by clients. Apart from the quasi-professional factor, some elements of the tangibles factor are also reflected by 'appearance'.

As can be seen in Table 6.13 under the heading 'Technical factors', clients distinguish between detecting and reporting errors or irregularities, while bankers combine these items ('traditional audit function'). This illustrates a phenomenon addressed in Chapter 3, that clients benefit primarily from the detection of errors and can sometimes benefit from the auditor not reporting these. To bankers, detection and independence are equally important and are therefore combined into one factor (traditional audit function). It appears that bankers only appreciate the combination of detection and reporting. Further, it appears that bankers distinguish 'whistle blowing' as a separate factor at all levels of analysis. They clearly distinguish between 'traditional' and 'whistle blowing' (reporting) duties. Clients, however, treat 'traditional' and 'whistle blowing' reporting duties equally at the P-D and P-A levels, combining them

\footnotetext{
"In particular, the knowledge of the audit team, necessary to identify points of interest regarding items such as tax or IO \& AIS, is reflected in the 'assurance' label of Zeithaml et al. (1990).
} 
in the factor of independence. At the performance level, 'whistle blowing'was distinguished as a separate factor. However, this factor also included some 'traditional' reporting duties. Hence, whereas bankers treat whistle blowing and traditional reporting duties differently, clients seem to treat these duties equally.

\subsection{Regression analyses}

\subsubsection{Introduction}

Section 2.6 addressed the issue of the appropriateness of using expectations for measuring service quality. In this discussion, comparisons of the 'power' of the different concepts of quality were often made on the basis of regression analyses. In these regression analyses, some measure of overall quality was used as the dependent variable and the factors resulting from the different concepts were used as independent variables. Since the discussion about the suitability of the P-D framework versus the $\mathbf{P}$ framework is continuing, it appeared appropriate to do tests on both levels. Additionally, as explained in Chapter 5, we decided to test the P-A framework.

Before using the factors as independent variables in the regression analyses, the possibility of treating the statements in the questionnaire as the independent variables was tested. However, as might be expected, there was a high degree of multicollinearity between the variables. Therefore, no reliable interpretation could be based on the outcomes of these regression analyses. As a result, it was decided that the factors should be used as independent variables.

This section will first discuss the procedures followed in the regression analysis. Then the results of the different regression analyses for clients and bankers will be presented separately, first on the 'performance' level, then on the 'performance minus desired expectations' level, and finally on the 'performance minus adequate expectations' level.

As will be seen in this section, clients and bankers attribute different weights to the various audit quality attributes in their overall audit quality judgments. The most important determinants of overall audit quality in the perception of clients are the auditor's professional and communication skills. Bankers also 
use these attributes as determinants of overall audit quality. However, in addition to these, 'appearance" is a crucial attribute in their overall audit quality assessment. The first impression, based on items such as clothes or behaviour, counts! It will also be seen that independence is treated very differently by clients and bankers. In contrast to clients, bankers treat independence very favourably in their overall audit quality judgment, which was expected based on the agency theory analysis in Chapter 3. Finally, it will be seen that 'performance minus adequate expectations' is a very powerful conceptualization of audit quality in this study, at least for the clients sample.

\subsubsection{Introduction to regression analysis}

The number of variables to be included in the regression model was primarily determined by the Adjusted $\mathrm{R}^{2}{ }^{20}$ In order to determine the sequence in which independent variables are added to or deleted from the model, three techniques are available (Norusis, 1993b):

- Forward selection. In forward selection, the first variable considered for entry into the equation is the one with the largest positive or negative correlation with the dependent variable. The next variables are sequentially entered, based on their correlation with the dependent variable;

Backward elimination. In backward elimination, all variables are included in the model. Variables are then eliminated, based on specific removal criteria; and

Stepwise selection. This is a combination of forward and backward selection and is probably the most commonly used. Basically, the model starts with zero variables in the equation (as is the case in forward selection), but, after each addition, variables already in the equation are examined for removal. This method was chosen in our analyses.

${ }^{210}$ Adjusted $\mathrm{R}^{2}$ corrects $\mathrm{R}^{2}$ for the number of variables used in the regression model. This is necessary " since $\mathrm{R}^{2}$ will always increase with the number of variables used in the equation, even though there may not be any true statistical relationship between the dependent variable and the variables added to the model. 
In the final stage, the data was tested for violations of a number of assumptions. Several checks were performed:

Non-linearity. Linear regression assumes that the relationship between the independent variable(s) and the dependent variable is linear. In order to test the validity of this assumption, several checks were made:

- the residuals were plotted against the standardized predicted value; - the residuals were plotted against each of the independent variables. None of these scatterplots showed any sign of a nonlinear relationship. Multicollinearity. This refers to the problem of intercorrelation between the independent variables. In order to test for multicollinearity, the coefficients in the correlation matrices were analyzed. No significant correlation was observed, which was according to expectations, considering the effort that had been put into ensuring the independence of the factors during the factor analyses. 


\subsubsection{Regression analysis at the performance level: clients}

Table 6.14 shows that four variables remained in the final equation resulting from the stepwise selection for clients at the performance level. All four variables had strong values for Cronbach Alpha in the factor analysis.

Obviously, a client's perception of audit quality depends very strongly on the auditor's ability to detect errors/irregularities and his knowledge of matters of interest to the client ('partner in business"). So, it appears that clients base their overall audit quality assessment primarily on the auditor's professional skills, at this level of analysis. The functional service quality items 'empathy' and 'communication' are also statistically significant at a 0.10 alpha level, but their importance in the determination of overall audit quality is limited.

Factors related to the reporting of findings (straightforwardness and whistle blowing) show a negative relationship with overall audit quality, although this is not statistically significant.

\begin{tabular}{|c|c|c|c|}
\hline 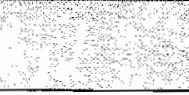 & lents (Performance leva) & $(\mathrm{B}) \mathrm{B}$ ) & (sigen \\
\hline $\begin{array}{l}\text { Variables in } \\
\text { equation }\end{array}$ & $\begin{array}{l}\text { Constant } \\
\text { CPF1 (Empathy) } \\
\text { CPF2 (Detection ability) } \\
\text { CPF5 (Parmer in Business) } \\
\text { CPF7 (Communication) }\end{array}$ & $\begin{array}{r}5.447(.100) \\
.193(.100) \\
.469(.102) \\
.289(.103) \\
.171(.099)\end{array}$ & $\begin{array}{l}54.680(.0000) \\
1.936(.0577) \\
4.609(.0000) \\
2.801(.0069) \\
1.720(.0906)\end{array}$ \\
\hline $\begin{array}{l}\text { Variables not in } \\
\text { equation }\end{array}$ & $\begin{array}{l}\text { CPF3 (Straightforwardness) } \\
\text { CPF4 (Whistle blowing) } \\
\text { CPF6 (Appenrance) } \\
\text { CPF8 (Quasi-professional) }\end{array}$ & $\begin{array}{l}.008 \\
.021 \\
.103 \\
.081\end{array}$ & $\begin{array}{r}.078(.9379) \\
.210(.8341) \\
.995(.3237) \\
.776(.4408)\end{array}$ \\
\hline $\begin{array}{l}\text { Multople } \\
.611\end{array}$ & $\begin{array}{l}\text { Adjusted } R^{2} \\
331\end{array}$ & $\begin{array}{l}\text { Nhmber of case } \\
64\end{array}$ & \\
\hline
\end{tabular}

Table 6.14 Regression analysis results for the clients sample, analyzed at the performance level

${ }^{26}$ Thus the regression function in the final stage reads:

Overall Audit Quality $=5.447+0.193 \mathrm{CPF} 1+0.469 \mathrm{CPF} 2+0.289 \mathrm{CPF} 5+0.171 \mathrm{CPF} 7+\mathrm{e}$

${ }^{22}$ For variables not in equation, "Beta in' is given in stead of B. Beta differs slightly from B because it is a standardized value. This holds for the remainder of this section. See also Table 6.20 . 


\subsubsection{Regression analysis at the performance level: bankers}

As can be seen in Table 6.15, six variables remained in the final regression equation for bankers at the performance level. The factors selected all had acceptable levels for Cronbach Alpha in the factor analysis. For bankers, appearance turned out to be a very important determinant of audit quality. This was rather unexpected, given the hypothesis that bankers would be interested primarily in technical performance. It was also very interesting given the finding in Section 5.4 that clients perceive a certain degree of overperformance in this area! It seems that bankers" relatively lower and perhaps more superficial exposure to auditors (compared to clients) makes this 'first impression' factor important: the first impression is used as a 'surrogate' for audit quality. Next in importance are two factors related to the auditor's detection ability and his independence ('whistle blowing' and 'traditional audit function'). Interestingly, 'whistle blowing' shows a positive relationship with overall audit quality, implying that bankers appreciate an auditor who publicly reports on issues regarding fraud, illegal acts and internal control. On the other hand, directly reporting fraud to tax authorities was not found to be significantly related to overall audit quality and even shows an - insignificant - negative relationship. Finally, the 'functional" items of thoroughness, accessibility and reliability were found to be significant determinants of overall audit quality, while empathy just failed to be significant at $\mathrm{p}=0.10$. Thus, in addition to the appearance factor, bankers seem to primarily appreciate a thorough, reliable and independent professional.

\begin{tabular}{|c|c|c|c|}
\hline \multicolumn{2}{|c|}{ Annkers ferformance level) } & $\mathrm{B}$ & $(\sin )$ \\
\hline Variables in equation & $\begin{array}{l}\text { Constant } \\
\text { BPF2 (Traditional audit function) } \\
\text { BPF3 (Reliability) } \\
\text { BPF4 (Appearance) } \\
\text { BPF5 (Whistle blowing) } \\
\text { BPF6 (Thoroughness) } \\
\text { BPF7 (Accessibility) }\end{array}$ & $\begin{array}{l}5.447(.102) \\
.296(.101) \\
.178(.105) \\
.459(.098) \\
.301(.107) \\
.205(.100) \\
.200(.104)\end{array}$ & $\begin{array}{l}53.252(.0000) \\
2.934(.0045) \\
1.693(.0946) \\
4.644(.0000) \\
2.811(.0063) \\
2.057(.0432) \\
1.917(.0591)\end{array}$ \\
\hline $\begin{array}{l}\text { Variables not in the } \\
\text { equation }\end{array}$ & $\begin{array}{l}\text { BPFI (Empathy) } \\
\text { BPFA (Reporting fraud to tax authorities) }\end{array}$ & $\begin{array}{r}.147 \\
.010\end{array}$ & $\begin{array}{l}1.631(1073) \\
-113(.9106)\end{array}$ \\
\hline $\begin{array}{l}\text { Multiple } R \\
.626\end{array}$ & $\begin{array}{l}\text { Adjusted } \mathbb{R}^{2} \\
.343\end{array}$ & mber of castes & \\
\hline
\end{tabular}

Table 6.15 Regression analysis results for the bankers sample, analyzed at the performance level 


\subsubsection{Regression analysis at the performance minus desired expectations level: clients}

As Table 6.16 shows, only three variables remained in the final regression equation for clients at the P-D level. Of these three variables, only one had a strong Cronbach Alpha in the factor analysis: responsiveness. The importance of this factor for overall audit quality assessments is remarkable. It appears that the desired level of expectations regarding this factor is very significant for the determination of overall audit quality. The other two significant factors (reporting accuracy and client's agent) have very weak Cronbach Alphas. Caution is therefore required in interpreting the regression analysis of these variables. Interestingly, independence has a negative relationship with overall audit quality, although the relationship just fails to be significant at $\mathrm{p}$ $=0.10$. Being a partner in business also just fails to have a statistically significant (positive) relationship with overall audit quality.

\begin{tabular}{|c|c|c|c|}
\hline (4) & erfommanee nimus desired level) & $\begin{array}{l}\mathrm{B} \\
(\mathrm{SE}, \mathrm{B})\end{array}$ & $\begin{array}{l}\text { (sig }) \\
\text { ( }),\end{array}$ \\
\hline Variables in equation & $\begin{array}{l}\text { Constant } \\
\text { CPMDF } \Perp \text { (Responsiveness) } \\
\text { CPMDF3 (Reporting accuracy) } \\
\text { CPMDF6 (Client's agent) }\end{array}$ & $\begin{array}{l}5.426(.101) \\
.397(.107) \\
.255(.101) \\
.299(.108)\end{array}$ & $\begin{array}{ll}53.479 & (.0000) \\
3.717 & (.0004) \\
2.514 & (.0146) \\
2.763 & (.0076)\end{array}$ \\
\hline $\begin{array}{l}\text { Variables mot in the } \\
\text { equation }\end{array}$ & $\begin{array}{l}\text { CPMDF2 (Independence) } \\
\text { CPMDF4 (Thoroughness) } \\
\text { CPMDF5 (Assurance) } \\
\text { CPMDF7 (Partar in business) } \\
\text { CPMDF8 (Quasimprofessiona) }\end{array}$ & $\begin{array}{r}-.156 \\
.090 \\
.133 \\
.159 \\
-.051 \\
\end{array}$ & $\begin{array}{r}-1.502(.139) \\
.835(.4017) \\
1.277(.2068) \\
1.524(.1328) \\
-478(.6347)\end{array}$ \\
\hline $\begin{array}{l}\text { Mulliple } R \\
.583\end{array}$ & $\begin{array}{l}\text { Adjusted } R^{2} \\
.306\end{array}$ & \multicolumn{2}{|c|}{$\begin{array}{l}\text { Nowber of canes } \\
64\end{array}$} \\
\hline
\end{tabular}

Table 6.16 Regression analysis results for the clients sample, analyzed at the $P$-D level 


\subsubsection{Regression analysis at the performance minus desired expectations level: bankers}

Table 6.17 shows that only three variables remained in the final equation resulting from the stepwise selection for bankers at the P-D level. Of these three variables, both 'traditional audit function' and "partner in business" had very good Cronbach Alphas. However, 'communication' had a weak Cronbach Alpha, which limits its interpretability. Obviously, bankers base their overall audit quality judgments simply on the auditor's professional skills at this level of analysis. Desired expectations regarding these attributes are very significant. In addition, the 'technical' attribute 'whistle blowing' just failed to be significant at $p=0.10$, underlining the importance of technical items at this level. All other factors are clearly insignificant.

\begin{tabular}{|c|c|c|c|}
\hline U. & enformance minus desired thevel) & $\begin{array}{l}\mathrm{B} \\
(\mathrm{SE} B)\end{array}$ & $(\operatorname{sig} 1)^{2}+4$ \\
\hline Variables in equation & $\begin{array}{l}\text { Constant } \\
\text { BPMDF1 (Traditional audit function) } \\
\text { BPMDF2 (Parmet in business) } \\
\text { BPMDF6 (Communication) }\end{array}$ & $\begin{array}{l}5.492(.110) \\
.316(.110) \\
3818(.111) \\
319(.113)\end{array}$ & $\begin{array}{r}49.863(0000) \\
2.874(.0052) \\
3.481(.0008) \\
2.835(.0059)\end{array}$ \\
\hline $\begin{array}{l}\text { Variables not in the } \\
\text { equation }\end{array}$ & $\begin{array}{l}\text { BPMDF3 (Thoroughness) } \\
\text { BPMDF4 (Punctuallity) } \\
\text { PBMDF5 (Appearance) } \\
\text { PBMDF7 (Whistle blowing) } \\
\text { PBMDF8 (Empathy) }\end{array}$ & $\begin{array}{l}.075 \\
.057 \\
.057 \\
.157 \\
.008\end{array}$ & $\begin{array}{r}.765(.4468) \\
.581(.9629) \\
.580(.5639) \\
1.625(.1082) \\
.080(.9365)\end{array}$ \\
\hline $\begin{array}{l}\text { Multiple } R \\
\$ 14\end{array}$ & $\begin{array}{l}\text { Adjusted R } \\
235\end{array}$ & \multicolumn{2}{|c|}{$\begin{array}{l}\text { Number of caseg" } \\
81\end{array}$} \\
\hline
\end{tabular}

Table 6.17 Regression analysis results for the bankers sample, analyzed at the P-D level 


\subsubsection{Regression analysis at the performance minus adequate expectations level: clients}

Table 6.18 shows that four variables remained in the final equation resulting from the stepwise selection for clients at the P-A level. Of these four variables, three (accessibility, partner in business and detection ability) had reasonably good Cronbach Alphas. However, 'thoroughness' had a weak Cronbach Alpha, which limits its interpretability. As was the case for the clients sample at the performance level, the auditors' professional skills reflected in partner in business, detection ability and thoroughness - are very important. For the four significant factors, adequate level expectations seem to be relevant in the explanation of overall audit quality. Of the three attributes that are not significant, two have a negative relationship with overall audit quality: 'independence' and 'quasi-professional' (which includes items on which clients perceive some degree of overperformance (see Chapter 5). Interestingly, the adjusted $\mathrm{R}^{2}$ is the highest of all regression analyses performed in this chapter.

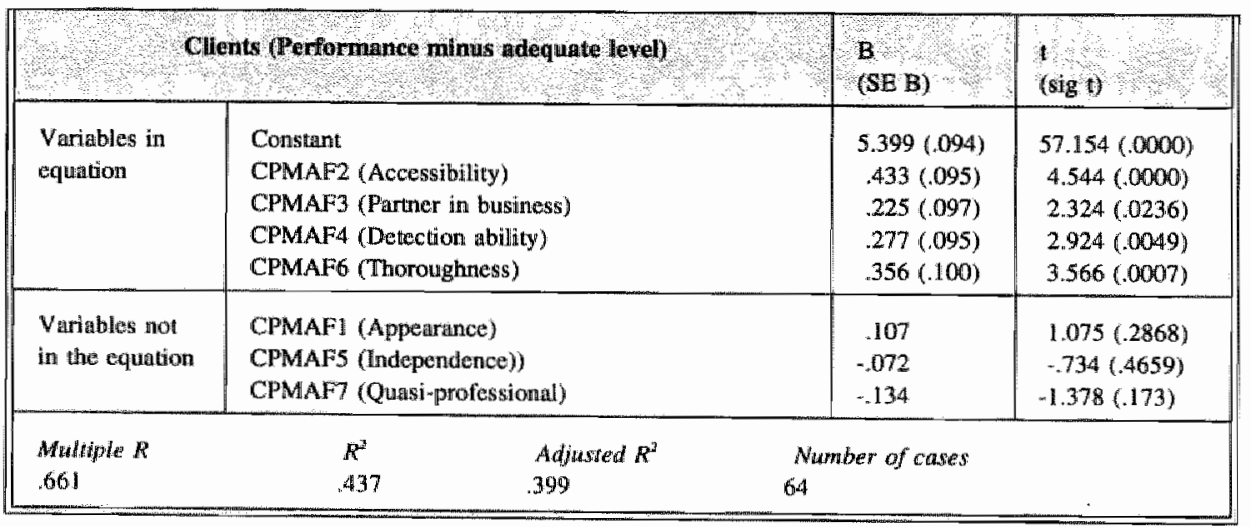

Table 6.18 Regression analysis results for the clients sample, analyzed at the $P-A$ level 


\subsubsection{Regression analysis at the performance minus adequate expectations level: bankers}

Table 6.19 shows that four variables remained in the final equation resulting from the stepwise selection for bankers at the P-A level. All these variables had strong Cronbach Alpha values. All other factors are clearly insignificant. The results show that bankers again stress the importance of the auditor's professional and communication skills: performing well on the traditional audit function, informing the banker on subjects of interest with regard to the client (whistle blowing) and informing the client on relevant points of interest (communication and partner in business). In contrast to clients, however, the bankers' performance minus adequate expectation level has a rather low value for adjusted $\mathrm{R}^{2}$, implying that adequate expectations might not be very relevant for overall audit quality assessments by bankers.

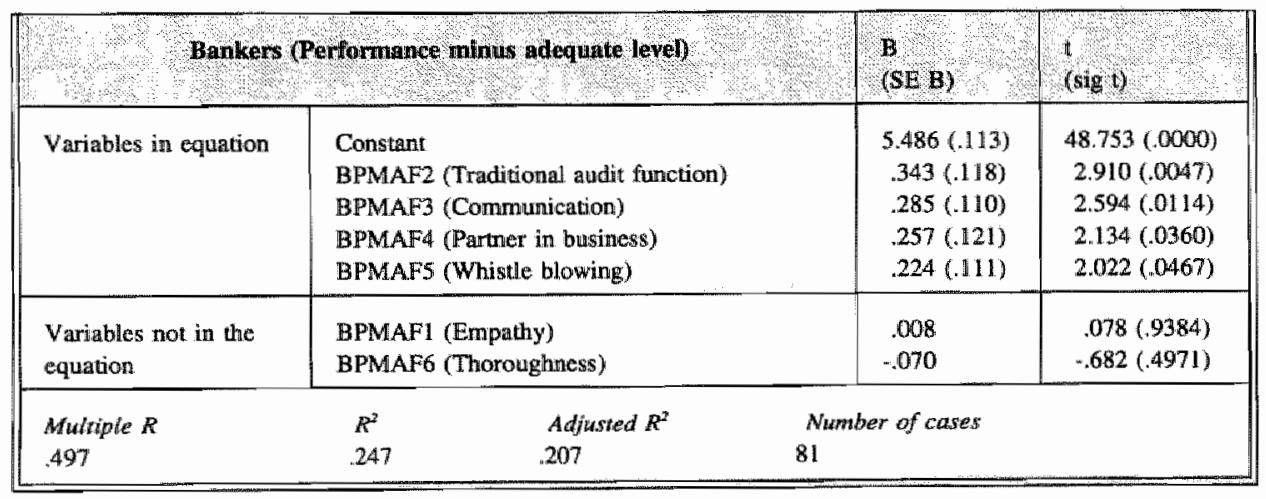

Table 6.19 Regression analysis results for the bankers sample, analyzed at the P-A level 


\subsection{Comparison of regression analyses}

In Table 6.20 a comparison is made of the regression analyses at the different stages.

\begin{tabular}{|c|c|c|c|c|c|c|}
\hline \multirow{2}{*}{$\begin{array}{l}\text { Awdit gaillih concept } \\
\text { Chent } / \text { Bankers }\end{array}$} & \multicolumn{2}{|c|}{ Performance } & \multicolumn{2}{|c|}{$\begin{array}{l}\text { Perfommance } \\
\text { minus flesired } \\
\text { (P D) }\end{array}$} & \multicolumn{2}{|c|}{$\begin{array}{l}\text { Performamce minus } \\
\text { adequate } \\
(\mathbf{P} / \mathbf{A})\end{array}$} \\
\hline & $c$ & B & $\mathrm{C}$ & B & $\mathrm{c}$ & 1 \\
\hline \multicolumn{7}{|c|}{ FUNCTIONAL FACTORS (included as variables in regression) } \\
\hline \multicolumn{7}{|l|}{ Tarygibles } \\
\hline Reliability & & $0.155^{*}$ & & & & \\
\hline Responsiveness & & & $0.393^{* *:}$ & & & \\
\hline \multicolumn{7}{|l|}{ Assurance } \\
\hline Empathy & $0.200^{*}$ & & & & & \\
\hline Pantuer in Business & $0.290^{* * *}$ & & & $0.340^{* * *-*}$ & $0.228^{* *}$ & $0.215^{* *}$ \\
\hline Appearance & & $0.421^{4 * * 0}$ & & & & \\
\hline Commumication & $0.177^{\circ}$ & & & $0.278^{*+\cdots * *}(!)$ & & $0.258^{\prime \prime *}$ \\
\hline Accessibility & & $0.1 .75^{*}$ & & & $0.445^{* * *}$ & \\
\hline \multicolumn{7}{|l|}{ Punctuallity } \\
\hline \multicolumn{7}{|c|}{ TECENICAL FACTORS (included as variables in regression) } \\
\hline Truditional audit function & & $0.266^{m * *}$ & & $0.282^{* * * *}$ & & $0.292^{* * * * 1}$ \\
\hline Detection ability & $0.476^{4 * *}$ & & & & $0.286^{* * *}$ & \\
\hline \multicolumn{7}{|l|}{ Independence } \\
\hline Whistle blowing & & $0.256^{\ldots * *}$ & & & & $0.201^{* *}$ \\
\hline $\begin{array}{l}\text { Reporting liand to tax } \\
\text { authorities }\end{array}$ & & & & & & \\
\hline
\end{tabular}




\begin{tabular}{|c|c|c|c|c|c|c|}
\hline \multirow{2}{*}{$\begin{array}{l}\text { Audit qualing concept } \\
\text { Clientsibankers: }\end{array}$} & \multicolumn{2}{|c|}{ Performance } & \multicolumn{2}{|c|}{$\begin{array}{l}\text { Perrominare } \\
\text { munas desined } \\
\text { (P-D) }\end{array}$} & \multicolumn{2}{|c|}{$\begin{array}{l}\text { Perrormance minus } \\
\text { adgquate } \\
(\mathbf{S})\end{array}$} \\
\hline & c & B & c & $\mathbf{B}$ & c & B \\
\hline \multicolumn{7}{|c|}{ MIXED FACTORS (included as variables in regression) } \\
\hline Thoroughness & & $0.187^{* *}$ & & & $0.350^{-\cdots+}(0)$ & \\
\hline \multicolumn{7}{|l|}{ Straightforwardness } \\
\hline Reporting accuracy & & & $0.264^{* *}(1)$ & & & \\
\hline \multicolumn{7}{|l|}{ Quasi-professional } \\
\hline Client's agent & & & $0.292^{*+*+*}(!)$ & & & \\
\hline Adjusted $\mathbf{R}^{2}$ & $\mathbf{0 . 3 3 1}$ & 0.343 & 0.306 & 0.235 & 0.399 & 0.207 \\
\hline
\end{tabular}

Table 6.20 Comparison of factors in regression analyses at different level ${ }^{23}$

$\begin{array}{lll}* & = & \text { significant at } p=0.10 \\ * * & = & \text { significant at } p=0.05 \\ * * * & = & \text { significant at } p=0.01 \\ ! \quad= & \text { Cronbach Alphat value }<0.60\end{array}$

Each column of Table 6.20 contains the results of one regression analysis. This table makes it possible to test the hypotheses generated in Section 3.6. The remainder of this section will discuss the findings for each hypothesis.

\section{Hypothesis 1}

\section{Functional audit quality attributes have higher weights in clients' overall audit quality assessments than technical audit quality attributes; on the other hand, technical audit quality attributes have higher weights in bankers' overall audit quality assessments than functional audit quality attributes.}

The importance of functional and technical audit quality can be derived from Table 6.20 , by computing the sum of $B$ values of the technical and functional

${ }^{23}$ Cells give $B$ values for the factors included in the regression analysis, significant at $p=$ 0.10 . These $\underline{B}$ values are slightly different from the $B$ values in Tables 6.14 to 6.19 . B is the slope of the regression function, representing the influence of a change in the independent variable on the dependent variable. $B$ values are standardized values of $B$, resulting from the multiplication of the regression coefficient $(B)$ by the ratio of the standard deviation of the independent variable $\left(S_{x}\right)$ to the standard dewiation of the dependent variable $\left(S_{y}\right)$. B values are better suited for interpretation as indicators of the relative importance of independent variables. 
factors. Since the factors that resulted from the principal components extraction method (Norusis, 1993a) all have an equal mean of 0 and an equal standard deviation of 1 , the addition of the Betas is allowed and results in an indication of the importance of the functional and technical factors in overall audit quality judgments. ${ }^{24}$.5.

For clients, the hypothesis is clearly confirmed. At all levels it is obvious that functional factors are more important than technical factors. It appears that clients base their judgments regarding auditors' overall audit quality primarily on professional skills (reflected in 'partner in business' and 'detection ability') and on communication skills ('communication' and - to some degree - 'empathy' and 'accessibility'). For bankers, the hypothesis is clearly not confirmed. In particular at the performance level - the only level at which the regression 'fit' is comparable with the 'fit' found for clients it is obvious that functional factors are more important than technical factors. As discussed earlier, it is interesting to see that a rather 'superficial' attribute such as 'appearance' plays such an important part in bankers' overall audit quality assessments. This seems to indicate that the rather low frequency of contacts between auditors and bankers induces bankers to base their overall audit quality judgment on their first impression. At the P-D level, a similar pattern results, this time without 'appearance'. At the P-A level, the functional and technical attributes are more or less equally important. To summarize, functional attributes are more important in the overall audit quality assessment of both bankers and clients, but this pattern is more obvious for clients than for bankers.

\footnotetext{
${ }^{24}$ However, it is obvious that the outcome of this process is severelly influenced by the 'cutoff at significance level $p=0.10$. Factors exceeding this level were not included in Table 6.20 and are therefore excluded from this process.

${ }^{25}$ Another limitation with regard to the interpretation of the results for this hypothesis is the fact that it is only possible to compare the technical and functional attributes that were identified in this study. This is relevant, since the $\mathrm{R}^{2}$ values indicate that the variation in overall audit quality has not been fully explained by the attributes that have been identified in this study.
} 


\section{Hypothesis 2}

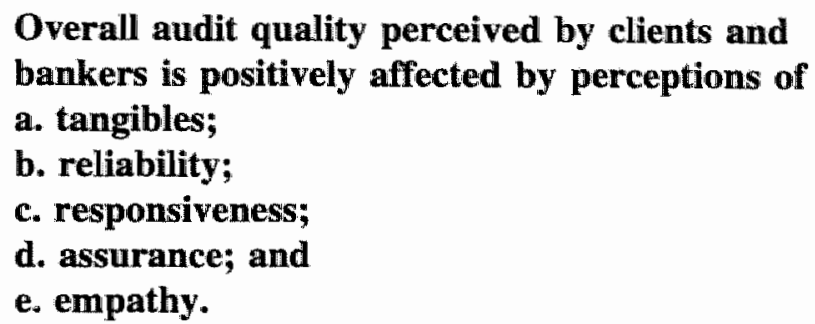

a. As discussed earlier, tangibles are reflected in the 'quasi-professional' factor and - to some extent - in the 'appearance' factor. For clients, this hypothesis was not confirmed since no significant relationship between either of these factors and overall audit quality could be found. Perhaps this can be explained by the finding in Section 5.4 that clients perceive 'overperformance' on some of the appearance items. It is probable that some clients appreciate appearance items, while other clients find them annoying. However, as discussed earlier, there is a remarkably strong relationship for bankers between overall audit quality and 'appearance' at the performance level. As was concluded earlier it is probable that the 'superficial' and low intensity contact that bankers have with auditors leads them to place a high value on first impression attributes such as 'appearance'. Expectations regarding appearance or tangibles are, however, irrelevant in the perception of bankers. Therefore, for bankers the hypothesis is partly confirmed.

b. As previously mentioned in this chapter in the discussion of the factor structures, the reliability factor identified by Zeithaml et al. (1990) is reflected by 'reliability' and 'thoroughness'. For clients, the hypothesis was not confirmed. The only significant relationship between thoroughness' and overall audit quality was found at the P-A level. However, the Cronbach Alpha value of this variable was suspect, raising doubts about the reliability of this conclusion. For bankers, the hypothesis could be confirmed, but only at the performance level. Obviously, although perceived performance regarding 'reliability' is relevant for overall audit quality assessments by bankers, expectations regarding this attribute are not.

c. Responsiveness is expressed by 'responsiveness', 'accessibility', 'straightforwardness' and 'punctuality'. For clients, responsiveness and accessibility are irrelevant in overall audit quality assessments at the performance level, but important at the P-D and P-A levels. For this 
attribute expectations are relevant, and performance is offset against expectations in overall audit quality assessments. For bankers, accessibility is only significant at the performance level. Therefore, the hypothesis has been confirmed to some degree for both clients and bankers, depending on the concept of audit quality used.

d. Apart from 'assurance", the factor 'partner in business' is also included in the assurance factor identified by Zeitharnl et al. (1990), since it incorporates items regarding the knowledge of the audit team. For clients, this hypothesis is clearly confirmed: at the performance and PA level, this attribute is an important determinant of overall audit quality, whereas it just failed to be significant for $\mathrm{p}=0.10$ at the P-D level (see Table 6.16). For bankers, the hypothesis is also confirmed. At the P-D and P-A levels, 'partner in business' is a significant determinant of overall audit quality. At the performance level, this factor was not identified. However, some of the 'knowledge' items were included in 'reliability', which is significant at this level.

e. Apart from the 'empathy' factor itself, the factor 'communication' has some similarity to empathy. For clients this hypothesis is clearly confirmed at the performance level, where both factors are significantly related to overall audit quality. However, expectations at the desired and adequate levels are irrelevant for clients' overall audit quality assessments. For bankers, the hypothesis is more clearly confirmed. Although empathy only just failed to be significant at $\mathrm{p}=$ 0.10 (see Table 6.15) at the performance level, communication was clearly significant at the P-A and P-D levels.

\section{Hypothesis 3}

\section{Technical audit quality attributes related to an auditor's 'traditional' duties have a higher weight in the determination of overall audit quality than those related to 'non-traditional' duties, for both clients and bankers.}

For clients, this hypothesis cannot be confirmed. As was mentioned in Subsection 6.2 .9 , clients do not clearly distinguish between traditional and nontraditional (or whistle blowing) duties, as regards either detection ability or independence. For bankers, the hypothesis is confirmed. At the performance level, the Beta for 'whistle blowing' is slightly smaller than for 'traditional 
audit function'. At the P-D level, the Beta for "traditional audit functional" is significantly stronger than for 'whistle blowing' (which just failed to be significant at $p=0.10$ ). Bankers" desired level expectations are obviously more relevant for overall audit quality in the case of traditional auditors' duties than for 'whistle blowing'. At the P-A level, 'traditional audit function' again outweighs 'whistle blowing'.

\section{Hypothesis 4}

\section{Perceived detection ability has a positive impact on overall audit quality, for both clients and bankers.}

For clients, this hypothesis is partly confirmed. At the performance level, detection ability is clearly the most significant determinant of overall audit quality. But this is not true at the P-D level. It seems that the desired level of expectations regarding technical quality is not relevant for the client's audit quality assessments. At the P-A level, detection ability again emerges as an important determinant of overall audit quality. Desired levels are therefore irrelevant, but adequate levels are certainly not! For bankers, this hypothesis is clearly supported at all levels. The traditional audit function is considered to be one of the most important determinants of overall audit quality at the performance, P-D and P-A levels. In contrast to clients, therefore, it seems that bankers do include the desired expectation level regarding technical quality in their overall quality assessment.

\section{Hypothesis 5}

\section{For bankers, perceived auditor independence has a positive impact on overall audit quality.}

This hypothesis is clearly confirmed. As mentioned before, the traditional audit function, which includes auditor independence on the classical issues, is an important determinant of overall audit quality at all levels of analysis. Regarding the whistle-blowing items, bankers obviously appreciate being informed about points of interest in their client's company, due presumably to their lack of internal information as compared with clients. These results demonstrate very significant positive relationships between whistle blowing and overall audit quality at the performance and the P-A level, and a nearly significant relationship at the P-D level (see Table 6.17). 


\section{Hypothesis 6}

\section{For clients, perceived auditor independence has a negative impact on overall audit quality.}

The findings clearly demonstrate that clients (the auditee's management) do not rate independence positively in their overall audit quality assessments. Independence does not emerge as a significant determinant of overall audit quality at the performance level (where the traditional independence items are included in the "straightforwardness" factor, which had an insignificant negative relationship with overall audit quality). At the P-D level, independence has a negative relationship with overall audit quality which is nearly significant at $\mathrm{p}=0.10$. At the $\mathrm{P}-\mathrm{A}$ level, independence had an insignificant negative relationship with overall audit quality. Regarding nontraditional items, there is a very insignificant negative relationship between "whistle blowing' and overall audit quality at the performance level (see Table 6.14). At the P-D level, some 'whistle blowing' elements are included in the independence factor, which has a negative relationship with overall audit quality that is nearly significant at $\mathrm{p}=0.10$ (see Table 6.16). At the PA level, there is a very insignificant negative relationship with overall audit quality and the 'independence' factor, which includes several 'whistle blowing' elements (see Table 6.18). Therefore, there is some evidence that managers behave as agents who would rather not have an auditor who reports errors or irregularities regarding traditional items, which is in line with the agency theory as described in Chapter 3.

\subsection{Summary}

This chapter has presented the findings regarding the first research question: What technical and functional audit quality attributes are distinguished by clients and bankers, and what is their relationship with and influence on overall audit quality assessments by these two groups?

In order to address this research question, we performed factor and regression analyses on the data. Based on the discussion in Section 2.6, it was decided to perform these analyses for the two respondent groups on three levels: performance, performance minus 'desired level' expectations and performance minus 'adequate level" expectations. It is interesting to see that the inclusion of the adequate level expectations did provide some interesting insights, both from an interpretation point of view and for statistical reasons: note that the adjusted $\mathrm{R}^{2}$ of the P-A model for clients was the highest of all models tested, even though the P-A model for bankers was rather disappointing, giving the lowest value for adjusted $\mathrm{R}^{2}$. The importance of adequate level expectations 
for bankers is low, probably because bankers do not have to make direct trade-offs regarding the 'purchase' of audit services, in contrast to clients, who do have to make trade-offs between, e.g., audit quality and audit costs. Although testing the reliability of the various conceptualizations of service quality was not the primary objective of this study, the P-A results do support the need for further investigations regarding the value of this concept in the determination of overall audit quality. Even though the results are promising - at least for the clients sample - more empirical tests, with different types of conceptualization (see Parasuraman et al., 1994b), are necessary, in order to optimize the measurement of the adequate level of expectation (see Section 5.3.4).

These findings also illustrate that further research is necessary on the reasons why expectations are relevant at some levels and not at others, or relevant for one group and not for the other, or relevant for some attributes while not for all. In this respect, the studies addressed in Section 2.6 concerning the determinants of expectations are important. They might enable decisionmakers in service companies to gain insight into the relevance of different types of expectations for quality judgments and into ways to manipulate these expectations.

Some interesting findings emerged as a result of the analyses. First, it was interesting to find that clients do not rate independence positively in their overall audit quality assessments. As expected, based on the agency theory, clients appreciate good detection skills, but they would like the auditor to keep his findings on any errors or irregularities in the company confidential. Further, clients rate good communication skills and good business advice very positively. Bankers appreciate both detection skills and independence, in line with the agency theory. These abilities are more important with respect to the 'traditional' duties than on the 'whistle blowing' duties. Like the clients, they appreciate good communication skills and good business advice, but they are also very sensitive to the 'first impression', probably as a result of the low frequency of their direct contacts with auditors. 
The empirical results have been summarized in Table 6.21. This table indicates for each (slightly restated) hypothesis, whether it has been confirmed by the empirical tests or not.

\begin{tabular}{|c|c|c|}
\hline \multicolumn{2}{|c|}{ Hypothesis } & \multirow{2}{*}{$\frac{\text { Confirmed }}{\text { Yes }}$} \\
\hline & $\begin{array}{l}\text { For clients' overall audit quality assessments, } \\
\text { functional audit quality attributes are more } \\
\text { important than technical. }\end{array}$ & \\
\hline $1 \mathrm{~B}$ & $\begin{array}{l}\text { For bankers" overall audit quality assessments, } \\
\text { technical audit quality attributes are more } \\
\text { important than functional. }\end{array}$ & No \\
\hline $2 \mathrm{~A}$ & $\begin{array}{l}\text { Clients' overall audit quality perception is } \\
\text { positively affected by perceptions of } \\
\text { a. tangibles } \\
\text { b. reliability } \\
\text { c. responsiveness } \\
\text { d. assurance } \\
\text { e. empathy }\end{array}$ & $\begin{array}{l}\text { No } \\
\text { No } \\
\text { Yes (partly) } \\
\text { Yes } \\
\text { Yes (partly) }\end{array}$ \\
\hline $2 B$ & $\begin{array}{l}\text { Bankers' overall audit quality perception is } \\
\text { positively affected by perceptions of } \\
\text { a. tangibles } \\
\text { b. reliability } \\
\text { c. responsiveness } \\
\text { d. assurance } \\
\text { e. empathy }\end{array}$ & $\begin{array}{l}\text { Yes (partly) } \\
\text { Yes (partly) } \\
\text { Yes (partly) } \\
\text { Yes } \\
\text { Yes }\end{array}$ \\
\hline $3 \mathrm{~A}$ & $\begin{array}{l}\text { 'Traditional' technical audit quality is more } \\
\text { important for clients' overall audit quality } \\
\text { assessment than 'non-traditional'. }\end{array}$ & No \\
\hline $3 B$ & $\begin{array}{l}\text { 'Traditional' technical audit quality is more } \\
\text { important for bankers' overall audit quality } \\
\text { assessment than 'non-traditional'. }\end{array}$ & Yes \\
\hline
\end{tabular}




\begin{tabular}{|c|c|c|}
\hline \multicolumn{2}{|c|}{ Hypothesis } & \multirow{2}{*}{$\frac{\text { Confirmed }}{\text { Yes (partly) }}$} \\
\hline $4 \mathrm{~A}$ & $\begin{array}{l}\text { Perceived detection ability has a positive impact } \\
\text { on clients' overall audit quality assessment. }\end{array}$ & \\
\hline $4 \mathrm{~B}$ & $\begin{array}{l}\text { Perceived detection ability has a positive impact } \\
\text { on bankers' overall audit quality assessment. }\end{array}$ & Yes \\
\hline 5 & $\begin{array}{l}\text { For bankers, perceived auditor independence } \\
\text { has a positive impact on overall audit quality. }\end{array}$ & Yes \\
\hline 6 & $\begin{array}{l}\text { For clients, perceived auditor independence has } \\
\text { a negative impact on overall audit quality. }\end{array}$ & No \\
\hline
\end{tabular}

Table 6.21 Summary of confirmation of hypotheses 



\section{CHAPTER 7 AUDIT ENGAGEMENT CHARACTERISTICS AND TECHNICAL AUDIT QUALITY}

\subsection{Introduction}

The second research question for this empirical study was to test the effect of audit engagement characteristics on clients' and bankers' technical ${ }^{1}$ audit quality judgments. Based on the discussion in Chapter 4 , several audit engagement characteristics were expected to have significant influences on clients' and bankers' perceptions ${ }^{2}$ of the auditor's detection ability and auditor independence. As described in Chapter 4, this aspect has received extensive attention in previous research. However, the methodology used in this study is different from most previous research:

1. It focuses explicitly on perceptions rather than on actual detection ability and independence; and

2. It is based on actual engagements, which distinguishes this study from the commonly-used method of presenting respondents with hypothetical situations.

Chapter 4 discussed the engagement characteristics that are hypothesized to have an effect on technical audit quality. These engagement characteristics are:
Audit firm size (Big Six versus non-Big Six);
Client size;
Client's financial health;
Length of tenure; and
Provision of MAS by incumbent auditor.

${ }^{4}$ Since the hypotheses on the relationship between audit engagement characteristics and audit quality were based on agency theory and on DeAngelo"s ( $1981 \mathrm{a}$ and $1981 \mathrm{~b}$ ) definition of audit quality, the empirical tests were confined to technical audit quality. Therefore the effect of the audit engagement characteristics on functional audit quality attributes has not been tested.

${ }^{2}$ For this purpose, measurements were made only at the (perceived) performance level, without correcting for expectations, because we are primarily interested in the influence of engagement characteristics on the auditor's perceived technical performance. The respondent's expectations might also be influenced by the engagement characteristics; if this were the case, the potential effect of the engagement characteristic on perceived performance might be mitigated by the adjustment of the expectation level. Therefore, in this chapter, technical audit quality will be measured only at the performance level. 
The probable effects of these engagement characteristics on technical audit quality were discussed in Chapter 4 , where the hypotheses were based on DeAngelo's (1981a and 1981b) work on quasi-rents and audit quality. This resulted in the following set of hypotheses:

\begin{tabular}{|l|l|}
\hline Hypothesis 7 & $\begin{array}{l}\text { An auditor's perceived detection ability is higher for } \\
\text { Big Six firms than for non-Big Six firms. }\end{array}$ \\
\hline Hypothesis 8 & $\begin{array}{l}\text { An auditor's perceived detection ability increases } \\
\text { with the incumbent auditor's level of MAS } \\
\text { provision. }\end{array}$ \\
\hline Hypothesis 9 & $\begin{array}{l}\text { An auditor's perceived detection ability decreases } \\
\text { with } \\
\text { a. client size; and } \\
\text { b. client's financial health. }\end{array}$ \\
\hline Hypothesis 10 & $\begin{array}{l}\text { An auditor's perceived detection ability is related to } \\
\text { tenure. }\end{array}$ \\
\hline Hypothesis 11 & $\begin{array}{l}\text { Perceived auditor independence is higher for Big } \\
\text { Six firms than for non-Big Six firms. }\end{array}$ \\
\hline Hypothesis 12 & $\begin{array}{l}\text { Perceived auditor independence decreases with } \\
\text { a. client size; and } \\
\text { b. client's financial health. }\end{array}$ \\
\hline Hypothesis 13 & $\begin{array}{l}\text { Perceived auditor independence is related to } \\
\text { a. tenure; and } \\
\text { b. incumbent auditor's level of MAS provision. }\end{array}$ \\
\hline
\end{tabular}

In order to test these hypotheses, the engagement characteristics were regressed as independent variables on

1. The individual (perceived) performance statements regarding technical audit quality in the questionnaire; and

2. The technical audit quality factors that were identified at the performance level for clients and bankers. ${ }^{3}$

${ }^{3}$ The factors can be used to assess the impact of the engagement characteristics at a higher level of analysis, since they result from the combination of several correlated individual statements. 
Section 7.2 will discuss the regression technique that was used to test the relationship between engagement characteristics and technical audit quality. Then the results of the regression analyses will be presented. The hypothesized effects of each of the engagement characteristics will be tested, for the bankers and clients samples separately. Finally, Section 7.3 will summarize the findings regarding this research question by briefly discussing the hypotheses. This section will demonstrate that both client size and client's financial health are very significant determinants in the bankers' technical audit quality judgments. There were no systematic relationships between the other engagement characteristics and the perceptions of bankers or clients regarding auditors' detection ability or independence.

\subsection{Regression model and results}

\subsubsection{Regression model}

To examine the effects of engagement characteristics on technical audit quality, the engagement characteristics were treated as the independent variables and the scores on the (perceived) performance questions and factors regarding technical audit quality as the dependent variables. Several checks were performed to search for any violation of the assumptions underlying the regression analysis technique. Specifically, we searched for non-linearity and multicollinearity, using techniques that were described in Section 6.3.2. In addition to the computation of correlation coefficients between the independent variables, several other tests for the detection of multicollinearity were performed, as suggested by Judge et al. (1980). These included the performance of partial regression and factor analyses on the independent variables. These checks did not reveal any violation of assumptions.

The regression models were constructed for clients and bankers separately. The dependent variables were the statements on the performance level relating to technical quality and the technical quality factors resulting from the factor analyses on the performance level. The independent variables were measures used to describe the relevant engagement characteristics. For each of the technical audit quality statements in the questionnaire and each of the technical audit quality factors identified (in Chapter 6) at the performance level, the following general regression function was generated: 
Technical audit quality $=$

f (firm size; client size; client's financial health; length of tenure; MAS fee part)

or:

$T A Q_{p x}=\quad C+\alpha B 6_{x}+\beta A T C S_{x}+\phi C F H_{x}+\delta L T_{x}+\varepsilon\left(M A S F_{x} / T F_{x}\right)+e$,

where

$C=$

Constant;

$T A Q_{p x}=\quad$ Technical audit quality statement/factor $\mathrm{p}$, for audit engagement $\mathrm{x}$;

$B 6_{x}=\quad$ Dichotomous Big Six variable for engagement $\mathrm{x}$;

$T C S_{x}=\quad$ Total sales of client involved in engagement $\mathrm{x}$ (Dutch

Guilders);

$\mathrm{CFH}_{\mathrm{x}}=\quad$ Financial health of client in engagement $\mathrm{x}$ assessed by banker (scale from 1 to 5 );

$L T_{x}=\quad$ Length of tenure for audit engagement $\mathrm{x}$ (years);

$M A S F_{x} T F_{x}=\quad$ MAS fee part for engagement $\mathrm{x}=$ MAS fee/total fee for engagement $\mathrm{x}$; and

$e=\quad$ Error term.

Table 7.1 lists the results of the regression analyses, in which these engagement characteristic measures were regressed on the technical audit quality statements and factors identified earlier in this study, for clients (57 observations) and bankers ( 60 observations) 4 separately. The cells give the parameters (B values) and the significance levels (between parentheses) for the measures of audit engagement characteristics used in these regression functions. In the remainder of this section, the results for each of the engagement characteristics will be discussed in a separate subsection.

${ }^{4}$ For some observations, not all the engagement characteristics were known. These observations were deleted from the analyses in this chapter. Therefore, the number of observations mentioned here is below the total number of observations mentioned in Section 5.4 .1 . 


\begin{tabular}{|c|c|c|c|c|c|c|c|}
\hline Yauriblet & $\begin{array}{l}\text { Banker } \\
\text { (Wilent } \\
\text { (n) }\end{array}$ & $\frac{\mathrm{BG}}{\mathrm{NBG}}$ & $\begin{array}{l}\text { Total cilent } \\
\text { sales } \\
\text { TCS }\end{array}$ & 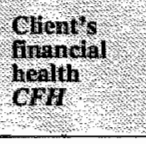 & $\begin{array}{l}\text { Lengh of } \\
\text { tenure } \\
L T\end{array}$ & $\begin{array}{l}\text { Was } \\
\text { for part } \\
\mathrm{MAST}^{2}\end{array}$ & 6 \\
\hline \multirow{2}{*}{$\begin{array}{l}\text { Detect } \\
\text { errors in } \\
\text { financial } \\
\text { statements }\end{array}$} & $\begin{array}{l}B \\
(1934)\end{array}$ & $\begin{array}{l}-.3923 \\
(.8636) \\
\end{array}$ & $\begin{array}{l}-.0023 \\
(.01711)^{* *}\end{array}$ & $\begin{array}{l}.3432 \\
(.0039)\end{array}$ & $\begin{array}{l}01129 \\
(.3254) \\
\end{array}$ & $\begin{array}{r}1543 \\
(7600) \\
\end{array}$ & $\begin{array}{l}6.1290 \\
(.0000) \\
\end{array}$ \\
\hline & C.0674) & $\begin{array}{c}3795 \\
(3464) \\
\end{array}$ & $\begin{array}{l}.0011 \\
(.6635) \\
\end{array}$ & $\begin{array}{c}-.0302 \\
(.8735)\end{array}$ & $\begin{array}{l}.0124 \\
(5427) \\
\end{array}$ & $\begin{array}{r}-1.8113 \\
(.1019) \\
\end{array}$ & $\begin{array}{l}5.14000 \\
(.0000) \\
\end{array}$ \\
\hline \multirow{2}{*}{$\begin{array}{l}\text { Report } \\
\text { emors in } \\
\text { financial } \\
\text { statements }\end{array}$} & $\begin{array}{l}\text { B } \\
(.2106) \\
\end{array}$ & $\begin{array}{l}1522 \\
(.5704) \\
\end{array}$ & $\begin{array}{l}.0028 \\
(.0134)^{* *}\end{array}$ & $\begin{array}{l}-4345 \\
(.0019) * *\end{array}$ & $\begin{array}{l}0128 \\
(4034)\end{array}$ & $\begin{array}{r}-2771 \\
(6404) \\
\end{array}$ & $\begin{array}{l}6.5681 \\
(.0000) \\
\end{array}$ \\
\hline & $\begin{array}{l}C \\
(.0633)\end{array}$ & $\begin{array}{l}-.0334 \\
(.9248) \\
\end{array}$ & $\begin{array}{l}.0032 \\
(1718) \\
\end{array}$ & $\begin{array}{r}.2205 \\
(.1911) \\
\end{array}$ & $\begin{array}{l}.0009 \\
(.9593) \\
\end{array}$ & $\begin{array}{l}-.0101 \\
(.9916) \\
\end{array}$ & $\begin{array}{l}6.0692 \\
(0000) \\
\end{array}$ \\
\hline \multirow{2}{*}{$\begin{array}{l}\text { Detuect } \\
\text { smoothing } \\
\text { in financial } \\
\text { staliements }\end{array}$} & $\begin{array}{l}\mathbb{B} \\
(2559) \\
\end{array}$ & $\begin{array}{l}.0153 \\
(.9449) \\
\end{array}$ & $\begin{array}{l}.0026 \\
(.0055) *\end{array}$ & $\begin{array}{l}.4059 \\
(.0005)^{*}\end{array}$ & $\begin{array}{l}.0146 \\
(.2489) \\
\end{array}$ & $\begin{array}{l}1582 \\
(.7466) \\
\end{array}$ & $\begin{array}{l}6.3510 \\
(00000) \\
\end{array}$ \\
\hline & $\mathbb{C}_{(1268)}$ & $\begin{array}{l}1.004 \\
(.0195)^{* *}\end{array}$ & $\begin{array}{r}-.0005 \\
(.8666) \\
\end{array}$ & $\begin{array}{l}0211 \\
(9147) \\
\end{array}$ & $\begin{array}{l}.0031 \\
(.8843) \\
\end{array}$ & $\begin{array}{l}-1.8740 \\
(.1042) \\
\end{array}$ & $\begin{array}{l}4.51333 \\
(.0000) \\
\end{array}$ \\
\hline \multirow{2}{*}{$\begin{array}{l}\text { Report } \\
\text { smoothing } \\
\text { in financial } \\
\text { statements }\end{array}$} & $\begin{array}{l}\text { B. } \\
(.3165) \\
\end{array}$ & $\begin{array}{l}.1865 \\
(4075) \\
\end{array}$ & $\begin{array}{l}-.0032 \\
(.0009)^{* * * *}\end{array}$ & $\begin{array}{l}-.4547 \\
(.0002) * *\end{array}$ & $\begin{array}{l}.0059 \\
(.6443) \\
\end{array}$ & $\begin{array}{l}-.0115 \\
(.9816)\end{array}$ & $\begin{array}{r}6.5184 \\
(.0000) \\
\end{array}$ \\
\hline & $\begin{array}{l}\mathrm{C} \\
(.0714)\end{array}$ & $\begin{array}{l}3403 \\
(.4270) \\
\end{array}$ & $\begin{array}{l}-.0021 \\
(.4574) \\
\end{array}$ & $\begin{array}{r}1232 \\
(5418) \\
\end{array}$ & $\begin{array}{l}.0275 \\
(.2071) \\
\end{array}$ & $\begin{array}{r}-6872 \\
(.5552) \\
\end{array}$ & $\begin{array}{l}4.9052 \\
(0000)\end{array}$ \\
\hline \multirow{2}{*}{$\begin{array}{l}\text { Detect } \\
\text { going- } \\
\text { concern } \\
\text { problems }\end{array}$} & $\begin{array}{l}\mathrm{B} \\
(3006)\end{array}$ & $\begin{array}{l}.0492 \\
(.8190) \\
\end{array}$ & $\begin{array}{l}{ }_{n} 0025 \\
(.0063)^{*}\end{array}$ & $\begin{array}{l}-.4338 \\
(.0002)^{* * *}\end{array}$ & $\begin{array}{l}.0016 \\
(.8967) \\
\end{array}$ & $\begin{array}{r}4134 \\
(3865) \\
\end{array}$ & $\begin{array}{l}7.1115 \\
\text { CoOONy }\end{array}$ \\
\hline & $\begin{array}{l}\mathrm{C} \\
(.1140)\end{array}$ & $\begin{array}{c}.1914 \\
(.5620) \\
\end{array}$ & $\begin{array}{l}.0044 \\
(.0445)^{* * *}\end{array}$ & $\begin{array}{l}1906 \\
(.2240) \\
\end{array}$ & $\begin{array}{l}-.0071 \\
(.6693)\end{array}$ & $\begin{array}{r}1078 \\
(.9044) \\
\end{array}$ & $\begin{array}{r}6.2784 \\
(, 0000) \\
\end{array}$ \\
\hline \multirow{2}{*}{$\begin{array}{l}\text { Publicly } \\
\text { report } \\
\text { going." } \\
\text { concern } \\
\text { problems }\end{array}$} & $\begin{array}{l}\mathrm{B} \\
(.3148)\end{array}$ & $\begin{array}{r}-.0390 \\
(.8783) \\
\end{array}$ & $\begin{array}{l}-.0027 \\
(.0134)^{3 * *}\end{array}$ & $\begin{array}{l}-.4775 \\
(.0004)^{* * * *}\end{array}$ & $\begin{array}{l}-.0125 \\
(.3910) \\
\end{array}$ & $\begin{array}{l}8222 \\
(.1481) \\
\end{array}$ & $\begin{array}{l}6.7561 \\
0.00001) \\
\end{array}$ \\
\hline & $\begin{array}{l}\mathrm{C} \\
(.1233) \\
\end{array}$ & $\begin{array}{l}.0746 \\
(.8718) \\
\end{array}$ & $\begin{array}{l}-.0026 \\
(.3844) \\
\end{array}$ & $\begin{array}{r}-3340 \\
(.1303) \\
\end{array}$ & $\begin{array}{l}-.0270 \\
(.2513) \\
\end{array}$ & $\begin{array}{l}-1.8255 \\
(.1511) \\
\end{array}$ & $\begin{array}{l}6.4941 \\
(.00009)\end{array}$ \\
\hline \multirow[t]{2}{*}{$\begin{array}{l}\text { Detect TO } \\
\text { deficiencies }\end{array}$} & $\begin{array}{l}\text { B } \\
(2769) \\
\end{array}$ & $\begin{array}{l}1223 \\
(.50309\end{array}$ & $\begin{array}{l}.0027 \\
(.0072)^{*}\end{array}$ & $\begin{array}{l}-.4428 \\
(.0004)^{* * *}\end{array}$ & $\begin{array}{r}-.0039 \\
(.7696) \\
\end{array}$ & $\begin{array}{r}-.3520 \\
(4988) \\
\end{array}$ & $\begin{array}{l}6.6942 \\
60000) \\
\end{array}$ \\
\hline & $\begin{array}{l}\mathrm{C} \\
(.1581)\end{array}$ & $\begin{array}{l}6785 \\
(.08801)^{*}\end{array}$ & $\begin{array}{r}-.0027 \\
(.2799) \\
\end{array}$ & $\begin{array}{l}.0573 \\
(7509) \\
\end{array}$ & $\begin{array}{l}-, 0361 \\
(.0661)^{*}\end{array}$ & $\begin{array}{r}.8976 \\
(.3898) \\
\end{array}$ & $\begin{array}{l}4.9533 \\
0.00001 \\
\end{array}$ \\
\hline \multirow{2}{*}{$\begin{array}{l}\text { Publicly } \\
\text { report fo } \\
\text { deficiemcies }\end{array}$} & $\begin{array}{l}B \\
(.2823)\end{array}$ & $\begin{array}{l}0448 \\
(8709)\end{array}$ & $\begin{array}{l}.0021 \\
(.0658)^{4} \\
\end{array}$ & $\begin{array}{l}.4888 \\
(0008)\end{array}$ & $\begin{array}{r}-.0234 \\
(.1405) \\
\end{array}$ & $\begin{array}{r}2375 \\
(6967) \\
\end{array}$ & $\begin{array}{l}6.9342 \\
(0000) \\
\end{array}$ \\
\hline & $\begin{array}{l}\mathrm{C} \\
(2112) \\
\end{array}$ & $\begin{array}{l}.9456 \\
(.0322)^{\text {min }}\end{array}$ & $\begin{array}{l}-.0052 \\
(.0700)^{4}\end{array}$ & $\begin{array}{l}.1969 \\
(.3361) \\
\end{array}$ & $\begin{array}{l}-0351 \\
(.1130) \\
\end{array}$ & $\begin{array}{r}.8461 \\
(.4727) \\
\end{array}$ & $\begin{array}{l}4.6760 \\
\text { (6000) }\end{array}$ \\
\hline \multirow[t]{2}{*}{ Detect fraud } & $\begin{array}{l}\mathrm{B} \\
(.1914) \\
\end{array}$ & $\begin{array}{l}02000 \\
(.9251)\end{array}$ & $\begin{array}{l}-.0023 \\
(0115)^{* * *}\end{array}$ & $\begin{array}{l}.2555 \\
(.0195)^{*} \\
\end{array}$ & $\begin{array}{l}-.0049 \\
(.6886)\end{array}$ & $\begin{array}{r}.3814 \\
(.4199) \\
\end{array}$ & $\begin{array}{r}6.4200 \\
(.00001 \\
\end{array}$ \\
\hline & $(0616)$ & $\begin{array}{l}4881 \\
(.2381) \\
\end{array}$ & $\begin{array}{l}.0007 \\
(.7988)\end{array}$ & $\begin{array}{l}1044 \\
(.5912) \\
\end{array}$ & $\begin{array}{l}0130 \\
(5331) \\
\end{array}$ & $\begin{array}{r}1.2475 \\
(.2678) \\
\end{array}$ & $\begin{array}{l}50959 \\
0.00009 \\
\end{array}$ \\
\hline \multirow{2}{*}{$\begin{array}{l}\text { Prublicly } \\
\text { report } \\
\text { ingternal } \\
\text { fraud }\end{array}$} & $\begin{array}{l}\text { Bi } \\
(1345) \\
\end{array}$ & $\begin{array}{l}-3398 \\
(3032) \\
\end{array}$ & $\begin{array}{l}-.0018 \\
(.1901)\end{array}$ & $\begin{array}{l}4074 \\
(0158)^{* * *}\end{array}$ & $\begin{array}{l}.0099 \\
(.5964) \\
\end{array}$ & $\begin{array}{r}-3771 \\
(.6042) \\
\end{array}$ & $\begin{array}{l}6.4419 \\
(0000)\end{array}$ \\
\hline & $\begin{array}{l}\mathrm{C} \\
(.0900)\end{array}$ & $\begin{array}{l}5424 \\
(.3421)\end{array}$ & $\begin{array}{l}.0040 \\
(.2845)\end{array}$ & $\begin{array}{l}.2035 \\
(4496) \\
\end{array}$ & $\begin{array}{r}0360 \\
(.2142) \\
\end{array}$ & $\begin{array}{l}5106 \\
(.7416) \\
\end{array}$ & $\begin{array}{l}4.11748 \\
(.00000\end{array}$ \\
\hline
\end{tabular}




\begin{tabular}{|c|c|c|c|c|c|c|c|}
\hline Meriablet & $\begin{array}{l}\text { Bankefl } \\
\text { Chent } \\
\left(\mathrm{A}^{2}\right)\end{array}$ & I 16 W & $\begin{array}{l}\text { Tolal ellient } \\
\text { rales } \\
\text { TCs }\end{array}$ & 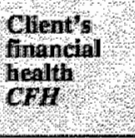 & $\begin{array}{l}\text { Length of } \\
\text { tenime } \\
\mathrm{LT}\end{array}$ & $\begin{array}{l}\text { MAs } \\
\text { respart } \\
\text { MAsWl } \\
T H\end{array}$ & \\
\hline \multirow{2}{*}{$\begin{array}{l}\text { Report } \\
\text { frand to tax } \\
\text { andinorities }\end{array}$} & $\begin{array}{l}B \\
(1485)\end{array}$ & $\begin{array}{r}-1414 \\
(.7175) \\
\end{array}$ & $\begin{array}{l}.0036 \\
(.0270)^{* * *}\end{array}$ & $\begin{array}{l}-.3197 \\
(.1060)\end{array}$ & $\begin{array}{l}-.0186 \\
(.4039)\end{array}$ & $\begin{array}{l}.6594 \\
(.4465)\end{array}$ & $\begin{array}{l}5.8770 \\
(.0000) \\
\end{array}$ \\
\hline & $\mathbb{C}$ & $\begin{array}{l}.2026 \\
(.7269) \\
\end{array}$ & $\begin{array}{l}.0065 \\
(0902)\end{array}$ & $\begin{array}{l}3094 \\
(.2613) \\
\end{array}$ & $\begin{array}{c}-.0094 \\
(.7484) \\
\end{array}$ & $\begin{array}{r}-11.5431 \\
(.3305)\end{array}$ & $\begin{array}{l}4.0913 \\
(.0000)\end{array}$ \\
\hline \multirow[t]{2}{*}{$\begin{array}{l}\text { Dietect. } \\
\text { illegenall ants }\end{array}$} & $\begin{array}{l}\mathrm{B} \\
(.1605)\end{array}$ & $\begin{array}{l}5026 \\
(.1003) \\
\end{array}$ & $\begin{array}{r}.0012 \\
(.3538) \\
\end{array}$ & $\begin{array}{l}-.3055 \\
(.0471)^{*}\end{array}$ & $\begin{array}{l}.0187 \\
(.2809) \\
\end{array}$ & $\begin{array}{l}-.6178 \\
(.3569) \\
\end{array}$ & $\begin{array}{l}5.6907 \\
(.0000)\end{array}$ \\
\hline & C.1506) & $\begin{array}{l}.9972 \\
(.0320)^{*}\end{array}$ & $\begin{array}{c}-.0039 \\
(.1956) \\
\end{array}$ & $\begin{array}{l}.0791 \\
(.7129)\end{array}$ & $\begin{array}{r}-.0241 \\
(.2970) \\
\end{array}$ & $\begin{array}{r}-1.2173 \\
(3277) \\
\end{array}$ & $\begin{array}{l}4.1022 \\
(.0000) \\
\end{array}$ \\
\hline \multirow{2}{*}{$\begin{array}{l}\text { Poblicly } \\
\text { repent } \\
\text { illegall acts }\end{array}$} & $\begin{array}{l}\mathrm{B} \\
(.1848)\end{array}$ & $\begin{array}{r}-.0932 \\
(.7444) \\
\end{array}$ & $\begin{array}{c}.0003 \\
(.8248) \\
\end{array}$ & $\begin{array}{l}-.4083 \\
(.0058)^{*}\end{array}$ & $\begin{array}{l}-0114 \\
(4846)\end{array}$ & $\begin{array}{l}-9487 \\
(.1372)\end{array}$ & $\begin{array}{l}6.5268 \\
(.0000)\end{array}$ \\
\hline & $\begin{array}{l}\mathrm{C} \\
(1723)\end{array}$ & $\begin{array}{l}6437 \\
(1686) \\
\end{array}$ & $\begin{array}{l}-.0058 \\
(.0614)^{*}\end{array}$ & $\begin{array}{r}.0555 \\
(.7996) \\
\end{array}$ & $\begin{array}{l}-.0328 \\
(.1654) \\
\end{array}$ & $\begin{array}{r}-1.8392 \\
(.1489) \\
\end{array}$ & $\begin{array}{l}5.4553 \\
(0000)\end{array}$ \\
\hline $\begin{array}{l}\text { Factor: } \\
\text { "Traditional } \\
\text { audit. } \\
\text { function }\end{array}$ & $\begin{array}{l}\text { B } \\
(2284)\end{array}$ & $\begin{array}{l}.0830 \\
(.7290)\end{array}$ & $\begin{array}{l}(.0028 \\
(.0064) * * *\end{array}$ & $\begin{array}{l}-3407 \\
(.0060)^{* * * *}\end{array}$ & $\begin{array}{l}-.0053 \\
(.6973)\end{array}$ & $\begin{array}{l}3780 \\
(.4764)\end{array}$ & $\begin{array}{l}8598 \\
(.0140)\end{array}$ \\
\hline \multirow{2}{*}{$\begin{array}{l}\text { Finctor: } \\
\text { Whistle } \\
\text { blowing }\end{array}$} & $\begin{array}{l}\mathrm{B} \\
(1471)\end{array}$ & $\begin{array}{l}11112 \\
(.5958) \\
\end{array}$ & $\begin{array}{l}.0002 \\
(8124) \\
\end{array}$ & $\begin{array}{l}-.2464 \\
(.0218)^{* * *}\end{array}$ & $\begin{array}{l}-.00184 \\
(.4846) \\
\end{array}$ & $\begin{array}{r}-.64444 \\
(.1680) \\
\end{array}$ & $\begin{array}{l}.9277 \\
(0028) \\
\end{array}$ \\
\hline & $\begin{array}{l}C \\
(2186)\end{array}$ & $\begin{array}{l}3082 \\
(.2598) \\
\end{array}$ & $\begin{array}{l}.0036 \\
(0500)^{* *}\end{array}$ & $\begin{array}{l}. .0848 \\
(.5096) \\
\end{array}$ & $\begin{array}{l}.0299 \\
(.0336)^{\text {*t* }}\end{array}$ & $\begin{array}{l}. .9725 \\
(.1926) \\
\end{array}$ & $\begin{array}{l}.7208 \\
(.0775) \\
\end{array}$ \\
\hline $\begin{array}{l}\text { Factor: } \\
\text { Detection } \\
\text { ability }\end{array}$ & $(0960)$ & $\begin{array}{l}4038 \\
(.1748)\end{array}$ & $\frac{0022}{(.2575)}$ & $\begin{array}{l}1197 \\
(.3917)\end{array}$ & $\begin{array}{l}.0084 \\
(.5752)\end{array}$ & $\begin{array}{l}-.8202 \\
(.3095)\end{array}$ & $\begin{array}{l}.5154 \\
(2406)\end{array}$ \\
\hline
\end{tabular}

Table 7.1 Regression of engagement characteristics on technical audit quality

* = significant relationship between engagement characteristic and technical audit quality variable/factor at $\mathrm{p}=0.10$

*** = sỉgnificant relationship between engagement characteristic and technical audit quality variable/factor at $p=0.05$

**** = significant relationship between engagement characteristic and technical audit quality variable/factor at $\mathrm{p}=0.01$.

\subsubsection{Audit fïm size}

As described earlier, employees at a notary's office had made the completed questionnaires anonymous. However, they first registered whether the questionnaire described a Big Six or a non-Big Six engagement. As a result, firm size was measured only as a dichotomous variable. In the regression analysis, firm size was included as a dummy variable, assuming values of either 0 or 1 . For the clients sample, the Big Six dummy was found as a significant variable at $\mathrm{p}=0.05$ for three individual technical audit quality 
items. In particular, Big Six firms were considered to be more successful in 'the detection of smoothing in the financial statements and of illegal acts, and were considered to be more independent in reporting deficiencies in the client's internal organization. At a significance level of $p=0.10$, Big Six auditors were also considered to be more successful in detecting 10 deficiencies. Perhaps the finding that clients consider Big Six auditors more likely to detect and report deficiencies in the client's internal organization can be explained by the fact that Big Six firms are supposed to pay more attention to compliance testing, given the fact that - on average - they are confronted with larger clients and therefore more advanced internal organizations. Moreover, it is interesting to note that while Big Six and nonBig Six firms are perceived as having the same detection ability for 'plain' errors in the financial statements, clients perceive a considerable difference in the larger firms' ability to detect smoothing. Obviously, clients believe that Big Six firms have more knowledge or better tools to test financial statement decisions of a more 'judgmental' nature, such as decisions on provisions, depreciation and valuation. However, the fact that no significant relationship could be found between the Big Six variable and any of the technical audit quality factors indicates that these relationships are incidental rather than indicating a systematic relationship between audit firm size and technical audit quality.

For the bankers sample, no significant relationship was found between technical audit quality variables or factors and firm size, even at $\mathrm{p}=0.10$.

All in all, it is obvious that the hypothesized relationship between firm size and perceived technical audit quality - both detection and reporting emerges to only a very limited degree from the tests performed. There are several possible explanations for this departure from the mainstream findings in audit research. First, this study measured perceived technical audit quality. The research findings might indicate that firm size is not an important implicit or explicit determinant in the formulation of clients' and bankers' perceptions. Second, this study tested actual cases rather than hypothetical cases. Much of the previous research on perceptions of (technical) audit quality (McKinley et al., 1985; Knapp, 1991) has been based on hypothetical cases, in which the audit firm size category was explicitly mentioned. This potential source of bias has been eliminated in this study. In his interviews with leading representatives of the financial community, Schilder (1994, p. 239) found hardly any reference to firm size as an explanatory variable for auditor independence. While research findings indicate that small firms are more exposed to competition and a perceived lack of independence, he 
suggests compensating effects: '(...) maybe smaller audit firms are more involved in their client's business, due to their larger advisory role. So a relationship with compensating effects is possible between "Size of audit firm", "Competition" and "Value of auditor to client".'

\subsubsection{Client size}

Client size - measured by total client sales ${ }^{5}$ - is seen as a determinant of 'whistle blowing' in the perception of clients. Both the whistle blowing factor and one of its underlying ${ }^{6}$ variables - the detection of going concern problems - are significant at $\mathrm{p}=0.05$. In addition, three other "whistle blowing' variables - reporting of fraud to tax authorities, and public reporting of IO deficiencies and illegal acts - have a negative relationship with total client sales at $\mathrm{p}=0.10$.

For bankers, client size is an important determinant of the factor "traditional audit function'. This is also demonstrated by the significance of nearly all 'traditional' technical audit quality items. In addition, several 'whistle blowing' items are significant, although the 'whistle blowing' factor was not significant, even at $p=0.10$. At $p=0.05$, negative relationships were found for the detection of fraud and IO deficiencies, the reporting of fraud to tax authorities and the detection and reporting of

Financial statement errors;

Smoothing; and

Going concern problems.

In addition, the public reporting of 10 deficiencies was related to client size at $\mathrm{p}=0.10$.

Thus it seems that the importance of client size is regarded very differently by clients and bankers. Bankers perceive a negative relationship between client size and both detection ability and independence, for most of the auditor's duties. They conclude that the technical quality of an audit decreases with auditee size. As regards detection ability, this is in line with the hypothesis that respondents would perceive that increasing size and

"As an alternative, 'total client's assets" was considered. However, in previous research these two measures of size were regarded as substitutes for each other (see, e.g., Brinn et al., 1994).

${ }^{6}$ See Table 6.2. 
complexity of companies might complicate the audit and result in a relatively lower level of technical audit quality. The negative relationship for bankers between independence and auditee size is in line with the hypothesis that larger client size leads to a shift in power towards the client, reflecting the greater importance of the client to the auditor.

Clients do not perceive a negative relationship between auditee size on the one hand and detection ability and independence regarding traditional duties on the other. Being more closely involved in the audit process, they obviously believe that auditors are able to adapt their techniques to the specific requirements of increases in company size and complexity. Further, they believe that auditor independence is only influenced by the relative importance of a client in issues that go beyond an auditor's well established, traditional duties.

\subsubsection{Client's financial health}

Clients do not perceive a relationship between their own financial health and the auditor's technical performance. Even at $\mathrm{p}=0.10$, no significant relationship could be found.

A very consistent pattern of positive relationships ${ }^{7}$ was found between the audited company's financial health and the technical audit quality as perceived by bankers. On all technical quality variables and factors but one (the reporting of fraud to tax authorities) there was a significant positive relationship, indicating that bankers believe that auditors do a better job in both the detection and independence area if the client is in good financial circumstances. This is also illustrated by the fact that overall audit quality is significantly explained by the client's financial health, in the perception of bankers. $^{8}$

'Since the client's financial health was rated as 1 if excellent, and as 5 if very poor, Table 7.1 actually gives the relationship between "unhealthy" and technical audit quality.

${ }^{8}$ In addition to the technical audit quality variables and factors included in Table 7.1, the engagement characteristic measures were also regressed on overall audit quality (for bankers and clients separately). Client's financial health proved to be the only significant variable, with a significance level of $\mathrm{p}=0.0001$ (for the bankers sample). 
The theoretical analysis underlying the hypotheses regarding the influence of the client's financial health on technical audit quality - that the auditor will do more audit work and will be more independent because litigation and reputation damage risks are bigger where the client is in financial trouble is not reflected in bankers' perception of technical audit quality. There are three possible explanations for this phenomenon:

Bankers might believe that there will be more pressure from a client whose financial health is bad, since the ability to continue as a going concern might be enhanced by 'flattering' financial statements. Thus, in their view, auditors might be exposed to more serious threats of engagement termination and might therefore be less inclined to report errors or irregularities. However, although this is an acceptable explanation for the independence issue, it fails to explain why detection ability is also considered to drop with a decrease in financial health;

Bankers might be unable to distinguish between client's performance and auditor's performance. Put differently, perhaps bankers might hold auditors responsible for the client's bad financial performance; and A very opportunistic reason for this finding might be that, in the light of an impending financial crisis, bankers might already be looking for a 'scape-goat'. Bankers might be inclined to hold the auditor responsible for failing to warn the banker in time to safeguard his financial interests.

\subsubsection{Length of tenure}

No systematic relationship was found between length of tenure and technical audit quality, for either bankers or clients. For clients, length of tenure is primarily seen to negatively influence the detection of IO deficiencies. The longer the tenure, the less likely it is (in the perception of the client) that an auditor will be able to detect deficiencies in the internal organization.

Obviously, clients observe that auditors become less critical over the years with regard to the client's internal organization. They seem to believe that auditors, once they have assessed the quality of the internal organization in one year, pay less attention to the testing of the organization in later years. Finally, for clients, a negative relationship was found between tenure and the whistle blowing factor. However, this is primarily due to the inclusion in this factor of the IO variable (see Table 6.2). 
Tenure is obviously not perceived as an important determinant of technical audit quality by bankers. No significant relationship between technical audit quality and tenure was found.

One potential explanation for this lack of significant relationships between technical audit quality and tenure was the possibility of a non-linear relationship between technical audit quality and tenure. In particular, we looked for the relationship found by Knapp (1991), where tenure first had a positive effect on technical audit quality (reflecting the increase in client experience) and then, after several years, a negative effect. In order to test for this effect, the technical audit quality statements were plotted as dependent variables against length of tenure (in years) as the independent variable. However, no such pattern could be found. As was the case for audit firm size, it appears that the method used in this study, examining perceptions based on actual engagements, might explain why we did not find relationships that have been found in research using fictitious cases.

\subsubsection{Provision of MAS by incumbent auditor}

For both clients and bankers, no significant relationship between the ratio MAS fee/total fee and technical audit quality could be established, even at $p$ $=0.10$. Obviously, the provision of MAS is not seen as an issue for either detection ability or independence. For independence, this was not unexpected, given the inconclusive nature of both theoretical and empirical research in this area. For detection ability, the hypothesized positive relationship between detection ability and the MAS level could not be confirmed. Probably the nature of MAS work is such that neither clients nor bankers perceive any positive impact on the detection quality of the audit.

\subsection{Summary}

In Chapter 4 , seven hypotheses were generated concerning the impact of engagement characteristics on detection ability and independence, based on agency theory and DeAngelo"s (1981a and 1981b) quasi-rent analysis. Before giving overall conclusions for this chapter, the findings for each of these hypotheses will be presented. 


\section{Hypothesis 7 An auditor's perceived detection ability is higher for Big Six firms than for non-Big Six firms.}

In the perception of clients, this hypothesis is only weakly confirmed. On some issues, Big Six firms are indeed considered better able to detect errors or irregularities. However, these findings are not systematically reflected in a relationship with any of the technical audit quality factors. In the perception of bankers, no significant relationship could be found between firm size and detection ability.

Hypothesis 8

An auditor's perceived detection ability increases with the incumbent auditor's level of MAS provision.

This hypothesis was clearly not supported by the findings, for either clients or bankers.

Hypothesis 9
An auditor's perceived detection ability decreases with
a. client size; and
b. client's financial health.

For clients, this hypothesis was not supported by the findings. For bankers, however, part (a) of the hypothesis was clearly supported, whereas the findings were overwhelmingly in conflict with part (b) of the hypothesis. Bankers appear to believe that detection ability is positively related to the client's financial health.

Hypothesis 10

An auditor's perceived detection ability is related to tenure.

No pattern of relationships between perceptions of detection ability and length of tenure was found, for clients or bankers, except that clients appear to believe that ability to detect deficiencies in the internal organization erodes over time. 
Hypothesis 11

Perceived auditor independence is higher for Big Six firms than for non-Big Six firms.

No substantiall support could be found for this hypothesis, for either clients or bankers.

Hypothesis 12

Perceived auditor independence decreases with

a. client size; and

b. client's financial health.

For clients, no systematic evidence could be found for this hypothesis. For bankers, however, the same applies as for hypothesis 9: part (a) of the hypothesis was clearly supported, whereas our findings conflicted with part (b) of the hypothesis. Bankers appear to believe that independence is better where the client's financial condition is better.

Hypothesis 13 Perceived auditor independence is related to

a. tenure; and

b. incumbent auditor's level of MAS provision.

No systematic relationship between auditor independence and either length of tenure or the incumbent auditor's provision of MAS was found, for either clients or bankers.

The findings regarding these hypotheses are summarized in Figure 7.1. 


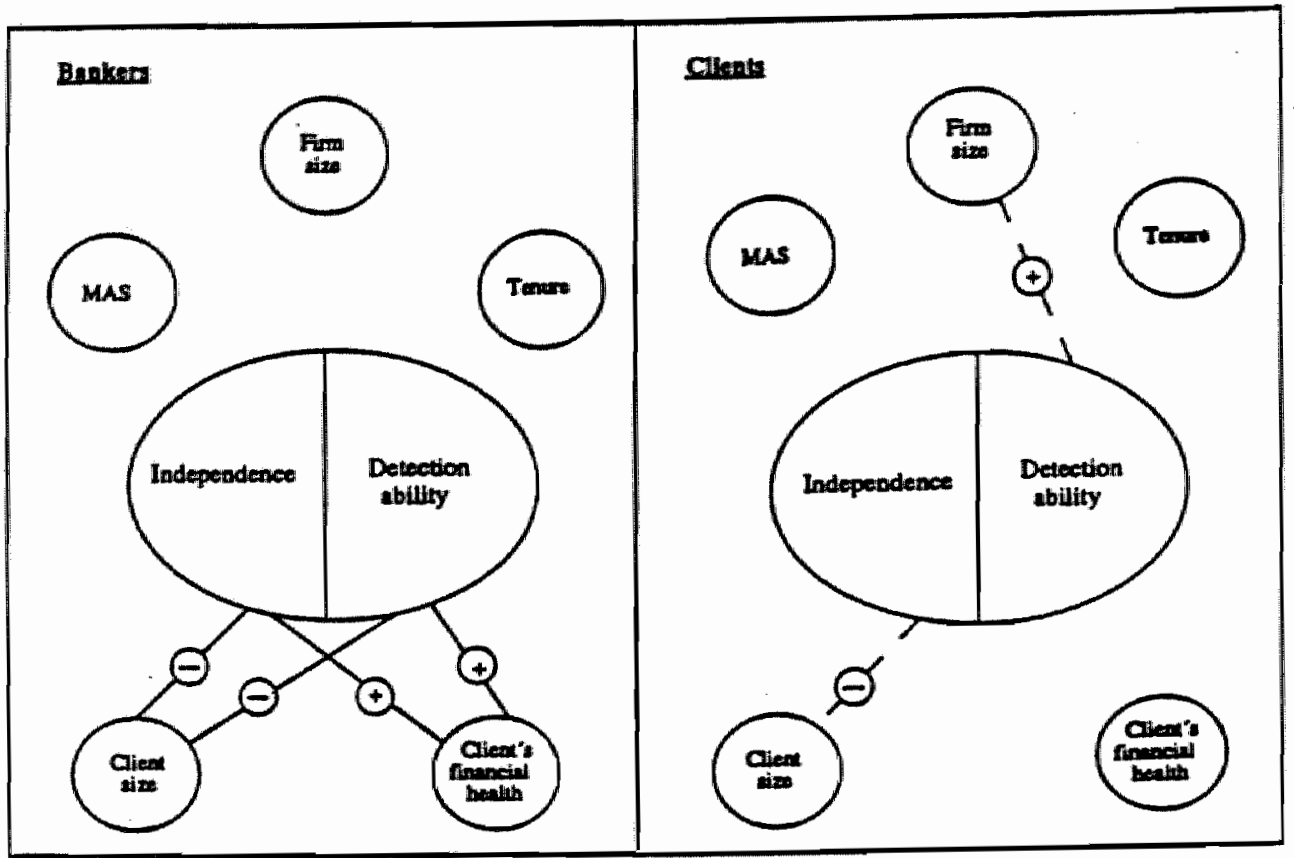

Figure 7.1 The impact of engagement characteristics on technical audit quality
(4)
$=$ systematic positive impact of audit engagement characteristic on
technical audit quality attribute. $\Theta-=\begin{aligned} & \text { systematic negative impact of audit engagement characteristic on } \\ & \text { technical audit quality attribute. }\end{aligned}$
$\oplus \ldots \ldots$ incidental positive impact of audit engagement characteristic on technical audit quality attribute.
$=$ incidental negative impact of audit engagement characteristic on technical audit quality attribute.


It is interesting to note from Figure 7.1 that engagement characteristics that are more related to the supply side - audit firm size, MAS provision and length of tenure - are not seen as significant in the determination of technical audit quality, except that firm size is seen by clients as a significant determinant of some technical quality aspects. However, since no significant relationship with quality was found for any of the technical audit quality factors, the individual relationships found for firm size appear to be incidental rather than structural.

On the other hand, those characteristics associated with the demand side are very clearly associated with technical audit quality, at least in the perception of bankers. Both client size and client's financial health were found as very significant determinants of perceived technical audit quality by bankers. This finding is very interesting, since these two variables have received only moderate attention in previous audit research. In particular, the finding with regard to the influence of the client's financial condition is different from the (scarce) findings in previous research. The significance of this relationship between perceived technical audit quality and the client's financial health might be largely explained by the perception of bankers that large clients and clients in financial trouble are more convincing in their 'power play' against the auditor in conflict situations. Another explanation for the poor perceived performance of auditors where the client's financial health is bad might be that bankers do not distinguish between the client's and the auditor's performance. They might hold the auditor - partially - responsible for either the client's bad financial position or for warning the banker too late about the impending financial distress.

Finally, it is interesting to note that the findings do not support any serious concern regarding 'political' issues such as length of tenure and MAS provision. Restrictions have recently been implemented with respect to these topics in some countries. Our findings in this regard are consistent with the findings of Schilder (1994). 



\section{CHAPTER 8 SUMMARY AND DISCUSSION}

\subsection{Summary}

\subsubsection{Introduction}

Compared to the extensive body of marketing research on service quality, the research on audit quality is rather limited. This rather limited amount of attention devoted to audit quality is typical of most professional service industries. Lapierre and Filiatrault (1995) state that the 'theoretical and empirical literature dealing with professional services is far less developed than that of more traditional services. More precisely, there has been very little effort to investigate business to business professional services quality". This lack of interest is surprising, given the findings of several researchers that concern about service quality is important in the service industry, including the professional service segment: ' $(. .$.$) the need to better understand$ service quality was also recognized as essential for professional service firms' (Lapierre and Filiatrault, 1995). Dart and Freeman (1994) state that professional service organizations are becoming increasingly aware of the advantages of paying attention to marketing (including service quality), given the rapid developments in the professional service market, including the elimination of restrictions on advertising or other forms of promotion, increases in the number of professionals, changing technologies and dissatisfaction among the users of professional services. Given these developments and the current competitive nature of the audit market, the investigation of the nature and determinants of audit quality is an interesting subject, for both theoretical and practical reasons.

\subsubsection{Research design}

This study measured the perceptions of overall audit quality held by the management of audited companies (clients) and account managers of banks (bankers). These groups were chosen because they are important users of audit services and because both have more or less frequent direct contacts with auditors, enabling them to make audit quality assessments based upon their own perceptions.

Applying models and techniques developed in marketing research, we searched for functional and technical audit quality attributes. Functional audit quality was defined as the degree to which the process of carrying out the 
audit and communicating its results meets a consumer's expectations. Technical audit quality was defined as the degree to which the audit meets a consumer's expectations with respect to the detection ('detection ability') and reporting ('independence') of errors and irregularities regarding the audited company and its financial statements. The comparison of (perceived) performance with expectations is a quality concept that originates from marketing research (Parasuraman et al., 1985). Although not undisputed, this concept has received considerable attention (see Chapter 2). Recent research in this area deals with the types of expectations that are used in quality assessments. Based on the findings of Zeithaml et al. (1991), we believe that expectations at the desired and adequate levels are relevant in quality assessments. The former level of expectations is based on how customers believe an 'ideal' product or service should perform, while the latter level of expectation is based on how 'bad' a product or service can perform, before it is considered to be inadequate.

Given these definitions, the following research questions were addressed in this study:

1. What technical and functional audit quality attributes are distinguished by clients and bankers and what is their relationship with and influence on overall audit quality assessments ${ }^{1}$ by these two groups?

2. What is the influence of audit engagement characteristics on technical audit quality perceptions of clients and bankers?

The first research question deals with the attributes of audit quality. Insight into these attributes and into their impact on overall audit quality is useful, since it helps decision-makers to identify service quality attributes and to assess their importance for overall service quality. The theoretical basis for the hypotheses concerning this research question was addressed in Chapter 3 , and our empirical findings were discussed in Chapter 6 . The second research question addresses the impact on technical audit quality of some characteristics of the relationship between the auditor and his client, such as audit firm size, client size, client's financial health, length of tenure and the provision of Management Advisory Services (MAS). Hypotheses regarding this research question were generated in Chapter 4 and the empirical results were addressed in Chapter 7 .

\footnotetext{
'The overall audit quality assessment and the underlying questions were answered for the auditor in his audit role. Thus the auditor's quality in other roles was not included in the quality assessment.
} 
Chapter 5 discussed the use, in this study, of a research instrument based on techniques used in marketing research - in particular, the SERVQUAL technique as described by Zeithaml et al. (1990). Both clients and bankers were asked to give (perception) ratings on the following subjects:

Overall audit quality;

Expectations (at desired and adequate levels) and performance regarding a wide range of functional audit quality attributes (such as 'having time for the client"s questions'); and

Expectations (at desired and adequate levels) and performance regarding a wide range of technical audit quality attributes (such as the detection and reporting of errors in the financial statements).

In addition to these ratings, clients and bankers were asked to give factual information on engagement characteristics.

Respondents were asked to rate the performance of auditors for engagements with which they were familiar. Clients were asked to rate the performance of their own auditor, while bankers were asked to rate the performance of the auditor of a randomly selected client. Because the goal was to compare the quality assessments of bankers and clients, it was essential to have engagements that were similar or at least comparable for both groups. In cooperation with the management of nation-wide operating banks, account managers were asked to randomly select clients from their portfolio which were audited by a Dutch Registered Accountant and where the bank was a major stakeholder. The bank sent the questionnaires to the account managers (bankers) and to the management of the audited companies (clients), for each of the selected engagements. In order to limit problems because of the sensitivity and confidentiality of the data that was requested (quality assessments, rating of financial position, fee data), the completed questionnaires were sent by the respondents to a notary's office that made the data anonymous. The rate of return was $48.1 \%$ for bankers and $35.7 \%$ for clients. Given the sensitivity of the data and the relatively long time that the completion of a questionnaire consumed, these rates were considered to be satisfactory.

\subsubsection{Descriptive results}

Before addressing the research questions in more detail, the scores on the statements about technical and functional audit quality in the questionnaire were calculated. Several findings emerged as a result of this first analysis (Chapter 5). First, both clients and bankers expressed fairly good overall 
ratings. On a 7-point Likert scale, overall audit quality was rated by clients and bankers, respectively, at 5.42 and 5.47 . However, although the overall ratings were quite good, it appeared that the perceived performance on individual (technical and functional) quality items was mostly below the desired and, for a considerable number of questions, even below the adequate expectation level. The finding that there are significant gaps between desired expectation and perceived performance levels, even though the overall quality level is quite high, is not uncommon and theoretically acceptable. However, the fact that respondents indicated that - on average - the adequate level is not met by perceived performance for individual items, but that overall performance is still quite good, warrants further research.

Second, the results indicated that bankers have higher expectations regarding technical audit quality attributes (independence and detection ability) than clients. For independence, this is in line with the analysis in Section 3.4 that clients might perceive 'independence in-fact' as awkward, since, as a consequence, auditors might reveal information to outside stakeholders (such as stockholders or bankers) that the client's management would rather have kept a secret. The lower expectations of clients regarding the detection of errors or irregularities might be explained by the fact that (1) bankers have to rely more heavily on the auditors for their information needs than clients and (2) clients are directly confronted with the trade-off between higher levels of audit quality and the associated audit costs.

Third, the expectation gaps were not wider for non-traditional ${ }^{2}$ auditor's duties (detection and reporting of fraud or illegal acts) than for traditional duties (detection and reporting of errors or smoothing in the financial statements, of going concern problems and of deficiencies in the internal organization). This finding is in contrast with most expectation gap studies, which indicated that the gaps were wider for the non-traditional duties. However, this might be explained by the fact that both clients and bankers belong to the group of well-informed and knowledgeable users of audit services. For this group, most expectation gap studies revealed only moderate gaps.

${ }^{2}$ See Chapter 3 for this classification. 
Finally, it is interesting to note the 'overperformance" on issues related to the appearance of auditors. For items included in this quality attribute - such as the building of the audit firm or the way its employees are dressed perception levels clearly exceed the desired levels. It is also interesting to note that the most significant underperformance for functional audit quality is on 'bill specification'. This had already been mentioned by both clients and bankers during the pretests of the research instrument.

\subsubsection{Methodology and results for research question 1: attributes of audit quality}

The next stage of the data analysis was a factor analysis to create combinations (factors) of the individual technical and functional statements. Factor analysis was performed on the individual statements for the following concepts (levels) of audit quality, for clients and bankers separately:

perceived performance;

perceived performance minus desired expectations (P-D); and

perceived performance minus adequate expectations ( $P$-A).

The factor structures that emerged from these analyses were compared with each other and with the generic SERVQUAL structure (claimed to be applicable to all types of service industries) suggested by Zeithaml et al. (1990). This comparison demonstrated that the factor structures found at the different levels of analysis do not fully correspond with the 'generic' structure. Several specific technical and functional factors emerged that are more or less unique to the auditing industry. Further, it is obvious that factor structures differ over the categories of respondents (in this study: clients and bankers). This comparison showed that clients distinguish between detection ability and (reporting) independence, while bankers combine these factors. This finding was expected, since clients were hypothesized to appreciate detection ability, while not appreciating independence, whereas bankers were hypothesized to appreciate both components of technical audit quality (see above).

At the final stage of the analysis for the first research question, the factors were used as independent variables and regressed on overall audit quality. The regression models that resulted from these analyses were compared. Differences between bankers and clients and between the different concepts of audit quality were analyzed and were used to test hypotheses on the importance of several technical and functional audit quality aspects for overall audit quality judgments. 
Table 8.1 summarizes the technical and functional factors ${ }^{3}$ that were found to be significant for the determination of overall audit quality. ${ }^{4}$ The table contains 6 factor structures, representing the three conceptualizations of audit quality, for clients and bankers separately.

\begin{tabular}{|c|c|c|c|c|c|c|}
\hline Audit quality concept: & \multicolumn{2}{|c|}{ Performance } & \multicolumn{2}{|c|}{$\begin{array}{l}\text { Performanee } \\
\text { ninus desined } \\
(\mathrm{P}-\mathrm{D})\end{array}$} & \multicolumn{2}{|c|}{$\begin{array}{l}\text { Performance } \\
\text { nulimus } \\
\text { adequate } \\
(\mathbf{P} \mathbf{A})\end{array}$} \\
\hline Clients/Bankers: & $c$ & B & c & B & c & $\mathbf{B}$ \\
\hline \multicolumn{7}{|c|}{ FUNCTIONAL FACTORS (included as variables in regression) } \\
\hline Erapathy & * & & & & & \\
\hline Reliability & & * & & & & \\
\hline Responsiveness & & & ***** & & & \\
\hline Partmer in Business & $* * * *$ & & & $* * *$ & $* *$ & $* *$ \\
\hline Appearance & & $* * *$ & & & & \\
\hline Communication & * & & & & & *** \\
\hline Accessibility & & * & & & **a* & \\
\hline \multicolumn{7}{|c|}{ TECHNICAL FACTORS (included as variables in regression) } \\
\hline Traditional Audit function & & 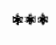 & & $* * *$ & & *** \\
\hline Detection ability & $* * *$ & & & & ****** & \\
\hline Whistle blowing & & $* * * *$ & & & & * \\
\hline
\end{tabular}

Table 8.1 Significance of audit quality attributes for overall audit quality

$* \quad=\quad$ significant at $\mathrm{p}=0.10$
$* * \quad=\quad$ significant at $\mathrm{p}=0.05$
$* * * \quad=\quad$ significant at $\mathrm{p}=0.01$

${ }^{3}$ In order to facilitate interpretation of this table, the 'mixed' factors are not included (see Chapter 6).

"Factors with a low Cronbach Alpha value have been eliminated from this table, given the low degree of reliability of these variables (see Chapter 6). 
From these analyses, the following findings resulted:

Clients base their overall audit quality assessments on professional (detection ability; partner in business) and communication (communication; responsiveness; accessibility) skills. The auditor should not only be able to find errors or irregularities, he should also identify opportunities and risks for his client in a broad range of areas. Just doing the audit, without proper reflection on issues such as tax, internal organization and accounting information systems, corporate finance or general management, is not enough. In addition, the auditor should be 'a great communicator', listening carefully to his client's needs, frequently discussing his findings with management and being available when needed. Finally, clients (the management of the audited companies) do not seem to appreciate auditor independence. No significant positive relationship was found between independence and clients' overall audit quality assessments, so independence is not included in Table 8.1. In some analyses, negative relationships were found, although these were not quite statistically significant. Thus the analysis in Section 3.4 that clients might appreciate an independent appearance, while not appreciating independence in fact, may hold.

Bankers base their overall audit quality assessments on professional (traditional audit function, ${ }^{5}$ whistle blowing, partner in business) and communication (communication, accessibility) skills, and on 'appearance'. As for the professional and communication skills, there is quite some overlap with the quality assessments by clients. Again, the auditor should not just find errors or irregularities, but should also advise the client on a range of issues. The auditor's technical performance on "traditional" duties was seen as more important than his performance on 'whistle-blowing' issues such as the detection and reporting of fraud and illegal acts. The major differences with the assessment of clients are:

1. The positive relationship between auditor independence and overall audit quality, both for traditional and non-traditional ('whistle-blowing') duties. This was expected, since detection ability is only valuable to outsider stakeholders if the errors or irregularities are reported when they are found; and

${ }^{5}$ Traditional audit function includes both the detection ability and independence regarding the auditor's "traditional" duties. 
2. The importance of the 'appearance' factor. Presumably the rather 'superficial' and 'low intensity' type of contact that bankers have with auditors leads them to highly value 'the first impression'.

A comparison of the $R^{2}$ of the regression functions for the three different quality concepts ('levels') provides insight into the usefulness of these concepts. ${ }^{6}$ As reported in previous studies (see Section 2.6), the $\mathrm{R}^{2}$ at the performance level is better than at the P-D level. This is very clearly the case for bankers. For them, the 'fit' between the individual statements and overall audit quality assessments is best for performance, then for P-D and clearly the worst for the P-A concept of audit quality. Bankers seem to relate their quality assessments purely on perceived performance, instead of correcting this performance for their desired or adequate expectations. With regard to 'adequate expectations', this might be explained by the fact that bankers are not actively involved in the 'hiring' of an auditor and therefore only 'enjoy' the benefits of the audit service while not directly experiencing the 'sacrifices'. For clients, the P-A level clearly has the best $\mathrm{R}^{2}$ level, followed by 'performance' and finally by P-D. This shows that, for clients, the adequate level is seen as a very important yardstick. Perhaps clients perceive the audit as something that is 'imposed' on them by their 'principals' (or by law) and therefore compare the audit service performance with what they consider to be just acceptable. However more research regarding the nature of service expectations and their impact on quality assessments is necessary to draw stronger conclusions in this matter. Nonetheless, the value of incorporating adequate level expectations in quality assessment studies has been emphasized by this study.

\subsubsection{Methodology and results for research question 2: influence of audit engagement characteristics}

In order to answer the second research question, the engagement characteristics were regressed as independent variables on the technical audit quality questions and factors. In this way, we tested for the effect on

${ }^{6} \mathrm{R}^{2}$ is the proportion of the sample variability of the dependent variable that can be explained by its linear relationship with the independent variable (Newbold, 1984). 
detection ability and auditor independence of the following engagement characteristics: ${ }^{7}$
Audit firm size;
Client size;
Client's financial health;
Length of tenure; and
Provision of MAS by incumbent auditor.

Audit firm size was generally not seen as an important determinant of technical audit quality, for either detection ability or auditor independence. The only effect found was the perception of clients that Big Six auditors are better able to detect 'smoothing' and illegal acts and to detect and report deficiencies in the internal organization. ${ }^{8}$ Further, no significant size effect could be found, for either the clients or the bankers sample. This is in contrast with most of the existing audit research findings in this area. The methodology used in this study, which tests quality perceptions using actual engagements, might explain this result. Further research of this type should be done in order to validate our results. In this regard, the results of this study are in line with the findings of Schilder (1994), who interviewed several representatives of the financial community on the subject of auditor independence. He also concluded that audit firm size is irrelevant for perceptions of auditor independence.

Client size was seen as a very relevant negative ${ }^{9}$ determinant of technical audit quality by bankers: the larger the client, the lower the banker-perceived technical audit quality. Obviously, bankers conclude that the complex internal organization and accounting information systems of large clients result in lower 'added value' of the auditor in the detection of errors or irregularities. Moreover, bankers obviously believe that large clients are more important to the auditor (in terms of audit fees or prestige) and are therefore better able to

"The relevance of each of these engagement characteristics was hypothesized, based on agency theory and on De Angelo*s (1981a) analysis of quasi-rents (see Section 4.1). Relationship marketing (see, e.g., Gummesson, 1987) suggests the relevance of other engagement characteristics for service quality perceptions.

sthe occurrence of a significant relationship on some individual items will be referred to as an incidental effect in the remainder of this chapter.

This type of relationship will be called 'systematic", since the influence of the engagement characteristics is significant for nearly all technical audit quality statements and factors. 
impair auditor independence. This very significant impact of client size on technical audit quality in the perception of bankers is remarkable, especially since this variable has hardly been tested in previous audit research. Clients perceived no systematic relationship between their size and technical audit quality for the traditional duties of the auditor. However, they do seem to believe that larger clients are better able to keep the auditor from 'blowing the whistle' regarding non-traditional duties.

Client's financial health was seen as a very significant determinant of both technical and overall audit quality by bankers. The better the client's financial position, the better the quality of the auditor, they seem to believe. Three potential explanations were given for this finding. First, bankers might believe that a client who is in a bad financial condition might more effectively and more firmly threaten the auditor with the termination of the engagement: the possibility of an auditor-auditee conflict might be larger under these circumstances. Second, bankers might believe that an auditor is partially responsible if a client is confronted with financial distress. This would imply that bankers believe the auditor has not done enough to either warn the client about the impending problems or has been insufficiently energetic in suggesting ways to change the course of affairs. This overall dissatisfaction with the auditor"s performance might then also be reflected in the assessment of the auditor's technical quality. Finally, in discussing this result with practitioners and researchers, a very opportunistic reason for this relationship was suggested. One might argue that, in the light of an impending financial crisis, bankers might already be looking for a 'scapegoat', for someone they can blame for the financial loss they are anticipating. Under these circumstances, bankers might be inclined to hold the auditor responsible for failing to warn the banker in time to safeguard his financial interests. Validation of this potential explanation will require further (behavioral) research.

For clients, their financial health did not have any convincing influence on (perceived) technical audit quality.

Length of tenure was generally not seen as an important determinant of technical audit quality. The only significant finding was the clients' perception that the auditor's ability to find deficiencies in the internal organization erodes over time. Perhaps the lack of a systematic relationship with technical audit quality was due to our methodology, which tests perceptions of audit quality using actual engagements. Due to the limitations in the research designs of some previous audit research in this area, the external validity of their findings might be disputable. 
The provision of MAS hardly seems to bother either bankers or clients. No significant relationship was found with the perception of technical audit quality, which was hardly surprising, given the inconclusiveness of the extensive empirical research in this area. Perhaps the very mixed nature of MAS makes it difficult to test its overall effect on technical audit quality. Further research should be done to test whether different types of MAS have different effects on perceived technical audit quality.

The findings regarding the second research question are summarized in Figure 8.1 .

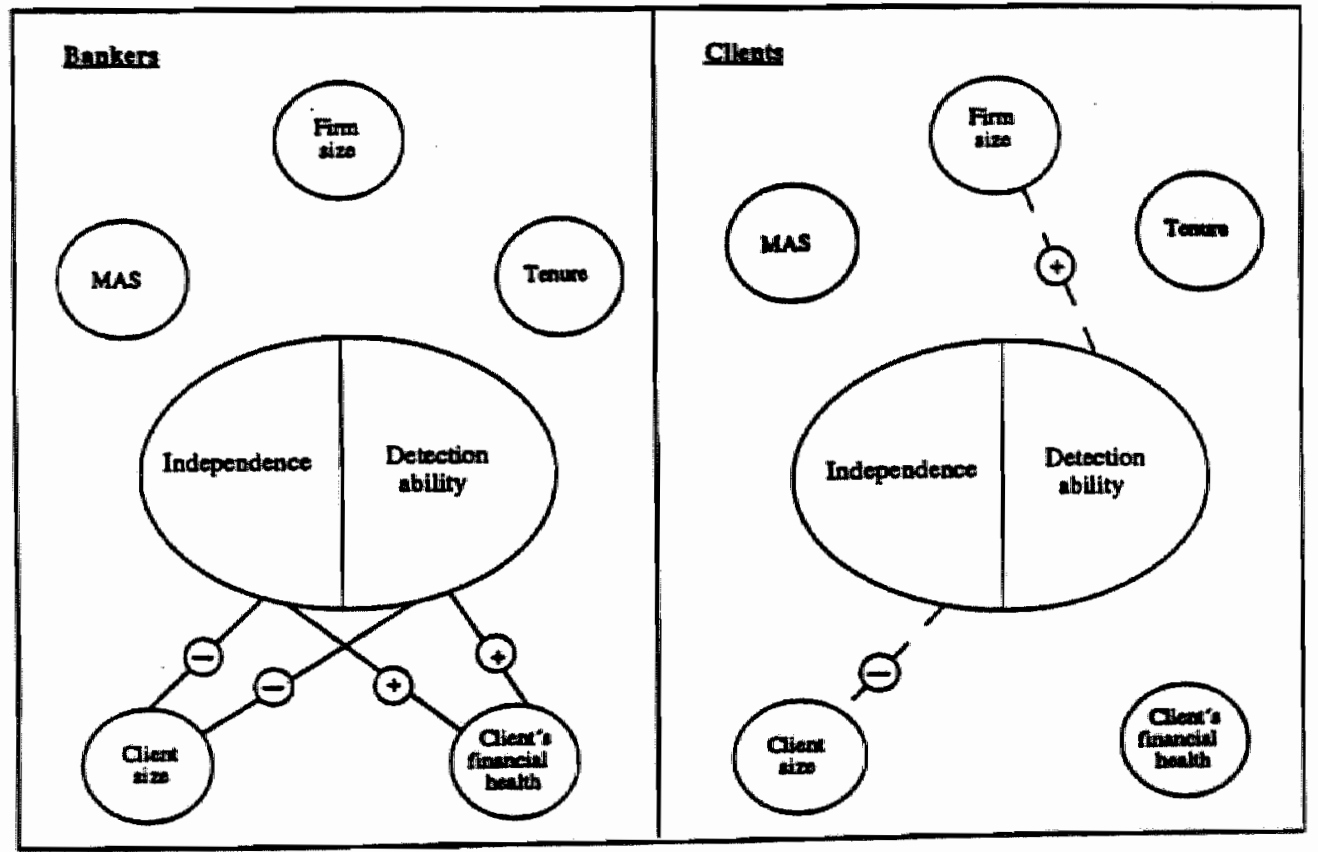

Figure 8.1 The impact of engagement characteristics on technical audit quality
$+$
$=$ systematic positive impact of audit engagement characteristic on technical audit quality attribute.
$\Theta-$ = systematic negative impact of audit engagement characteristic on technical audit quality attribute.
$\odot \ldots \ldots=$ incidental positive impact of audit engagement characteristic on technical audit quality attribute. technical audit quality attribute.
$=$ incidental negative impact of audit engagement characteristic on 
Figure 8.1 shows that bankers' perceptions of the determinants of overall audit quality are - to some degree - in line with the implications of agency theory. In the perception of bankers, client size is negatively related to independence, and client's financial health is positively related to independence. For detection ability, similar patterns were observed. Clients do not seem to base their perceptions on agency-related considerations. Although several incidental relationships were found between audit engagement characteristics and technical audit quality, notably between firm size and detection ability, this relationship was not considered to be systematic.

\subsection{Limitations of the study}

Several limitations of this study have already been discussed in previous chapters. Chapter 5 discussed the method of data collection which was used. Although this method made it possible to achieve acceptable rates of return, given the sensitive and confidential nature of the questions, some limitations are inherent to this method:

The number of questionnaires was limited, since the cooperating banks had considerable difficulty in finding enough clients meeting the strict criteria imposed. Even though tests confirmed the stability of the factor structures and empirical evidence exists for the appropriateness of samples exceeding a number of fifty for factor analysis (Molz, 1988), larger samples might have increased the study's reliability and validity; As illustrated by the descriptive results of the engagement characteristics, the samples did not include companies with an annual turnover exceeding one billion Dutch Guilders. Further, the samples only included a limited number of very small companies ${ }^{10}$, given our requirement that the auditor should issue an auditor's report for the client (which is not normally done for very small clients in the Netherlands). It is conceivable that the inclusion of such companies perhaps with entirely different expectations and perceptions of performance - would have changed the findings; and Since random selection of audit engagements meeting the criteria proved to be technically impossible, account managers were explicitly instructed to randomly select engagements meeting the established

\footnotetext{
${ }^{10}$ About $10 \%$ of the sample consisted of engagements with client sales below 5 million Guilders.
} 
criteria from their portfollio. As a result, the researchers had no direct control over the selection of audit engagements. However, the prime purpose of this study was not to obtain insight into the level of perceived performance, expectations and quality in the Dutch audit market, but to test the relationships between levels of quality, and between levels of quality and engagement characteristics. There is a risk, however, that account managers selected engagements in which they were familiar with the auditors and better able to answer the various questions, which might have led to a bias in the responses.

Further, several limitations are inherent in the research methodology:

The proper conceptualization of (service) quality is still under debate, notably in marketing research. In particular, the role of expectations in quality assessments is still the subject of ongoing research. Although several conceptualizations of audit quality were tested, the use of these specific constructs is debatable. In this regard, the $\mathbf{R}^{2}$ values are encouraging, but obviously leave room for further improvements. In particular, the conceptualization of the adequate level of expectations in this study - and hence: of the zone of tolerance - is debatable. More research is needed in order to test the appropriateness of the conceptualization used in this study (see Parasuraman et al., 1994b); and

The use of factor analysis introduces some degree of subjectivity in the research process. Although every effort was made to minimize this effect, subjectivity could not be eliminated.

\subsection{Topics for further research}

Several topics for further research have already been identified in previous chapters. First, the debate in the marketing literature about the proper conceptualization of service quality has not yet ended. The findings show that expectations, at both desired and adequate level, should be included in quality assessments. But since we cannot explain all the differences between the factor structures identified for the various concepts of audit quality, further research in this area appears necessary.

As was concluded earlier in this chapter, the SERVQUAL questionnaire provides a good basis for tests of audit quality. The refinements made to the questionnaire may have enhanced its applicability to audit quality. 
However, further refinement of the questionnaire used here might enhance the explanation of overall audit quality.

Tests for the impact of engagement characteristics on technical audit quality produced findings which were, in some cases, different from those of previous studies. This might result from our methodology, which measured quality perceptions using actual engagements. Modifications to the empirical method could include (1) the extension of the sample (see limitations), (2) the inclusion of user groups other than clients and bankers, such as stockholders or employees and (3) the inclusion of other engagement characteristics. This study used only characteristics derived from DeAngelo's paradigm of quasirents. However, a number of other engagement characteristics might be related to technical audit quality. For example, the possible effect of the client's growth rate was not considered. One might hypothesize that a high growth rate might lead to rapid changes in activities, internal organization and internal control. It would be interesting to test whether respondents believe that an auditor is able to properly reflect these changes in his audit. ${ }^{11}$

Finally, future research should distinguish between several types of MAS, to see whether specific forms of MAS are perceived to influence either detection ability or independence. This study did not identify MAS as a significant determinant of audit quality, probably because of the multidimensionality of MAS.

In previous chapters, some remarks have been made about the importance of audit quality. Although some research findings could be presented in this area, there is still no solid theoretical framework concerning the relationships between technical, functional and overall audit quality as perceived by different categories of respondents on the one hand and purchase intentions/decisions on the other. Again, these types of relationships have received some attention in the current marketing literature. However, specific research in this area in the audit market is very scarce.

\footnotetext{
"This is just one example of an engagement characteristic that might have additional importance for the determination of audit quality (at least in the perception of bankers). Several other potentially significant engagement characteristics might be hypothesized.
} 


\subsection{Theoretical implications}

Several theoretical implications follow from this study. First, it seems that the SERVQUAL technique is a useful basis for the assessment of audit quality. An attempt has been made to design an instrument that is better suited to the particular characteristics of the audit market. Although the results obtained are satisfactory (in terms of providing insight into the determinants and components of audit quality), further refinement of the instrument might enhance its capacity to explain overall audit quality. In particular, a process of adding and deleting new statements, based on discussions with the users of audit services, might result in an increase in the $\mathrm{R}^{2}$ value of the regression model which explains variations in overall audit quality. Use of the instrument on a systematic and longitudinal basis might provide insight into changes in the various user groups' expectations and perceptions of performance regarding (components of) the audit service.

With regard to the inclusion of expectations in service quality studies, this study has produced several findings. Although expectations were not significant for all quality attributes, they proved to be very significant for some. More knowledge about the nature and importance of expectations might be very important for the closing of quality gaps. Further, expectations should not be measured only at the desired level, but also at the adequate level. In this study, the adequate level provided the best 'fit' (expressed by $\mathrm{R}^{2}$ ) between the individual audit quality items and overall audit quality assessments by clients. This concept should be further explored and tested.

Expectation gap researchers can learn from SERVQUAL and the current discussion in the field of marketing research about the nature and importance of different types of expectations. They should be aware of the different types of expectations that have been identified. If questions regarding expectations are formulated as 'ideal' type expectations, it is not surprising, and certainly not alarming, that gaps are found, since most quality studies have found that perceived performance does not reach the very high desired/ideal expectation level. Moreover, the importance of the various gaps for the overall quality or 'image' of the auditor/audit profession might be very different. Although expectation gap studies sometimes show alarming gaps, the overall importance of these might be limited.

Several of the findings with regard to the importance of engagement characteristics were not in line with previous findings. However, this study differs from most other perception studies in that it tests these relationships 
based on actual cases. In conventional studies, respondents are confronted with hypothetical cases, in which the engagement characteristics are included in the questionnaire as experimental variables. There is a risk that these variables are interpreted by respondents as 'red flags', influencing the directionality of their answers. ${ }^{12}$ This risk has been eliminated in this study. More research of this type is necessary to validate the general applicability of our findings. The importance of client size and the client's financial health in the bankers' assessments of technical audit quality is noteworthy. In most research on engagement characteristics, these variables are not included. Future inclusion of these variables in this type of research is recommended.

\subsection{Practical implications}

This study is a contribution to a better understanding of the complicated issue of audit quality perceptions. The application of SERVQUAL-related techniques in the audit industry is quite new and provides insight into the importance of the various elements of the 'audit service' as perceived by the users of these services. The findings of this study have a variety of practical implications for audit practitioners, standard-setters and professional bodies, and the educators of auditing students. These implications will be discussed in turn.

\section{Audit practitioners}

It might well be rewarding for audit practitioners to conduct this type of study regarding their own clients, to discover what types of service quality gaps exist. For instance, this study indicates significant substandard performance for 'specification of bills', while significant overperformance was measured in this study for items related to 'appearance'. This 'appearance' factor consists of items like the building of the audit firm or the way its employees are dressed. Although appearance obviously impresses bankers - perhaps as a result of the rather low-intensity relationship between bankers and auditors - it is very likely from our findings that an appreciable number of clients find the auditor's overperformance in this area unpleasant. It is also interesting to measure expectations (in this study, different types of expectations) in addition to perceived performance. Although they are not

\footnotetext{
${ }^{12}$ This nisk is acknowledged by Shockley $(1981$, p. 296): 'Subjects may not respond in an experimental setting in the same fashion as in more realistic contexts.'
} 
significant for all aspects of the audit service, expectations do seem to play an important role in quality assessment on several aspects. For these aspects, audit firms can influence quality assessments not only by changing their performance, but also by changing the expectations at either the desired or adequate level. The ongoing discussion in the marketing literature on the importance of expectations for quality assessments may well provide insight into how expectations can be influenced.

It is remarkable to see that the technical audit quality judgment of account managers of banks depends so much upon client characteristics, in particular client size and - even more important - the client's financial health. The latter factor is significant not only for technical audit quality, but even for overall audit quality. Several potential explanations have been given for this phenomenon. This finding should motivate auditors to involve bankers more directly - of course with the permission of the client - in cases where the client is in financial distress, in order to explain the auditor's position more clearly and to avoid conflicts over the auditor's role. Moreover, the auditor is warned to do a particularly good job under these circumstances. In addition to the increased likelihood of being sued if a client goes bankrupt (where the auditor is perceived to have 'deep pockets' - to be able to compensate such losses), the banker's inclination to hold the auditor responsible for corporate failure also increases, given their perception of decreasing technical audit quality. Finally, this finding implies that the auditor should be careful in the acceptance and continuation of certain engagements. Serving clients that are in a bad financial condition might both negatively affect the auditor's image and result in a higher risk of litigation, given the perception of bad technical audit quality.

Auditors are not supposed to 'just' perform the audit. Both bankers and clients expect the auditor to give some added value, by making a diagnosis of the audited company in terms of risks and opportunities in various areas. Although this finding is - or should be - common knowledge for most audit practitioners, it may still be that most 'audit budgets' are consumed by 'basic' audit activities, before the auditor is able to make a good analysis of the risks and opportunities the audited company might envisage. Risk analysis - which is an explicit or implicit part of each audit - should be designed to identify the risks and opportunities in the areas discussed and should be carried out at a relatively high level within the audit firm. The outcomes of this analysis should be interpreted by the audit manager or partner, in order to identify points of interest to the client. As far as bankers are concerned, auditors should not worry about a potential negative impact on perceived 
independence as a result of their MAS. On the contrary, bankers expect the auditor to give advice in these areas.

Finally, in addition to their professional skills, audit practitioners should possess good communication skills, in the eyes of both bankers and clients. Listening to the client's needs, discussing findings and being available are crucial elements of the audit service. In the human resource management of audit firms, both professional and communication skills should be considered.

$\underline{\text { Standard setters and professional bodies }}$

To standard setters, this type of research might be relevant by providing evidence about the perceptions of the financial community. In order to draw generally applicable conclusions, this study should be widened to include other user groups of audit services, such as stockholders and employees. Nonetheless, some provisional implications can be derived from this study.

First, it seems that the 'traditional' audit function is only a part of what the financial community would like the auditor to do. As reported in Chapter 3, Hooton and Landsittel (1991, p. 11) expressed their concern that the audit should not just be directed at reporting 'on results - that is, a snapshot of an enterprise's financial position at a given moment in time and the results of its efforts for an elapsed period, but on the processes that generated these results and the financial presentation of them.' Similar views are expressed by the COSO and Cadbury reports, briefly discussed in Chapter 3. If, as we concluded, anditors should be taking this role of identification of risks and opportunities more seriously, then perhaps standard setters and professional bodies should also pay more attention to the development of these duties. This might better satisfy the desires of the users of audit services than the present focus of some professional bodies and standard setters on closing expectation gaps on issues such as fraud or illegal acts. The findings demonstrate that (1) these expectation gaps are smaller than for the traditional duties $^{13}$ and (2) gaps on these duties are less important in the assessment of overall audit quality than gaps on traditional duties or advisory activities.

${ }^{13}$ This finding is in contrast with most expectation gap studies. 
Second, standard setters and professional bodies should be concerned about the identification of the auditor's quality with the client's financial position. As discussed in Chapter 3, the public image of the auditing profession is sometimes damaged by cases in which an auditor has given an unqualified opinion shortly before the audited company goes bankrupt. However, the findings suggest that the image of the auditor concerned has been harmed even before this situation comes to a head, simply because the company's financial position is bad. It seems that further clarification is needed of the responsibilities of management and auditor for the assessment of the ability of a company to continue as a going concern. Perhaps the recent UK regulations in this regard (see the Cadbury report: Committee on the Financial Aspects of Corporate Governance, 1992) will be successful in reducing the 'going concern' expectation gap.

Third, standard setters and professional bodies should pay attention to the low degree of perceived technical audit quality for large clients. Obviously, bankers believe that the likelihood of an auditor finding an error or irregularity in a large company is low. Professional bodies might consider assessing whether this perception is a proper reflection of the actual audit quality or merely a perception without justification in practice. If this assessment shows serious quality gaps for large clients, special guidelines or quality control measures (such as peer review) might be considered for this type of clients. The finding that large auditees are better able to impair auditor independence should motivate standard setters and professional bodies to (1) limit the (financial) importance of one client in an auditor's portfolio, in order to reduce the auditor's dependence upon the fee of a single client and (2) consider issuing special guidelines or quality control measures (such as peer review) for large clients.

Finally, it seems that the respondents were hardly bothered by the 'MAS' and 'tenure' issues, which have motivated regulators in several countries to define specific limitations for auditors in this regard. For MAS, the results showed that bankers see the auditor's advisory services (as included in 'partner in business') as an explicit positive component of overall audit quality. However only two user groups were selected for this study. It is not unlikely that other user groups have different idleas about these issues. In order to determine whether these issues require any further attention of regulators, this type of research should be widened to include these other user groups. Professional bodies and regulators should stimulate this type of research, because it might show the areas in which expectations and performance should be changed in order to reduce 'expectation gaps'. 


\section{Educators}

Most of the implications for audit practitioners and standard setters also apply to educators. Any major change in the audit profession should be reflected in auditing education, since it is here that the professional attitudes of future generations of auditors are shaped. Therefore we believe that audit education should pay more attention to:

Communication skills;

Detection of potential risks and opportunities for the client in areas such as tax, corporate finance, internal organization and information systems;

Behaviour when the client is in a bad financial position;

Adequate use of audit techniques and attitude in auditing large clients. In short, audit education should include more than just lectures on audit theory and the training of professional skills. Given the expectations and quality assessments of the users of audit services, audit education should pay more attention to attitude training and to a wider variety of advisory topics, so helping the 'young' auditor to become a professional partner in business. The forthcoming Dutch requirement of a 3-year apprenticeship before admission as a fully qualified Registered Accountant should provide opportunity for this type of training. 


\section{APPENDIX 1 SERVQUAL QUESTIONNAIRE (PERCEIVED PERFORMANCE LEVEL)}

\section{Tangibles}

P1 XYZ has modern-looking equipment.

P2 XYZ's physical facilities are visually appealing.

P3 XYZ's employees appear neat.

P4 Materials associated with the service are visually appealing at XYZ.

\section{Reliability}

P5 When $X Y Z$ promises to do something by a certain time, it does so.

P6 When you have a problem, $X Y Z$ shows a sincere interest in solving it.

P7 $X Y Z$ performs the service right the first time.

P8 $\quad X Y Z$ provides its services at the time it has promised.

P9 XYZ insists on error-free records.

\section{Responsiveness}

P10 Employees in XYZ tell you exactly when services will be performed.

P11 Employees in XYZ give you prompt service.

P12 Employees in XYZ are always willing to help you.

P13 Employees in XYZ are never too busy to respond to your requests promptly.

\section{Assurance}

P14 The behaviour of employees in XYZ instills confidence in you.

Pl5 You feel safe in your transactions with $X Y Z$.

P16 Employees in $\mathrm{XYZ}$ are consistently courteous with you.

P17 Employees in XYZ have the knowledge to answer your questions.

\section{Empathy}

P18 XYZ gives you individual attention.

P19 XYZ has operating hours convenient to all of its customers.

P20 XYZ has employees who give you personal attention.

P21 $X Y Z$ has your best interesits at heart.

P22 Employees of $X Y Z$ understand your specific needs. 



\section{REFERENCES}

Abdel-Khalik, RA., Solomon, 1. Research Opportunities in Auditing: The Second Decade, American Accounting Association, Sarasota, 1988

American Institute of Certified Public Accountants, Auditing Standards Board, Statement on Auditing Standards No. 53, The Auditor"s Responsibility to Detect and Report Errors and Irregularities, AICPA, New York, 1988a

American Institute of Certified Public Accountants, Auditing Standards Board, Statement on Auditing Standards No. 54, Illegal Acts by Clients, AICPA, New York, $1988 \mathrm{~b}$

American Institute of Certified Public Accountants, Auditing Standards Board, Statement on Auditing Standiards. No. 59. The Auditor's Consideration of an Entity's Ability to Continue as a Going Concern, AICPA, New York, 1988c

American Institute of Certified Public Accountants, Statement on Quality Control Standards 1, AICPA, New York, 1991

Anderson, T., Zéghal, D., The Pricing of Audit Services: Further Evidence from the Canadian Market, Accounting and Business Research, 1994

Andersson, T.D., Another Model of Service Quality: A Model of Causes and Effects of Service Quality Tested on a Case Study within the Restaurant Industry, in: Quality Management in Services, Kunst, P.E.J., Lemmink, J.G.A.M. (eds), Van Gorcum, Assen/Maastricht, 1992

Arens, A.A. Laebbecke, J.K., Auditing, an Integrated Approach, 4th edition, Prentice-Hall International Inc., Englewood Cliffs, 1988

Arrington, C.E., Hillison, W.A., Williams, P.F." The Psychology of Expectations Gaps: Why Is There So Much Dispute About Auditor Responsibility?, Accounting and Business Research, Autumn 1983

Backhaus, K., Erichson, B., Plinke, W., Weiber, R., Multivariate Analysemethoden: Eine Anwendungsorientierte Einfuhnung, 7. Auflage, Springer Lehrbuch. 1994

Barkess, L., Simnett, R., The Provision of Other Services by Auditors: Independence and Pricing Issues, Accounting, and Business Research, 1994 
Bartlett, R.W., A Heretical Challenge to the Incantations of Audit Independence, Accounting Horizons, March 1991

Beck, P.J., Frecka, T.J., Solomon, I. An Empirical Analysis of the Relationship Between MAS Involvement and Auditor Tenure: Implications for Auditor Independence, Journal of Accounting Literature, 1988

Benstion, G.J., The Market for Public Accounting Services: Demand, Supply and Regulation, Journal of Accounting and Public Policy, 1985

Berendsen, J.G., Maatschappii, Ondememing en Accountant, sen Onderzoek naar Ontwikkelingen in de Maratschappelijke Positie van de Openbare Accountant in de Jaren na 1945, VU Uitgeverij, Amsterdam, 1990

Bloemer, J., Lemmink, J.G.A.M., Diagnostic Value of In-Company Evaluations of Customers' Perceived Service Quality, unpublished paper, University of Limburg, Maastricht 1991

Bolton, R.N., Drew, J.H., A Multistage Model of Customers' Assessments of Service Quality and Value, Joumal of Consumer Research, March 1991

Boomsma, S., Borrendam, van, A.., Kwaliteit in Diensten, Kluwer, Deventer, 1987

Bos, H.H., Weegmeesters in de Taaltuin, Beeldworming van de Accountant in de Nederlandse Lituratuur, Eburon, Delft, 1989

Boulding, W. Kalra, A., Staelin, R., Zeithaml, V.A., A Dynamic Process Model of Service Quality: From Expectations to Behavioral Intentions, Journal of Marketing Research, February 1993

Boyd, H.W., Westfall, R., Stasch, S.F., Marketing Research: Text and Cases, 6th edition, Irwin, Homewood, 1985

Brandt, D. $R_{m}$ A Procedure for Identifying Value-enhancing Service Components Using Customer Satisfaction Survey Data, in: C. Surprenant (ed.), Add Value to your Service, Proceedings Series, American Marketing Association, Chicago, 1987 
Brouwer, M., Reuyl, J.C.n Service Quality Perceptions: Differences Between Consumers, Managers and Contact Personnel, an Empirical Study in the Retail Banking Sector, paper presented at the 21 st Annual Conference of the European Marketing Academy, Aarhus, Denmark, 1992.

Brown, S.W., Swartz, T.A., A Gap Anallysis of Professional Service Quality, Joumal of Marketing, April 1989

Canadian Institute of Chartered Accountants, Macdonald Commission, Report of the Commission to Study the Public's Expectations of Audits, CICA, Toronto, 1988

Carcello, J.V., Hermanson R.H., MoGrath, N.T., Audit Quality Attributes: The Perceptions of Audit Partners, Preparers, and Financial Statement Users, Auditing: A Journal of Practice and Theory, Spring 1992

Carman, J.M., Consumer Perceptions of Service Quality: An Assessment of the Servqual Dimensions, Joumal of Retailing, Spring 1990

CBS, 95 Jaren Statistiek In Tijdreeksen 1899-1994, SDU Uitgeverij, Den Haag, 1994

Chow, C., Rice, S., Qualified Audit Opinions and Auditor Switching, The Accounting Review, April 1982

Commission on Auditor's Responsibillities, Cohen Commission, Report, Conclusions and Recommendations, New York, AICPA, 1978

Committee on the Financial Aspects of Corporate Governance, Report of the Committee on the Financial Aspects of Corporate Governance (Cadbury Report), London, 1992.

Committee of Sponsoring Organisations of the Treadway Commission, Internal Control, Integrated Framework (COSO Report), New York, 1992

Copley, P.A., Doucet, M.S., The Impact of Competition on the Quality of Governmental Audits." Auditing: A Journal of Practice and Theory, Spring 1993a

Copley, P.A.. Doucet, M.S., Auditor Tenure, Fixed Fee Contracts, and the Supply of Substandard Single Audits, Public Budgeting and. Finance, Fall 1993b 
Craswell. A.T., Francis, J.R., Taylor, S.L., The Audit Market and Evidence of Auditor Brand Name Reputations and Industry Specializations, unpublished paper, Uniwersity of Sydney, January 1994

Cronin, J.J., Taylor, S.A., Measuring Service Quality: A Reexamination and Extension, Joumal of Marketing, July 1992

Cronin, J.J., Taylor, S.A., SER VPERF Versus SERVQUAL: Reconciling Performance-Based and Perception-Minus-Expectations Measurement of Service Quality, Journal of Marketing, January 1994

Crosby, P.B., Quality is Free, McGraw-Hill Inc., New York, 1979

Darby, M.R., Karni, E., Free Competition and the Optimal Amount of Fraud, Journal of Law and Economics, April 1973

Dart, J., Freeman, K., Dissatisfaction Response Styles Among Clients of Professional Accounting Firms, Joumal of Business Research, 1994

Dassen, R.J.M., Leer van het Gewekte Vertrouwen: Agency Avant-la-lettre?, Maandblad voor Accountancy en Bedrijfseconomie, September 1989

Davidson, R.A., Neu, D., A Note on the Association Between Audit Firm Size and Audit Quality, Contemporary Accounting Research, Spring 1993

Davis, K., The Case For and Against Business Assumption of Social Responsibilities, Academy of Management Joumal, 1973

Dawis, L.R., Ricchiute, D.N., Trompeter, G., Audit Effort, Audit Fees, and the Provision of Nonaudit Services to Audit Clients, The Accounting Review, January 1993

DeAngelo, L.E., Auditor Independence, 'Low Balling', And Disclosure Regulation, Journal of Accounting and Economics, August 1981 a

DeAngelo, L.E., Auditor Size and Audit Quality, Journal of Accounting and Economics,

December 1981b 
DeAngelo, L.E., Mandated Successful Efforts and Auditor Choice, Iloumal of Accounting and Economics, 1982

DeFond, M.L., The Association between Changes in Client Firm Agency Costs and Auditor Switching, Auditing: A Journal of Practice and Theory, Spring 1992

Deis, D.R., Jr., Giroux, G.A., Determinants of Audit Quality in the Public Sector, The Accounting Review, July 1992

DiPrivio, A., Quality Assurance in Service Organizations, Chilton Book Company, Radnor, 1987

Dopuch, N., Simunic, D., Competition in Auditing: An Assessment, paper presented at Symposium on Auditing Research IV, University of Illinois, Urbana-Champaign, 1982

Eichenseher, J.W., Market Reactions to Auditor Changes by OTC Companies, Auditing: A Journal of Practice and Theory, Fall 1989

Evers, C.J., Pearson, D.B., Lessons Learned from Peer Review, Journal of Accountancy, April 1989.

Farmer, T.A., Rittenberg L.E., Trompeter, G.M., An Investigation of the Impact of Economic and Organizational Factors on Auditor Independence, Auditing: A Journal of Practice and Theory, Fall 1987

Firth, M., Auditor-Client Relationships and Their Impact on Bankers' Perceived Lending Decisions, Accounting and Business Research, Summer 1981

Firth, M., Auditor Reputation: The Impact of Critical Reports Issued by Government Inspectors, RAND Journal of Economics, Autumn 1990

Flint, D., Philosophy and Principles of Auditing, Macmillan Education Lid., Hampshire, 1988

Francis, J.R., Simon, D.T., A Test of Audit Pricing in the Small-Client Segment of the U.S. Market, The Accoumting Review, January 1987

Galbraith, J.K., The New Industrial State, 4th edition, Penguin Books, New York, 1986 
Garvin, D.A., What Does "Product Quality" Really Mean?, Sloan Management Review, Fall 1984

Green, P.E., Tull, D.S., Albaum, G., Research for Marketing Decisions, 5th edition, Prentice Hall International Editions; 1988

Grönroos, C., A Service Quality Model and its Marketing Implications, European Journal of Marketing, 1984

Grónroos, C., Relationship Approach to Marketing in Service Contexts: The Marketing and Organizational Behavior Interface, Journal of Business Research, 1990

Gummesson, E., The New Marketing -Developing Long-term Interactive Relationships, Long Range Planning, No. 4, 1987

Hedvall, M.B., Paltschik, M., Intrinsic Service Quality Determinants for Pharmacy Customers, International Journal of Service Industry Management, $1991 \mathrm{a}$

Hedvall, M.B., Paltschik, M., Perceived Service Quality in Pharmacies: With Empirical Results from Sweden, Journal of Social and Administrative Pharmacy, $1991 \mathrm{~b}$

Hentschel, B., Die Messung wahrgenommener Dienstleistungsqualität mit SERVQUAL, Eine kritische Auseinandersetzung, Marketing ZFP, IV Quartal 1990

Hepp, G.W., Mengel, J.F., Improving the Quality of Government Audits, Journal of Accountancy, June 1992

Hers, P., Top 30: Accountants Blijven Floreren, Financieel Economisch Magazine, 11 July 1992

Hill, J.W., Ramsay, R.J., Simon, D.T., Audit Fees and Client Business Risk During the S\&L Crisis: Empirical Evidence and Directions for Future Research, Journal of Accounting and Public Policy, 1994

Hooton, J.G., Landsittel, D.L., Addressing "Early Warning" and the Public Interest: Auditor Involvement with Internal Control, The CPA Journal, June 1991 
Humphrey, C., Moizer, P.. Turley, S., The Audit Expectation Gap in Britain - An Empirical Investigation, unpublished paper, University of Manchester, 1991a

Humphrey, C., Turley, S., Moizer, P.n Protecting Against Detection: The Case of Auditors and Frand, unpublished paper, University of Manchester, $1991 \mathrm{~b}$

Humphrey, C., Moizer, P., Turley, S., The Audit Expectations Gap -Plus Ca Change, Plus C'est la Même Chose?, paper presented at European Accounting Association, Maastricht, 1991 c

Hunger, J.R., Die deutschen Wirtschaftsprïfer, Image und Selbstwerständnis einer Profession, IdW Verlag GmbH, Düsseldorf, 1981

IFAC, Assuring the Quality of Audit and Related Services: A Proposed Statement of Policy of Council, Accountancy, March 1991

Institute of Chartered Accountants in England and Wales, Auditing Practices Committee, Exposure Draft of an Auditing Guideline. The Implications for Detecting and Reporting Fraad and Other Illegal Acts, Accountancy, 1988a

Institute of Chartered Accountants in England and Wales, Auditing Practices Committee, Exposure Draft of an Auditing Guideline, The Implications for Auditors of the Financial Services Act 1986, Accountancy, 1988b

International Organization for Standardization, ISO 8402: Quality - Vocabulary, 1987

International Organization for Standardization. ISO Draft Guide: Quality Systems-Quide to Quality Management for Services, Technical Committee no. 176/SC1/WG6, ISO, April 1989

Ishikawa, K., What is Total Quality Control? The Japanese Way, Prentice-Hall Inc., Englewood Cliffs, New Jersey, 1985

Johnson, W.B.. Lys, T., The Market for Audit Services; Evidence from Voluntary Auditor Changes, Journal of Accounting and Economics, 1990

Judge, G.G., Griffiths, W.E., Hill, R.C., Tsoung-Chao, L., The Theory and Practice of Econometrics, John Wiley \& Sons Inc., New York, 1980 
Juran, J.M., Quality Control Handbook, McGraw-Hill, 3rd edition, 1974

Kasper, J.D.P., Lemmink, J.G.A.M., After Sales Service Quality: Views Between Industrial Customers and Service Managers, Industrial Marketing Management, August 1989

Kasper, J.D.P., De Vries, W., Helsdingen, van, P., Services Marketing Management: An Internationall Perspective, Irwin, Chicago, 1996 (forthcoming)

Kinney, W.R., Audit Technology and Preferences for Auditing Standards, Journal of Accounting and Economics, 1986

Knapp, M.C.y Audit Conflict: An Empirical Study of the Perceived Ability of Auditors to Resist Management Pressure, The Accounting Review, April 1985

Knapp, M.C., An Empirical Study of Audit Committee Support for Auditors Involved in Technical Disputes with Client Management, The Accounting Review, July 1987

Knapp, M.C., Factors that Audit Committee Members Use as Surrogates for Audit Quality, Auditing: A Joumal of Practice and Theory, Spring 1991

Kollenburg, van, I.C.E., De Deugd in het Midden , BDO Camps Obers Groep, Eindhoven, 1991

Kuhnberger, M., Armerkungen zum Argument vom "Hohen Grad an Professionalisierung der Deutschen Wirtschaftsprifer als Garantie fuir Vertrauenswürdige JahresabschluBinformationen" Eine Kritische Bestandsaufnahme, ZFBE, June 1987

Lapierre, J., Filiaurault, P., An Analysis of the Foundations of Research on the Quality of Professional Services to Organizations, in: Kunst, P.E.J., Lemmink, J.G.A.M. (eds.), Managing Service Quality, Series on Quality Management in Services, Vol. 2, Paul Chapman Publishing Ltd., London, 1995 (forthcoming)

Leeflang, P.S.H., Boxem, G., Dijk, van, J.A., De Markt voor Accountantsdiensten in Nederland (deel 1), Maandblad voor Accountancy en Bedrijfseconomie, Maart 1992a

Leeflang, P.S.H., Alkema, S., Rosbergen, E., Vriens, M., De Markt voor Accountantsdiensten in Niederland (deel 2), Maandblad voor Accountancy en Bedrijfseconomie, April 1992b 
Lemmink, J.G.A.M., Kwaliteitsconcurrentie tussen Ondememingen, University of Limburg.
Maastricht, 1991

Lemmink, J.G.A.M., Metingen ten behoeve van Kwaliteitsmanagement, Recente Ontwikkelingen $\frac{\text { in het Marktonderzoek, Jaarboek NVM '92-'93, Nederlandse Vereniging van Marktonderzoekers, }}{1992}$

Limperg Instituut, Opvattingen over Accountants, Limperg Instituut, Amsterdam, 1987

Loscalzo, M., Preparing for Quality Review, The CPA Joumal, December 1988

Loscalzo, M., Quality Review, One Year After, The CPA Journal, June 1991

Macklin, M., How Three Firms Benefited From Peer Review, Joumal of Accountancy, June 1989

Maijoor, S., The Economics of Accounting Regulation: Effects of Dutch Accounting Regulation for Public Accountants and Firms, University of Limburg, Maastricht, 1991

Maijoor, S., Meuwissen, R., Buijink, W., Audit Firm Size, Client Portfolio Structure and Audit Firm Quality, paper presented at MARS, Maastricht, October 1993

Martin, W.B., Defining what Quality Service is for You, Cornell Hotel and Restaurant Administration Quarterly, February 1986a

Martin, W.B., Measuring and Improving your Service Quality, Cornell Hotel and Restaurant Administration Quarterly, May $1986 \mathrm{~b}$

Mautz, R.K., Matusiak, L.W., Concurring Partner Review Revisited, Journal of Accountancy, March 1988

McKinley, S., Pany, K., Reckers, P.M.J., An Examination of the Influence of CPA Firm Type, Size, and MAS Provision on Loan Officer Decisions and Perceptions, Journal of Accounting Research, Autumn 1985

Mednick, R., Reinventing the Audit, Joumal of Accountancy, August 1991 
Menon, K., Williams, D.D., Auditor Credibility and Initial Price Offerings, The Accounting Review, April 1991.

Miller, J.A, Studying Satisfaction, Modifying Models, Eliciting Expectations, Posing Problems, and Making Meaningful Measurements, in: Keith Hunt (ed.), Conceptualization and Measurement of Consumer Satisfaction and Dissatisfaction, Report No. 77-103, Marketing Science Institute, Cambridge Massachusetts, May 1977

Mills, P.K., On the Quality of Services in Encounters: An Agency Perspective, Journal of Business Research, 1990

Molz, R., Managerial Domination of Boards of Directors and Financial Performance, Journal of Business Research, 1988

Monroe, G.S., Woodliff, D.R., An Empirical Investigation of the Audit Expectation Gap:

Australlian Evidence, unpublished paper, University of Western Australia, 1993

Moore, G., Scott, W.R., Auditors' Legal Liability, Collusion with Management, and Investors' Loss, Contemporary Accounting Research, Spring 1.989

Morris, M.H., Fuller, D.A., Pricing an Industrial Service, Industrial Marketing Management, 1989

Nederlands Instituut voor de Publieke Opinie en het Marktonderzoek, NIPO-

Accountantsonderzoek 1991, Amsterdam, 1991

Neijzen, J.A., Trompetter, M., Kwaliteitszorg in Dienstverlenende Organisaties, Kluwer, Deventer, 1989

Newbold, P., Statistics for Business and Economics, Prentice-Hall, Inc., Englewood Cliffs, New Jersey, 1984

Nichols, D.R., Smith, D.B., Auditor Credibility and Auditor Changes, Journal of Accounting Research, Auturnn 1983

Nillesen, J.P.H., Reuyl, J.C., Service Quality in a Monopoly: Zeithaml's Service Quality Model for 'Public' Markets, in: Wiele, v.d., T, and Timmers, J.G., (eds.), Proceedings of the Workshop on Quality Management, Brussels, May 1991 
NIVRA, Kwaliteit, Discussienota Mei 1992. Een Integrale Conceptie voor de

Kwaliteitsbevordering wan Dienstverlening door Accountants, NIVRA, Amsterdam, 1992

NIVRA, Management Letter en Accountantsverslag; Communicatie door Accountants Nader

Belicht, NIVRA, Amsterdam, 1994

NIVRA, Richtlijn 3.03: Verantwoordelijkheid voor en Handelwijze bij het Ontdekken van Onjuistheden in de Verantwoording, in: RADAR Richtlijnen Controle, NIVRA, Amsterdam, 1995

Norusis, M.J., SPSS For Windows, Advanced Statistics, Release 6.0, SPSS Inc. 1993a

Norusis, M.J., SPSS For Windows, Base System User's Guide, Release 6.0, SPSS Inc., 1993b

O*Keefe, T.B., Simunic, D.A., Stein, M.T., The Production of Audit Services: Evidence from a Major Public Accounting Firm, paper, University of British Columbia, Vancouver, September 1992

Oliver, R.L., A Cognitive Model of the Antecedents and Consequences of Satisfaction Decisions, Journal of Marketing Research, November 1980

Palmrose, Z.V., Audit Fee and Auditor Size: Further Evidence, Journal of Accounting Research, Spring $1986 a$

Palmrose, Z.V., The Effect of Nonaudit Services on the Pricing of Audit Services: Further Evidence, Journal of Accounting Research, Autumn $1986 \mathrm{~b}$

Palmrose, Z.V., An Analysis of Auditor Litigation and Audit Service Quality, The Accounting Review, January 1988a

Palmrose, Z.V., Public Accounting Firms and the Acquisition of Nonaudit Services by Public and Closely-Held Companies, Auditing: A Journal of Practice and Theory, Fall 1988b

Palmrose, Z.V.., The Relation of Audit Contract Type to Audit Fees and Hours, The Accounting Review, July 1989 
Parasuraman, A., Berry, L.L., Zeithaml, V.A., Guidelines for Conducting Service Quality Research, Marketing Research, December 1990

Parasuraman, A., Zeithaml, V.A., Berry, L.L., A Conceptual Model of Service Quality and its Implications for Future Research, Journal of Marketing, Fall 1985

Parasuraman, A., Zeithaml, V.A., Berry, L.L., SERVQUAL: A Multiple-Item Scale for Measuring Customer Perceptions of Service Quality, Report 86-108, Marketing Science Institute, Cambridge, Massachusetts, August 1986

Parasuraman, A., Zeithaml, V.A., Berry, L.L., SERVQUAL: A Multiple-Item Scale for Measuring Consumer Perceptions of Service Quality, Journal of Retailing, 1988

Parasuraman, A., Zeithaml, V.A., Berry, L.L., More on Measuring Service Quality: The Critical Role of Expectations, Working paper, Texas University, 1993

Parasuraman, A., Zeithaml, V.A., Berry, L.L., Reassessment of Expectations as a Comparison Standard in Measuring Service Quality: Implications for Further Research, Journal of Marketing, January $1994 \mathrm{a}$

Parasuraman, A., Zeithaml, V.A., Berry, L.L., Alternative Scales for Measuring Service Quality: A Comparative Assessment Based on Psychometric and Diagnostic Criteria, Journal of Retailing, Nr. 3, 1994b

Parkash, M., Venable, C.F., Auditee Incentives for Auditor Independence: The Case of Nonaudit Services, The Accounting Review, January 1993

Peter, J.P., Churchill Jr., G.A., Brown, T.J., Caution in the Use of Difference Scores in Consumer Research, Journal of Consumer Research, March 1993

Plumlee, R.D., The Standard of Objectivity for Internal Auditors: Memory and Bias Effects, Journal of Accounting Research, Autumn 1985

Poel, J.H.R., van de, Judgment and Control; Individual and Organizational Aspects of Performance Evaluation, Wolters-Noordhoff, Groningen, 1986

Porter, B.A., Narrowing the Audit Expectation Gap - A Contemporary Approach, paper presented for the Asian-Pacific Conference, Fresno, California, October 1989 
Porter, B.A., The Audit Expectation-Performance Gap and the Rolle of External Auditors in

Society, thesis presented at Massey University, Massey, 1990

Porter, B.A., Am Empirical Study of the Audit Expectation-Performance Gap, paper presented at the European Accounting Association Annual Congress, Maastricht, April 1991

Porter, B.A., Do External Auditors Have the Role of Society's Corporate Watchdogs? -An Empirical Investigation, paper presented at 1992 European Accounting Association Congress, Madrid, 1992

Porter, B.A., An Empirical Study of the Audit Expectation-Performance Gap, Accounting and Business Research, Winter 1993

Prakash, V., Validity and Reliability of the Confirmation of Expectations Paradigm as

Determinants of Consumer Satisfaction, Journal of the Academy of Marketing Science, Fall 1984

Reeken, van, A.J., Begrippen rondom 'Kwaliteit', Bedriffskunde, 1987

Roberts, R.W. Glezen, G.W., Jones, T.W., Determinants of Auditor Change in the Public Sector, Journal of Accounting Research, Spring 1990

Robertson, J.C., Dawis F.G., Auditing, 4th edition, Business Publications Inc., Plano, Texas, 1985

Schilder, A., Auditor Independence: A Real 1ssue?, Business Ethics, A European Review.

October 1992

Schilder, A., Auditor Independence, An Exploratory Study on Some Core Issues of Accountants" Ethics, Woltersgroep, Groningen, 1994

Schmenner, R.W., How Can Service Businesses Surwive and Prosper?, Sloan Management Review, Spring 1986

Schroeder, M.S., Solomon, 1., Vickrey, D., Audit Quality: The Perceptions of Audit-Committee Chairpersons and Audit Partners, Auditing: A Joumal of Theory and Practice, Spring $\$ 986$ 
Schultz Jr., J.J., Gustavson, S.G., Actuaries" Perceptions of Variables Affecting the Independent Auditor's Legal Liability, The Accounting Review, July 1978

Scott, D.R., Walt, van der, N.T., Choice Criteria in the Selection of International Accounting Firms, European Journal of Marketing, No. 1, 1995

Shockley, R.A., Perceptions of Auditor Independence: An Empirical Analysis "The Accounting Review, October $\mathbb{1 9 8 1}$

Shockley, R.A., Holt, R.N., A Behavioral Investigation of Supplier Differentiation in the Market for Audit Services, Journal of Accounting Research, Autumn 1983

Siegel, S., Castellan, N.J., Nonparametric Statistics for the Behawioral Sciences, 2 nd edition, McGraw-Hill Inc. 1988

Simon, D.T., Francis, J.R., The Effects of Auditor Change on Audit Fees: Tests of Price Cutting and Price Recovery, The Accounting Review, April 1988

Simunic, D.A., The Pricing of Audit Services: Theory and Evidence, Joumal of Accounting

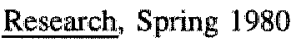

Simunic, D.A., Auditing, Consulting and Auditor Independence, Joumal of Accounting Research, Autumn 1984

Simunic $_{i n}$ D.A., Stein, M.T., Audit Risk in a Client Portfolio Context, Contemporary Accounting Research, Spring 1990

Singhvi, S.S., Desai, H.B., An Empirical Analysis of the Quality of Corporate Financiall Disclosure, The Accounting Review, January 1971

Stauffer ${ }$ C.D., Macklin, M., Rafal, D.E., How to Prepare for Your First Review, Joumal of Accountancy, August 1989

Steiner, B., Der Pruifungsbericht des AbschlluBpriffers; Bedeutung, Inhalt und Entwicklung eines "Adressatenbezogenen" Prüfungsberichts GemäB \&321 HGB als Grundlage für die Unternehmenskontrolle und -Führung -Zugleich ein Plädoyer für eine prüfungsbezogene Beratung durch den Abschlußprüfer, Verlag Dr. Otto Schmidt KG, Köln, 1991. 
Sutton, S.G., Lampe, J.C.. A Framework for Evaluating Process Quality for Audit Engagements, Accounting and Business Research, 1991

Teas, R.K., Expectations, Performance Evaluation, and Customers' Perceptions of Quality, Journal of Marketing, October 1993

Teas, R.K., Expectations as a Comparison Standard in Measuring Service Quality: An Assessment of a Reassessment, Joumal of Marketing, January 1994

Tyson, T.N., Quality and Profitability, Management Accounting, Nowember 1987

Vogels, R., Lemmink, J.G.A.M., Kasper, J.D.P., Some Methodological Remarks on the SERVQUAL Model, in: Avlontis, G.J., Papavasiliou, N.K., Kouremenos, A.G. (eds.), Marketing Thought and Practice in the 1990s, Vol. 1, Athens, 1990

Vriens, M., Leeflang, P.S.H., Rosbergen, E., Wilms, T.J.M. De Markt voor Accountantsdiensten in Nederland (deel 3), Maandblad voor Accountancy en Bedrijfseconomie, April 1992

Wallage, Ph., Methodiek en Mate van Structuur, Een Beschouwing over het Proces van Accountantscontrole, Amsterdam, 1991

Walt, van der, Scott, D., Woodside, A.G., CPA Service Providers: A Profile of Client Types and Their Assessment of Performance, Journal of Business Research. 1994

Ward, D.D., Elder, R.J., Kattelus, S.C., Further Evidence on the Determinants of Municipal Audit Fees, The Accounting Review, April 1994

Watts, R.L., Zimmerman, J.L.., Agency Problems, Auditing, and the Theory of the Firm: Some Evidence, Journal of Law and Economics, October 1.983

Wilson, T.E., Ir., Grimlund, R.A., An Examination of the Importance of an Auditor's Reputation, Auditing: A Journal of Practice and Theory, Spring 1990

Woolf, E., We Must Stem the Tide of Litigation, The Accountant, April 1985 
Wyer, J.C., White, G.T.y Janson, E.C.y Audits of Public Companies by Smaller CPA Firms: Clients, Reports, and Quality, Auditing: A Journal of Practice and Theory, Spring 1988

Zeithaml, V.A., Berry, L.L., Parasuraman, A., Communication and Control Processes in the Delivery of Service Quality, Journal of Marketing, April 1988

Zeithaml, V.A., Parasuraman, A., Berry, L.L., Delivering Quality Service, The Free Press, New York, 1990

Zeithaml, V.A., Berry, L.L., Parasuraman, A., The Nature and Determinants of Customer Expectations of Service, Marketing Science Institute, May 1991

Zenisek, T.J., Corporate Social Responsibility: A Conceptualization Based on Organisation Literature, Academy of Management Review, 1979 


\section{NEDERLANDSE SAMENVATTING}

(Summary in Dutch)

\section{Kwaliteit van accountantsdiensten:}

Een empirische studie van de attributen en determinanten van percepties aangaande de kwaliteit van accountantsdiensten

Dit proefschrift beschrijft de opzet en resultaten van een empirisch onderzoek naar de percepties van cliënten en van bankiers aangaande de kwaliteit van dienstverlening door accountants. In kringen van zowel wetenschap als bedrijfsleven wordt veelal het standpunt ingenomen, dat aandacht voor kwaliteit van dienstverlening een belangwekkend onderwerp is. Enerzijds wordt deze opvatting gevoed door het groeiende aandeel van de dienstverlenende sector in de mondiale economie, anderzijds door de opvatting dat aandacht voor kwaliteit juist in de dienstensector een belangrijk concurrentie-voordeel kan opleveren. Ook op de markt voor accountantsdiensten is dit waarschijnlijk het geval. Gelet op de dynamische ontwikkelingen in deze markt, zoals sterke concurrentie, claims, het loslaten van het reclameverbod in een aantal landen en publieke discussies over de taken en verantwoordelijkheden van openbare accountants, is de aandacht van zowel accountantskantoren als beroepsorganisaties en regelgevers voor kwaliteit niet verwonderlijk.

Niettemin moet worden vastgesteld, dat de aandacht voor het gestructureerd meten en evalueren van kwaliteit in dienstverlening nog enigszins in de kinderschoenen staat. Dit geldt in het bijzonder ten aanzien van professionele dienstverlening, waartoe ook de accountantsdiensten worden gerekend. Onder meer door het werk van Parasuraman, Zeithaml en Berry is het inzicht in het oordeel van consumenten aangaande de kwaliteit van dienstverlenende organisaties evenwel sterk toegenomen. In hoofdstuk 2 worden deze inzichten beschreven. Hierbij staan twee uitgangspunten centraal:

Bij het oordelen over de kwaliteit van een bepaald produkt of dienst spiegelen consumenten hun waarnemingen (percepties) aangaande de prestaties van een dienstverlener aan de verwachtingen die zij dienaangaande koesteren. Naarmate de gepercipieerde prestatie gelijk is aan deze verwachting of deze zelfs overtreft, is sprake een goede kwaliteit. In dit kader worden onderscheiden verwachtingen op ideaal en op aanvaardbaar niveau. Het eerste niveau geeft de verwachtingen weer die een consument heeft ten aanzien van de prestaties van een ideale dienstverlener. Het tweede niveau wordt bepaald door het niveau van dienstverlening dat de consument nog net acceptabel vindt. 
Zolang de gepercipieerde prestatie binnen de grenzen van deze twee typen verwachtingen ligt, bevindt de dienstverlening zich binnen de'tolerantie-zone";

De kwaliteit van dienstverlening kent een technische en een functionele dimensie. De technische dimensie heeft betrekking op de uitkomst van de dienstverlening, de functionele dimensie op het proces van dienstverlening. In het voorbeeld van een kapper wordt de technische dimensie bepaald door de vraag of de haren zijn geknipt in overeenstemming met het tevoren overeengekomen model; de functionele dimensie daarentegen wordt bepaald door aspecten als wachttijd, type en geluidsniveau van de muziek, alsmede uiterlijk van het personeel, van de inrichting of zelfs van de andere bezoekers.

In hoofdstuk 3 worden deze technische en functionele dimensies nader uitgewerkt voor accountantsdiensten. Voor wat betreft de functionele dimensies wordt in belangrijke mate aansluiting gezocht bij de dimensies van het SERVQUAL-model van Zeithaml et al. (1990), dat reeds bij een groot aantal typen diensten is toegepast. Gebaseerd op een kwaliteitsconcept waarin percepties worden gespiegeld aan verwachtingen, is door deze onderzoekers een vragenlijst ontwikkeld waarin een groot aantal functionele dienstverleningsaspecten is opgenomen. Op basis van onderzoek aan de hand van dergelijke vragenlijsten, hebben Zeithaml et al. (1990) de volgende kwaliteitsattributen onderscheiden:

Uiterlijke kenmerken;

Betrouwbaarheid;

Alertheid;

Zekerheid; en

Inlevingsvermogen.

Voor wat betreft de technische dimensie is in hoofdstuk 3 aansluiting gezocht bij een groot aantal onderzoeken naar verwachtingskloven ten aanzien van dienstverlening door accountants. In deze onderzoeken zijn een aantal attributen van technische kwaliteit onderscheiden, die alle samenhangen met het ontdekken (detectievaardigheid) en rapporteren (onafhankelijkheid) door de accountant van de volgende onregelmatigheden:

Onjuistheden in de verantwoording (inclusief winstverschuiving);

Onzekerheid omtrent de continuilteit van de gecontroleerde huishouding;

Lacunes in de administratieve organisatie en interne controle van de gecontroleerde huishouding;

Fraude binnen de gecontroleerde huishouding; en

Onwettig handelen binnen de gecontroleerde huishouding. 
Hierbij is uitsluitend gekozen voor de verantwoordelijkheden die voortvloeien uit de controle-taak van de accountant. Mogelijke andere vormen van dienstverlening door accountantskantoren vormen geen onderwerp van onderzoek in deze studie. Gelet op de regelgeving en de publieke opvattingen ten tijde van het empirisch onderzoek, werden de eerste drie taken van de accountant aangemerkt als traditionele taken, de laatste twee als niettraditionele taken.

In hoofdstuk 4 wordt een overzicht gegeven van bestaand theoretisch en empirisch onderzoek met betrekking tot de invloed van relatie-karakteristieken (eigenschappen in de relatie tussen de accountant en zijn cliënt) en technische kwaliteit. In dit verband wordt, mede op basis van de agency-theorie, de mogelijke invloed op zowel de detectievaardigheid als de onafhankelijkheid besproken van de:

Omvang van het accountantskantoor;

Omvang van de cliënt;

Financiële gezondheidstoestand van de cliënt;

Duur van de relatie tussen de accountant en zijn cliënt; en

Hoeveelheid adviesdiensten die de accountant aan de cliënt levert.

In hoofdstuk 5 wordt de onderzoeksopzet beschreven. Centraal staan de volgende twee onderzoeksvragen:

1. Welke technische en functionele kwaliteitsattributen met betrekking tot accountantsdiensten worden onderscheiden door cliënten en bankiers en wat is hun relatie met, en invloed op, de algemene oordelen over de kwaliteit van accountantsdiensten door deze twee groepen?

2. Wat is de invloed van de relatie-karakteristieken op de percepties van technische accountantskwaliteit van cliënten en bankiers?

De eerste onderzoeksvraag is betrekkelijk nieuw binnen het gebied van audit research. Een belangrijke bijdrage van het onderhavige onderzoek bestaat derhalve in de toepassing van onderzoektechnieken uit de marketing-literatuur binnen het vakgebied van audit research. Voor de tweede onderzoeksvraag is, in afwijking van het meeste bestaande onderzoek op dit gebied, gekozen voor een onderzoeksopzet waarbij de percepties van het management van de gecontroleerde cliënten (cliënten) en van de account managers van banken (bankiers) konden worden gemeten aan de hand van bestaande controleopdrachten.

Voorts wordt in hoofdstuk 5 beschreven op welke wijze deze onderzoeksdoelstellingen zijn geconcretiseerd. Hierbij zijn de volgende aspecten van belang: 
Het onderzoeksinstrument is gebaseerd op de SERVQUAL-techniek. Hiertoe is het bestaande SERVQUAL-instrument aangepast aan de specifieke eigenschappen van accountantsdiensten;

Teneinde een vergelijking te kunnen maken tussen de kwaliteitsoordelen van cliënten en bankiers is ernaar gestreefd, om per controle-opdracht zowel een oordeel te krijgen van de betrokken cliënt als van de bankier die bij de betreffende cliënt als huisbankier geldt. Om dit te bewerkstelligen is de medewerking gevraagd van een aantal banken bij de benadering van de cliënten en de hierbij betrokken account managers van de bank. Door inschakeling van een notariskantoor kon de anonimiteit van de respondenten gegarandeerd worden, hetgeen gelet op de gevoeligheid van de gevraagde informatie gewenst was. De respons van cliënten (66 vragenlijsten, $36 \%$ ) en bankiers ( 89 vragenlijsten, $48 \%$ ) is acceptabel, mede gezien de gevoeligheid van de verlangde informatie en de lengte van de vragenlijsten.

Tenslotte worden in hoofdstuk 5 per vraag de gemiddelden en standaarddeviaties van de antwoorden van bankiers en cliënten weergegeven. Daaruit blijkt, dat het gemiddelde totaaloordeel van zowel cliënten als bankiers over de kwaliteit van het functioneren van de accountant positief is (5,42 respectievelijk 5,47, op een 7 -puntsschaal). Op individuele attributen blijft de prestatie van de accountants over het algemeen beneden het ideale verwachtingenniveau, doch dit beeld is in overeenstemming met de uitkomsten van SERVQUAL-onderzoek ten aanzien van andere vormen van dienstverlening. Opmerkelijk is echter, dat de prestatie in een aantal gevallen ook achterblijft bij het niveau van de aanvaardbare verwachtingen. Hierbij wordt opgemerkt, dat het onderzoek op het gebied van meting van aanvaardbare verwachtingen nog zeer schaars is. Nader onderzoek is gewenst teneinde meer inzicht te krijgen in de conceptualisering van dit niveau en in de betekenis ervan voor kwaliteitspercepties.

Voorts blijkt uit deze eerste analyse, dat bankiers zowel ten aanzien van detectievaardigheid als ten aanzien van onafhankelijkheid hogere verwachtingen hebben dan cliënten. Hiervoor worden verschillende mogelijke verklaringen gegeven. Enigszins onverwacht is de bevinding, dat de verwachtingskloven voor de niet-traditionele taken (met name fraude en onwettig handelen) zeker niet groter zijn dan die voor de traditionele taken. Deze bevinding wijkt af van de resultaten van de meeste verwachtingskloofonderzoeken. Tenslotte blijkt uit dit onderzoek, dat accountants de verwachtingen van met name cliënten op het gebied van uiterlijke kenmerken sterk overtreffen, zodanig zelfs dat dit een negatieve lading lijkt aan te nemen. Kennelijk zijn accountants in de ogen van sommige cliënten net even 
te chique en te vriendelijk en zijn hun gebouwen enigszins 'overdone'. Allerminst overdone is daarentegen de specificatie van de accountants-nota, die ver achterblijft bij de verwachtingen van cliënten en bankiers.

Hoofdstuk 6 bespreekt het onderzoek naar de eerste onderzoeksvraag (zie onder hoofdstuk 5, sub 1). Met behulp van factor-analyse zijn de attributen van accountantskwaliteit geïdentificeerd. Vervolgens is met behulp van regressie-analyse de invloed van deze attributen op het totaal-oordeel van cliënten en bankiers aangaande de kwaliteit van accountantsdiensten gemeten. Uit dit onderzoek blijkt, dat cliënten hun oordeel over de kwaliteit van de accountant met name baseren op de professionele en de communicatieve vaardigheden van de accountant. De accountant wordt met name geacht om onjuistheden in de verantwoording en andere onregelmatigheden in de gecontroleerde huishouding te ontdekken, alsmede om attentiepunten te signaleren op het gebied van jaarverslaggeving, belastingen, interne organisatie en communicatie, financiering en algemene bedrijfsvoering. Voorts wordt een goede communicatie essentieel geacht. Het luisteren naar de cliënt en identificeren van diens behoeften, maar ook het tijdig bespreken met het management van bevindingen binnen of buiten de eigen organisatie staan daarbij voorop. Onafhankelijkheid van de accountant (ofwel: de durf om ontdekte onjuistheden en onregelmatigheden te rapporteren aan derden) wordt echter niet gewaardeerd door cliënten. Geconcludeerd wordt, dat klanten de schijn van onafhankelijkheid van een accountant zeker zullen waarderen (hierdoor wordt immers het belang van een accountantscontrole voor derdenbelanghebbenden vergroot), maar het in hun eigen praktijk wellicht als 'lastig' ervaren...

Voor bankiers zijn eveneens de professionele en communicatieve vaardigheden van het grootste belang. Echter, niet onverwacht, onafhankelijkheid staat bij de bankiers hoog in het vaandel. De waarde van een accountant die wel fouten vindt, maar ze vervolgens niet extern rapporteert, is voor externe belanghebbenden (onder wie de bankiers) zeer beperkt. Zeer interessant is het om te zien, dat voor bankiers het attribuut 'uiterlijke kenmerken' van groot gewicht is. Verondersteld wordt, dat door de lage frequentie waarmee een bankier de accountant van zijn cliënt ontmoet, de eerste indruk belangrijk is.

Hoofdstuk 7 bespreekt de uitwerking van de tweede onderzoekswraag (zie onder hoofdstuk 5, sub 2). Met behulp van regressie-analyse is gezocht naar verbanden tussen de relatiekarakteristieken en de beoordeling door cliënten en bankiers van de detectievaardigheid en onafhankelijkheid van de accountant. 
De omvang van het accountantskantoor, blijkt slechts een beperkte invloed op de perceptie van technische kwaliteit te hebben. Bankiers zagen geen enkele relatie met technische kwaliteit, terwijl cliënten slechts op enkele gebieden een hogere detectievaardigheid aan grote accountantskantoren toeschreven dan aan kleinere. De omvang van de cliënt blijkt voor bankiers zeer sterk gerelateerd te zijn aan het oordeel over zowel de detectievaardigheid als de onafhankelijkheid van de accountant. Kennelijk beschouwen bankiers de complexe organisatie en bedrijfsvoering van grote cliënten als een verzwarende factor voor de accountant in zijn controle-proces, waardoor het bieden van toegevoegde waarde in hun ogen beperkt wordt. Ten aanzien van de onafhankelijkheid zien bankiers bovendien wellicht het risico, dat grotere cliënten, vanwege hun grotere belang voor de accountant in termen van declaratiewaarde, met meer succes de accountant onder druk kunnen zetten dan kleine cliënten. In de perceptie van cliënten zelf speelt omvang evenwel geen grote rol, noch in de detectievaardigheid, noch in de onafhankelijkheid. Alleen ten aanzien van de niet-traditionele taken werd door cliënten een lagere onafhankelijkheid aangenomen bij grote bedrijven. De financiële gezondheidstoestand van de cliënt werd door bankiers als een zeer belangrijke determinant van technische kwaliteit gezien. Naarmate het slechter gaat met de cliënt, is het slechter gesteld met de technische vaardigheid van de accountant, aldus de bankiers. Mogelijk gaan bankiers ervan uit, dat de accountant met name onder druk zal worden gezet (en dus in zijn onafhankelijkheid wordt bedreigd) als het slecht gaat met de cliënt. Wellicht speelt hierin ook de perceptie van bankiers een rol, dat de accountant mede verantwoordelijk is voor de financiële malaise van de cliënt, of dat de accountant de bankier niet tijdig heeft geinformeerd over de gang van zaken. De duur van de relatie tussen de accountant en zijn cliënt en de hoeveelheid adviesdiensten die de accountant aan de cliënt levert, bleken geen van beide een systematische invloed te hebben op de oordelen over technische kwaliteit van cliënten of bankiers.

Tenslotte wordt in hoofdstuk 8 een samenvatting gegeven van opzet en bevindingen van het onderzoek, aangevuld met de beperkingen van het onderhavige onderzoek, aanbevelingen voor toekomstig onderzoek en implicaties voor theorie en praktijk. Ten aanzien van de beperkingen wordt onder meer gewezen op de beperkte omvang van het aantal waarnemingen. Alhoewel het aantal waarnemingen in beginsel toereikend is voor de uitgevoerde statistische toetsen, was een verdergaande differentiatie van de populatie niet mogelijk. In toekomstig onderzoek zou in dit verband kunnen worden gemeten, of het beoordelingsproces aangaande de kwaliteit van accountantsdiensten door MKB-cliënten op een andere wijze geschiedt dan 
door grotere cliënten. Voorts wordt benadrukt, dat er met name in de marketing-literatuur nog diepgaand wordt gediscussieerd over de conceptualisering van kwaliteit. Toekomstig onderzoek kan uitwijzen, of de in deze studie gehanteerde concepten voor verbetering vatbaar zijn. Bij de praktische implicaties zijn aanbevelingen gegeven voor openbare accountants, voor regelgevers en beroepsorganisaties alsmede voor opleiders. In dit verband wordt gewezen op de grote invloed die de omvang van de cliënt en a fortiori diens financiële gezondheidstoestand hebben op het oordeel van bankiers op de perceptie van accountantskwaliteit. Grote waakzaamheid en, voor zover mogelijk, intensief contact met alle betrokkenen kan de positie van de accountant in dergelijke posities wellicht verhelderen. Voorts wordt erop gewezen, dat het ten behoeve van een adequate dienstverlening van belang is om regelmatig de verwachtingen en percepties van klanten (en derden-belanghebbenden) te meten. Op deze wijze kan worden bepaald, op welke gebieden verbetering noodzakelijk is. Op basis van dit onderzoek komt naar voren, dat de dienstverlening van accountants een adequate mix moet zijn van goede technische prestaties en een open communicatie met het management. Met name dit laatste element zou in de opleiding tot accountant nader belicht moeten worden. 



\section{CURRICULUM VITAE}

Roger Dassen was born on 22 September 1965 in Kerkrade. After attending the grammar-school of "Rolduc", he studied Economics and Business Administration (1984 to 1988) and Accountancy (1989) at the University of Limburg. He became a registeraccountant in 1990.

In 1988 he started working for Bakker \& Versteegh, a regional audit firm that merged into Deloitte \& Touche. Currently, he works as an audit manager for Deloitte \& Touche, in particular in the segment of large national clients.

From 1990 on, Roger was involved in teaching Accountancy at the University of Limburg, on a part-time basis. In 1993 he was appointed deputy director of the University's Postgraduate Accountancy Curriculum. As a PhD Student of the Maastricht Accounting and Auditing Research Center (MARC), he has worked on several research projects.

In 1990, the NIVRA "Simninghe Damsté-prijs" was awarded to him for a publication in the field of auditing. 